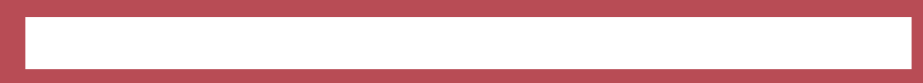

\title{
LOS PRIMEROS GRADOS DE LA UNIVERSIDAD \\ DE BAEZA (1549-1580)
}

RAFAEL RAMIS BARCELÓ

PEDRO RAMIS SERRA

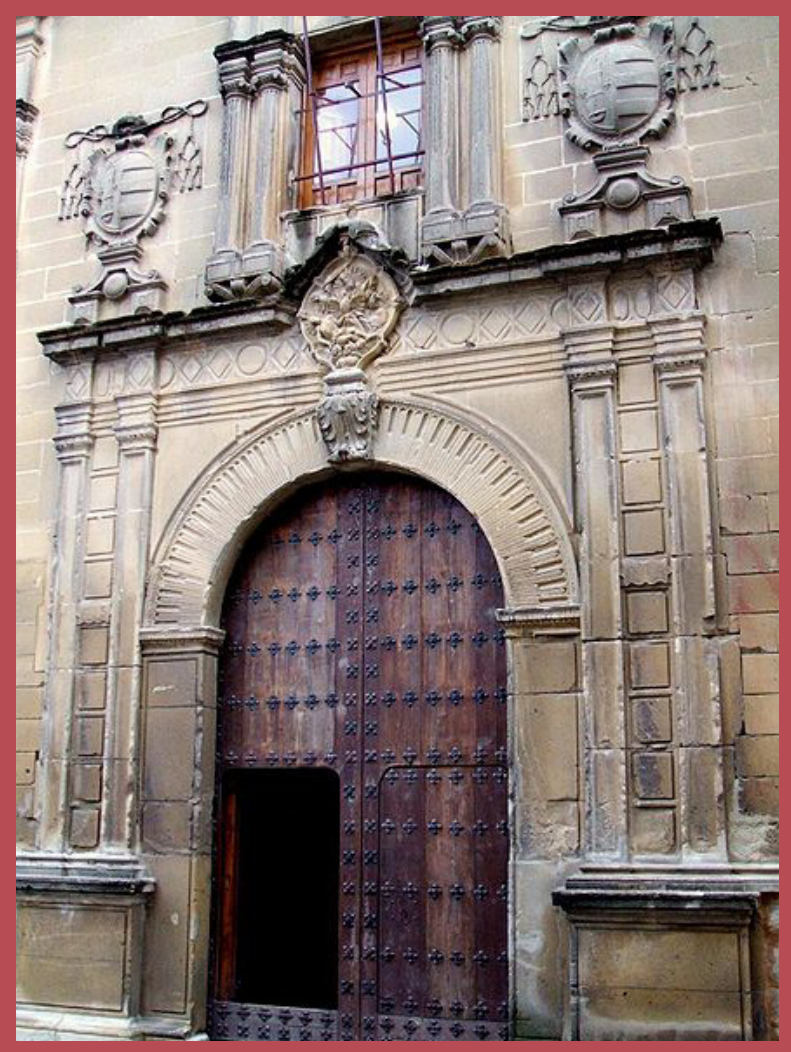



LOS PRIMEROS GRADOS DE LA UNIVERSIDAD DE BAEZA 
The Figuerola Institute

Programme: History of Universities

The Programme "History of Universities" of the Figuerola Institute of Social Science History -a part of the Carlos III University of Madrid- is devoted to improve the overall knowledge on the highlearning academic institutions, since their inception in the Late Middle Ages, until our days. The Programme uses an interdisciplinary approach, and it is open to all branches of related knowledge, such as the history of institutions, of science, and of cultural and social events. A number of experts from several countries have participated in the Programme, bringing in their specialized knowledge and dedication to the subject of their expertise.

To give a better visibility of its activities, the Programme has published in its Book Series a number of monographs on the different aspects of its academic discipline.

Publisher:

Carlos III University of Madrid

Book Series:

History of Universities

Editorial Committee:

Manuel Ángel Bermejo Castrillo, Universidad Carlos III de Madrid

Gianpaolo Brizzi, Alma Mater Studiorum - Università di Bologna

Elena Hernández Sandoica, Universidad Complutense de Madrid

Françoise Hiraux, Université catholique de Louvain

Manuel Martínez Neira, Universidad Carlos III de Madrid

More information at www.uc3m.es/history_universities 
LOS PRIMEROS GRADOS DE LA UNIVERSIDAD DE BAEZA (1549-1580)

Rafael Ramis Barceló

Pedro Ramis Serra

DYKINSON

2018 
Motivo de cubierta: Zarateman, Una de las portadas renacentistas de la Antigua Universidad de Baeza (Jaén, Andalucía, España), Licencia CCo. https:// commons.wikimedia.org/wiki/File:Baeza_-_Antigua_Universidad_o9.JPG

Historia de las Universidades, 43

ISSN: 1886-0710

(C) 2018 Rafael Ramis Barceló y Pedro Ramis Serra

\section{Editorial Dykinson}

c/ Meléndez Valdés, 61 - 28015 Madrid

Tlf. (+34) 915442846

E-mail: info@dykinson.com

http://www.dykinson.com

Preimpresión: TALLERONCE

ISBN - 978-84-9148-718-0

D.L. $-\mathrm{M}-22044-2018$

Versión electrónica disponible en e-Archivo

http://hdl.handle.net/10016/27079

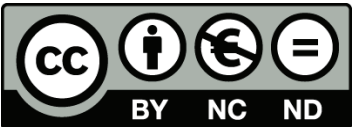

Licencia Creative Commons Atribución-NoComercial-SinDerivadas 3.o España 
A Llorenç Barceló Gual, Catalina Carbonell Costa y Rafael Ramis Corró, in memoriam 

ÍNDICE

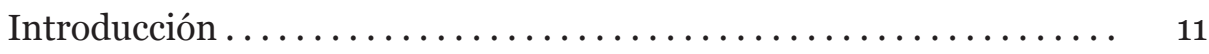

Estudio preliminar $\ldots \ldots \ldots \ldots \ldots \ldots \ldots \ldots \ldots \ldots \ldots \ldots \ldots \ldots \ldots \ldots$

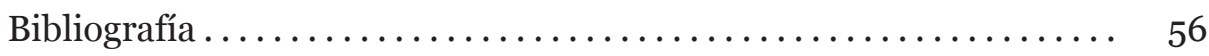

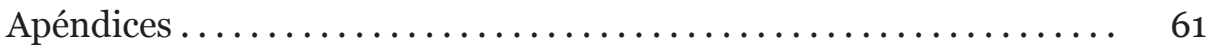




\section{SIGLAS}

AHUB Archivo Histórico de la Universidad de Baeza

AGS Archivo General de Simancas

\section{ABREVIATURAS}

B. A. Bachiller en Artes

B. T. Bachiller en Teología

D. T. Doctor en Teología

Fr. Fray

Gram. Gramática

L. A. Licenciado en Artes

L. T. Licenciado en Teología

Ldo. Licenciado

M. A. Maestro en Artes

Mtro. Maestro

Not. Notario

O. Carm. Ordo Fratrum Beatissimae Mariae Virginis de Monte Carmelo

O. de M. Ordo Beatae Mariae Virginis de Redemptione Captivorum

O. P. Ordo Praedicatorum

O.S.A. Ordo Fratrum Sancti Augustini

O. SS.T. Ordinis Sanctae Trinitatis et Captivorum

Pbro. Presbítero

Secr. Secretario 


\section{INTRODUCCIÓN}

La Universidad de Baeza ha sido una institución que ha interesado mucho menos por sí misma que como telón de fondo de grandes personajes y acontecimientos. La mano de San Juan de Ávila en su proceso fundacional y en la guía espiritual de los primeros maestros, así como los conflictos con la Inquisición, han robado el protagonismo a una sede que merece la atención por su contribución a la promoción del saber y de la espiritualidad de la segunda mitad del siglo XVI.

El título del libro, Los primeros grados de la Universidad de Baeza (15491580 ), intenta reflejar exactamente su contenido: se estudian los actos académicos y la colación de los grados durante esta primera etapa de la Universidad, en la que aparecen destacados protagonistas, de quienes se desconocía con exactitud, en muchas ocasiones, su quehacer académico. Con ello, se puede cruzar la información suministrada por Kagan al estudiar las matrículas, la evolución de las cátedras que había detallado Sala Balust y el ambiente intelectual y espiritual descrito por Álvaro Huerga.

Para conocer el desarrollo de una institución académica, tras estudiar los estatutos, es imprescindible analizar las matrículas, las cátedras y los grados. Aunque Kagan se interesara por las matrículas en un sentido meramente cuantitativo, proporcionó ya datos de valor. Lo que quedaba por hacer con mayor urgencia era la nómina de graduados, a la que consagramos todo el apéndice documental, que contiene los actos y los grados, y representa más de dos tercios del presente libro. A nuestro entender se trata de una "radiografía" de la vida académica biacense, hecha a partir de estos exámenes, en los que consignamos no solamente la información sobre el graduado, sino también acerca del Rector, el Canciller, y los maestros, sin dejar otros detalles como posibles testigos ilustres o el notario que dejó fe de los hechos.

No resulta fácil dar un tratamiento homogéneo a este conjunto de materiales, puesto que están dispuestos de manera mucho más fragmentaria durante los primeros años que en los últimos. Son asimismo frecuentes los casos de homonimia y de dispersión de datos, que hemos procurado presentar de la forma más ordenada posible. Pedimos disculpas de antemano al benévolo lector (que, sin duda, conoce los problemas intrísecos a este tipo de estudios) por los posibles errores. 
La justificación del arco temporal elegido es doble: por un lado, en un mismo manuscrito aparece la documentación desde 1549 hasta 1580 y, por otro, historiográficamente puede decirse que, mediante la visita de Fr. Luis Rodero, con la que acaba el lomo que aquí estudiamos, se pone un jalón fundamental a una escalada de enfrentamientos entre el claustro de profesores y los patronos de la Universidad.

En el Estudio preliminar hemos intentado extraer las principales conclusiones que se desprenden de la documentación presentada en el apéndice. Sin dejar de apuntar algunas cuestiones fundamentales sobre la historia de la Universidad de Baeza, ponemos énfasis en los datos menos trabajados, de modo que evitamos repetir muchas ideas que el lector puede encontrar en los trabajos de Escolano, Álvarez, Higueras, Rodríguez-Moñino...

Así como el primer apartado del Estudio Preliminar repasa las fuentes y la bibliografía y el segundo hace un breve resumen sobre los orígenes de la institución, el resto está elaborado esencialmente sobre fuentes manuscritas y proporciona muchos datos que resultaban desconocidos.

Puede decirse que la Universidad de Baeza tuvo algunas particularidades en el contexto en el que nació y se desarrolló: fue una institución pensada para servir a la ciudad de Baeza y a la diócesis de Jaén en la promoción del saber y de la espiritualidad, que no se desvió de su propósito de enseñanza y formación cristiana integral, desde las primeras letras hasta la teología. En este sentido, Baeza fue una Universidad pequeña, aunque -quizás por las tensiones entre unos poderes bien repartidos y equilibrados- no cayó en la dispersión de otras, ni en las artimañas de muchos conventos y colegios-universidad, que conferían grados de todas las disciplinas, sin que existiese una Facultad para cada una de ellas.

La Universidad de Baeza, durante los años aquí estudiados, fue una institución orientada por las directrices de San Juan de Ávila y sus discípulos más aventajados. Tenían una preocupación fuertemente espiritual que, sin dejar de atender la escolástica tomista, la conjugaban con un estudio serio de la Sagrada Escritura, en un momento crucial para el saber teológico, en general, y, particularmente, en las universidades hispánicas. Álvaro Huerga, en su magnífico estudio sobre los alumbrados, escribió, sin punto alguno de exageración, que "Baeza se convirtió en vanguardia de cultura y religión gracias a su Universidad" ${ }^{\prime \prime}$.

1 A. Huerga, Los alumbrados de Baeza, Jaén, Instituto de Estudios Giennenses, 1978, p. 189. 
A lo largo del libro comparecen figuras destacadas para la historia intelectual de la segunda mitad del siglo XVI: Diego Pérez de Valdivia, Diego de Ávila, Hernando de Herrera... Muchos de ellos, Rectores y Cancilleres de la institución, fueron sospechosos ante los ojos de la Inquisición. La documentación nos ayuda a constatar que no solamente los sacerdotes seculares, sino también dominicos, trinitarios o mercedarios participaban de ese foco renovador de espiritualidad y de saber.

¿Fueron, quizás, maestros desaprovechados? ¿Hubieran llevado a cabo una mejor labor en otra Universidad? El lector que recorra las páginas del libro puede reflexionar sobre ello: en un momento de gran efervescencia religiosa, Baeza fue un pequeño foco de conocimiento y un lugar de concurrencia de unos maestros que, pese a sus diferencias, participaban de un ideario similar. Es cierto que algunos, por su formación y altura intelectual, hubieran podido enseñar en Alcalá o en Salamanca, pero en Baeza lo hicieron de forma más discreta y menos expuesta.

Como foco que fue, generó lumbre y hubo alumbrados. Pero el alumbradismo de Baeza debe estudiarse en su contexto andaluz, e incluso castellano. Asimismo, la persecución inquisitorial, vista con la debida perspectiva, no resulta tan distante de otras querellas del momento como, por ejemplo, el conflicto entre hebraístas y vulgatistas en Salamanca. Fueron años de gran intensidad espiritual, en la que varias universidades hispanas estuvieron en la vanguardia, que fue frenada -a menudo, sin contemplaciones- por la actividad inquisitorial.

En Baeza, los maestros estuvieron, quizás más alejados del "mundanal ruido" y pudieron forjar un itinerario que resultó altamente ilustrativo para los alumnos de aquella pequeña institución. Como enseñó Juan de Ávila, la mejor predicación que podía hacerse era a través del ejemplo de vida. Frente a la ligereza en la colación de grados de otras instituciones menores, Baeza tuvo una Universidad y un profesorado consciente de su misión, que llevó a cabo con dignidad, pese a los vaivenes a los que estaba sometido por parte de los patronos y de la vigilancia del Tribunal de la Inquisición.

El cumplimiento de los plazos, el orden seguido en los exámenes, las calificaciones variadas y el número de reprobados muestran que la Universidad de Baeza mantenía un nivel apreciable en la colación de los grados. Sentado este punto, cabe preguntarse por qué tuvo un carácter tan marcadamente local y regional. La respuesta estaría en las demás universidades que la circundaban: las ciudades de Granada y Sevilla tenían la firme voluntad de lograr un autén- 
tico Estudio General de todos los saberes y la Universidad de Almagro ejercía una competencia directa, puesto que colacionaba (muy fraudulentamente, al parecer) los grados de Artes y Teología.

En definitiva, los orígenes de la Universidad de Baeza tienen interés en la historia de la cultura y de las universidades hispánicas. Se trata de un modelo académico singular, forjado a partir de personalidades relevantes en el panorama intelectual y espiritual hispano. El análisis de la colación de grados ayuda a entender con mayor detalle el devenir de esta institución.

$$
* *
$$

Este libro se encuadra en el marco de los proyectos de investigación de los grupos de filosofía y de historia del derecho de la Universitat Pompeu Fabra, encabezados respectivamente por los profesores José Juan Moreso y Tomàs de Montagut, y como resultado en las líneas de trabajo del Instituto de Estudios Hispánicos en la Modernidad (Unidad Asociada al CSIC).

Debemos expresar nuestro reconocimiento más afectuoso a D. Antonio Ortega Ruiz y a D. Felipe del Pozo, de la Universidad Internacional de Andalucía, por todas las facilidades para poder consultar la documentación digitalizada.

Manifestamos una vez más nuestra gratitud al Prof. Manuel Martínez Neira por su interés en este trabajo, que se incluye en la colección de monografías de Historia de las Universidades que dirige.

Dedicamos el libro a Llorenç Barceló Gual y Catalina Carbonell Costa, fallecidos en el último lustro, y a Rafael Ramis Corró, cuando en 2018 se cumplen cincuenta años de su defunción.

$\mathrm{Al}$ igual que en los demás libros de esta colección, no incluimos índice analítico al final, porque está colgado en la red y es de libre acceso. Los lectores interesados podrán hacer búsquedas ad libitum en el PDF con mucha mayor precisión y amplitud que la que proporcionaría cualquer índice.

Palma, marzo de 2018 


\section{ESTUDIO PRELIMINAR}

La Universidad de Baeza del siglo XVI ha sido estudiada especialmente por algunos personajes que contribuyeron a forjarla y por su ambiente cultural y religioso. Sin embargo, los grados universitarios han sido mucho más desatendidos. Lo más relevante de este libro es el apéndice documental, en el que el lector encontrará sintetizada la colación de grados de Baeza desde 1549 hasta 1580 . A fin de que comprenda mejor los datos allí consignados, dedicaremos las páginas siguientes a encuadrarlos.

En este estudio trataremos, en primer lugar, las fuentes y la bibliografía, para pasar después a la historia de la institución: tras un repaso sucinto a la erección de la Universidad, nos centraremos en la consolidación de la misma, y en el estudio de los profesores y los alumnos, para concluir con una síntesis sobre los grados y lo que se desprende de ellos.

\section{Las fuentes y la bibliografía: estado de la cuestión}

La Universidad de Baeza ha despertado mayor interés por causas extrínsecas que intrínsecas. Es decir, el hecho, por ejemplo, de que Juan de Ávila fuese un protagonista crucial de su puesta en marcha, así como también el proceso a los alumbrados, ha hecho que la Universidad biacense haya sido analizada como el marco de fondo para estudiar ambas cuestiones.

En los últimos años se han escrito trabajos muy útiles sobre el estado de la cuestión de la Universidad, sus fuentes y su historiografía: cabe señalar los de Inmaculada Arias de Saavedra ${ }^{1}$ y los de Antonio Ortega Ruiz ${ }^{2}$, en los que el lector interesado hallará abundante información bibliográfica, que no volveremos a repetir íntegramente aquí.

Debemos distinguir, de entrada, entre la historiografía sobre la propia Universidad y la existente sobre Baeza en su marco cultural. Ambas perspec-

1 I. Arias de Saavedra, "La Universidad de Baeza en la Edad Moderna. Estado de la cuestión y síntesis de su trayectoria”, en L. E. Rodríguez-Sampedro y J. L. Polo (eds.), Universidades hispánicas: colegios y conventos universitarios en la Edad Moderna (II) Miscelánea Alfonso IX, 2009, Salamanca, Universidad de Salamanca, 2010, pp. 15-43.

2 A. Ortega Ruiz, La Universidad de Baeza. Documentos para su historia, Baeza, Universidad Internacional de Andalucía, 2015. 
tivas son necesarias para conocer el contexto de estos años que estudiamos, pues se iluminan mutuamente al examinar los graduandos.

Desde el prisma de la historia universitaria, cabe indicar que muy poco se dice de Baeza en la obra de Vicente de la Fuente ${ }^{3}$, y que sólo se tiene un primer trazo de la historia de la Universidad gracias al empeño de Francisco Escolano ${ }^{4}$ en 1945 y, sobre todo, de María Encarnación Álvarez ${ }^{5}$, una aportación muy valiosa, aunque centrada especialmente en el siglo XVIII. Pocas novedades aporta Cándido M. Ajo ${ }^{6}$ en su vasta historia de las universidades. $\mathrm{Kagan}^{7}$, en un trabajo muy renovador, se centra en los estudiantes y en las matrículas, en perspectiva comparada, y proporciona datos de valía. Un escrito breve, aunque interesante, es el de José García Oro y María José Portela ${ }^{8}$, que encuadra a Baeza en el marco de los Colegios-Universidad de Castilla y trabaja con documentación del siglo XVI. Asimismo reviste interés el artículo de García Cordero ${ }^{9}$ sobre el ideario de la Universidad biacense.

En la historiografia de Baeza, el gran clásico es la obra de Patón ${ }^{10}$, que proporciona algunas nociones sobre la Universidad. El libro de Cózar ${ }^{11}$ es el

3 V. de la Fuente, Historia de las Universidades, Colegios y demás establecimientos de enseñanza de España, Madrid, Viuda e Hija de Fuentenebro, 1884-1889, Tomo II, Cap. XXVIII.

4 F. Escolano, "Documentos y noticias de la antigua Universidad de Baeza", Hispania, 5 (1945), pp. 38-71.

5 M. E. Álvarez, “La Universidad de Baeza y su tiempo (1538-1824)”, Boletín del Instituto de Estudios Giennenses, 27 y 28 (1961), pp. 9-72 y 9-140.

6 C. M. Ajo, Historia de las Universidades Hispánicas, Madrid-Ávila, CSIC, 19571979: tomo II, pp. 96-99; tomo III, pp 317-318; tomo V, pp. 523- 525.

7 R. L. Kagan, Universidad y sociedad en la España Moderna, Madrid, Tecnos, 1988.

8 J. García Oro y M. J. Portela Silva, "Baeza la universidad de los patronos" en Monarquía y Escuela en la España del Renacimiento. Escuelas, colegios y universidades en la Corona de Castilla, Santiago de Compostela, Ed. El Eco Franciscano, 2003, pp. 365-401.

9 J. C. García Cordero, "La Universidad de Baeza entre los siglos XVI y XVII. Ideario pedagógico de un centro avanzado de pensamiento, pionero en la enseñanza, investigación-acción, la promoción, la orientación y en programas de promoción de la mujer", Códice: Revista de la Asociación de Amigos del Archivo Diocesano de Jaén, 7-8 (1992), pp. 39-52

10 B. Ximenez Patón, Historia de la antigua y continuada nobleza de la ciudad de Jaen muy famosa, muy noble y muy leal guarda e defendimiento de los Reynos de España y de algunos varones famosos hijos della... Jaén, Pedro de la Cuesta, 1628.

11 F. de Cózar, Noticias y documentos para la Historia de Baeza, Jaén, Imprenta Rubio, 1884. (Edición facsímil, Universidad de Granada, 2006). 
referente de la historia biacense decimonónica. En la obra coordinada por Rodríguez Molina ${ }^{12}$ se pueden encontrar datos indirectos de interés. Lo mismo puede decirse de la historia eclesiástica de Rodríguez-Moñino ${ }^{13}$.

Del entrecruzamiento entre la historia de Baeza y el de la Universidad podemos destacar algunos trabajos de gran relevancia: el de Higueras ${ }^{14}$, sobre los documentos latinos, el de Rodríguez Moñino ${ }^{15}$, sobre el Archivo de la Universidad y el de Pedro Cátedra ${ }^{16}$, sobre la imprenta. El artículo de Beltrán de Heredia sobre los alumbrados de Jaén ${ }^{17}$, el de Sánchez Gómez ${ }^{18}$ sobre Diego de Valdivia y el libro de Huerga sobre los alumbrados en su contexto espiritual e inquisitorial son asimismo clásicos sobre la materia. También se ha publicado con acierto sobre el humanismo giennense y su influencia en Bae$\mathrm{za}^{19}$. Mención aparte merece la influencia de San Juan de Ávila, que ha sido muy estudiada, así como y la relevancia de la formación de predicadores en la Universidad ${ }^{20}$.

12 J. Rodríguez Molina (coord.), Historia de Baeza: historia, literatura, arte, Baeza, Ayuntamiento de Baeza y Universidad de Granada, 1985.

13 R. Rodríguez-Moñino Soriano, Aproximación a la historia eclesiástica de la ciudad de Baeza (Jaén). (Del esplendor renacentista y barroco a la crisis liberal del XIX), Jaén, Instituto de Estudios Giennenses y Diputación Provincial de Jaén, 2000.

14 J. Higueras Maldonado, Documentos latinos del siglo XIII al XVII en los archivos de Baeza (Jaén), Jaén, Instituto de Estudios Giennenses, 1974.

15 R. Rodríguez-Moñino Soriano, El Archivo de la antigua Universidad de Baeza. Los manuscritos y las Bulas (Introducción y Catálogo), Baeza, Universidad Antonio Machado, 1989.

16 P. Cátedra García, Imprenta y lecturas en la Baeza del siglo XVI, Salamanca, Sociedad de Estudios Medievales y Renacentistas, 2001.

17 V. Beltrán de Heredia, "Los alumbrados de la diócesis de Jaén: un capítulo inédito de la historia de nuestra espiritualidad”, Miscelánea Beltrán de Heredia. Colección de artículos sobre historia de la teología española, Vol. III, Salamanca, San Esteban, 1973, pp. 235-334.

18 J. M. Sánchez Gómez, "Un discípulo del P. Mtro. Avila en la Inquisición de Córdoba. El Dr. Diego Pérez de Valdivia, catedrático de Baeza”, Hispania, 9 (1949), pp. 104-134.

19 J. Moreno Uclés, "Humanismo Giennense (s. XV-XVIII). Un foco humanista en Baeza”, Boletín del Instituto de Estudios Giennenses, 158 (1995), pp. 167- 295.

20 L. Sala Balust, "Introducción” en Obras completas del beato Juan de Avila, Biblioteca de Autores Cristianos, Madrid, 1952, especialmente, pp. 110-140. J. Cózar Castañar, “Juan de Ávila en la Universidad de Baeza en el siglo XVI", El Maestro Ávila. Acta del Congreso Internacional (Madrid 27-30 del XI de 200o), Madrid, Edice, 2002, pp. 317-322. Véase también M. D. Rincón González, “Criterios de selección en la Universidad de Baeza: Huarte de San Juan y los planteamientos avilistas: Quod natura non donat, Academia non 
La documentación histórica de la Universidad de Baeza nos ha llegado en buenas condiciones y con series bastante completas, descritas sucintamente por Cándido $\mathrm{Ajo}^{21}$ y Rodríguez Moñino. El archivo de la antigua Universidad (custodiado desde hace años en el IES Santísima Trinidad de Baeza) fue digitalizado parcialmente por la Universidad Internacional de Andalucía en 2011, y muy amablemente se nos permitido acceder a las fuentes.

Sentado lo anterior, cabe recordar, como indica Ortega Ruiz, que "no se ha abordado un estudio amplio, profundo y riguroso sobre la historia integral de la Universidad de Baeza desde su creación hasta su clausura ${ }^{22}$ ".

Lo que pretendemos en este libro es estudiar los primeros pasos de la actividad académica ya plenamente consolidada, es decir, desde que se nombra un Canciller y se empiezan a conferir los grados académicos. La verdadera identidad universitaria de una institución, desde una perspectiva ad extra, estriba en la colación de los grados con plena validez real y pontificia. No estudiamos los primeros pasos de la Universidad, porque han sido muy atendidos por la historiografía.

Nos centramos, así pues, en los años 1549-1580, siguiendo el primer libro de grados de la Universidad, que muestra la vida escolar, los actos académicos y, muy especialmente, la colación de los grados. Antes de entrar en esta época, debemos resumir, aunque sea muy brevemente, las etapas anteriores que permitieron crear la universidad biacense.

\section{Los orígenes de la Universidad}

Como indican García Oro y Portela, "Baeza, la primitiva sede de la Iglesia de Jaén, era en el siglo XVI una ciudad de segundo orden pero con conciencia municipal muy viva, como casi todos los municipios de señorío eclesiásti$\mathrm{co}^{23}$. El hermanamiento entre el cabildo de la colegiata de Baeza y el cabildo de Jaén hicieron que las relaciones fueran muy estrechas, bajo la supervisión episcopal.

García Cordero apunta sendas circunstancias económicas para entender

praestat, enim vero labor omnia vincit improbus", Elucidario 1 (2006), pp. 135-146 y M. D. Rincón González, "La Universidad de Baeza y la formación del predicador (retóricas, manuales y otros recursos)”, AAVV, Humanismo y pervivencia del mundo clásico: homenaje al profesor Antonio Prieto, Alcañiz-Madrid, 2008, IV.2, pp. 997-1007.

21 C. M. Ajo, Historia de las Universidades Hispánicas, vol. VII, 1967, pp. 105-106.

22 A. Ortega Ruiz, La Universidad de Baeza..., p. 12.

23 J. García Oro y M. J. Portela Silva, "Baeza la universidad de los patronos”, p. 365. 
el marco fundacional de la Universidad: la superación de las hambrunas que habían azotado la región durante el primer tercio del siglo y una proporción alta de canónigos y beneficiados, que defendían con celo sus rentas ${ }^{24}$. La bonanza económica se ligó a los ideales humanistas de algunos de estos clérigos.

Como cristalización de las tendencias humanistas en las localidades andaluzas encontramos la creación de los Colegios-Universidad de Sevilla (el Colegio de Santa María de Jesús, fundado por el Arcediano Maese Rodrigo Fernández de Santaella en las postrimerías del siglo XV, y el de Santo Tomás, regentado por los dominicos ${ }^{25}$ ), Granada ${ }^{26}$ y Osuna $^{27}$. El caso de Baeza, que solamente contempló estudios de Artes y de Teología (salvo un breve lapso a caballo entre los siglos XVII y XVIII, en la que hubo estudios de cánones), debe ser analizado en este mismo contexto, si bien luego tuvo algunas particularidades, como veremos.

En su momento mostramos que no puede decirse que existiera, en puridad, una "política universitaria ${ }^{28}$ " de los Austrias, sino que más bien confirmaron las querencias de señores civiles y eclesiásticos que concebían las universidades como una forma de perpetuar su memoria y su legado. No podemos olvidar tampoco la fuerza de las órdenes religiosas y militares, que dieron vida a las universidades de Ávila, Almagro, Santo Tomás de Sevilla... De ahí que, para un lector contemporáneo, la geografía universitaria ${ }^{29}$ parezca más bien caótica y dispersa. Mientras que en la Corona de Aragón, los municipios vindicaban para sí una sede universitaria, en la Corona de Castilla, por el peso señorial (eclesiástico y civil), se crearon muchas universidades colegiales, especialmente siguiendo los modelos de Sigüenza y Alcalá.

24 J. C. García Cordero, “La Universidad de Baeza entre los siglos XVI y XVII...”, p. 40.

25 J. A. Ollero Pina, La Universidad de Sevilla en los siglos XVI y XVII, Sevilla, Universidad de Sevilla, 1993, pp. 96-106.

26 I. Arias de Saavedra, "La Universidad de Granada en la Edad Moderna: Estudio y estado de la cuestión”, en L. E. Rodríguez-San Pedro Bezares y J. L. Polo Rodríguez (eds.), Universidades Hispánicas. Modelos territoriales en la Edad Moderna (II). Miscelánea Alfonso IX, 2007, Salamanca, Universidad de Salamanca, 2008, pp. 237-268.

27 M. S. Rubio Sánchez, El Colegio-Universidad de Osuna (1548-1824), Sevilla, Caja de Ahorros, 1976.

28 R. Ramis Barceló, "La política universitaria de los Austrias en la Península Ibérica" en G. P. Brizzi y A. Mattone (ed.), Le origini dello Studio Generale sassarese nel mondo universitario europeo dell'eta moderna, Bolonia, CLUEB, 2013, pp. 103-116.

29 M. Peset y M. Menegus, "Espacio y localización de las Universidades Hispánicas", Cuadernos del Instituto Antonio de Nebrija, 3 (2000), pp. 189-232. 
Por su fisonomía, la Universidad de Baeza era colegial y se puede estudiar en comparación con las de Sevilla, Osuna, Granada, El Burgo de Osma o incluso Alcalá. Sin embargo, estas sedes buscaron y lograron expandir sus estudios rápidamente, primero hacia cánones, y después, en algunas de ellas, hacia leyes y medicina. Sin embargo, la Universidad de Baeza, ante todo, fue una institución de formación humana y religiosa para futuros clérigos. De ahí que las escuelas buscasen una enseñanza humanística y religiosa gradual e integral desde las primeras letras y que el estudio verdaderamente "superior" fuese única y exclusivamente el de la teología.

Como hemos indicado, muchas universidades acabaron desviándose del proyecto colegial inicial o abusando de la colación de grados en disciplinas que no contaban con una Facultad docente. En Baeza se siguió un plan de estudios meramente clerical, como el de los conventos-universidad, que proliferaron especialmente en el siglo XVII (Almagro, Pamplona, Tortosa...) o el de instituciones de adscripción institucional compleja, como la Universidad de El Escorial o la de Tarragona, concebidas durante la segunda mitad del siglo XVI.

En el caso de Baeza, como es sabido, la propuesta partió del clérigo biacense Rodrigo López, residente en la ciudad de Roma, que quería crear unas Escuelas para niños con el objetivo de enseñarles la doctrina cristiana. Consiguió su objetivo mediante la concesión de la bula "Altitudo Divinae Provindentiae", el 4 de marzo de 1538.

Según Sala Balust, "la bula autorizaba asimismo la edificación de todas las dependencias necesarias; nombraba administradores perpetuos al ya mencionado Rodrigo López, doctor en ambos derechos, hombre de unos setenta años de edad, y a su hermano, el Mtro. Pedro López, arcediano de Campos y canónigo de Palencia, sexagenario, ambos residentes en la corte romana, notarios y familiares de Su Santidad; y les concedía, además, amplia facultad para elegir y nombrar otros en su lugar, que, lo mismo que ellos, pudiesen hacer estatutos y constituciones, reformarlos y cambiarlos, según lo exigiesen las necesidades de los tiempos y el buen régimen y gobierno del Colegio $0^{30 "}$.

La bula indicaba literalmente que “...concedemos al citado Rodrigo plena y libre autorización para hacer que se construya y edifique en dicha Ciudad, en lugar apto y conveniente para ello, además de las cámaras y mansiones necesarias, un Colegio o Escuela bajo la predicha advocación de la santa Trinidad con una capilla para celebrar sus misas, y también un Gimnasio para niños

30 L. Sala Balust, “Introducción”, p. 111. 
y pupilos a los que deberá instruirse en la doctrina cristiana, en lectura y escritura por medio de un preceptor encargado de esta enseñanza ${ }^{31}$ ". La bula continuaba indicando también que debía construirse "otro Gimnasio para pupilos y adolescentes y demás deseosos de aprender en el que se enseñe gramática, y un tercero en el cual [...] se lean al menos el evangelio, las homilías, los himnos, el salterio, las epístolas del apóstol San Pablo y demás canónicas, otros tratados y libros de las sagradas escrituras ${ }^{32}$ ".

Para la construcción y sostenimiento de las escuelas, Rodrigo López aportaba una cantidad que excedía los mil ducados y las rentas de los beneficios eclesiásticos a los que renunciaba (que ascendía a unos trescientos ducados anuales). Sala Balust indica que "el 6 de agosto de 1539, en Roma y en su casa, sita en la región de San Eustaquio, otorgó el doctor Rodrigo López un poder nombrando sus subadministradores, procuradores y gestores con plenísimas facultades en todo lo que al Colegio se refiriese (elección de sitio, edificación, administración, etc.) a Juan de Ávila, 'Maestro en sagrada teología, residente en Granada', y al clérigo Francisco Delgadillo 33 ".

En definitiva, Juan de Ávila y Francisco Delgadillo fueron designados subadministradores suyos y encargados directos de llevar a cabo todo lo necesario para erigir las Escuelas. Realizaron gestiones para conseguir los locales adecuados para las mismas. Como apunta Ortega Ruiz ${ }^{34}$, en diciembre de 1539, Diego de Sevilla, en nombre de Rodrigo y Pedro López, compró a Diego de Molina una casa por 65500 maravedíes "para haçer el colegio que en esta ciudad se ha de haçer a vocaçion de la santísima trinidad...”.

El mismo Ortega indica que "a esta casa se unirán las donadas por Francisco Delgadillo en junio de 1540, otra finca de Día Sánchez de Quesada, y la que vende Andrés de Santisteban por la importante suma de 470 ducados de oro (176250 maravedíes) "a vos el muy reverendo señor el maestro Juan de Ávila como a patrón y administrador del dicho Collegio...” en agosto de $1540^{35}$ ”.

Las Escuelas, en poco más de un año, se hicieron realidad. Eran una fun-

31 J. Higueras Maldonado, Documentos latinos..., p. 57.

32 Ibidem.

33 L. Sala Balust, "Introducción”, p. 111.

34 A. Ortega Ruiz, "La Universidad de Baeza: de la plasmación del ideal avilino a su clausura”, en M. D. Rincón González y R. Manchón Gómez (eds.), El maestro Juan de Ávila (150o?-1569) un exponente del humanismo reformista, Salamanca, Universidad Pontifícia de Salamanca - Jaén, Universidad de Jaén, 2014, pp. 593-618, especialmente, pp. 597-598.

35 A. Ortega Ruiz, La Universidad de Baeza..., p. 14. 
dación privada, creada con el objetivo de enseñar a leer, escribir y doctrina cristiana a los jóvenes de Baeza, sostenida íntegramente con bienes y rentas propios de los fundadores y bajo el impulso intelectual y espiritual de Juan de Ávila. En 1542, los copatronos solicitaron al Papa la ampliación de los estudios de humanidades y la facultad de otorgar grados académicos.

El 23 de octubre de 1542, Paulo III, mediante un rescripto de la Sagrada Penitenciaría firmado por el Obispo sabinense, concedió poderes a las Escuelas de Baeza para otorgar los títulos de Bachiller, Maestro y Doctor como en el resto de las Universidades de Estudios Generales ${ }^{36}$. Se preceptuaba asimismo que recibiesen los grados de manos del maestrescuela de la Santa Iglesia de Jaén o de otra persona constituida en dignidad eclesiástica, elegida por el administrador. El mismo documento facultaba a los maestros a ampliar los estudios a textos de Virgilio, Ovidio, Terencio y otros de humanidades ${ }^{37}$.

Con ello, se ponían las bases, a todos los efectos, para convertir las escuelas en una Universidad. Las escuelas, sin perder su inicial advocación de la Santísima Trinidad, se transformaron jurídicamente en una Universidad, orientada a la educación de clérigos. Por esa razón, en Baeza se configuró definitivamente un itinerario pensado para la completa formación sacerdotal. Para Melquíades Andrés, "Baeza es la primera universidad abierta únicamente a aspirantes al sacerdocio ${ }^{38 ”}$. De ahí que Huerga la llamase directamente una "universidad pastoral ${ }^{39}$ ".

Juan de Ávila tomó elementos de las Universidades de Alcalá de Henares y de Salamanca, a las que había concurrido, teniendo en cuenta asimismo los patrones institucionales de Granada y Sevilla. Pese a conceder una gran importancia a la teología positiva ${ }^{40}$, no siguió el modelo parisino y alcalaíno

36 L. Sala Balust, "Introducción", p. 124.

37 J. Higueras Maldonado, Documentos latinos..., p. 133.

38 M. Andrés, La Teología española en el siglo XVI, Vol. I, Madrid, BAC, 1976, p. 41.

39 A. Huerga, Los alumbrados de Baeza, p. 10.

40 Para M. Andrés, La Teología española en el siglo XVI, Vol. I, p. 26. "Particularidad de las facultades de Teología de Baeza y de Gandía fue la cátedra de «Positivo», que funcionó durante varios años junto con la de «Escolástico» en la universidad de Baeza (1546-1564). En ella fue profesor Carlevar, sacerdote de la intimidad del beato Avila y del doctor Loarte, Rector y alma de la universidad de Baeza y procesado por la Inquisición (c. 1552). En la universidad de Baeza, el Beato Avila, con poder ilimitado para crear facultades, únicamente establece la de Artes y la de Teología. Siguiendo muy exageradamente el criterio de Juan López de Medina y de Cisneros sobre el Derecho, el Beato no quiere que se enseñen en su universidad Ciencias Humanas, como leyes, medicina y cánones. Su hito era 
de las tres vías, sino que se concentró en la escolástica tomista. Para Álvaro Huerga, "lo más importante, con todo no es la economía, sino la selección de un profesorado competente en letras y en espíritu. Ávila colocó en Baeza a la flor y nata de sus discípulos ${ }^{41}$ ".

La Universidad de Baeza estableció su formación a través de tres peldaños consecutivos: en primer lugar, las escuelas de niños, las de Artes (con sus secciones de mínimos, menores y mayores para la enseñanza de gramática), la Facultad de Filosofía, y la de Teología. Las clases comenzaron en 1542 y la primera colación de grados aparece registrada en 1549 .

\section{Los comienzos y la estructura de la Universidad}

Tras un mandamiento para proveer las bulas de la universidad, en agosto de $1549^{42}$, en el mes de noviembre de 1549, el maestro Juan de Ávila hizo un poder a favor de Bernardino de Carleval o Carlevar (uno de sus discípulos predilectos ${ }^{43}$ ) para que eligiese un Canciller para la colación de grados ${ }^{44}$. El 30 de noviembre de 1549 escogió a Diego Flores, arcediano de Castro del Río45.

Diego de Flores (en tanto que autoridad eclesiástica encargada de conceder los grados universitarios) el día 1 de diciembre otorgó los primeros títulos de la Universidad a varios de los profesores del Colegio: a Bernardino de Carleval y a Gaspar Loarte, de Licenciado y Doctor en Teología, para que pudieran examinar de dicha disciplina; y a Hernando de Herrera, Hernando de Aguayo y Diego Pérez de Valdivia, de Licenciado y Maestro en Artes, "para que todos juntamente empiecen a hazer cuerpo de universidad y para que puedan como tales maestros hallarse a los exámenes que se hubieren de hazer ${ }^{46}$ " en la Facultad de Artes. Todos ellos, según Huerga, "fueron personasclave en la vida de la incipiente Universidad. Que, a la par se convertía en nuevo faro de saber, fue punto de mira que trajo en guardia al Santo Oficio. La Universidad de Baeza va a ser considerada por la Inquisición como una

la formación de sacerdotes. Esta cátedra de «Positivo» resulta por demás interesante, por ser la primera de este nombre que conozco y por haber sido creada cuando la división de la teología, en positiva y en escolástica, no era aún muy común en las escuelas”.

41 A. Huerga, Los alumbrados de Baeza, p. 10.

42 AHUB, Libro de grados 1549-1580, ff. 1r-v.

43 L. Sala Balust, "Introducción”, pp. 11-18.

44 AHUB, Libro de grados 1549-158o, f. 2.

45 AHUB, Libro de grados 1549-1580, ff. 3r-v.

46 AHUB, Libro de grados 1549-1580, ff. 4r-v. 
sospechosa colmena donde se alimentan las larvas del Alumbradismo. Sus profesores son, lo mismo que Ávila, cristianos nuevos casi en su totalidad47".

$\mathrm{El} 7$ de enero de 1550 se eligió Rector de la Universidad de Baeza a Bernardino de $\mathrm{Carleval}^{48}$, que estuvo en el cargo hasta 1552 , en que fue nombrado Rector Fernando de Aguayo, quien hasta el momento se había desempeñado como Vicerrector. El mismo día se matricularon los primeros estudiantes de la Universidad totalmente constituida ${ }^{49}$ y recibieron los grados Pedro Díaz Soriano, juez eclesiástico de Baeza, y Jerónimo Calderón ${ }^{50}$.

La primera graduación colectiva de estudiantes de Artes tuvo lugar el 2 de marzo de 1550, en el que Juan de Santistevan, Luis Hernández, Juan Álvarez, Alonso de Xodar, Pedro Tornero, Alonso Garrido, Antón del Jesús, Hernando López, Nicolás de Torres y Francisco Sánchez recibieron el Bachillerato en Artes de manos del maestro Hernando de Herrera ${ }^{51}$.

No poseemos los textos de las primeras ordenaciones, sino disposiciones dispersas en los textos manuscritos. Sabemos que Bernardino Carleval, Rector, dispuso el 21 de octubre de 1551 que ninguno de los bachilleres en Artes puediera ser admitido al grado de Licenciado hasta el acabado el cuarto año ${ }^{52}$.

En paralelo, Juan de Ávila intentó dejar la universidad biacense y todas sus iniciativas educativas bajo el amparo de la naciente Compañía de Jesús. Parece ser que entre 1551 y 1556 se llevaron a cabo negociaciones, que llegaron a estar muy avanzadas ${ }^{53}$. Sin embargo, por lo que se desprende de la documentación que tenemos, las reticencias de la Compañía a conservar en sus puestos a los maestros que estaban enseñando ya en Baeza y la postura de ciertos jesuitas hacia los conversos, descendientes de los cuales eran el propio Maestro Juan de Ávila y buena parte de sus discípulos, impidieron la culminación del proyecto ${ }^{54}$.

Sentado lo anterior, cabe recordar que el gobierno de la Universidad de Baeza se hallaba repartido entre dos autoridades que en muchas ocasiones anduvieron en conflicto: por un lado, los patronos y, por otra, el claustro de la Universidad, presidido por el Rector. Los dos patronos, llamados también ad-

\footnotetext{
47 A. Huerga, Los alumbrados de Baeza, p. 11.

48 AHUB, Libro de grados 1549-1580, f. 5 r.

49 AHUB, Libro de grados 1549-1580, ff. 5 r-v.

50 AHUB, Libro de grados 1549-1580, f. $5 \mathrm{v}$.

51 AHUB, Libro de grados 1549-1580, f. $7 \mathrm{r}$.

52 AHUB, Libro de grados 1549-1580, f. 16r.

53 L. Sala Balust, "Introducción”, p. 177.

54 A. Huerga, Los alumbrados de Baeza, p. 17.
} 
ministradores, eran oficios permanentes, que se ocupaban del nombramiento y de la gestión de la Universidad: convocaban las cátedras vacantes, ordenaban los pagos del arca, nombraban algunos oficiales subalternos (especialmente, el bedel ${ }^{55}$ ) y participaban en la elección de Rector y consiliarios. Esta última era su competencia más conflictiva, puesto que entraba en colisión con el claustro, que era el órgano corporativo más importante, que se pronunciaba sobre cuestiones académicas y administraba los fondos. En la época de Pedro Fernández de Córdoba, estas tensiones llegaron al cénit.

El Rector ${ }^{56}$ era máxima autoridad de carácter académico, resultaba elegido por cinco personas, en votación secreta: los dos patronos, el Rector saliente y los dos consiliarios mayores. Ello dio lugar a algunos conflictos ${ }^{57}$, especialmente cuando faltaba uno de ellos. La elección ordinaria se hacía por un año el 9 de septiembre. Ese mismo día se elegían a los consiliarios mayores.

El Canciller, como se ha dicho ya, era el encargado de conferir los grados con autoridad apostólica. La elección del mismo la hacían los dos patrones ${ }^{58}$, conjuntamente con el Rector y el claustro. En muchas ocasiones, el Canciller propuesto por los patrones no era aceptado por los profesores, mientras que cuando éstos proponían una alternativa, era rápidamente bloqueada por los patrones, quienes invocaban las bulas apostólicas para resguardar sus derechos.

El 1 de octubre de 1552, el Maestro Fernando de Aguayo, Rector, juntamente con los maestros del claustro, ordenó e hizo una constitución en la que prescribieron penas para los profesores si faltaban a sus lecciones o no entraban al tiempo en el que estaban obligados. La constitución mandaba que no se les multase solamente una hora, sino media y un cuarto, y se descontase de su salario (seis ducados, pagados tres por la Universidad y otros tres de la renta del Colegio, en dos pagas, la de Navidad y por San Juan). Preceptuaba asimismo que, si sobrase dinero, quedase en las arcas del Colegio. Se dispuso

55 Consignamos aquí los nombres de los bedeles, secretarios y notarios apostólicos: Alonso Díaz Vázquez, Licenciado, secretario; Alonso Medel, clérigo, notario apostólico y secretario de la Universidad y colegio de la Santísima Trinidad de la ciudad de Baeza; Antón López, Bachiller, secretario; Antonio Conejero, bedel; Bartolomé de Navarrete, bedel; Bartolomé de Valsalobre, bedel; Francisco Ribero, bedel; Francisco Truchado, bedel; Juan de Cárdenas, bedel; Juan Núñez, Licenciado, secretario; Luis de Molina, Maestro, notario apostólico; Sebastián Rodríguez, Bachiller, secretario.

56 M. E. Álvarez, “La Universidad de Baeza...”, pp. 21-22.

57 AHUB, Libro de acuerdos desde 1558 hasta 1577, f. 118v.

58 AHUB, Libro de grados 1549-1580, f. 232 r. 
también que el catedrático que faltase a conclusiones, huyendo de ser presidente, se le multara con dos reales de su salario, con un real, si fuese lector y no miembro de la Facultad, y si solo fuere maestro y no lector, medio real. Dichas penas debían ser pagadas a estudiantes pobres. Asimismo, se prescribió que si un lector estaba legítimamente ocupado y no hubiera provisto sustituto, se multaría su ausencia por entero. Y si alguno tuviera ocupación justa para no estar en conclusiones, con licencia del presidente, no incurriría en la pena ${ }^{59}$. Asimismo, el Claustro, reunido el 24 de mayo de 1553, acordó que ningún estudiante jurase cursos a otro de Artes y de Teología si no fuere pidiéndolo al Rector, delante del secretario ${ }^{60}$.

El 11 de octubre de 1553, el claustro determinó que que Lucas Rodríguez, mayordomo de la Universidad, ocupado en otros negocios, fuese sustituido por Francisco de Herrera ${ }^{61}$. Asimismo, el claustro, el 11 de noviembre de 1553, decidió recibir y admitir en su cátedra a Juan Ximénez, con las siguientes condiciones: tenía que pasar a vivir del Santo Espíritu al Colegio; no tenía que hacer más vistas que los otros maestros, debía leer cuatro horas y obrar de conformidad a los estatutos hechos por el Claustro ${ }^{62}$.

En estos primeros años, el devenir de la institución se vio comprometido por la vigilancia férrea que imponía la Inquisición, que prendió a algunos de los maestros, como Bernardino de Carleval y lo llevó a Córdoba ${ }^{63}$. Esta circunstancia hizo que en los primeros años la institución iniciara un despegue lento, acompañado de frecuentes dificultades.

En 1562 se juntó el claustro y debatió acerca del tiempo en el que el Rector tenía que desempeñar su cometido y cómo tenía que hacerse: al final se dispuso que la elección fuera por cinco votos secretos ${ }^{64}$. Y en 1565 se eligieron Cancilleres al prior del Monasterio de Santo Domingo y al Ministro del Monasterio de la Santísima Trinidad de Baeza, para que indistintamente pudieran conferir el grado, de manera que el Rector y los consiliarios "llamen al que de ellos por bien tuvieren sin ser menester ayuntar el claustro para ello ${ }^{65}$ ".

En virtud de la Bula Equum reputamus et rationi consonum ${ }^{66}$ (de 17 de

59 AHUB, Libro de grados 1549-1580, f. $17 \mathrm{v}$.

60 AHUB, Libro de grados 1549-1580, f. 19v.

61 AHUB, Libro de grados 1549-1580, f. 20 .

62 AHUB, Libro de grados 1549-1580, f. 20 .

63 A. Huerga, Los alumbrados de Baeza, p. 56.

64 AHUB, Libro de acuerdos desde 1558 hasta 1577, f. 12 r.

65 AHUB, Libro de acuerdos desde 1558 hasta 1577, f. 26v.

66 J. Higueras Maldonado, Documentos latinos..., pp. 149-159. 
enero de 1565), el Papa Pío V concedió la ampliación de cátedras y se confirieron a la Universidad de Baeza las jurisdicciones y prerrogativas acostumbradas en las demás sedes universitarias. Muchos autores han querido ver en esta bula el espaldarazo definitivo al proyecto de Juan de Ávila ${ }^{67}$ : sin negar su influencia, creemos que sería más acertado referirnos al impulso que desarrollaron en las escuelas de Baeza algunos de sus discípulos, que habían estado bajo su clara orientación intelectual y espiritual.

De hecho, el brillo de la Universidad biacense proviene, ante todo, de una pléyade de hombres doctos, conscientes de su misión sacerdotal y sensibles al humanismo y a una teología espiritual renovadora. Todos ellos, ciertamente, estaban muy influidos por Juan de Ávila, pero -como podremos ver- fueron sus seguidores, los catedráticos de Baeza, quienes, con su empuje y saber, forjaron una etapa destacada en la historia universitaria del siglo XVI. Para Beltrán de Heredia, "en Baeza y sus contornos la instrucción religiosa había alcanzado por estos días un nivel excepcional. La lectura de libros piadosos, fomentada también por el autor del Audi filia y sus discípulos, iba transformando aquellos pueblos. De la imprenta establecida allí a la sombra de la Universidad comienzan a salir libros clásicos y modernos ${ }^{68 "}$.

Volviendo al texto de la bula, hay que afirmar que su tenor literal muestra que Baeza era considerada una universidad, a todos los efectos y con todos los honores. El claustro mantuvo a lo largo de los años sucesivos numerosas sesiones, con tal de ajustar su texto a la realidad de las escuelas de Baeza. El 8 de septiembre de 1566 se decidió que el Rector, juntamente con los patronos tuviera poder en la administración de la hacienda y todos los demás bienes de la Universidad ${ }^{69}$. El 22 de septiembre de 1568 hubo un acuerdo del claustro para aprobar los estatutos ${ }^{70}$ que habían redactado Bernardino de Carleval y Pedro Fernández de Córdoba. El 19 de abril de 1570 fueron admitidos definitivamente para su uso $^{71}$. Desde ese momento hasta 1609, fueron los estatutos bajo los cuales se rigió la Universidad. La historiografía ha discutido si hubo una redacción primitiva debida a Juan de Ávila o si dichos estatutos estuvieron inspirados en ellos ${ }^{72}$. No hay una conclusión clara al respecto.

67 J. Esquerda Bifet, Introducción a la doctrina de San Juan de Avila, Madrid, BAC, 2000, pp. 64-65 y A. Huerga, Los alumbrados de Baeza, pp. 9-10.

68 V. Beltrán de Heredia, "Los alumbrados de la diócesis de Jaén...”, p. 256.

69 AHUB, Libro de acuerdos desde 1558 hasta 1577, f. 38v.

70 AHUB, Libro de acuerdos desde 1558 hasta 1577, f. 47v.

71 AHUB, Libro de acuerdos desde 1558 hasta 1577, f. 53r.

72 Véase A. Ortega Ruiz, La Universidad de Baeza..., p. 17, M. E. Álvarez, "La Univer- 
Lo que es seguro es que Pedro Fernández de Córdoba, administrador, que fundó un Colegio para filósofos y teólogos, y otro para gramáticos ${ }^{73}$, pasó a tener cada vez más protagonismo, acaparando paulatinamente mayor poder, en detrimento del claustro, que se opuso a sus veleidades. En tanto que patrono munificente y autoritario, Fernández de Córdoba quiso tener un protagonismo esencial en todas las dimensiones de la Universidad, y ello levantó la crispación del claustro.

En agosto de 1571 se produjo una visita por parte de Miguel González de Prida, vicario general de Jaén, en la que comparcieron los maestros, que expusieron con libertad sus críticas y algunos desencuentros que había en la institución, especialmente con los patronos ${ }^{74}$. Esta visita, finalmente, fue suspendida. Sin embargo, en relación a estas fricciones, sabemos que el 10 de septiembre de 1571, el claustro pidió que el Rector "sea en su modo y manera y tercero patron 75 ", de manera que pudiera actuar conjuntamente con los patronos. Fernández de Córdoba quiso establecer una nueva sede de la Universidad, bajo la advocación de San Juan Bautista. El claustro e incluso los patrones recelaron de esta iniciativa y se suscribió una concordia en 1574 para deliminar estas escuelas de San Juan Bautista de las ya existentes, de la Trinidad ${ }^{76}$.

La visita se reanudó el 15 de septiembre de 1574, momento en el que fueron llamados al Palacio episcopal de Jaén los administradores de la Universidad, los cuales apelaron y la visita sufrió un parón ${ }^{77}$. El 17 de septiembre de dicho año se deliberó que, para todos aquellos asuntos que se tuvieran que tratar temas de gran importancia, el bedel convocara a los asistentes un día antes $^{78}$. El 6 de diciembre de 1575 se decidió que, aunque la bula apostólica confiriese algunas atribuciones al Vicecanciller, dado que esa figura no existía, el claustro anulaba esa disposición y otorgaba todo lo que estaba previsto al Vicecanciller al Canciller ${ }^{79}$.

El 10 de septiembre de 1576, el doctor Bernardino de Carleval, patrón y

sidad de Baeza...”, p. 135 y J. García Oro y M. J. Portela Silva, "Baeza la universidad de los patronos", pp. 378.

73 M. E. Álvarez, "La Universidad de Baeza...”, pp. 14-15.

74 J. García Oro y M. J. Portela Silva, "Baeza la universidad de los patronos”, pp. 381-384.

75 AHUB, Libro de acuerdos desde 1558 hasta 1577, f. 59v.

76 J. García Oro y M. J. Portela Silva, “Baeza la universidad de los patronos”, p. 379.

77 Ibidem, p. 384.

78 AHUB, Libro de acuerdos desde 1558 hasta 1577, f. 82v.

79 AHUB, Libro de acuerdos desde 1558 hasta 1577, f. 91r. 
administrador de las escuelas y Universidad, procesado a la sazón por la Inquisición, dijo que estaba indispuesto y que, en la elección de Rector que tenía que hacer, no se podía hallar presente y que "daua por esta vez solamente su poder cumplido quan bastante de derecho se requiere al muy magnífico y muy reverendo señor Pedro Fernandez de Cordoua canonigo de la Sancta Iglesia de Jaen y protector de esta dicha Universidad ${ }^{80}$ ". Este gesto consolidó aún más los poderes del otro administrador.

En la esta línea, el mismo Pedro Fernández de Córdoba, el 9 de octubre de 1577, "requirio a los señores del claustro de dicha Universidad le dexen libremente nonbrar el dicho cançiller y no se entremetan a hazer eleçion ni nonbramiento ahora ni en tiempo alguno que si lo uiren hecho o hizieren ahora y en todo tiempo lo contradize, por quanto no tienen facultad para ello y solamente perteneçerle a su merçed, y al señor Doctor Carleval como patronos ${ }^{81}$. Frente a la oposición del claustro, como veremos seguidamente, Fernández de Córdoba propuso a Fr. Alonso de Rojas como Canciller. El 4 de noviembre, ante notario, el canónigo Fernández de Córdoba volvió a proponer a Rojas para la colación de un grado ${ }^{82}$. Ese mismo día, el claustro terminó por elegir a Rojas como Canciller ${ }^{83}$.

Antes de pasar al estudio más detallado de los Rectores y los Cancilleres durante este período, cabe detenernos brevemente sobre el claustro. En las actas aparece un conjunto de profesores fuertemente cohesionado, que vindicaba sus atribuciones contra lo que consideraban abusos de poder por parte de los patronos. A causa de estos enfrentamientos, a veces la sintonía inicial que existía entre los maestros se fue perdiendo, especialmente tras la muerte de Juan de Ávila. Asimismo, cabe señalar que el claustro no solamente tomaba medidas de carácter académico, sino también se preocupaba por otras cuestiones, como el vestido de los estudiantes "de manteo y bonete " $^{84}$ o por sus buenas costumbres, algo que queda de manifiesto en la colación de los grados. Asimismo, el 24 de agosto de 1574, por ejemplo, el claustro tomó medidas para el alquiler de casas a los estudiantes forasteros, y que el claustro se obligase por el precio ${ }^{85}$.

80 AHUB, Libro de acuerdos desde 1558 hasta 1577, f. 93v.

81 AHUB, Libro de acuerdos desde 1558 hasta 1577, f. 107r.

82 AHUB, Libro de acuerdos desde 1558 hasta 1577, f. 108r.

83 AHUB, Libro de acuerdos desde 1558 hasta 1577, f. $108 \mathrm{r}$.

84 AHUB, Libro de acuerdos desde 1558 hasta 1577, f. 5 r.

85 AHUB, Libro de acuerdos desde 1558 hasta 1577, f. 81r. Para tratar estas cuestiones se escogieron a los maestros Juan de Urrutia y Melchor de Peralta. 


\section{Rectores, Cancilleres y profesores}

Muchos de los profesores fueron Rectores y Cancilleres de la Universidad. Según Beltrán de Heredia, la tutela de San Juan de Ávila fue fundamental en los primeros maestros de la Universidad: "a ella había dedicado en la última etapa de su vida los más solícitos desvelos, quedando al frente de las aulas los discípulos más aventajados en letras y virtud: Diego Pérez de Valdivia, Valentín Vélez, doctores Loarte, Herrera, Medina y, sobre todo, el maestro Bernardino de Carlebal ${ }^{86 "}$.

En el apartado anterior hemos expuesto los primeros pasos de la Universidad. A la sazón, en un mismo manuscrito quedaban consignados los claustros y los grados. El 25 de abril de 1557, el claustro, presidido por el Rector, Bernardino de Carleval, escogió como Canciller a Fr. Gerónimo de Mendoza ${ }^{87}$. El 9 de mayo de 1557 se eligió como Vicecanciller a Fr. Miguel de Yepes, ministro de la Trinidad ${ }^{88}$. Se sabe también que el 14 de junio de 1558, Fr. Gerónimo Caro, dominico, fue elegido Vicecanciller por virtud de las bulas de $\mathrm{Su}$ Santidad ${ }^{89}$. Finalmente, el 7 de septiembre de 1558, el Rector Carleval pudo escoger como Rector al doctor Diego Pérez de Valdivia y por consiliarios a los doctores Valentín Vélez, Hernando de Herrera, Pedro Díaz Soriano y Juan Bautista de Sarantes ${ }^{90}$.

\subsection{Rectores y Cancilleres}

En ese año se empezó el Libro de acuerdos desde 1558 hasta 1577, que ofrece una información sistemática sobre el funcionamiento interno de la Universidad. En la primera página da fe de la elección de Pérez de Valdivia y sus consiliarios ${ }^{91}$. Desde entonces conocemos la nómina de los Rectores de la Universidad y de los Cancilleres, que se escogían anualmente. Diego Pérez repitió como Rector durante muchos años. Lo fue también en $1559^{92}$, mientras que en 1560, el Rectorado recayó en Valentín Vélez ${ }^{93}$.

86 V. Beltrán de Heredia, “Los alumbrados de la diócesis de Jaén...”, p. 254.

87 AHUB, Libro de grados 1549-1580, f. 33r.

88 AHUB, Libro de grados 1549-1580, f. 33r.

89 AHUB, Libro de grados 1549-1580, f. 41r.

90 AHUB, Libro de grados 1549-1580, f. 42r.

91 AHUB, Libro de acuerdos desde 1558 hasta 1577, f. $1 \mathrm{v}$.

92 AHUB, Libro de acuerdos desde 1558 hasta 1577, f. 5v.

93 AHUB, Libro de acuerdos desde 1558 hasta 1577, f. 8r. 
En 1564 se escogió al Maestro Sepúlveda como catedrático de Mayores ${ }^{94}$. En 1564 se eligió al Rector Soriano ${ }^{95}$. En 1565 fue elegido nuevamente Rector Diego Pérez de Valdivia ${ }^{96}$, y fue reelegido para los años siguientes, $1566^{97}$ y $1567^{98}, 1568^{99}, 1569^{100}$. El 25 de septiembre de 1568 se reunió el claustro porque Juan de Ocón, Canciller, residía en Úbeda y la distancia resultaba un problema. Eligieron, para dispensar los grados con más comodidad, como Canciller a Fr. Remigio Tamariz, Prior del Convento de Santo Domingo de Baeza $^{101}$.

En 1570 se escogió Rector a Diego de Carleval ${ }^{102}$ y al año siguiente al doctor Diego de Medina ${ }^{103}$, que renunció. El 17 de octubre de 1571 se eligió como Rector a Diego de Ávila ${ }^{104}$. Ese año decidieron que fuera Canciller el Dr. Antonio de la Raya, maestrescuela de Jaén ${ }^{105}$, mientras que en 1572, el cargo recayó en Fr. Diego de Villalobos, prior de Santo Domingo ${ }^{106}$. Por la muerte del Dr. Diego de Ávila, el 2 de junio de 1572, se escogió como Rector a Diego de Carleval ${ }^{107}$. El 16 de septiembre de dicho año fue elegido nuevamente Rector de la Universidad el Dr. Diego Pérez de Valdivia ${ }^{108}$, que tuvo necesidad de ausentarse de la ciudad por unos días, por lo que el 24 de octubre de ese año fue nombrado Vicerrector el Dr. Ojeda ${ }^{109}$.

En este contexto se sitúa la visita del inquisidor Alfonso Tamarón, que siguió de cerca a Hernán Núñez, Diego de Herrera, Diego Pérez de Valdivia y Bernardino Carleval, es decir, a la plana mayor de los profesores de la Universidad y de los adláteres preferidos de Juan de Ávila ${ }^{110}$.

94 AHUB, Libro de acuerdos desde 1558 hasta 1577, f. $21 \mathrm{v}$.

95 AHUB, Libro de acuerdos desde 1558 hasta 1577, f. 22v.

96 AHUB, Libro de acuerdos desde 1558 hasta 1577, ff. 30v-31r.

97 AHUB, Libro de acuerdos desde 1558 hasta 1577, f. 39r.

98 AHUB, Libro de acuerdos desde 1558 hasta 1577, f. 42r.

99 AHUB, Libro de acuerdos desde 1558 hasta 1577, f. 46r.

100 AHUB, Libro de acuerdos desde 1558 hasta 1577, ff. 49v-50r.

101 AHUB, Libro de grados 1549-158o, f. $101 \mathrm{v}$.

102 AHUB, Libro de acuerdos desde 1558 hasta 1577, f. 53r.

103 AHUB, Libro de acuerdos desde 1558 hasta 1577, f. 6or.

104 AHUB, Libro de acuerdos desde 1558 hasta 1577, f. 64r.

105 AHUB, Libro de acuerdos desde 1558 hasta 1577, ff. 66r-v.

106 AHUB, Libro de acuerdos desde 1558 hasta 1577, f. 68r.

107 AHUB, Libro de acuerdos desde 1558 hasta 1577, f. $69 \mathrm{r}$.

108 AHUB, Libro de acuerdos desde 1558 hasta 1577, ff. 71v-72r.

109 AHUB, Libro de acuerdos desde 1558 hasta 1577, f. 73r.

110 A. Huerga, Los alumbrados de Baeza, pp. 38-41. 
El 29 de marzo de 1573 fue designado Canciller el Maestro Almagro ${ }^{111}$, que fue elegido Rector el 9 de septiembre de dicho año ${ }^{112}$. Pedro de la Hoya, trinitario, desempeñó el cargo de Canciller el 29 de octubre de $1573^{113}$, aunque su nombramiento fue impugnado el 2 de enero de 1574, por ser contrario a las bulas $^{114}$. El 31 de enero de dicho año, el claustro escogió a Gil Martínez Dávalos como Canciller ${ }^{115}$. El 9 de septiembre de 1574 se nombró Rector a Diego Pérez de Valdivia ${ }^{16}$. Mientras éste estuvo ausente, encerrado en las cárceles inquisitoriales $^{117}$, el maestro Ojeda fungió como Vicerrector ${ }^{118}$.

Fr. Pedro de Guzmán, prior de los dominicos de Baeza, fue elegido Canciller el 7 de octubre de $1574^{119}$. El 24 de enero de 1575, para la "buen governacion destas scuelas por la ausencia del doctor Diego Perez" ${ }^{120 ", ~ s e ~ e l i g i o ́ ~ R e c t o r ~}$ al doctor Ojeda. El 22 de abril de dicho año, se le resignó como Rector, porque "anda yndispuesto y muy cansado y tiene munchas [sic] ocupaciones en su oficio de prior ${ }^{121}$ ”. El 23 de abril de 1575, el claustro nombró Rector a Diego de Sepúlveda $^{122}$. El 8 de septiembre de 1575 se designó como Canciller al P. Diego Manuel, Comendador de la Orden de la Merced de Baeza ${ }^{123}$ y al día siguiente el Dr. Sepúlveda fue reelegido Rector ${ }^{124}$. El 13 de febrero de 1576 fue escogido Canciller Fr. Alonso de Rojas, prior del Convento de Santo Domingo ${ }^{125}$ que, ante las ausencias del Dr. Antonio de Raya ${ }^{126}$, fue confirmado nuevamente el 4 de junio de $1576^{127}$. El 10 de septiembre de dicho año fue designado Rector el maestro Juan de Córdoba ${ }^{128}$. El 10 de marzo de 1577 se nombró Canciller a Fr.

\footnotetext{
111 AHUB, Libro de acuerdos desde 1558 hasta 1577, f. 74v.

112 AHUB, Libro de acuerdos desde 1558 hasta 1577, f. 75v.

113 AHUB, Libro de acuerdos desde 1558 hasta 1577, f. 78r.

114 AHUB, Libro de acuerdos desde 1558 hasta 1577, ff. 78v-79r.

115 AHUB, Libro de acuerdos desde 1558 hasta 1577, f. 79v.

116 AHUB, Libro de acuerdos desde 1558 hasta 1577, f. 81v.

117 A. Huerga, Los alumbrados de Baeza, pp. 83-84.

118 AHUB, Libro de acuerdos desde 1558 hasta 1577, f. 84r.

119 AHUB, Libro de acuerdos desde 1558 hasta 1577, f. 84r.

120 AHUB, Libro de acuerdos desde 1558 hasta 1577, f. 84v.

121 AHUB, Libro de acuerdos desde 1558 hasta 1577, f. 86v.

122 AHUB, Libro de acuerdos desde 1558 hasta 1577, f. 88r.

123 AHUB, Libro de acuerdos desde 1558 hasta 1577, f. 89r.

124 AHUB, Libro de acuerdos desde 1558 hasta 1577, f. 89r.

125 AHUB, Libro de acuerdos desde 1558 hasta 1577, f. 92r.

126 J. Higueras Maldonado, Documentos latinos..., p. 190.

127 AHUB, Libro de acuerdos desde 1558 hasta 1577, f. 93r.

128 AHUB, Libro de acuerdos desde 1558 hasta 1577, f. 94r.
} 
Alonso de Rojas ${ }^{129}$, a fin de que diese unos grados y el 18 de mayo del mismo año fue designado Canciller el P. Sebastián Ximenez, ministro del Convento de la Santísima Trinidad ${ }^{130}$.

El 9 de septiembre de 1577 fue escogido Rector nuevamente el Dr. Diego Pérez de Valdivia ${ }^{131}$, que había sido sentenciado y al que se le había prohibido predicar perpetuamente ${ }^{132}$. El 29 de julio de 1578, el Rector Pérez de Valdivia nombró como sustituto y Vicerrector al Dr. Pedro de Ojeda, quien el 8 de septiembre delegó su cargo en el Dr. Melchor de Molina ${ }^{133}$, que convocó al día siguiente la elección de Rector, que recayó en la persona del doctor Gaspar de Salcedo ${ }^{134}$. Sabemos que el Canciller a la sazón era Fr. Agustín de Salucio, dominico ${ }^{135}$. El 21 de marzo de 1579 fue elegido Rector el Dr. Melchor de Molina $^{136}$ y el 9 de septiembre del mismo año, en un clima de confrontación, se eligió Rector: el Dr. Melchor de Molina tuvo dos votos y el Dr. Juan de Córdoba, otros dos. Para desempatar, quisieron que los profesores presentes votasen. La mayoría se inclinó por el Dr. Molina, quien aceptó el cargo ${ }^{137}$. El 30 de enero de 1580 el Claustro accedió a que Dr. Becerra sustituyese por unos días al Rector Melchor de Molina ${ }^{138}$.

La situación era muy tensa. El 4 de enero de 1580 había sido propuesto como Canciller Fr. Juan de Vilches, prior del convento de Santo Domingo. Acto seguido, hubo un protesto indicando que el nombramiento era nulo, puesto que el verdadero patrón no era Luis Carrillo, sino Diego Pérez de Valdivia, tal y como constaba en la escritura pública otorgada por el Dr. Bernardino de Carleval. Carrillo, el 26 de enero de dicho año, escogió como Canciller a Fr. Fernando de Montesinos, comendador del Convento de la Merced ${ }^{139}$. El telón de fondo era el enfrentamiento con los administradores y, muy particularmente, con Pedro Fernández de Córdoba. El 6 de marzo de dicho año, se

129 AHUB, Libro de acuerdos desde 1558 hasta 1577, f. 103v.

130 AHUB, Libro de acuerdos desde 1558 hasta 1577, f. 104v.

131 AHUB, Libro de acuerdos desde 1558 hasta 1577, f. 105r.

132 A. Huerga, Los alumbrados de Baeza, p. 84.

133 AHUB, Libro de acuerdos desde 1558 hasta 1577, f. $111 \mathrm{v}$.

134 AHUB, Libro de acuerdos desde 1558 hasta 1577, f. 112r.

135 AHUB, Libro de grados 1549-1580, f. 221v.

136 AHUB, Libro de acuerdos desde 1558 hasta 1577, f. $117 \mathrm{r}$.

137 AHUB, Libro de acuerdos desde 1558 hasta 1577, ff. 118v-119v.

138 AHUB, Libro de grados 1549-1580, f. $250 \mathrm{ov}$.

139 AHUB, Libro de acuerdos desde 1558 hasta 1577, f. 124 r. 
eligió como Canciller para dar los grados a Fr. Juan de Vilches ${ }^{140}$. El Rector Melchor de Molina delegó, el 26 de abril de 1580, en Dr. Pedro de Ojeda ${ }^{141}$.

El Dr. Diego Pérez, desde su marcha, adeudaba unos dineros al arca de la Universidad, aunque el claustro, el 31 de agosto de 1580, pidió que hicieran "suelta" de esas deudas, "por los muchos beneficios que esta Uniuersidad a recibido de dicho señor doctor Diego Perez ${ }^{142}$ ". El 9 de septiembre de 1580 fue nombrado Rector el doctor Francisco de Becerra, catedrático de Prima de Santo Tomás en la Universidad ${ }^{143}$. Se tuvo que pedir permiso nuevamente a los patronos y, ante el visitador de las escuelas, Frey Luis Rodero ${ }^{144}$, capellán de Su Majestad, se volvió a proceder a la elección de Rector ${ }^{145}$. Rodero dio por válida la propuesta hecha en la persona del doctor Becerra, quien finalmente fue nombrado para el cargo ${ }^{146}$.

Rodero se hizo cargo de las críticas de los diversos miembros del claustro a los patronos, especialmente a Fernández de Córdoba. En su informe, detalló que eran necesarios unos nuevos estatutos para la institución y poner la Universidad de Baeza bajo la protección regia, a fin de evitar los abusos. Esta visita marcó un jalón fundamental en la historia de la institución, la cual inició una nueva etapa de confrontación que duró hasta la promulgación de los Estatutos de $1609^{147}$.

\subsection{Breve prosopografía}

En este apartado detallaremos una breve información de estos personajes, a fin de que el lector pueda hacerse cargo de su trayectoria. Se trata de unos datos extractados de forma sintética, con el fin de facilitar una ubicación de cada uno de estos protagonistas de la historia de la Universidad de Baeza. Algunas notas puestas a pie de página invitan a profundizar.

140 AHUB, Libro de acuerdos desde 1558 hasta 1577, f. 125r.

141 AHUB, Libro de grados 1549-158o, f. $257 \mathrm{v}$.

142 AHUB, Libro de acuerdos desde 1558 hasta 1577, f. 128v.

143 AHUB, Libro de acuerdos desde 1558 hasta 1577, f. 129r-v.

144 AGS, CRC, 216, 1, Visita hecha al Colegio y Universidad de Baeza por el juez Fray Luis Rodero...

145 AHUB, Libro de acuerdos desde 1558 hasta 1577, f. $130 \mathrm{v}$.

146 AHUB, Libro de acuerdos desde 1558 hasta 1577, f. 131r.

147 J. García Oro y M. J. Portela Silva, "Baeza la universidad de los patronos”, pp. 384-393. 
Alonso de Barzana, S. I., completó sus estudios en la Universidad de Baeza, en la que enseñó brevemente en 1560. Después ingresó en la Compañía de Jesús ${ }^{148}$, siendo sacerdote experimentado y, desde el noviciado, pidió a Francisco de Borja que le enviase a misiones, algo que consiguió en 1569, zarpando en la expedición del virrey Francisco de Toledo. Fue uno de los componentes de la segunda incursión de misioneros jesuitas a Perú.

Alonso de Rojas, O.P., fue Prior del Convento de Santo Domingo de Baeza, y Canciller en 1576.

Alonso de Sepúlveda, O. P., Mtro. y Prior de Santo Domingo, así como Rector de la Universidad. Lector de Prima en diversos conventos ${ }^{149}$.

Alonso de Vergara fue Canciller en 1563.

Alonso de Vilches, vecino de Baeza, Prior de Cazalilla, M. A., fue catedrático de Artes y D. T. en Baeza en 5-5-1576 $6^{150}$.

Alonso Garzón, M. A., regente de Artes, catedrático de Artes y Filosofía desde 1562 hasta $1566^{151}$.

Alonso Pretel, L. T. por la Universidad de Sigüenza en 3-11-1563 y M. A. por la Universidad de Zaragoza a 4-6-1558. Admitido e incorporado en Baeza el 296-1580 y con el grado de D. T. Catedrático de Teología. Canónigo. Denunció el libro de Huarte de San Juan ante el Tribunal de la Inquisición en $1579^{152}$.

Álvaro de Vergara O. P., Prior de Sto. Domingo, fue Canciller en 1563.

Antonio de Raya Navarrete (1536-1606), fue Colegial de San Clemente de Bolonia en $1559^{153}$. Doctor en ambos derechos. Maestrescuela de la Iglesia de Jaén y Canciller en 1576, fue Inquisidor de Cerdeña, Lerena, Granada y Valladolid. Fue nombrado obispo de Cuzco en 1594. Al parecer, pidió que le nombraran un auxiliar y volvió a España en 1606.

148 W. Soto Artuñedo, “Alonso de Barzana, S. I. Apóstol de Andalucía y Sudamérica”, Archivo Teológico Granadino, 79 (2016), pp. 5-130.

149 R. Ortega Sagrista, "La extinguida Universidad de Santa Catalina Mártir de la ciudad de Jaén”, Boletín del Instituto de Estudios Giennenses, 54 (1967), pp. 9-27, especialmente p. 16.

150 J. Higueras Maldonado, Documentos latinos..., p. 190.

151 L. Sala Balust, "Introducción”, p. 138.

152 M. de Iriarte, El doctor Huarte de San Juán y su examen de ingenios. Contribución a la historia de la Psicología diferencial, Madrid, CSIC, 1948, p. 88.

153 B. Cuart Moner, "Algunas notas sobre los colegiales de San Clemente en la Administración Americana (siglos XVI-XVIII)”, Studia Historica, 7 (1989), pp. 799-823. 
Agustín Salucio, O.P. (1523-1601), fue natural de Chipiona. Bautizado en la Iglesia Parroquial de Nuestra Señora de la O. Ejerció como Prior del convento de Sto Domingo y Canciller de la Universidad en 1578. Maestro en Sagrada Teología. Destacó por su oratoria sagrada muy barroca. Rechazó la mitra de Córdoba. Predicó ante Felipe II y Felipe III ${ }^{154}$. Autor del célebre Discurso acerca de la justicia y buen govierno de España en los estatutos de limpieça de sangre y si conviene o no alguna limitación en ellos.

Benito Sánchez de Padilla fue lector en la Facultad de Artes.

Bernardino de Carleval (o Carlevar). Discípulo de Juan de Ávila. D. T. el 1-121549. Catedrático de Sagrada Escritura ${ }^{155}$. Rector en 1555, fue Patrón y administrador de la Universidad. Fue procesado por la Inquisición en $1554^{156}$ y posteriormente junto con otros profesores de la Universidad ${ }^{157}$.

Blas de la Cavallería, natural de Almagro, catedrático de Artes y Filosofía, M. A. en Alcalá, incorporado en Baeza el 11-11-1570 y D. T. en Baeza el 6-6-1574, fue asimismo catedrático de Teología de Vísperas ${ }^{158}$.

Diego Ciurana de Peralta, natural de Baeza, fue catedrático de Lengua Latina del Aula de Mayores, L.A y M. A. en Baeza el 1-12-1578.

Diego de Ávila, O.SS.T. (Baena, ca. 1556- ca. 1611). Tomó el hábito trinitario en Sevilla en 1572. Fue lector de Artes y ministro del Convento Trinitario, Colegial de Santa Catalina de Baeza, L. A. y D.A. en Baeza el 17-12-1578, catedrático de Artes. Se graduó en Teología en Baeza. Fue catedrático en la Universidad de Sevilla y predicador para Felipe II y Felipe III. Provincial de la Orden. Sabía griego y hebreo y era poeta en lengua latina y castellana. Dejó a su muerte numerosos manuscritos explicando lugares de las Sagradas Escrituras ${ }^{159}$.

Diego de Ocón, O.SS.T, natural de Úbeda, tomó el hábito en 1558. Ministro del Convento de Sta. Catalina de Baeza, fue Canciller en 1578, Lector en la Uni-

154 H. Sancho, "El Maestro Fr. Agustín Salucio, O.P. Contribución a la Historia Literaria Sevillana del siglo XVI," Archivo Hispalense, 16 (1952), pp. 9-47.

155 L. Sala Balust, "Introducción”, pp. 136-140.

156 Ibidem, p. 214.

157 Idem, p. 57. Véase A. Huerga, Los alumbrados de Baeza, pp. 55-6o.

158 V. Parelló, "Limpieza de sangre y conflictividad social en Castilla en los siglos XVI y XVII”, en P. Juan i Tous y H. Notebaum (eds.), El olivo y la espada: estudios sobre el antisemitismo en España (siglos XVI-XX), Tübingen, M. Niemeyer Verlag, 2003, pp. 91105, especialmente, p. 103.

159 J. Pujana, La reforma de los Trinitarios durante el reinado de Felipe II, Salamanca, Secretariado Trinitario, 2006, pp. 225, 374. 
versidad, admitido y graduado de D. T. en Baeza el 22-1-1579. Incorporó el grado a la Universidad de Tarragona en $1584^{160}$. Fue definidor ${ }^{161}$ y provincial de Andalucía ${ }^{162}$.

Diego de Sepúlveda, O.P., fue incorporado a la Universidad de Baeza el 19-4-1570 y recibió el grado de $\mathrm{D}$. $\mathrm{T}$.

Diego de Villalobos, O.P., Prior de Sto. Domingo de Baeza. Fue incorporado a la Universidad de Baeza el 19-4-1570.

Diego Flores, Arcediano de Castro del Río, fue Canciller en 1549.

Diego Lucas de Córdoba, Arcediano de Jaén, fue Canciller en $1558^{163}$.

Diego Manuel, O. de M., Comendador de Ntra. Sra. de la Merced de Baeza, fue Canciller en 1575. Había viajado a Perú1 ${ }^{164}$.

Diego Pérez de Valdivia (Baeza, ¿̇1525? - Barcelona, 28 de febrero de 1589). Quizás fue la personalidad más rica e influyente entre todos los profesores de Baeza. Discípulo de Juan de Ávila. B. A. y Lector de Artes (1549). Pidió los grados de L. A. y M. A. Recibió el grado de D. T. en Baeza el 22-11-1554. Fue Rector y Vicerrector en numerosas ocasiones. Fue catedrático en Teología, de Sagrada Escritura y Canciller en $1570^{165}$. Fue Arcediano de Jaén en 1569. Fue procesado y estuvo en la cárcel de la Inquisición de Córdoba ${ }^{166}$. En sus últimos años fue catedrático en la Universidad de Barcelona ${ }^{167}$. Escribió numerosas obras $^{168}$.

160 R. Ramis Barceló, "Grados mayores en la Universidad de Tarragona (1580-1624)", Analecta Sacra Tarraconensia, 90 (2017), p. 142.

161 J. Pujana, La reforma de los Trinitarios durante el reinado de Felipe II, p. 634.

162 A. Cabazán, Apuntes para la historia de Úbeda recopilacion de datos exparcidos en diferentes obras, con nuevas noticias y documentos inéditos, Ubeda, Imp. de José Martínez Montero, 1887, p. 211.

163 L. Coronas Tejada, “Los judeoconversos en el reino de Jaén”, Boletín del Instituto de Estudios Giennenses, 97 (1978), pp. 79-105, especialmente p. 91.

164 V. M. Barriga, Los mercedarios en el Perú en el siglo XVI: 1525-158o, Vol. 2, Arequipa, Editorial La Colmena, 1939, p. 253.

165 J. Melgares Raya, Diego Pérez de Valdivia, (1524-1589): Rector de Baeza, arcediano de Jaén, apóstol de Cataluña, Jaén, Seminario Diocesano, D.L., 1990.

166 A. Huerga, Los alumbrados de Baeza, pp. 80-84, 135, 178.

167 J. M. Madurell Marimon, "Diego Pérez de Valdivia en Barcelona", Analecta Sacra Tarraconensia, 30 (1957), pp. 343-371.

168 P. M. Pérez Aguilera, "De Sacra ratione concionandi de Diego Pérez de Valdivia (Baeza, 1524 - Barcelona 1589)”, Boletín del Instituto de Estudios Giennenses, 191 (2005), pp. 119-135. 
Fernando de Pedraza, natural de Baeza, recibió el grado de M.A en Baeza el 8-91575, así como el de D. T. el 7-3-1580. Fue maestro en la Facultad de Artes y Catedrático de Teología.

Fernando Montesinos, O. de M., comendador de la Orden de la Merced, fue Canciller en 1579 y D. T ${ }^{169}$.

Francisco de Becerra y Baeza, natural de Úbeda, D.T. por Sigüenza el día 24-101575, fue incorporado en Baeza 25-9-1579, como catedrático de Prima de Sto. Tomás; M. A. por Baeza 29-6-1580. Fue canónigo Magistral de su Colegiata y Comisario del Santo Oficio de la Inquisición de Córdoba en 1629. Fue D. T. por el Colegio de Maese Rodrigo y Universidad de Sevilla y regente allí de una cátedra. Visitador del obispado de Jaén por nombramiento del obispo-cardenal Baltasar de Moscoso y Sandoval ${ }^{170}$.

Francisco de Sepúlveda consiguió todos los grados en la Universidad de Baeza. Fue catedrático de gramática de mayores desde $1564^{171}$.

Gabriel de Guevara, maestrescuela y canónigo de Jaén, fue gobernador por el Obispo-Cardenal de Jaén, del Consejo de S.M. en 1-11-1549.

Gaspar de Godoy, vecino de Úbeda, L. A. por Sevilla, fue incorporado a Baeza el 28-8-1573. Fue M. A. y catedrático propietario de Artes, así como también B. T.

Gaspar de Salcedo [Maestro Salcedo] recibió el grado de M. A. en Baeza el 1312-1565. Fue D. T. el 6-6-1574. Fue sucesivamente catedrático de Artes, catedrático de Vísperas de Sto. Tomás y catedrático de Prima. Fue Rector de la Universidad y Prior de la Iglesia de la Magdalena de Jaén.

Gaspar de Loarte, S. I. (Medina del Campo, ca. 1498 - Valencia 1578). Discípulo de Juan de Ávila. Se había graduado en la Universidad de Salamanca. Fue catedrático de Prima de Teología hasta $1552^{172}$, se le dió el grado de M. A. y D. T. en Baeza el 1-12-1549. Fue Rector en 1551. Ingresó en la Compañía de Jesús. Tuvo serios problemas por su condición de cristiano nuevo. Fue nombrado Rector del Colegio en Génova (1555-1562), desempeñó el mismo cargo en Messina (1562-1566) ${ }^{173}$.

169 J. Simón Díaz, Bibliografía de la literatura hispánica, Vol. 15, Madrid, CSIC, 1992, p. 293.

170 G. de la Jara, Historia de Úbeda en sus documentos, Asociación Cultural Ubetense “Alfredo Cazabán Laguna”, vol. II (online).

171 L. Sala Balust, "Introducción”, p. 139.

172 L. Sala Balust, "Introducción”, pp. 136-137.

173 J. O’Malley, Los primeros jesuitas, Santander, Mensajero Sal Terrae, 1993, pp. 147-152. 
Gerónimo Caro, O.P. Como D. T. se incorporó 5-6-1558 en Baeza y graduado en M. A., fue Vicecanciller a 14-6-1558. Fue Prior de Santo Domingo. Según Huerga, "era una de las figuras intelectuales de más fuste en Sevilla al mediar el siglo XVI. En 1551 obtuvo el galardón de maestro en teología. El 4 de febrero de 1558 el cabildo de la catedral le encargó los sermones de los lunes de

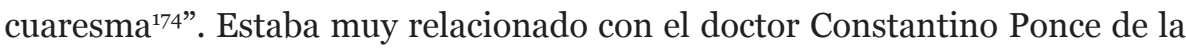
Fuente. Fue acusado de luteranizante y prendido por la Inquisición de Sevilla en $1559^{175}$.

Gerónimo de Falces obtuvo el grado de M.A. en 1563. Fue profesor de Griego desde $1561^{176}$.

Gerónimo de Mendoza, O. P., fue Canciller de la Universidad en 1557.

Gerónimo Núñez, O.SS.T., fue Ministro de la Trinidad y Canciller de la Universidad.

Gil Ramírez de Ávalos, [Gil Dávalos] vecino de Baeza, recibió el grado de M. A. el 31-1-1574 en Baeza.

Gonzalo de Carvajal, (¿Baeza?, s. XVI - ¿Córdoba?, 19.III.1605). Hijo de don Luis de Escavias Carvajal, regidor de Baeza, y de doña Beatriz Flores. Arcediano de Castro desde 1543. Secretario del Santo Oficio de Córdoba. Fue asimismo patrono del Colegio de la Asunción de Córdoba, y fundador y primer administrador de la Cofradía de niños expósitos de Córdoba. Fue Canciller de la Universidad $^{177}$.

Hernán Núñez, M. A., fue incorporado el 15-5-1563 y designado Rector en 1563. Discípulo de Juan de Ávila. Fue uno de los principales acusados en el proceso de la Inquisición contra los Alumbrados de Baeza ${ }^{178}$.

Hernando de Herrera, canónigo de la colegiata de Úbeda, fue B. A. y Lector de

174 Á. Huerga, "Dominicos andaluces procesados por la Inquisición en el siglo XVI", en A. Bernal Palacios (ed.), Praedicatores, Inquisitores II, Los Dominicos y la Inquisición en el mundo ibérico e hispanoamercano. Actas del $2^{\circ}$ Seminario internacional sobre los Dominicos y la Inquisición, Sevilla, 3-6 de Marzo de 2004, Roma, Angelicum U. P., 2006, pp. 307-322. La cita está en la p. 313.

175 Véase K. Wagner, El doctor Constantino Ponce de la Fuente. El hombre y su biblioteca, Sevilla, Excma. Diputación Provincial de Sevilla, 1979, p. 45.

176 L. Sala Balust, "Introducción”, p. 138.

177 A. J. Díaz Rodríguez, "Diccionario biográfico de la catedral de Córdoba (II): los miembros del cabildo en época moderna”, Historia y Genealogía, 6 (2016), pp. 33-63, p. 48.

178 A. Huerga, Los alumbrados de Baeza, p. 40. 
Artes del Colegio desde $1549^{179}$ y, desde 1557, catedrático de Vísperas. Pidió los grados de L. A y M. A. Recibió el grado de D.T. en Baeza 4-11-1555. Acusado en el proceso de la Inquisición contra los Alumbrados de Baeza ${ }^{180}$. Fue condenado y obligado a abjurar de levi. Se le suspendieron las facultades de predicar, confesar y administrar los sacramentos durante seis años.

Hernando de Aguayo recibió el grado de D.T. en Baeza en 22-11-1554. Discípulo y colaborador de Juan de Ávila ${ }^{181}$. Catedrático de Vísperas de Teología en $1549^{182}$. Fue Rector de la Universidad en 1552.

Juan Bautista de Sarantes fue incorporado como L. T. el 20-9-1564 y se le dio el grado de D. T. en Baeza. Fue catedrático de Artes hasta $1560^{183}$.

Juan de Córdoba (ca. 1522). Hijo de don Diego Fernández de Córdoba, conde de Cabra $^{184}$. Recibió el grado de M. A. el 20-1-1555 en Baeza. Fue Rector en 1577 y Vicerrector, así como canónigo de la Colegiata y Deán.

Juan de Gante fue incorporado como M.A. el 19-5-1563. Enseñó retórica en la Universidad de Baeza desde $1561^{185}$.

Juan de Ocón, arcediano de Ubeda, fue provisor del Obispado, así como fundador del Convento de Carmelitas Descalzos de Úbeda, en 1587. Ejerció como Canciller de la Universidad en 1558.

Juan de Pedraza, D. T. por Sevilla, fue incorporado a la Universidad de Baeza el 6-11-1551 y recibió el grado de M. A. en Baeza el 6-11-1567. Fue catedrático de Teología, Prior de la parroquial del Salvador de Baeza, así como vicario y Prior de San Juan de Arjona.

Juan de Vilches, O. P., Prior del Convento de Sto. Domingo de Baeza, fue Canciller en $1579^{186}$.

Juan Ximenez (Jiménez) fue profesor de Gramática ${ }^{187}$. Fue admitido en la cátedra

179 L. Sala Balust, "Introducción”, p. 136-139.

180 A. Huerga, Los alumbrados de Baeza, pp. 75-80 y 169.

181 L. Sala Balust, "Introducción”, p. 135.

182 Ibidem, p. 136.

183 Idem, p. 138.

184 A. J. Díaz Rodríguez, "Las casas del deán don Juan de Córdoba: lujo y clientela en torno a un capitular del Renacimiento”, Hispania Sacra, 123 (2009), pp. 77-104

185 L. Sala Balust, "Introducción”, p. 138.

186 J. M. Delgado Barrado y M. A. López Arandia, Poderosos y privilegiados: los caballeros de Santiago de Jaén, siglos XVI-XVIII, Madrid, CSIC, 2009, p. 170.

187 L. Sala Balust, "Introducción”, p. 125. 
con unas condiciones por parte del Claustro. Fue investigado por el Tribunal de la Inquisición en 1549.

Luis de Medina fue incorporado en la Universidad el 24-5-1558. Recibido y aceptado por la Universidad el 5-6-1558, fue graduado de M. A. y recibió la L.T. en Baeza el 14-11-1563. Fue catedrático de Vísperas de Teología desde $1562^{188}$.

Luis Gómez recibió el grado de M. A. en 1557. Fue profesor de gramática de menores entre 1554 y $1556^{189}$.

Martín Ligero se graduó de M. A. en 1557. Ejerció como profesor de griego entre 1557 y $1558^{190}$.

Melchor de Molina recibió el grado de D. T. Fue prior de San Pablo ${ }^{191}$. Se le nombró profesor de gramática de mínimos desde $1566^{192}$. Ejerció como Decano de la Facultad de Teología y como Rector en $1579^{193}$.

Melchor de Soria y Vera (Jaén, 1558 - Toledo, 1643). Nació en una familia noble. Recibió el grado de M. A. por Alcalá el 17-11-1574, y el de B. T. en Alcalá el 4-61578. Fue incorporado en Baeza 25-9-1579 como catedrático de Artes. Fue párroco de San Ildefonso y en 1599 marchó a la Archidiócesis de Toledo, donde ejerció como obispo auxiliar y obispo de Troya. En 1625 fue propuesto como Calificador del Consejo del Santo Oficio de la Inquisición de Toledo. Escribió sobre cuestiones teológico-económicas ${ }^{194}$.

Miguel de Yepes, O.SS.T. Tomó el hábito el año 1528 en Talavera' ${ }^{195}$. Ministro de la Santísima Trinidad. Vicecanciller de la Universidad, fue Canciller en 1557.

Pedro Almagro de Molina fue natural de Almodóvar del Campo, diócesis de Toledo. Recibió el grado de L. A. por Alcalá, fue incorporado en Baeza el 10-111568, M. A. y recibió el grado de D. T. el 7-3-1580 en Baeza. Fue Rector de la

188 Ibidem, p. 138.

189 Idem, p. 137.

190 Idem, p. 138.

191 V. Beltrán de Heredia, "Los alumbrados de la diócesis de Jaén...”, p. 270.

192 L. Sala Balust, "Introducción”, p. 139.

193 J. Martínez Rojas, El Episcopado de D. Francisco Sarmiento de Mendoza (15801595): la reforma eclesiástica en el Jaén del XVI, Jaén, Instituto de Estudios Giennenses, 2004, p. 480.

194 J. J. Duro Cobo, "Melchor de Soria y Vera: un escolástico preocupado por los problemas económicos el siglo XVI en Castilla”, Revista de estudios regionales, 82 (2008), pp. 313-342.

195 J. Pujana, La reforma de los Trinitarios..., p. 172. 
Universidad. Era, al parecer, sobrino de Juan de Ávila ${ }^{196}$. Catedrático de Artes desde $1568^{197}$, fue Rector y catedrático de Sto. Tomás.

Pedro de Arias, O. P., fue Prior del Monasterio de Sto. Domingo de Baeza, así como Canciller de la Universidad.

Pedro de Guzmán, O. P., Prior de Sto. Domingo de Baeza, fue Canciller en 1574.

Pedro de Ojeda (†1616), recibió los grados de D. T. y M. A. Discípulo de Juan de Ávila. Predicador. Catedrático de Artes desde $1567^{198}$. Catedrático de Teología escolástica y positiva. Fue Rector y Vicerrector de la Universidad, así como Prior de San Andrés de Baeza ${ }^{199}$.

Pedro de la Hoya, O.SS.T. (1537-1617), era natural de Jaén y fue Ministro de la Trinidad de Baeza. Recibió el grado de Presentado ${ }^{200}$. Ejerció como Canciller en 1573. Murió con fama de santidad.

Pedro Díaz Soriano Vega fue Juez Eclesiástico de Baena. Fue incorporado como M. A. el 7-1-1550. Fue maestro de la cátedra de Artes en $1551^{1^{201}}$. Recibió el grado de D. T. en Baeza el 25-11-1563 y fue Rector en 1565.

Pedro Fernández de Córdoba fue patrono del Colegio y canónigo de Jaén, residente en la Catedral de Baeza, así como catedrático de Teología. En 1568 decidió financiar un nuevo edificio para la Universidad, con la iglesia aneja de San Juan Evangelista en el sitio de la ermita de San León, junto al arco del Barbudo. Tuvo frecuentes enfrentamientos con el Claustro por su gestión, que incluso llegaron a Roma ${ }^{202}$.

Pedro Paulo Ferrer, S. I. Natural de Málaga. Estudió y fue profesor de Artes en la Universidad de Baeza ${ }^{203}$. Opositó a la canonjía magistral de la catedral de Málaga. Después ingresó en la Compañía de Jesús y se trasladó a Portugal, al colegio de Évora.

Remigio Tamariz, O.P., fue Prior de Santo Domingo de Baeza y Prior de Santa Catalina de Jaén. Ejerció como Canciller de la Universidad. Fue autor de un poema en octavas reales en ocho cantos sobre la vida de Santo Domingo. En

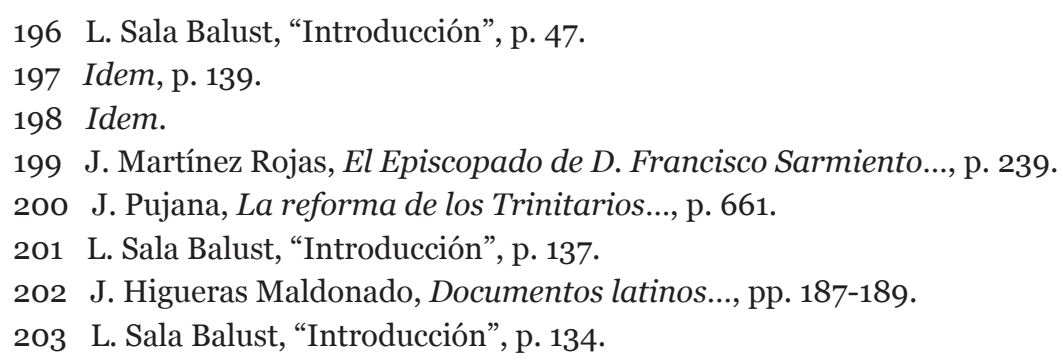


1578 intervino como teólogo de la Inquisición en el caso de los alumbrados de Extremadura $^{204}$.

Rodrigo Ochoa, natural de Baeza. Recibió el grado de M. A. en Baeza el 29-9-1571. Fue catedrático propietario de Artes y B. T.

Sebastián de Sosa, O.SS.T., fue ministro de la Trinidad, consejero del Provincial de Andalucía y Canciller y Vicecanciller de la Universidad ${ }^{205}$.

Sebastián Ximenes, O.P., fue ministro del Convento de la Santisima Trinidad de Baeza y Canciller de la Universidad.

Valentín Vélez de Mendoza, discípulo de Juan de Ávila, recibió el grado de D.T. en Baeza el 22-11-1554. Sustituyó en la cátedra de Prima a Gaspar de Loarte y profesó hasta $1560^{206}$. Fue Rector en 1556. Hijo bastardo de Gaspar Vélez de Mendoza, caballero del hábito de Santiago, fue aceptado como canónigo de la Catedral de Jaén ${ }^{207}$.

\section{El acceso a los grados}

Los Estatutos de 1609 han sido ya editados y comentados en diferentes publicaciones ${ }^{208}$. Asimismo, el profesorado de la Universidad y la distribución de las cátedras durante este período resulta conocido desde la publicación del libro de Sala Balust. Entremos, pues, a examinar el acceso a los grados. Sin duda, no hubo grandes diferencias en la práctica de la colación durante el siglo XVI y la que queda preceptuada en dichos estatutos de comienzos de la centuria posterior. Vamos a estudiar, por separado, los grados de Artes y los de Teología, y lo haremos atendiendo especialmente a los actos que quedan consignados en los manuscritos.

\subsection{Facultad de Artes}

Los catedráticos de Artes enseñaban básicamente latinidad y filosofía. Los modelos para la enseñanza del latín eran, al igual que en las demás universi-

204 A. Larios Ramos, "Los Dominicos y la Inquisición”, Clio y Crimen, 2 (2005), pp. 81-126.

205 J. Pujana, La reforma de los Trinitarios..., pp. 192-193.

206 L. Sala Balust, “Introducción”, pp. 137-138.

207 J. M. Delgado Barrado y M. A. López Arandia, Poderosos y privilegiados..., p. 262.

208 A. Ortega Ruiz, La Universidad de Baeza... cit. 
dades, los autores clásicos, mientras que en filosofía se leía a Aristóteles (un año de súmulas, otro de lógica y otro de metafísica, con el mismo profesor, que impartía dos horas y media de clase por la mañana y hora y media por la tarde). Los sábados se reunían los catedráticos de filosofía con sus alumnos en el teatro de la Universidad para unas conclusiones o ejercicios de recapitulación.

Tras completar los estudios de latín y de filosofía, el estudiante podía pedir el examen de bachiller, que se hacía siguiendo el modelo de París y de Alcalá. Hay que señalar que se trataba de un acto solemne, que podía ser sustentado individualmente o, como era más corriente, en grupo, junto con los condiscípulos. El tribunal solía estar compuesto por tres catedráticos, que hacían diferentes preguntas al graduando (sobre las súmulas, los predicables de Porfirio y algunas cuestiones de filosofía natural). Normalmente, el maestro con el que había cursado la filosofía le concedía el grado. Tomemos, por ejemplo, lo que se indica en la colación de un grado de bachiller:

"En cumplimiento y execucion del Estatuto que trata lo que se debe hacer, después de examinados los estudiantes que se han de graduar de B. A. fueron ayuntado en el claustro en la capilla menor de esta dicha Universidad los muy Magfcos. y Rdos. señores [...], y entrando cada uno de los estudiantes y examinados, los dichos señores a los suficientes recogidos y virtuosos exortaron a la perseverancia y agradecieron sus trabajos y a los insuficientes y distraídos reprehendieron y corrigieron con la aspereza que por el dicho estatuto se manda y ansi salidos cada uno de los laureados del dicho claustro los dichos señores examinadores notaron en lo tocante a la suficiencia y en cuanto a la virtud y recogimiento ...209"

Para la colación de la licenciatura en Artes, era necesario un acto mayor (las responsiones magnas), una repetición y el examen secreto. Habitualmente pasaban varios meses entre cada uno de estos actos. Muchas veces, al igual que sucedía en Alcalá, entre las responsiones magnas y la repetición había responsiones parvas, que se celebraban al cabo de unos pocos días de las magnas. Las responsiones magnas se celebraban habitualmente, durante cuatro horas, ante un tribunal presidido por el maestro que había enseñado al graduando u otro que estuviera leyendo entonces. Previamente, el estudiante había facilitado al Rector, para su aprobación, una copia de las treinta conclusiones o materias del acto.

La mayor parte del claustro decidió, el 17 de septiembre de 1574, que no se diese colación a los exámenes secretos ${ }^{210}$. Para éstos, se llevaba a cabo el se-

209 AHUB, Libro de grados 1549-158o, f. $177 \mathrm{v}$.

210 AHUB, Libro de acuerdos desde 1558 hasta 1577, f. 83r. 
ñalamiento de capítulos ante el Rector y veinticuatro horas después, normalmente por la tarde, se desarrollaban las pruebas ante cinco maestros en Artes, que argüían al candidato tanto con cuestiones de dialéctica como de filosofía. En dicho examen no estaba el maestro propio, sino los demás. Finalmente, se calificaba la prueba y, si aprobaba, se otorgaba el título.

El Magisterio en Artes requería simplemente una petición ante el Rector y el claustro, y era costumbre que no se diese a aquellos estudiantes que no hubieran cursado cuatro años de Teología. Se trataba de un título de mera solemnidad, que ponía fin a la trayectoria académica en esta Facultad. Sin embargo, como tendremos ocasión de comentar después, los maestros eran muy reacios a colacionar el grado de Maestro a aquellas personas manifiestamente incompetentes.

Veamos este desarrollo con un ejemplo. Diego de Peralta, vecino de Baeza, recibió el grado de B.A. el día 9 de octubre de 1567 de manos del Dr. Diego de Ávila, siendo testigos Francisco Delgado, obispo de Jaén, y Juan de Ocón, Canciller ${ }^{211}$. El 15 de junio de 1568 sustentó responsiones magnas para Licenciado en Artes, que presidió el Dr. Diego de Ávila y aprobó ${ }^{212}$. El 18 de junio hizo las responsiones parvas, presididas por Diego de Ávila. El 13 de octubre del mismo año llevó a cabo la repetición, que presidió el maestro Almagro ${ }^{213}$. El 10 de junio de 1569 hizo un acto mayor, presidido por su maestro y aprobó. El Rector Pérez, al día siguiente, señaló capítulos para el examen secreto. Obtuvo el grado y el Canciller Ocón se lo confirió el 13 de junio de 1569.

\subsection{Facultad de Teología}

$\mathrm{Al}$ ser una Universidad pensada para la formación teológica, muchos estudiantes que completaban los grados de Artes estudiaban asimismo teología y hacían algunos ejercicios para la obtención de títulos en la Facultad. Siguiendo la orientación propia de las Universidades del momento, se atendía tanto la línea escolástica (dos cátedras de Santo Tomás y una Durando) como la escriturística (con una cátedra). Sin duda, como es sabido, los cristianos nuevos se mostraban muy competentes en la exégesis de la Biblia y enfatizaban la importancia de la teología bíblica.

Para Melquíades Andrés, "era el proyecto ambicioso de una especie de ins-

211 AHUB, Libro de grados 1549-1580, f. 98r.

212 AHUB, Libro de grados 1549-1580, f. 100v.

213 AHUB, Libro de grados 1549-1580, f. 104-105v. 
titutos bíblicos que elevasen el nivel escriturístico como elemento importante de restauración de los estudios teológicos y como punto de encuentro obligado con los protestantes y con los humanistas. Ello contribuiría a la vez a dar interna solidez teológica a los eclesiásticos y a dotar a la Iglesia de defensa segura frente a los ataques de los herejes ${ }^{214}$ ". En Teología escolástica se estudiaba a Santo Tomás y el catedrático de Durando leía habitualmente materias del Libro del Maestro de las Sentencias. En cuanto a la escolástica, sin duda, en Baeza se impartía una enseñanza muy tradicional.

Había a menudo actos públicos o ejercicios de recapitulación. Los sábados por la tarde se celebraba el acto de conclusiones, presidido por los catedráticos. Quienes simplemente querían ser Bachilleres en Teología, bastaba que hiciesen una tentativa parva, que era un examen sobre lecciones de los cuatro libros del Maestro de las Sentencias. Si más adelante cambiaban de idea y querían graduarse de Licenciados, tenían que hacer una tentativa magna. En cambio, quienes se graduaban de Bachiller con la intención de proseguir con la Licenciatura, no importaba que realizasen tentativa parva, y pasaban directamente a la tentativa magna, con lecciones de los cuatro libros del Maestro de las Sentencias. Para el examen de Licenciatura tenían que afrontar cuatro actos, de nombre algo variable: un acto mayor, un acto menor, una repetición y un acto de quodlibetos, que generalmente revestía forma de examen secreto.

Estos actos empezaban dos años después de haber concluido el estudiante las lecciones de teología y se solían esperar unos meses entre acto y acto, de manera que se obtenía la licenciatura unos cuatro años después de haber concluido los cursos. El grado de Doctor en Teología se confería a los estudiantes que lo solicitaban y que habían merecido unas mejores calificaciones. El doctorado era un acto meramente cerimonial, en el que el doctorando respondía a una cuestión disputada y luego se le colacionaba solemnemente el grado.

Veámoslo de nuevo con un ejemplo. Melchor Hernández de Herrera, tras haber recibido el grado de Maestro en Artes el 4 de diciembre de 1556, pidió al Rector Carleval hacer actos de Teología el 21 de diciembre de dicho año ${ }^{215}$. El primer acto lo llevó a cabo el 11 de mayo de $155^{8}$ y fue aprobado. El 18 de enero de 1559 hizo un acto menor de Teología, presidido por el Dr. Vélez, y aprobó. El Rector, Diego Pérez de Valdivia, le otorgó el grado de Bachiller en Teología. El 27 de octubre de 1559 llevó a cabo el primer acto para Licenciado,

214 M. Andrés, La Teología española en el siglo XVI, Vol. I, p. 184.

215 AHUB, Libro de grados 1549-1580, f. 32r. 
y fue presidido por el Dr. Diego Pérez. El 28 de enero de 1563 sostuvo el acto menor, presidido también por el Dr. Pérez de Valdivia. En octubre desarrolló la repetición ante el mismo maestro ${ }^{216}$ y el 11 de noviembre hizo el examen secreto y se le concedió el grado de Licenciado. El 12 de noviembre se examinó para recibir el grado de Doctor, en un acto presidido por el Dr. Herrera ${ }^{217}$, y el Canciller Juan de Ocón le concedió el grado al día siguiente ${ }^{218}$.

\subsection{Las calificaciones}

Existía una gradación de las calificaciones, que no siempre se especifica en la documentación manuscrita: la mejor de ellas era aprobado simpliciter (que equivaldría al habitual nemine discrepante), seguida de la calificación de aprobado por mediano, luego la de aprobado para que se gradúe y, finalmente, cuando los ejercicios no eran nada brillantes, se aprobaba por razón de los cursos seguidos (ratione cursuum). Si algún acto tenía un nivel demasiado bajo, se suspendía y no se podía proseguir.

Para entender las calificaciones, lo mejor es verlo con ejemplos. Así, Pedro Gutiérrez, vecino de Jaén, había conseguido el grado de Bachiller en Artes en 1573. Hizo las responsiones magnas para Licenciado en Artes en $1575^{219}$, presididas por el Dr. Cavalleria ${ }^{220}$. Sostuvo en 1576 una repetición para Licenciado en Artes, presidida por el maestro Godoy, quien decidió que se suspendiese el examen secreto ${ }^{221}$. Otro caso sería el de Cristóbal de Cámara, vecino de Torrejimeno, que recibió el grado de Bachiller en Artes en $1575^{222}$. Hizo en 1576 un acto mayor para Licenciado en Artes, presidido por su propio maestro y fue reprobado. Sabemos también que Francisco Fernández Alevín, vecino de Baeza, llevó a cabo las responsiones magnas para Licenciado en Artes en 1577. Hubo división de pareceres. Finalmente, fue aprobado por mediano y se mandó que la repetición se llevase a cabo tras dos años ${ }^{223}$.

Siguiendo con los ejemplos, Andrés de Albanchez, vecino de Baeza, hizo una repetición para Licenciado en Artes en 1575, presidida por el Dr. Salcedo.

216 AHUB, Libro de grados 1549-158o, f. $61 \mathrm{v}$.

217 AHUB, Libro de grados 1549-1580, f. 64v.

218 AHUB, Libro de grados 1549-158o, f. 65r.

219 AHUB, Libro de grados 1549-1580, f. 155r.

220 AHUB, Libro de grados 1549-158o, f. 164v.

221 AHUB, Libro de grados 1549-158o, f. 179v.

222 AHUB, Libro de grados 1549-1580, f. 167r.

223 AHUB, Libro de grados 1549-158o, f. 192v. 
Aprobó, "aunque tibio 224 ". Pasó al examen secreto y fue aprobado, y se le concedió el grado de Licenciado, pero quedó indicado que si solicitaba el grado de Maestro, tenía que esperar ocho años ${ }^{225}$. Mucho más gráfico es el caso de Juan Garrido, vecino del Castellar, quien hizo en 1576 el examen secreto para el grado de Licenciado. Una parte del claustro consideró que el examen se tenía que repetir. Al final, tras muchas tensiones en el claustro se decidió darle el grado de Licenciado en Artes, pero, para el de Maestro, se tenía que esperar "hasta de oy en cincuenta años ${ }^{226 "}$.

Hemos ido consignando en el apéndice estos datos curiosos, la mayoría de ellos referentes a la Facultad de Artes, puesto que los que pedían los grados en Teología ya habían pasado por la criba de los exámenes en Artes y su valía estaba mucho más acreditada.

Igualmente hay que llamar la atención sobre la importancia concedida a la actitud de los estudiantes. Algunos de ellos fueron graduados sin la debida carta por conducta y con quejas por el comportamiento disoluto. Por ejemplo, Francisco Barrera, vecino de Arjona, se graduó de Bachiller en Artes, y fue aprobado "ratione cursuum", aunque sin procesión ni carta por conducta ${ }^{227}$ Asimismo, Juan Pérez de Godoy, vecino de Jaén, fue aprobado como Bachiller en Artes en 1576, pero quedó constancia de su falta de virtud y reconocimiento. Se le dio una carta de enfermos ${ }^{228}$.

Quizás el caso más patente de mal comportamiento fue el de Luis Ximénez, vecino de Bedmar, que era escandaloso y decía palabras afrentosas. Queda patente al examinar su caso su falta de disciplina (fue considerado un alumno paseador, distraído) y que el Rector halló una mujer en su aposento ${ }^{229}$.

\section{Los graduados}

Nuestro estudio pone especial énfasis en los grados, porque así puede conocerse mucho mejor la realidad académica y el nivel de exigencia. Dependiendo del número de matriculados, de los requisitos y la dureza en las pruebas, la asistencia a las colaciones, los alumnos reprobados... podemos

224 AHUB, Libro de grados 1549-158o, f. 173r.

225 AHUB, Libro de grados 1549-1580, f. 173v.

226 AHUB, Libro de grados 1549-158o, f. $183 \mathrm{r}$.

227 AHUB, Libro de grados 1549-158o, f. 185v.

228 AHUB, Libro de grados 1549-158o, f. $177 \mathrm{v}$.

229 AHUB, Libro de grados 1549-158o, ff. 198r-v. 
hacernos una idea general del funcionamiento de la Universidad como institución que acreditaba títulos con validez jurídica.

En primer lugar analizaremos en la parte cuantitativa, a fin de saber cuántos grados se colacionaron en el lapso entre 1549 y 1580 . Seguidamente estudiaremos los lugares de procedencia de los graduandos y su perfil sociológico.

\subsection{Estudio cuantitativo}

Los datos sobre el período 1549-1580, desglosado en los seis grados que se colacionaban en la Universidad de Baeza, son:

\begin{tabular}{|c|c|c|c|c|c|}
\hline B. A. & L. A. & M. A. & B. T. & L. T. & D. T. \\
\hline 697 & 196 & 103 & 85 & 25 & 32 \\
\hline
\end{tabular}

Las proporciones son muy similares a otras Universidades del momento. Ante todo, el grado más demandado era el de Bachiller en Artes, que abría las puertas a otros, mientras que los grados en Teología eran mucho más escasos. Para conocer mejor el significado de estos grados, cabe acudir a los libros de matrículas, que ya fueron trabajados por Richard Kagan. Según este autor, Baeza "llegó a tener 600 estudiantes al año ${ }^{230}$ ", algo que muestra el poder de atracción de la sede biacense, sobre todo si la comparamos, como hace el propio Kagan con Granada y Santa María y Santo Tomás de Sevilla. Es cierto que no poseemos los registros de matrícula completos de estas instituciones, pero no hay duda de que Baeza era una sede concurrida. Algunos estudiantes recordaron, años después, que a la sazón había una nutrida presencia, y que en aquellos años habría unos cuatrocientos colegiales ${ }^{231}$.

Como hemos indicado antes, desde un punto de vista institucional, no hay duda de que la Universidad de Baeza era colegial, si bien había estudiantes que no eran colegiales. En cambio, si lo analizamos desde los grados que se colacionaron, hay que advertir que se trataba más bien de un "SeminarioUniversidad”, como el de Tarragona, puesto que la idea que presidía el plan de estudios de institución biacense era la selección y formación de los clérigos, desde las primeras letras hasta la teología, con la particular impronta de Juan de Ávila. De ahí, la fama de "seriedad" de la institución frente a otras que concedían los grados con ligereza y en disciplinas que no enseñaban.

230 R. L. Kagan, Universidad y sociedad en la España Moderna, p. 242.

231 A. Huerga, Los alumbrados de Baeza, p. 30. 
El ejemplo opuesto era la Universidad de Almagro, que pronto fue acusada de irregularidades en la colación de grados (de Artes y de Bachiller en Teología) y que pleiteó para lograr la facultad de conceder los grados mayores en Teología ${ }^{232}$. Almagro ejercía una competencia directa con Baeza, puesto que servía no sólo a dominicos y a la Orden de Calatrava, sino que resultaba un lugar idóneo para la graduación rápida y barata de clérigos.

Al contrario, por su ideal de formación clerical, Baeza bebía directamente de Alcalá, aunque sin la pretensión cisneriana de convertirse en un referente para toda la Monarquía, que pudiera incluso contrarrestar el modelo salmantino. La Universidad de Baeza era mucho más modesta en sus aspiraciones, aunque tenía un profesorado muy comprometido y estable, y ello puede verse en las graduaciones, hechas casi siempre con los debidos requisitos. Los primeros grados fueron para los profesores, que se ocuparon de no rebajar un punto en el nivel de exigencia. En el transcurso de los años, se ve a menudo la impotencia de los profesores y la tensión de los claustros al tener que graduar a algún candidato indigno.

El nivel del profesorado y del alumnado graduado era notable y, en este sentido, debe calificarse esta primera etapa de la Universidad de Baeza como una época próspera, enturbiada por la constante presencia de la Inquisición, que desconfiaba de la orientación intelectual de la institución y por la tirantez entre los patronos y el claustro.

Si comparamos las estadísticas de matrícula que proporciona Kagan con los datos de los grados, observamos que no hubo excesivos graduados y que muchos estudiantes se debieron perder por el camino, al no superar los ejercicios requeridos para cada grado. Hay que señalar, así pues, el carácter riguroso de la colación de grados en Baeza durante esta primera etapa.

Asimismo hay dos particularidades más que deben comentarse. En primer lugar, que en Baeza hubo muchos más Licenciados y Maestros en Artes que en otras universidades. La explicación está en que, al ser un centro de formación eclesial, y al tener un cursus académico muy marcado, el acceso a la teología estaba prácticamente condicionado a la posesión de los grados completos de la Facultad de Artes. Con ello, se procedía a una criba para el estudio de la teología.

En las universidades en las que el estudio de las Artes era un mero requisito para el acceso a las distintas facultades superiores, apenas hallamos Li-

232 J. C. Vizuete Mendoza, Los antiguos Colegios-Universidad de Toledo y Almagro (siglos XVI-XIX), Toledo, Universidad de Castilla-La Mancha, 2010, pp. 59-60. 
cenciados ni Doctores en Artes. No tenemos noticia de los grados en muchas Universidades vecinas (hay que lamentar, en este sentido, el incendio que quemó los libros de grados de Granada), si bien deben tenerse en cuenta los estudios sobre la Universidad de Sevilla ${ }^{233}$. Gozamos de pocos datos aún sobre los grados en otras universidades hispánicas del momento como Osuna, Alcalá, Valladolid o Salamanca. El caso de la Universidad de Barcelona, en la que enseñó Pérez de Valdivia, muestra una presencia muy escasa de grados en teología ${ }^{234}$. Si comparamos la Universidad de Baeza con instituciones parecidas, como el Seminario-Universidad de Tarragona, pese que de ella no tenemos datos de los grados menores ${ }^{235}$, hay que subrayar la gran abundancia de grados de Doctor en Teología conferidos en la sede de la archidiócesis catalana.

Ello nos remite a la segunda particularidad: así como la proporción de los grados en Artes es la acostumbrada en otras instituciones, en Teología consignamos más Doctores que Licenciados. Todo ello obedece a las incorporaciones de los grados: muchos maestros incorporaron sus grados de Doctor en Teología, obtenidos en otras sedes. Algo muy similar sucedía en Sevilla, en la que la rivalidad entre los conventos y las dos universidades hacía que fuesen pocos los estudiantes que realizasen en el seno de la institución académica todos los ejercicios para el grado de Doctor, y que buscasen la convalidación o la incorporación de títulos obtenidos en otras partes.

\subsection{Procedencia geográfica}

No podemos llevar a cabo una estadística completa de la procedencia geográfica, puesto que el manuscrito no la indica en los primeros grados. De los que conocemos, sabemos que la mayoría de los graduandos procedía de Baeza. Asimismo había muchos otros de la vecina Úbeda y también de Jaén. La gran mayoría de localidades que aparecen son de la diócesis de Jaén (Cazorla, Iznatoraf, Arjona, Arjonilla, Mengíbar, Linares, Porcuna, Sabiote, Bailén, Huelma, Alcaudete, Ibros, Rus, Almedina, Cambil, Lopera, Vilches, Villanueva del Arzobispo...), y las diócesis vecinas como la archidiócesis de Toledo

233 J. A. Ollero Pina, La Universidad de Sevilla..., pp. 467-483.

234 R. Ramis Barceló, "Los grados en teología en la Universidad de Barcelona durante el siglo XVI", Anuario de Historia de la Iglesia, 24 (2015), pp. 291-309.

235 R. Ramis Barceló, "Grados mayores en la Universidad de Tarragona (15801624)”, pp. 131-155. 
(Valdepeñas, Villarobledo, Iruela, Escalona, La Puebla...), Sevilla, Córdoba (Castro del Río), Guadix (Guadix, Huéscar), Granada (Cónchar), Cartagena (Pliego, Yeste, Beas, Lorca...) Hubo casos muy esporádicos de graduandos de otras diócesis, como Almería, Málaga, Calahorra, Sigüenza... Hay algún que otro caso excepcional, como el de Antonio Gómez, vecino de Elvas (Portugal).

Consta que algunos graduados habían recibido el Bachillerato en Artes por la Universidad de Granada. Asimismo, unos pocos se habían graduado en las Universidades de Sevilla y Alcalá. Todo ello nos permite concluir que los graduados de la Universidad de Baeza tenían un carácter claramente local y regional, puesto que prácticamente la mitad de ellos procedía de la ciudad de Baeza y que unas tres cuartas partes lo hacía de la diócesis de Jaén.

Aunque muchos de los alumnos eran de Baeza y alrededores, la ciudad se llenó de jóvenes estudiantes que, como sucedía en las demás Universidades, provocaban alborotos. Los libros de claustro son elocuentes en este sentido. Por ejemplo, en 1560 consta que los claustrales "han sido informados de que muchos estudiantes de esta universidad juegan publicamente naypes y otros juegos prohibidos por el derecho y ansi mismo tienen tablaqerias (sic) públicas en sus casas, y que de noche salen, en lugar de estudiar y exercitarse en buenas costumbres, con armas y hacen cosas de que los vezinos desta ciudad se agravian de los estudiantes y en desacato del Rector y claustro de la dicha universidad entran en ella con dagas y otras armas semejantes ${ }^{236}$ ". Era una tónica común en todas las universidades del momento.

\subsection{Perfiles sociológicos}

$\mathrm{Al}$ ser una universidad pensada para la formación de clérigos, sus egresados fueron esencialmente eclesiásticos, regulares y seculares. Muchos de ellos han sido mencionados al tratar los profesores, Cancilleres y Rectores. Hagamos aquí un rápido apunte conclusivo, a fin de conocer mejor sus rasgos. En la documentación manuscrita no se informa con detalle de la procedencia de todos los graduados, especialmente durante los primeros años. Sin embargo, de los que poseemos información se desprende que la Universidad de Baeza tuvo más egresados procedentes del clero secular que del regular.

Entre los seculares, encontramos un primer grupo de colegiales: el ya citado Alonso de Vilches, vecino de Baeza, prior de Cazalilla y colegial; Cristóbal de Biedma, vecino de Jaén, miembro de una destacada familia y colegial;

236 Copiamos de W. Soto Artuñedo, “Alonso de Barzana...”, p. 34. 
Juan de Peñas, natural de Huelma, colegial de Santiago; o Diego Delgadillo, vecino de Jaén, alumno del Colegio de Santa Catalina de Jaén y discípulo de Fr. Alonso Farfan.

Un segundo grupo serían los clérigos y sacerdotes, de los que no consta que tuviesen ningún beneficio en el momento de la obtención del grado: Garci Moreno, clérigo, vecino de Úbeda; Francisco de Aybar, presbítero, vecino de Iruela, diócesis de Toledo; Antonio Flores de Benavides, presbítero, vecino de Baeza; Francisco López de Pancorbo, presbítero, vecino de Jaén; Juan Félix de Quirós, sacerdote, natural de Granada y cura de Cónchar, al que los moriscos, en la rebelión de 1568, condujeron a la cárcel de Poqueira, y lo mataron $^{237}$; o Pedro de León, presbítero, vecino de Baeza.

Un tercer grupo lo consistirían los beneficiados y los canónigos, como Miguel de Calmaestra, natural de Arjonilla, prior de la Parroquial de Santo Domingo de Úbeda; Gonzalo de Molina, racionero; Francisco Cano, Prior de San Pedro; Andrés López, Clérigo, Prior de Rus; Gonzalo Ramírez de Molina, Racionero de Jaén ${ }^{238}$; Gaspar de Villalta, presbítero, vecino de Huéscar; Alonso Díaz de Navarrete, Beneficiado de San Miguel de Baeza; Juan de Urrutia, beneficiado, vecino de Santa Cruz de Campezo, obispado de Calahorra; Juan de Navarrete, canónigo, vecino de Baeza; o Miguel Sánchez de Ortega, canónigo de Sta. María del Alcázar de Baeza, natural de Villarejo de la Peñuela, diócesis de Cuenca, que fue incorporado a la Universidad y escribió una obra titulada Libro llamado el hombre nuevo (1582) ${ }^{239}$.

Entre los regulares, hay que destacar especialmente a los trinitarios y a los mercedarios. Entre los primeros, sobresale Fr. Diego de Sara, catedrático en el Convento de la Trinidad de Salamanca, que fue procesado por la Inquisición ${ }^{240}$; Fr. Cristóbal Alderete, vecino de Baeza, ministro del convento de los Trinitarios de Sevilla y calificador del Santo Oficio, así como Vicario Provincial de la Santísima Trinidad; Fr. Juan de Chirinos, natural de Córdoba; y otros como Fr. Pedro Navarro o Fr. Luis Bautista, profeso trinitario.

De los mercedarios cabe destacar Fr. Baltasar Castaño; Fr. Fernando Gutiérrez; Fr. Juan de Aguilar, natural de Sevilla; o Salvador de Santamaría, co-

237 L L. Padilla Mellado, Los habices de las Iglesias del Valle de Lecrín. Historia y arqueología, Tesis doctoral, Granada, Universidad de Granada, 2010, p. 356.

238 J. Martínez Rojas, El Episcopado de D. Francisco Sarmiento..., pp. 180-181.

239 P. Cátedra García, Imprenta y lecturas en la Baeza del siglo XVI, p. 157.

240 V. Beltrán de Heredia, Miscelánea Beltrán de Heredia, vol. 1, Salamanca, San Esteban, 1971, p. 59. 
mendador de Sevilla ${ }^{241}$. De los dominicos, hay que mencionar a Fr. Gabriel de Santoyo, provincial de los dominicos de Andalucía ${ }^{242}$; y Fr. Alonso de Mesa, prior del Convento de la Magdalena de la Guardia. Entre los agustinos, mencionamos a Fr. Juan Zapata, natural de Málaga, que partió para las Indias en 1580 y profesó en la provincia de México ${ }^{243}$.

\section{Conclusiones}

La Universidad de Baeza fue, durante los primeros años de su singladura académica, una institución destacada en el marco del saber y de la espiritualidad de la segunda mitad del siglo XVI. El principal objetivo de este libro es un análisis de los grados que se concedieron en Baeza desde 1549 hasta 1580, año en el que se produjo la polémica visita de Fr. Luis Rodero.

Tenemos que afirmar, en primer lugar, que Baeza tuvo una Universidad destacada por la solidez intelectual y espiritual de sus maestros, que configuraban un grupo compacto, alentado por San Juan de Ávila. Podemos ver, al reconstruir los actos y los grados, la presencia de figuras tan destacadas como Pérez de Valdivia, Herrera, Carleval, Loarte, Aguayo... que merecen un lugar destacado en la historia del pensamiento y de la espiritualidad hispana.

Gracias a su magisterio, muchos jóvenes se formaron en Baeza desde las primeras letras hasta la teología. Los actos y los grados muestran el itinerario claramente eclesial que seguían tanto los colegiales como el resto de los estudiantes. En este sentido, Baeza fue un vivero de clérigos, modelados bajo las directrices de la renovación espiritual y de la solidez intelectual.

En segundo lugar, debemos subrayar que las continuas presiones de la Inquisición jalonaron el período estudiado. En la década de 1550, tras las primeras graduaciones, y en la de 1570, la Universidad atravesó períodos muy convulsos por los procesos a los alumbrados, que trastocaron la vida académica.

241 L. Vázquez, "El Apostrofe de Artícela espiritual (1698) no puede ser el Acto de contrición de Tirso (1630)”, en Homenaje a Tirso de Molina, Madrid, Revista Estudios, 1981, pp. 157-175. La referencia está en la p. 171.

242 I. Fernández Terricabras, Felipe II y el Clero Secular: la Aplicación del Concilio de Trento, Madrid, Sociedad Estatal para la Conmemoración de los Centenarios de Felipe II y Carlos V, 2000, p. 89.

243 A. Valladares Reguero y R. Ruiz García, La emigración Jiennense a las Indias en el Siglo XVI (1492-1599), Jaén, Diputación Provincial de Jaén-Instituto de Estudios Giennenses, 1994, p. 218. 
En tercer lugar, debe señalarse que los grados colacionados en Baeza, si los comparamos con las matrículas, no fueron muy numerosos. Muchos estudiantes no completaron el itinerario académico que habían iniciado. En el período estudiado hemos contabilizado un total de 697 B.A., 196 L.A., 103 M.A., así como también 85 B.T., 25 L.T. y 32 D.T. El registro de los actos muestra que muchos estudiantes no superaban los ejercicios conducentes a los grados y que, por lo tanto, la dificultad para acceder a los mismos era destacada.

En cuarto lugar, hay que anotar que muchos profesores habían sido antes alumnos, como sucedía a en muchas instituciones de la época. Juan de Ávila había seleccionado a los primeros maestros y éstos se encargaron, a su vez, de formar a nuevos artistas y teólogos, que destacaron por su orientación espiritual y su vocación pastoral y misionera. Con los datos consignados en el apéndice se ofrece mucha mayor información sobre estos profesores y alumnos que, pasados los años, fueron destacados escritores y curas de almas, algunos de los cuales pasaron a las Indias.

En quinto lugar, cabe subrayar que hubo más egresados procedentes del clero secular que del regular. Entre estos últimos hay que destacar la presencia de mercedarios y trinitarios, mientras que los dominicos siempre incorporaron el título procedente de otra Universidad. Entre los clérigos seculares hallamos especialmente graduados procedentes de la misma diócesis de Jaén y de las vecinas.

La sede biacense, pese al hondo calado de sus maestros, tuvo una proyección más bien local y regional. Sus estudiantes, como muestran las matrículas y los grados, tenían una procedencia geográficamente limitada, especialmente por la competencia que ejercían las universidades más cercanas (Sevilla, Osuna, Granada y Almagro).

En fin, los grados de este primer período de la Universidad de Baeza clarifican diversos aspectos desconocidos y proporcionan muchos más datos sobre los comienzos de esta institución, que debe ser valorada y apreciada por sus rasgos identificativos: la formación clerical (en todas sus dimensiones) y su servicio a la diócesis y a la región. En las páginas siguentes el lector encontrará a sus protagonistas (como graduandos, maestros, Rectores, Cancilleres...) Sin duda, se trata de una de las épocas más intensas de la historia de la espiritualidad y del saber en la Universidad hispana de la segunda mitad del siglo XVI. 


\section{BIBLIOGRAFÍA}

Ajo, C. M., Historia de las Universidades Hispánicas, Madrid-Ávila, CSIC, 19571979.

Álvarez, M. E., "La Universidad de Baeza y su tiempo (1538-1824)”, Boletín del Instituto de Estudios Giennenses, 27 y 28 (1961), pp. 9-72 y 9-140.

Andrés, M., La Teología española en el siglo XVI, Vol. I, Madrid, BAC, 1976.

Arias de Saavedra, I., "La Universidad de Granada en la Edad Moderna: Estudio y estado de la cuestión”, en L. E. Rodríguez-San Pedro Bezares y J. L. Polo Rodríguez (eds.), Universidades Hispánicas. Modelos territoriales en la Edad Moderna (II). Miscelánea Alfonso IX, 2007, Salamanca, Universidad de Salamanca, 2008, pp. 237-268.

Arias de Saavedra, I., "La Universidad de Baeza en la Edad Moderna. Estado de la cuestión y síntesis de su trayectoria”, en L. E. Rodríguez-Sampedro y J. L. Polo (eds.), Universidades hispánicas: colegios y conventos universitarios en la Edad Moderna (II) Miscelánea Alfonso IX, 2009, Salamanca, Universidad de Salamanca, 2010, pp. 15-43.

Barriga, V. M., Los mercedarios en el Perú en el siglo XVI: 1525-1580, Vol. 2, Arequipa, Editorial La Colmena, 1939.

Beltrán de Heredia, V., "Los alumbrados de la diócesis de Jaén: un capítulo inédito de la historia de nuestra espiritualidad", Miscelánea Beltrán de Heredia. Colección de artículos sobre historia de la teología española, Vol. III, Salamanca, San Esteban, 1973, pp. 235-334.

Cabazán, A., Apuntes para la historia de Úbeda recopilacion de datos exparcidos en diferentes obras, con nuevas noticias y documentos inéditos, Ubeda, Imp. de José Martínez Montero, 1887.

Cátedra García, P., Imprenta y lecturas en la Baeza del siglo XVI, Salamanca, Sociedad de Estudios Medievales y Renacentistas, 2001.

Coronas Tejada, L., "Los judeoconversos en el reino de Jaén”, Boletín del Instituto de Estudios Giennenses, 97 (1978), pp. 79-105.

Cózar Castañar, J., "Juan de Ávila en la Universidad de Baeza en el siglo XVI", El Maestro Ávila. Actas del Congreso Internacional (Madrid 27-3o del XI de 200o), Madrid, Edice, 2002, pp. 317-322.

Cózar, F. de, Noticias y documentos para la Historia de Baeza, Jaén, Imprenta Rubio, 1884. (Edición facsímil, Universidad de Granada, 2006).

Cuart Moner, B., "Algunas notas sobre los colegiales de San Clemente en la Administración Americana (siglos XVI-XVIII)”, Studia Historica, 7 (1989), pp. 799-823. 
Delgado Barrado, J.M. y López Arandia, M.A., Poderosos y privilegiados: los caballeros de Santiago de Jaén, siglos XVI-XVIII, Madrid, CSIC, 2009.

Díaz Rodríguez, A.J., "Las casas del deán don Juan de Córdoba: lujo y clientela en torno a un capitular del Renacimiento", Hispania Sacra, 123 (2009), pp. 77-104.

Díaz Rodríguez, A.J., "Diccionario biográfico de la catedral de Córdoba (II): los miembros del cabildo en época moderna”, Historia y Genealogía, 6 (2016), pp. 33-63.

Duro Cobo, J.J., "Melchor de Soria y Vera: un escolástico preocupado por los problemas económicos el siglo XVI en Castilla", Revista de estudios regionales, 82 (2008), pp. 313-342.

Escolano, F., "Documentos y noticias de la antigua Universidad de Baeza", Hispania, 5 (1945), pp. 38-71.

Esquerda Bifet, J., Introducción a la doctrina de San Juan de Avila, Madrid, BAC, 2000.

Fernández Terricabras, I., Felipe II y el Clero Secular: la Aplicación del Concilio de Trento, Madrid, Sociedad Estatal para la Conmemoración de los Centenarios de Felipe II y Carlos V, 2000.

Fuente, V. de la, Historia de las Universidades, Colegios y demás establecimientos de enseñanza de España, Madrid, Viuda e Hija de Fuentenebro, 1884-1889.

García Cordero, J. C., "La Universidad de Baeza entre los siglos XVI y XVII. Ideario pedagógico de un centro avanzado de pensamiento, pionero en la enseñanza, investigación-acción, la promoción, la orientación y en programas de promoción de la mujer", Códice: Revista de la Asociación de Amigos del Archivo Diocesano de Jaén, 7-8 (1992), pp. 39-52

García Oro, J., y Portela Silva, M. J., "Baeza la universidad de los patronos" en Monarquía y Escuela en la España del Renacimiento. Escuelas, colegios y universidades en la Corona de Castilla, Santiago de Compostela, Ed. El Eco Franciscano, 2003, pp. 365-401.

Higueras Maldonado, J., Documentos latinos del siglo XIII al XVII en los archivos de Baeza (Jaén), Jaén, Instituto de Estudios Giennenses, 1974.

Huerga, A., Los alumbrados de Baeza, Jaén, Instituto de Estudios Giennenses, 1978.

Huerga, A., "Dominicos andaluces procesados por la Inquisición en el siglo XVI", en A. Bernal Palacios (ed.), Praedicatores, Inquisitores II, Los Dominicos y la Inquisición en el mundo ibérico e hispanoamercano. Actas del $2^{o}$ Seminario internacional sobre los Dominicos y la Inquisición, Sevilla, 3-6 de Marzo de 2004, Roma, Angelicum U. P., 2006, pp. 307-322. 
Iriarte, M. de, El doctor Huarte de San Juán y su examen de ingenios. Contribución a la historia de la Psicología diferencial, Madrid, CSIC, 1948.

Jara, G. de la, Historia de Úbeda en sus documentos, Asociación Cultural Ubetense "Alfredo Cazabán Laguna”, vol. II (online).

Kagan, R. L., Universidad y sociedad en la España Moderna, Madrid, Tecnos, 1988.

Larios Ramos, A., "Los Dominicos y la Inquisición”, Clio y Crimen, 2 (2005), pp. 81-126.

Madurell Marimon, J. M., "Diego Pérez de Valdivia en Barcelona”, Analecta Sacra Tarraconensia, 30 (1957), pp. 343-371.

Martínez Rojas, J., El Episcopado de D. Francisco Sarmiento de Mendoza (15801595): la reforma eclesiástica en el Jaén del XVI, Jaén, Instituto de Estudios Giennenses, 2004.

Melgares Raya, J., Diego Pérez de Valdivia, (1524-1589): Rector de Baeza, arcediano de Jaén, apóstol de Cataluña, Jaén, Seminario Diocesano, D.L., 1990.

Moreno Uclés, J., "Humanismo Giennense (s. XV-XVIII). Un foco humanista en Baeza", Boletín del Instituto de Estudios Giennenses, 158 (1995), pp. 167- 295.

O'Malley, J., Los primeros jesuitas, Santander, Mensajero Sal Terrae, 1993.

Ollero Pina, J. A., La Universidad de Sevilla en los siglos XVI y XVII, Sevilla, Universidad de Sevilla, 1993.

Ortega Ruiz, A., "La Universidad de Baeza: de la plasmación del ideal avilino a su clausura”, en M. D. Rincón González y R. Manchón Gómez (eds.), El maestro Juan de Ávila (150o?-1569) un exponente del humanismo reformista, Salamanca, Universidad Pontifícia de Salamanca - Jaén, Universidad de Jaén, 2014, pp. 593-618.

Ortega Ruiz, A., La Universidad de Baeza. Documentos para su historia, Baeza, Universidad Internacional de Andalucía, 2015.

Ortega Sagrista, R., "La extinguida Universidad de Santa Catalina Mártir de la ciudad de Jaén”, Boletín del Instituto de Estudios Giennenses, 54 (1967), pp. 9-27.

Padilla Mellado, L. L., Los habices de las Iglesias del Valle de Lecrín. Historia y arqueología, Tesis doctoral, Granada, Universidad de Granada, 2010.

Parelló, V., "Limpieza de sangre y conflictividad social en Castilla en los siglos XVI y XVII", en P. Juan i Tous y H. Notebaum (eds.), El olivo y la espada: estudios sobre el antisemitismo en España (siglos XVI-XX), Tübingen, M. Niemeyer Verlag, 2003, pp. 91-105. 
Pérez Aguilera, P. M., "De Sacra ratione concionandi de Diego Pérez de Valdivia (Baeza, 1524 - Barcelona 1589)", Boletín del Instituto de Estudios Giennenses, 191 (2005), pp. 119-135.

Peset, M. y Menegus, M., "Espacio y localización de las Universidades Hispánicas", Cuadernos del Instituto Antonio de Nebrija, 3 (2000), pp. 189-232.

Pujana, J., La reforma de los Trinitarios durante el reinado de Felipe II, Salamanca, Secretariado Trinitario, 2006.

Ramis Barceló, R., "La política universitaria de los Austrias en la Península Ibérica” en G. P. Brizzi y A. Mattone (ed.), Le origini dello Studio Generale sassarese nel mondo universitario europeo dell'eta moderna, Bolonia, CLUEB, 2013, pp. 103-116.

Ramis Barceló, R., "Los grados en teología en la Universidad de Barcelona durante el siglo XVI”, Anuario de Historia de la Iglesia, 24 (2015), pp. 291-309.

Ramis Barceló, R., "Grados mayores en la Universidad de Tarragona (15801624)”, Analecta Sacra Tarraconensia, 90 (2017), pp. 131-155.

Rincón González, M. D., "Criterios de selección en la Universidad de Baeza: Huarte de San Juan y los planteamientos avilistas: Quod natura non donat, Academia non praestat, enim vero labor omnia vincit improbus", Elucidario 1 (2006), pp. 135-146.

Rincón González, M. D., "La Universidad de Baeza y la formación del predicador (retóricas, manuales y otros recursos)", AAVV, Humanismo y pervivencia del mundo clásico: homenaje al profesor Antonio Prieto, Alcañiz-Madrid, 2008, IV.2, pp. 997-1007.

Rodríguez Molina, J., (coord.), Historia de Baeza: historia, literatura, arte, Baeza, Ayuntamiento de Baeza y Universidad de Granada, 1985.

Rodríguez-Moñino Soriano, R., El Archivo de la antigua Universidad de Baeza. Los manuscritos y las Bulas (Introducción y Catálogo), Baeza, Universidad Antonio Machado, 1989.

Rodríguez-Moñino Soriano, R., Aproximación a la historia eclesiástica de la ciudad de Baeza (Jaén). (Del esplendor renacentista y barroco a la crisis liberal del XIX), Jaén, Instituto de Estudios Giennenses y Diputación Provincial de Jaén, 2000.

Rubio Sánchez, M. S., El Colegio-Universidad de Osuna (1548-1824), Sevilla, Caja de Ahorros, 1976.

Sala Balust, L., "Introducción" en Obras completas del beato Juan de Avila, Biblioteca de Autores Cristianos, Madrid, 1952.

Sánchez Gómez, J. M., "Un discípulo del P. Mtro. Avila en la Inquisición de 
Córdoba. El Dr. Diego Pérez de Valdivia, catedrático de Baeza”, Hispania, 9 (1949), pp. 104-134.

Sancho, H., "El Maestro Fr. Agustín Salucio, O.P. Contribución a la Historia Literaria Sevillana del siglo XVI," Archivo Hispalense, 16 (1952), pp. 9-47.

Simón Díaz, J., Bibliografía de la literatura hispánica, Vol. 15, Madrid, CSIC, 1992.

Soto Artuñedo, W., "Alonso de Barzana, S. I. Apóstol de Andalucía y Sudamérica”, Archivo Teológico Granadino, 79 (2016), pp. 5-130.

Valladares Reguero, A., y Ruiz García, R., La emigración Jiennense a las Indias en el Siglo XVI (1492-1599), Jaén, Diputación Provincial de Jaén-Instituto de Estudios Giennenses, 1994.

Vázquez, L., "El Apostrofe de Artícela espiritual (1698) no puede ser el Acto de contrición de Tirso (1630)", en Homenaje a Tirso de Molina, Madrid, Revista Estudios, 1981, pp. 157-175.

Vizuete Mendoza, J. C., Los antiguos Colegios-Universidad de Toledo y Almagro (siglos XVI-XIX), Toledo, Universidad de Castilla-La Mancha, 2010.

Wagner, K., El doctor Constantino Ponce de la Fuente. El hombre y su biblioteca, Sevilla, Excma. Diputación Provincial de Sevilla, 1979.

Ximenez Patón, B., Historia de la antigua y continuada nobleza de la ciudad de Jaen muy famosa, muy noble y muy leal guarda e defendimiento de los Reynos de España y de algunos varones famosos hijos della... Jaén, Pedro de la Cuesta, 1628. 


\section{APÉNDICE}

LOS ACTOS Y GRADOS CONFERIDOS POR LA UNIVERSIDAD DE BAEZA

(1549-1580) 
Se presentan seguidamente las fichas de los estudiantes siguiendo un orden cronológico, de acuerdo con el tenor del Libro de grados 1549-1580. Todos los folios se refieren a dicho manuscrito. Los datos -en los diversos lustros- fueron dispuestos de forma ligeramente diferente, dependiendo del secretario o del notario.

Hemos adoptado una estructura común para cada ficha, siempre que ha sido posible: en la primera línea figura el nombre del estudiante o laureado; en la segunda línea, (si aparece en el manuscrito) la graduación que ya tenía antes de llegar a Baeza, su procedencia $u$ otros datos sobre su vida; en la tercera línea aparecen consignados los grados que recibió en la Universidad de Baeza, mientras que en las líneas sucesivas figuran las fechas de los diferentes actos y sus protagonistas; se indican también otros datos, como los testigos, en los pocos casos en los que figuran; en la penúltima línea aparecen consignados los secretarios o notarios, y, en la última, las referencias a los folios en los que se encuentra la documentación del personaje en cuestión.

Se recogen, por lo tanto, los datos de cada estudiante desde la primera vez que aparece en el manuscrito, y se agrupan de manera que pueda seguirse su carrera académica completa. No se recogen los datos posteriores a 1580 . Como los casos de homonimia son frecuentes, hemos puesto por separado los datos de personajes que no hemos identificado con certeza.

El orden ocupado en las graduaciones colectivas era significativo para saber la calificación intelectual del graduando en el conjunto. Como es sabido, los alumnos recibían el grado empezando por los más brillantes. El orden de presentación que aquí seguimos no altera esta circunstancia y el lector interesado puede fijarse en esta cuestión. Cabe indicar asimismo que, salvo que se indique otra cosa, el primer acto es el grado de B. A.

La información que aquí se recoge, pese a ser bastante completa, no es totalmente exhaustiva. Cabe suponer que se realizaron otros actos que no quedaron consignados. Indicamos también que cuando aparece un nuevo personaje (profesor, notario...) se proporciona la información íntegra, que en muchos casos se abrevia en los casos sucesivos. 


\section{BERNARDINO DE CARLEVAL}

Grado obtenido: D. T.

1-12-1549

Los otorgó el Arcediano Diego Flores, Canciller

Referencia: $4 \mathrm{r}$

\section{GASPAR LOARTE}

Grados obtenidos: D. T. / M. A.

1-12-1549

Los otorgó el Arcediano Diego Flores, Canciller

Referencia: 4rv

\section{HERNANDO DE HERRERA}

Grados obtenidos: M.A. / B. T. / L. T. / D. T.

1-12-1549 M. A. Arcediano Diego Flores Canciller

9-1-1555 Acto mayor o tentativa de Teología, presidida por el Dr. Bernardino de Carleval, Rector

26-9-1555 Acto mayor que se llama quodlibetos, presidido por el Dr. Valentín Vélez

10-9-1555 Repetición de para L. T. presidida por el Dr. Aguayo

26-9-1555 Acto mayor o quodlibetos presidido por Dr. V. Vélez

30-9-1555 Pide examen secreto al Dr. Aguayo, Rector

1-10-1555 Examinado de L. T.

4-10-1555 Diego Flores, Canciller dio el grado de L.T.

6-10-1555 Diego Flores, Canciller dio el grado de D.T.

P. Nieto, notario

Referencias: 4rv, 22v, 26r, 26v 27r

DIEGO PÉREZ [de Valdivia]

Grados obtenidos: M. A. / B. T. / L. A. / L. T. / D. T.

1-12-1549 M. A. Arcediano Diego Flores, Canciller

3-6-1550 B. T. Dr. Bernardino de Carleval

5-9-1557 Examen secreto

6-9-1557 Aprobado de L. A.

12-9-1557 Fr. Miguel de Yepes, Canciller

2-11-1554 Repetición para L. T., presidida por el Dr. Bernardino de Carleval

4-11-1554 Canciller Diego Flores dio el grado de L.T.

22-11-1554 Canciller Diego Flores dio el grado de D.T.

Hurtado, Sebastián Rodríguez, y P. Nieto, not.

Referencias: 4rv, 9v, 34r, 35r 


\section{FERNANDO DE AGUAYO}

Grados obtenidos: M. A. / L. T. / D. T. 1-12-1549 Arcediano Diego Flores, Canciller

31-10-1554 Repetición para L. T., presidida por el Dr. Bernardino de Carleval, Canciller

4-11-1554 Diego Flores dio el grado de L. T.

22-12-1554 Canciller Diego Flores dio el grado de D. T.

Hurtado y P. Nieto, notarios

Referencias: 4v, 21v, 22r

PEDRO DÍAZ SORIANO VEGA

Grados obtenidos: L. A. / M. A. / B. T. / L. T. / D. T.

7-1-1550 Canciller D. Flores le dio el grado de L.A.

12-4-1550 Incorporación.

22-1-1551 Recibido por Diego Flores, Canciller, arcediano de Castro y Canciller /

Rdo. Bernardino de Córdoba, Rector

11-11-1563 Otorgóle el grado el Mtro. Valentín Vélez

12-11-1563 Examen secreto para L. T.

13-11-1563 Presidióle el Dr. Vélez

14-11-1563 Mfco. Juan de Ocón, Canciller, diole el grado

25-11-1563 Canciller Juan Ocón le dio el grado de D. T.

Rodríguez, not., Nicolás de Torres, notario

Referencias: 5v, 7v, 13v, 65r, 66r

JERÓNIMO CALDERÓN

Grado obtenido: L. A.

7-1-1550

Referencia: $5 \mathrm{~V}$

PEDRO GONZÁLEZ DE QUESADA

Grado obtenido: D. T.

Incorporación 15-1-1550

Referencia: 6r

JUAN RAMÍREZ DE OVIEDO

Grados obtenidos: B. T. / L. T. / D. T.

20-1-1550 Se le dio el grado de B. T.

26-1-1550 Examen secreto

27-1-1550 Se le dio el grado de L. T.

1-2-1550 Se le dio el grado de D. T. 
Hurtado, notario

Referencia: 6r

FRANCISCO MANJÓN

Grados obtenidos: B. A. / L. A.

17-12-1549 Examen

21-1-1551 Dr. Gaspar Luarte le dio el grado de B.A.

22-1-1551 Hizo el examen

17-2-1551 Diego Flores, Canciller le dio el grado de M.A.

N. de Torres, notario

Referencias: 6v, 14r

HERNANDO NÚÑEZ

Grado obtenido: B. A.

12-2-1550 Mtro. Fdo. de Aguayo le dio el grado

Referencia: 6v

MARCOS LÓPEZ

Grados obtenidos: B. A. / L. A.

28-2-1550 Mtro. Fdo. de Aguayo le dio el grado de B.A.

5-3-1550 Pidió examen para L.A., hizo su repetición

7-3-1550 Hizo el examen y aprobó

9-3-1550 Canciller Flores le dio el grado

Referencias: 6v, $7 \mathrm{r}$

LUIS DE LINARES

Grado obtenido: B. A.

2-3-1550 Mtro. Hdo. de Herrera

Referencia: $7 \mathrm{r}$

JUAN DE SANTESTEVAN

Grados obtenidos: B. A. / L. A. / M. A. / B. T.

2-3-1550 Hdo. de Herrera le graduó de B. A.

21-10-1551 Admitido a repetición de L. A.

9-2-1552 Hernando de Aguayo, Vicerrector

11-2-1552 Valentin Vélez, Rector le dio el grado de M. A.

30-4-1552 Diego Flores, arcediano de Castro

23-1-1554 Diego Flores, Canciller, le dio el grado de B.T.

N. de Torres, not.

Referencias: 7r, 16r, 17r, 20v, 30v 


\section{LUIS HERNÁNDEZ}

Grado obtenido: B. A.

2-3-1550 Mtro. Hdo. de Herrera

Referencia: $7 \mathrm{r}$

JUAN ÁLVAREZ

Grado obtenido: B. A.

2-3-1550 Mtro. Hdo. de Herrera

Referencia: $7 \mathrm{r}$

ALONSO DE JODAR

Grado obtenido: B. A.

2-3-1550 Mtro. Hdo. de Herrera

Referencia: $7 \mathrm{r}$

PEDRO TORNERO

Grado obtenido: B. A.

2-3-1550 Mtro. Hdo. de Herrera

Referencia: $7 \mathrm{r}$

\section{ALONSO GARRIDO}

Grado obtenido: B. A.

2-3-155o Mtro. Hdo. de Herrera

Referencia: $7 \mathrm{r}$

ANTÓN DE JESÚS

Grado obtenido: B. A.

2-3-1550 Mtro. Hdo. de Herrera

Referencia: $7 \mathrm{r}$

HERNANDO LÓPEZ

Grado obtenido: B. A.

2-3-1550 Mtro. Hdo. de Herrera

Referencia: $7 \mathrm{r}$

N. DE TORRES

Grado obtenido: B. A.

2-3-1550 Mtro. Hdo. de Herrera

Referencia: $7 \mathrm{r}$ 


\section{FRANCISCO SÁNCHEZ}

Grado obtenido: B. A.

2-3-1550 Mtro. Hdo. de Herrera

Referencia: $7 \mathrm{r}$

DIEGO DE PAREDES

Grado obtenido: B. A.

15-4-1550 Mtro. Hdo. de Herrera le dio el grado

Hurtado, notario

Referencia: $7 \mathrm{v}$

\section{PEDRO DE CÓRDOBA}

\section{B. A.}

Grado recibido: L. A.

16-4-1550 Hecha su repetición para L.A., pidió el grado

17-4-1550 Canciller Flores le dio el grado

Hurtado, notario

Referencia: 8r

HERNANDO DE BAEZA

B.A. en Granada

Grados obtenidos: L. A. / B. T.

18-4-1550 Examen para L.A.

19-4-1550 Canciller Flores le dio el grado

25-4-1550 Pidió examen secreto

8-6-1550 Dr. Gaspar Loarte le dio el grado de B. T.

Hurtado, notario

Referencias: 8r, 8v, 9v

\section{MIGUEL MUÑOZ}

\section{B.A.}

Grado obtenido: L. A.

21-4-1550 Examen secreto para L. A. y aprobó el grado

25-4-2550 Canciller Flores le dio el grado

Hurtado, notario

Referencia: 8v

\section{LUIS DE NOGUERA}

Grados obtenidos: B. A. / L. A. / B. T.

19-4-1550 Asignación lección B. A. 
29-4-1550 Examen secreto de L.A. 11-5-1550 Rdo. Diego Flores, Rector 20-9-1554 Acto general de Teología presidido por el Dr. Carleval, Rector, que le dio el grado Hurtado y P. Nieto, notario

Referencias: 9r, 21v

RODRIGO DE ESCÓS

B. A.

Grados obtenidos: L. A. / M. A.

2-5-1550 Rdo. Diego Flores, Rector, para examen secreto

11-5-1550 Asignación y lección

23-1-1553 Diego Flores, Canciller

Hurtado, notario

Referencias: 9r, 20v

GONZALO DE VILLALTA

B. A. por Granada

Grados obtenidos: L. A. / M. A.

19-4-1550 Admisión para L. A.

6-5-1550 Examen Rdo. Diego Flores, Rector

8-5-1550 Asignación de lección

11-5-1550 Grado de M. A. por Diego Flores, Canciller

Hurtado, Torres, Nieto, notarios

Referencias: 8r, 9r, 13r, 20v

\section{ANTONIO HURTADO}

B. A. en Granada

Grados obtenidos: L. A. / M. A.

21-4-1550 Pidió examen de L. A.

8-5-1550 Diego Flores, Canciller: asignación de la lección

11-5-1550 Diego Flores, Canciller / Pedro de Sevilla

8-12-1550 Andrés de Arcas, canónigo

Hurtado, notario

Referencias: 8v, 9v

TOMÁS DE CARLEVAL

Grados obtenidos: B. A., L. A., B. T.

17-7-1550 Recibió el grado de B.A.

30-7-1550 Mtro. H. de Aguayo, Vicerrector 
7-8-1550 Diego Flores, Canciller, dio el grado de L.A. 10-8-1550 Exámenes para B. T. 28-10-1550 Dr. Pérez / Dr. Aguayo le examinaron Hurtado, notario

Referencias: 10r, 11v, 12r

\section{FRANCISCO GARCÍA}

\section{B. A. en Valencia}

Grado obtenido: L. A.

28-7-1550 Petición de repetición al Rector Aguayo

8-8-1550 Examen

10-8-1550 Diego Flores, Canciller dio el grado

Hurtado, notario

Referencias: 10r, $11 \mathrm{v}$

\section{JUAN GONZÁLEZ}

B. A.

Grado obtenido: L. A.

30-7-1550 Petición examen

3-8-1550 Examen

4-8-1550 Colación del grado

Hurtado, notario

Referencia: 10v

\section{FRANCISCO DE AYALA}

Grados obtenidos: B. A. / L. A.

5-8-1550 Mtro. Diego Pérez le dio el grado

7-8-1550 Examen

10-8-1550 Diego Flores, Canciller dio el grado

Hurtado, notario

Referencia: $11 \mathrm{r}-\mathrm{v}$

\section{BARTOLOMÉ ÁLVAREZ}

Grados obtenidos: B. A. / L. A.

18-9-1550 Mtro. Diego Pérez / Dr. Loarte / Mtro. Hdo. de Herrera / Ldo. Luis de Noguera

12-11-1550 Probación de cursos en Salamanca 1543 y examinado

4-12-155o Diego Flores, Canciller / Diego de Guzmán / Fco. de Ayala

Hurtado, notario

Referencias: 11v-12r 


\section{CRISTÓBAL CERÓN}

Grado obtenido: B. A.

1-10-1550 Mtro. Hndo de Herrera / Carleval / Mtros. Fdo. de Aguayo y Diego

Pérez

Hurtado, notario

Referencia: 11v

\section{VALENTÍN VÉLEZ}

\section{B. A.}

Grados obtenidos: L. A. / M. A. / B. T. / L. T. / D. T.

15-10-1550 Mtro. Diego Pérez, Diego Flores, Canciller / Diego de Guzmán / Fco. de Ayala

17-10-1550 Petición grado de M.A.

4-12-155o Diego Flores, Canciller dio el grado

5-12-1550 Dr. Bernardino Carleval, Rector

5-11-1551 Repetición para L. T., presidida por el Dr. Bernardino de Carleval

3-11-1554 Examen

4-11-1554 Canciller Diego Flores dio el grado de L. T.

22-11-1554 Canciller Diego Flores dio el grado de D. T.

Hurtado, Torres y Nieto, notarios

Referencias: 12r, 12v, 13r, 16v, 22r

\section{ANTONIO GODINO}

B. A.

Grados obtenidos: L. A. / M. A. / B. T.

17-3-1550 Examen para L. A.

23-3-1550 Repetición, presidida por Mtro. Herrera

25-3-1550 Canciller Flores le dio el grado

1-12-1550 Diego Flores le aprobó cuatro cursos de Teología

4-5-1553 Sustentó conclusiones presididas por Dr. Pedro González

10-5-1553 Recibió el grado de B.T.

Hurtado y Pedro Nieto, notarios

Referencias: 7r, 7v, 12v, 19r

DIEGO PÉREZ

Grado obtenido: B. A.

18-12-1550 Mtro. Diego Pérez / Dr. Gaspar Loarte, Canciller / Mtros. Bernardo de Herrera y Luis Noguera

N. de Torres, notario

Referencia: $13 \mathrm{v}$ 


\section{FRANCISCO SÁNCHEZ}

Grados obtenidos: L. A. / B. T. / M. A.

8-1-1551 Dr. Gaspar Loarte

9-1-1551 Diego Flores, Canciller

17-2-1551 Tentativa Dr. Gaspar Loarte / Ldos. J. de Córdoba y Fco. de Ayala

12-4-1554 Dr. Carleval le dio el grado

10-1-1555 Convalidación de suficiencia para M. A.

20-1-1555 Otorgado el grado por el Canciller Diego Flores

N. de Torres y P. Nieto, notarios

Referencias: 13v, 14r, 15r, 21v, 22v, 23r

\section{BENITO VANEGAS}

Grados obtenidos: L.A. / M. A. / B.T.

7-4-1551 Examen

9-4-1551 Grado de L.A. Gaspar Loarte, Rector

26-4-1551 Examen de Bernardino Carleval, Rector

27-1-1555 Diego Flores, Canciller, dio el grado de B.T.

N. de Torres, not.

Referencias: 14r-v, 15r, 23r

JUAN MEJÍAS

Grados obtenidos: L. A. / M. A.

7-4-1551 Gaspar Loarte, Rector

13-4-1551 Mtro. Hernando de Herrera

26-4-1551 Diego Flores, Canciller

N. de Torres, notario

Referencias: $14 \mathrm{r}, 15 \mathrm{r}$

\section{ALONSO HERNÁNDEZ}

Grado obtenido: L. A.

7-4-1551 Gaspar Loarte, Rector, le dio el grado

N. de Torres

Referencia: $14 \mathrm{r}$

\section{CRISTÓBAL VALVERDE}

B.A.

Grado obtenido: L.A.

17-8-1551 Mtro. Fdo. de Aguayo le admite para una repetición

20-8-1551 Examen secreto

22-8-1551 Diego Flores, Canciller, le otorga el grado 
N. de Torres, notario

Referencia: $15 \mathrm{r}$

GONZALO DE MOLINA

Racionero

Grados obtenidos: B.A. / L. A. / M.A.

4-10-1551 Mtro. Diego Pérez

8-5-1552 por Mtro. Gonzalo de Aguayo, Vicerrector

4-10-1552 Acto para L. A. con presencia de Mtro. Hdo. de Aguayo, Rector y presidido por Mtro. Diego Pérez

8-12-1552 Repetición para L. A., en presencia Mtro. Hdo Aguado, Rector y presidida por Mtro. Diego Pérez

15-12-1552 Puntos

16-12-1552 Examen

9-4-1553 Diego Flores, Canciller, le dio el grado de L. A.

16-6-1555 Canciller Flores da el grado de M.A.

N. de Torres, notario

Referencias: $15 \mathrm{v}, 17 \mathrm{v}, 18 \mathrm{r}-18 \mathrm{v}, 25 \mathrm{r}$

CRISTÓBAL GALLEGO

Grado obtenido: B. A.

18-10-1551 Mtro. Diego Pérez

N. de Torres

Referencia: $16 \mathrm{r}$

ALONSO PRETEL

Grado obtenido: B. A.

18-10-1551 Mtro. Diego Pérez

N. de Torres

Referencia: $16 \mathrm{r}$

ANTÓN GARCÍA

Grados obtenidos: B. A. / L. A.

18-10-1551 Mtro. Diego Pérez otorgó el grado

20-6-1555 Examen secreto, Aprobado de L. A.

23-6-1555 Grado otorgado por el Dr. Diego Flores

N. de Torres, P. Nieto, notario

Referencias: $16 \mathrm{r}, 25 \mathrm{v}$

JUAN GARCÍA DE PEDROSA

Grado recibido: B. A. 
18-10-1551 Mtro. Diego Pérez

6-5-1556 Acto mayor de artes, presidido por Dr. Vélez

N. de Torres y López, not.

Referencias: 16r, 31r

\section{ALONSO GIL}

Grado obtenido: B. A.

18-10-1551 Mtro. Diego Pérez

N. de Torres

Referencia: $16 \mathrm{r}$

\section{PAULO FERRER}

Grados obtenidos: B. A. / L. A. / M. A. / B. T. / L. T.

18-10-1551 Mtro. Diego Pérez

15-10-1552 Conclusiones generales para L. A. en presencia del Mtro. Hdo. de Aguayo, Rector

26-11-1552 Segundo acto, presidido por Mtro. Diego Pérez

30-5-1553 Mtro. Hdo. de Aguayo, Rector, le concede hacer repetición para L. A.

3-6-1553 Acto presidido por el Mtro. Diego Pérez

10-6-1553 Puntos

30-6-1553 Examen

18-7-1553 Diego Flores, Canciller, dio el grado de L.A.

16-6-1555 Diego Flores, Canciller, dio el grado de M.A.

19-1-1558 Tentativa para B. T., presidida por el Dr. Vélez y le dio el grado

12-2-1558 Repetición para L. T. presidida por Dr. Vélez y le dio la suficiencia

13-2-1558 Examen secreto de L. T.

14-2-1558 Aprobado para L. T.

N. de Torres notario, Pedro Nieto, secretario, Sebastián Rodríguez, not.

Referencias: 16r, 18r, 19r, 19v, 25r, 37r, 37v

JUAN VIZCAÍNO

Grado obtenido: B. A.

18-10-1551 Mtro. Diego Pérez

N. de Torres

Referencia: $16 \mathrm{r}$

CRISTÓBAL DE ALMAGRO

Grado obtenido: B. A.

18-10-1551 Mtro. Diego Pérez

N. de Torres

Referencia: $16 \mathrm{r}$ 
JUAN DEL ARCO

Grado obtenido: B. A.

18-10-1551 Mtro. Diego Pérez

N. de Torres

Referencia: $16 \mathrm{r}$

FRANCISCO DEL PINO

Grado obtenido: B. A.

18-10-1551 Mtro. Diego Pérez

N. de Torres

Referencia: $16 \mathrm{r}$

JORGE DE REOLI

Grado obtenido: B. A.

18-10-1551 Mtro. Diego Pérez

N. de Torres

Referencia: $16 \mathrm{r}$

ALONSO DE BARZANA [Barçana]

Grados obtenidos: B. A. / L. A. / M. A.

18-10-1551 Mtro. Diego Pérez le dio el grado

19-9-1555 Repetición para L. A. presidida por el Dr. V. Vélez

16-10-1555 Pide capítulos al Dr. Aguayo

16-10-1555 Aprobado de L. A.

25-11-1555 Diego Lucas de Córdoba, Canciller concede el grado

23-10-1557 Quodlibetal para grado de B. T., presidida por el Dr. Vélez

7-10-1558 El Rector admitióle para el grado de magisterio

12-10-1558 Juan Ocón, Canciller, le otorgó el grado

N. Torres, P. Nieto y Sebastián Rodríguez, not.

Referencias: 16r, 26r, 27v, 29r, 35r, 42v, 42v

\section{ALONSO DE VILLAREAL}

Grado obtenido: B. A.

18-10-1551 Mtro. Diego Pérez

N. de Torres

Referencia: $16 \mathrm{r}$

MELCHOR DE VERGARA

Grado obtenido: B. A.

18-10-1551 Mtro. Diego Pérez 
N. de Torres

Referencia: $16 \mathrm{r}$

ALONSO DE GALEOTE

Grado obtenido: B. A.

18-10-1551 Mtro. Diego Pérez

N. de Torres

Referencia: $16 \mathrm{r}$

ANTÓN DE PEROCHICO

Grados obtenidos: B. A. / L. A. / M. A.

18-10-1551 Mtro. Pedro Díaz

3-2-1554 Mtro. Diego Pérez preside un acto

26-3-1556 Acto mayor para licenciado, presidido por el Dr. Diego Pérez

23-10-1556 Repetición para grado de Licencia presidido por el Dr. H. de Herrera

21-12-1556 Diego Lucas, Canciller, dio el grado de L.A.

25-4-1557 Fr. Gerónimo de Mendoza, Canciller, dio el grado de M.A.

N. de Torres, P. Nieto, López, not.

Referencias: 16r, 20v, 3or, 31v, 32v, 33r

PEDRO NIETO

Grados obtenidos: B.A. / L.A.

18-10-1551 Mtro. Diego Pérez

28-9-1555 Repetición para L.A. presidida por el Dr. Aguayo

11-10-1555 Dr. Fdo. de Aguayo, Rector, señaló el examen secreto

12-10-1555 Examinado y aprobado de L. A.

25-11-1555 Diego Lucas de Córdoba, otorgó el grado

Motejano, not.

Referencias: 16r, 26v, 27r, 29r

DIEGO DE BAEZA

Grado obtenido: B. A.

18-10-1551 Mtro. Diego Pérez

N. de Torres

Referencia: $16 \mathrm{r}$

FRANCISCO CANO

Prior de San Pedro

Grados obtenidos: B. A. / L. A. / M. A.

18-10-1551 Mtro. Diego Pérez 
17-4-1556 Acto mayor para Licencia

5-5-1557 Repetición para L. A. presidida por el Dr. Ferrer

23-3-1560 Capítulos para examen secreto

24-3-1560 Examen y aprobado de L. A.

12-5-1560 Juan Ocón le dio el grado de L. A.

20-5-1563 Otorgóle el grado de M.A. Fr. Alonso de Vergara, Canciller

N. de Torres y Crist. de Cózar, not.

Referencias: 16r, 30v, 32v, 46v, 47v, 58r

BALTASAR DE LA MAESTRA

Grado obtenido: B. A.

18-10-1551 Mtro. Diego Pérez

N. de Torres

Referencia: $16 \mathrm{r}$

\section{LUIS GÓMEZ}

Grados obtenidos: B. A. / L. A. / M. A.

18-10-1551 Mtro. Diego Pérez

3-10-1555 Repetición para L. A. presidida por el Dr. Diego Pérez

1-11-1555 Pide capítulos al Dr. Bernardino de Carleval

2-11-1555 Aprobado el examen para Ldo. y Mtro.

25-11-1555 Diego Lucas de Córdoba concede el grado de L. A.

30-11-1557 Rdo. Diego Lucas, Canciller, otorga el grado de M.A.

N. de Torres y P. Nieto, notarios

Referencias: 16r, 27r, 28r, 29r, 36r

DIEGO SÁNCHEZ

Grado obtenido: B. A.

18-10-1551 Mtro. Diego Pérez

N. de Torres, not.

Referencia: $16 \mathrm{r}$

CRISTÓBAL IBÁÑEZ

Grado obtenido: B. A.

18-10-1551 Mtro. Diego Pérez

N. de Torres

Referencia: $16 \mathrm{r}$

ANDRÉS LÓPEZ

Clérigo, Prior de Rus 
Grados obtenidos: B. A. / B. T.

18-10-1551 Mtro. Diego Pérez

1-3-1572 Acto para B. T. que presidió el Dr. Diego de Ávila

22-3-1572 El Dr. Ávila le dio el grado

N. de Torres, J. Núñez, not. y secr.

Referencias: 16r, 139v, 140r

PÍO DELGADO

Grado obtenido: B. A.

18-10-1551 Mtro. Diego Pérez

N. de Torres, not.

Referencia: $16 \mathrm{r}$

\section{JUAN DE CÓRDOBA}

Licenciado

Grados obtenidos: M. A. / B. T.

5-11-1551 Mtro. Bernardino Carleval

14-1-1555 Se prepone al Dr. Fco. Sánchez por ser más antiguo

19-1-1555 Pide ser admitido para el grado de Maestro

20-1-1555 Graduado por el Canciller Diego Flores

7-2-1556 Grado de B.T. presidido por el Dr. Carleval

N. de Torres, not.

Referencias: 16v, 22v, 23r, 29r

BERNABÉ DE BAEZA

Grado obtenido: B. T.

5-11-1551 Mtros. Valentín Vélez, Hernando de Herrera, Luis Noguera

N. de Torres, not.

Referencia: $16 \mathrm{v}$

\section{PEDRO DE CISNEROS}

Clérigo

Grado obtenido: B. A.

18-2-1552 Mtros. Valentín Vélez, Antonio Hurtado, Hernando de Herrera

N. de Torres, not.

Referencia: $17 \mathrm{r}$

GONZALO [RAMÍREZ] DE MOLINA

B. A., Racionero de Jaén

Grados obtenidos: L. A. / M. A. / B. T. 
8-5-1552 Acto general presidido por Mtro. Gonzalo de Aguayo, Vicerrector 4-10-1552 Acto para L. A. con presencia de Mtro. Hdo. de Aguayo, Rector y presidido por Mtro. Diego Pérez

8-12-1552 Repetición para L. A., en presencia Mtro. Hdo. Aguayo, Rector y presidida por Mtro. Diego Pérez

15-12-1552 Puntos

16-12-1552 Examen

9-4-1553 Diego Flores, Canciller

16-6-1555 Tentativa para B. T.

20-11-1566 Presidió el Rector Pérez y diole el grado

N. de Torres y P. Nieto, Gil de Morales, not. y secr.

Referencias: 17v, 18r, 18v, 25r, 89r

\section{JORGE ÁLVAREZ}

\section{B. A.}

Grado obtenido: L. A.

16-9-1553 Acto mayor de Artes, en presencia del Rector Aguayo y presidiendo Mtro. Valentín Vélez

12-10-1553 Acto menor con los mismos maestros

18-11-1553 Repetición para L. A.

10-2-1554 Examen secreto, Mtro. Diego Pérez

15-4-1554 Mtro. Diego Flores le dio el grado

Pedro Prieto, secretario

Referencias: 20r, 21r, 21v

DIEGO MARTÍNEZ

Grado obtenido: B. A.

3-2-1554 Mtro. Pedro Díaz

P. Nieto, notario

Referencia: 20v

\section{JUAN DE MONTIJANO}

Grados obtenidos: B. A. / L. A.

3-2-1554 Mtro. Pedro Díaz

21-2-1555 Acto mayor para L. A.

17-5-1555 Recibido de Licenciado

19-6-1555 Repetición presidida por Mtro. Herrera

18-6-1555 Puntos para examen de Filosofía

23-6-1555 Examen secreto

Aprobado para el grado de Ldo. Otorgado por el Mtro. Diego Flores 
P. Nieto y A. López, notarios

Referencias: 20v, 23v, 24v, 25r, 25v

MARTÍN SÁNCHEZ DE PIDULA

Grado obtenido: B. A.

3-2-1554 Mtro. Pedro Díaz

P. Nieto, notario

Referencia: $20 \mathrm{~V}$

FRANCISCO PÉREZ

Grado obtenido: B. A.

3-2-1554 Mtro. Pedro Díaz

12-3-1556 Mtro. Herrera, para licencia

P. Nieto y A. López, notarios

Referencias: 20v, 29v

ANTONIO DE RAYA

Grado obtenido: B. A.

3-2-1554 Mtro. Pedro Díaz

P. Nieto, notario

Referencia: $20 \mathrm{~V}$

CRISTÓBAL DE LA CARCAYA?

Grado obtenido: B. A.

3-2-1554 Mtro. Pedro Díaz

P. Nieto, notario

Referencia: $20 \mathrm{v}$

DIEGO MORENO

Grado obtenido: B. A.

3-2-1554 Mtro. Pedro Díaz

P. Nieto, notario

Referencia: $20 \mathrm{v}$

ANTONIO DE CASAS

Grado obtenido: B. A.

3-2-1554 Mtro. Pedro Díaz

27-3-1556 Acto mayor para L. A.

P. Nieto y López, not.

Referencias: 20v, 3or 


\section{LUIS DE MEDINA}

Grados obtenidos: B. A. / L. A. / M. A. / B. T. / L. T. / D. T. 3-2-1554 Mtro. Pedro Díaz

16-4-1556 Acto mayor para L.A presidido por Dr. Pérez 4-6-1558 Incorporación a la Universidad de Baeza 4-6-1558 Diego Lucas, Canciller 5-6-1558 Recibido por la Universidad por el Canciller 16-2-1559 Tentativa para B. T. presidida por Dr. Herrera 6-10-1563 Repetición para L. T. Presidió Mtro. Carleval 2-11-1563 Examen secreto para L. T. 3-11-1563 Presidió Mtro. Carlevar 14-11-1563 Otorgóle el grado de L.T. el Mfco. Juan de Ocón 25-11-1563 Otorgóle el grado de D.T. el Mfco. Juan de Ocón P. Nieto, Pérez y Rodríguez, not.

Referencias: 20v, 30v, 39v, 40r, 40v, 60v, 64r, 65r, 66r

MELCHOR HERNÁNDEZ / FERNÁNDEZ DE HERRERA Grados obtenidos: B. A. / L. A. / M. A. / B. T. / L. T. / D. T. 3-2-1554 Mtro. Pedro Díaz

14-11-1556 Repetición, presidida por el Dr. Herrera 4-12-1556 Examen secreto presidido por el Dr. Herrera 21-12-1556 Diego Lucas, Canciller 11-5-1558 Pide al Rector Carleval hacer actos de Teología 12-5-1558 Acto de Teología presidido por el Dr. Herrera y aprobado 18-1-1559 Acto menor de Teología, presidido por el Dr. V. Vélez 27-10-1557 Diego Pérez, Rector, le da el grado 28-1-1563 Acto para L. T. presidido por el Dr. D. Pérez 29-1-1563 Acto de Teología, presidido por Dr. Pérez 14-10-1563 Acto menor para L. T.

30-10-1563 Repetición aprobada para L. T. preside Dr. Pérez 11-11-1563 Examen secreto 12-11-1563 Presidió el Dr. Herrera 13-11-1563 Otorgóle el Grado de D.T. el Mfco. Juan de Ocón P. Nieto, López, Sebastián Rodríguez, not.

Referencias: 20v, 32r, 32v, 38v, 39r, 44r, 45v, 56r, 61v, 63v, 64v, 65r

\section{PEDRO GARCÍA}

Grado obtenido: B. A. 3-2-1554 Mtro. Pedro Díaz

P. Nieto, not.

Referencia: 20v 


\section{PAULO MÉNDEZ}

Grado obtenido: B. A.

3-2-1554 Mtro. Pedro Díaz

P. Nieto

Referencia: $20 \mathrm{~V}$

JULIÁN SÁNCHEZ DE BARZANA

Grado obtenido: B. A.

3-2-1554 Mtro. Pedro Díaz

P. Nieto

Referencia: $20 \mathrm{~V}$

\section{DIEGO DE ÁVILA}

O.SS.T.

Grados obtenidos: B. A. / L. A. / M. A. / B. T. / L. T. / D. T.

3-2-1554 Mtro. Pedro Díaz

20-11-1556 Repetición presidida por el Dr. Vélez

7-12-1556 Examen secreto presidido por el Dr. Vélez

21-12-1556 Diego Lucas, Canciller

25-4-1557 Fr. Gerónimo de Mendoza, Canciller

23-3-1558 Ante Bernardino de Carleval pide actos para B. T.

24-3-1558 Acto de Teología presidido por Mtro. Vélez y aprobado

22-6-1558 Acto menor de Teología, presidido por el Dr. Vélez y aprobado

1-9-1558 Acto de Teología presidido Dr. Herrera y aprobado

20-9-1558 Acto de Teología y tentativa, presidido por el Dr. Pérez, Rector

23-2-1560 Acto de Teología presidido por Dr. Pérez

20-11-1560 Acto para L. T. presidido por Dr. Vélez, Rector

8-10-1563 Repetición para L. T. Presidió el Dr. Pérez

10-11-1563 Examen secreto. Presidió Mtro. Vélez

14-11-1563 Mfco. Juan de Ocón, otorgóle el grado de D.T.

P. Nieto, López y Sebastián Rodríguez, not.

Referencias: 20v, 32r, 32v, 33r, 38v, 41v, 42v, 46v, 49v, 6ov, 64v

\section{PEDRO MUÑIZ}

Vecino de Baeza

Grados obtenidos: B. A. / L. A. / M. A. / B. T.

3-2-1554 Mtro. Pedro Díaz

27-5-1563 Acto mayor para L. A. Presidió el Rector Pérez

22-10-1563 Examen secreto L. A.

23-10-1563 Presidió el Dr. Pérez 
1-11-1563 Otorgóle el grado Juan de Ocón, Canciller

29-10-1565 Juan de Ocón, Canciller

24-5-1567 Tentativa para B. T. Presidió el Dr. Fernández y diole grado

P. Nieto, Medel, secr. y Gil de Morales

Referencias: 20v, 58v, 62v, 64r, 84r, 92r

CRISTÓBAL DE CÓZAR

Grados obtenidos: B. A. / L. A. / M. A.

3-2-1554 Mtro. Pedro Díaz

12-3-1556 Acto para Licencia presidido por Dr. Herrera

29-10-1556 Repetición para Licenciado, presidida por el Dr. V. López

4-11-1556 Examen secreto, presidido por el Dr. Vélez y aprobación

21-12-1556 Diego Lucas, Canciller, otorgó el grado

9-5-1557 Miguel de Yepes, Vicecanciller, otorgó el grado

P. Nieto y López, not.

Referencias: 20v, 29v, 31v, 32v, 33v

BARTOLOMÉ DE VEGA

Grado obtenido: B. A.

3-2-1554 Mtro. Pedro Díaz

P. Nieto

Referencia: 20v

GREGORIO DE VICTORIA

Grado obtenido: B. A.

3-2-1554 Mtro. Pedro Díaz

P. Nieto

Referencia: 20v

ANTONIO DE PARRAGA

Grado obtenido: B. A.

3-2-1554 Mtro. Pedro Díaz

P. Nieto

Referencia: 20v

ANTONIO DE CALATRAVA

Grado obtenido: B. A.

3-2-1554 Mtro. Pedro Díaz

P. Nieto

Referencia: 20v 
FRANCISCO AMADOR

Grado obtenido: B. A.

3-2-1554

Mtro. Pedro Díaz

P. Nieto

Referencia: $20 \mathrm{v}$

LUIS AMADOR

Grado obtenido: B. A.

3-2-1554 Mtro. Pedro Díaz

P. Nieto

Referencia: $20 \mathrm{v}$

BENITO SÁNCHEZ DE PADILLA

Grados obtenidos: B. A. / L. A. / M. A. / B. T.

3-2-1554 Mtro. Pedro Díaz

3-5-1556 Acto mayor de Artes, Mtro. V. Vélez

10-2-1559 Repetición para L. A. presidida por Rector Diego Pérez y aprobó

14-5-1563 Examen secreto

15-5-1563 Presidió el Rector Pérez

8-6-1563 Otorgóle el grado Mfco. Fr. Álvaro de Vergara

10-10-1563 Mfco. Juan de Ocón

23-5-1565 Tentativa para B. T. presidida por el Dr. Luis de Medina, catedrático, y se le dio el grado

P. Nieto, López, Medel, not. y secret.

Referencias: 20v, 31r, 44r, 57r, 59v, 61r, 77r

DIEGO DE VALBOA

Grado obtenido: B. A.

3-2-1554 Mtro. Pedro Díaz

P. Nieto

Referencia: $20 \mathrm{v}$

AGUSTÍN BAPTISTA

Grado obtenido: B. A.

3-2-1554 Mtro. Pedro Díaz

P. Nieto

Referencia: 20v

JUAN BAUTISTA

Grado obtenido: B. A. 
3-2-1554 Mtro. Pedro Díaz

P. Nieto

Referencia: 20v

FRANCISCO DE HUETE

Grado obtenido: B. A.

3-2-1554 Mtro. Pedro Díaz

P. Nieto

Referencia: 20v

DIEGO DE VALCÁRCEL

Grados obtenidos: B. A. / L. A.

3-2-1554 Mtro. Pedro Díaz

13-5-1557 Repetición presidida por Dr. Vélez y aprobación

18-6-1557 Examen secreto de Artes

19-6-1557 Aprobado

12-9-1557 Fr. Miguel de Yepes, Canciller

P. Nieto y Sebastián Rodríguez, not.

Referencias: 20v, 33v, 34v, 35v

LUIS DE LA TORRE

Grados obtenidos: B. A. / L. A. / M. A.

3-2-1554 Mtro. Pedro Díaz

19-3-1556 Acto para Licencia

6-11-1556 Repetición, presidida por el Dr. Ferrer

21-12-1556 Diego Lucas, Canciller

25-4-1557 Fr. Gerónimo de Mendoza, Canciller

P. Nieto y López, not.

Referencias: 20v, 31v, 32v, 33r

ÁLVARO CERVANTES

Grado obtenido: B. A.

3-2-1554 Mtro. Pedro Díaz

P. Nieto

Referencia: 20v

PEDRO GALDÓS

Grado obtenido: B. A.

3-2-1554 Mtro. Pedro Díaz

P. Nieto

Referencia: $20 \mathrm{v}$ 


\author{
ÁLVARO DE ARANDA \\ Grado obtenido: B. A. \\ 3-2-1554 Mtro. Pedro Díaz \\ P. Nieto \\ Referencia: $20 \mathrm{~V}$
}

PEDRO GONZÁLEZ DE QUESADA [Mtro. Quesada]

L.A. por Alcalá

Grado obtenido: M. A.

22-10-1551 Mtro. Bernardino Hurtado presidió una tentativa

4-2-1554 Pide al Canciller Diego Flores y al Claustro licencia para ser M. A., con presencia de los Mtros. Hernando Aguayo, Agustín Vélez y Diego Pérez. Incorporóse a la Universidad

N. de Torres y P. Nieto, notario

Referencias: 16v, 21r

\title{
MTRO. BERNARDINO HURTADO
}

Grado obtenido: B. T.

10-1-1555 Acto menor para B. T., presidido por el Dr. H. de Aguayo

17-1-1555 Acto menor para B. T. presidido por el Dr. Diego Pérez

P. Nieto, notario

Referencias: 22v, 23r

ANTÓN MARTÍNEZ

Grado obtenido: L.A.

2-3-1555 Acto mayor para L. A. Presidió el Dr. Aguayo

4-5-1555 Acto menor presidido por Dr. Pérez

17-5-1555 Ante el Canciller Calevar examen secreto

25-5-1555 Repeticiones

P. Nieto y López, notario

Referencias: 23v, 24r, 24v

\section{HERNANDO LÓPEZ}

B. A.

Grado obtenido: L. A.

7-3-1555 Acto mayor para L. A. presidido por el Mtro. Herrera

8-11-1555 Pidió al Dr. Bernardino de Carleval, Rector, ser recibido en el examen secreto

9-11-1555 Aprobado el examen

P. Nieto

Referencias: 23v, 28rv 
FR. DIEGO DE SARA

O. SS.T., B. T., Prof. en la Trinidad de Salamanca

Grado obtenido: L. T. / D. T.

21-4-1555 Pidió al Dr. Bernardino de Carleval ser recibido el grado de Licencia 28-4-1555 Repetición. Examen secreto

Diole los grados el Canciller Diego Flores

Fco. López, not.

Referencia: $23 \mathrm{v}$

ANTÓN LÓPEZ

B. A.

Grado obtenido: L. T.

6-5-1555 Acto menor para L. T.

9-5-1555 Examinado de L. T. por el Dr. Bernardino Carleval, Rector.

17-5-1555 Licenciado por el Mtro. Carleval, Rector

Fco. López, not.

Referencia: $24 \mathrm{~V}$

\section{ANTONIO DEL JESÚS}

Grado obtenido: L. A.

30-5-1555 Acto presidido por el Mtro. Herrera para L.A.

1-6-1555 Acto menor para L. A. presidido por Mtro. Herrera

16-11-1555 Repetición de Artes, presidida por el Dr. Herrera

16-11-1555 Petición para L. A.

18-11-1555 Petición al Dr. Carleval de examen secreto

19-11-1555 Apadrinado por el Dr. Herrera, aprobó el examen

25-11-1555 Diego Lucas de Córdoba, Canciller, concede el grado

Fco. López, y Pedro Nieto, not.

Referencias: 25r, 26r, 28v, 29r

\section{HERNÁN LÓPEZ}

\section{B. A.}

Grado obtenido: L. A.

27-6-1555 Repetición de Artes para L. A. presidida por Mtro. Valentin Vélez

8-11-1555 Petición al Dr. Bernardino de Carleval para el examen secreto

9-11-1555 Apadrinado por el Dr. Valentín Vélez fue examinado por los Dres. Fe-

rrer, Molina, Córdoba, Jovano, Pérez, Aguayo, fue aprobado de L. A.

25-11-1555 Diego Lucas de Cordoba, Canciller, concede el grado

P. Nieto, not.

Referencias: 26r, 28v, 29r 


\section{PEDRO DE CARDONA}

B. T. en Granada

Grados obtenidos: L. T. / M. A.

19-10-1555 Pide al Dr. H. de Aguayo, Rector, ser admitido para el grado de L. T.

21-10-1555 Repetición y capítulos

23-10-1555 Diego Flores, Canciller

13-11-1559 Grado otorgado por Juan Ocón, Canciller

P. Nieto y Rodríguez, not.

Referencias: 27r, 28r, 46r

DIEGO PÉREZ

Grado obtenido: B. A.

16-1-1556 Acto mayor para el grado de Licenciado, presidido por el Dr. Diego Pérez

19-9-1556 Pide repetición al Bernardino de Carleval, Rector, para Licenciado 20-9-1556 Repetición presidida por el Dr. Ferrer

Francisco López, Sebastián Rodríguez, notarios

Referencias: 29r, 31r

MELCHOR DE MORABETE Y ALLÓN

Grado obtenido: B. A.

9-2-1556 Dr. Herrera

F. López

Referencia: $29 \mathrm{v}$

LUNGO DE ZÚÑIGA

Grado obtenido: B. A.

9-2-1556 Dr. Herrera

F. López

Referencia: 29v

DIEGO MEJÍAS

Grado obtenido: B. A.

9-2-1556 Dr. Herrera

F. López

Referencia: 29v

MELQUÍADES DIÉGUEZ

Grado obtenido: B. A.

9-2-1556 Dr. Herrera 
F. López

Referencia: 29v

FRANCISCO QUESADA

Grado obtenido: B. A.

9-2-1556 Dr. Herrera

29-5-1557 Acto mayor, presidido por el Dr. Herrera y aprobación 26-6-1557 Acto menor, presidido por el Dr. Herrera y aprobación F. López y Sebastián Rodríguez, not.

Referencias: 29v, 34r, 34v

\section{DIEGO HERNÁNDEZ}

Grados obtenidos: B. A. / L. A.

9-2-1556 Dr. Herrera

20-5-1557 Acto mayor, presidido por el Dr. Herrera y aprobación 26-6-1557 Acto menor, presidido por el Dr. Herrera y aprobación 22-11-1557 Repetición presidida por el Dr. V. Vélez y aprobada 7-6-1558 Examen secreto 8-6-1558 Aprobación de B. A. 14-6-1558 Fr. Geronimo Cano, Vicecanciller, concedió el grado F. López y Sebastián Rodríguez, not.

Referencias: 29v, 33v, 34r, 35v, 40r, 41r

\section{MARTÍN MORENO}

Grados obtenidos: B. A. / L. A.

9-2-1556 Dr. Herrera

29-5-1556 Acto mayor presidido por el Dr. Herrera y aprobación 26-6-1557 Acto menor presidido por el Dr. Herrera y aprobación 20-5-1558 Repetición para L. A., presidida por Mtro. Bautista de Sarantes y aprobada

14-6-1558 Examen secreto de L.A.

Fr. Gerónimo Cano, Vicecanceller, concedió el grado

F. López, Sebastián Rodríguez, not.

Referencias: 29v, 34r, 34v, 36v, 39r, 41r

NUÑO DE VILA

Grado obtenido: B. A. 9-2-1556 Dr. Herrera

F. López

Referencia: $29 \mathrm{v}$ 


\section{CRISTÓBAL VÁZQUEZ}

Grados obtenidos: B. A. / L. A.

9-2-1556 Dr. Herrera

29-5-1557 Acto mayor presidido por el Dr. Herrera y aprobación 26-6-1557 Acto menor, presidido por el Dr. Herrera y aprobación 27-5-1558 Repetición para L. A. y aprobación por el Dr. Vélez 10-6-1558 Examen secreto 11-6-1558 Aprobación L. A. 14-6-1558 Fr. Gerónimo Caro, Vicecanciller, concedió el grado F. López y Sebastián Rodríguez, not.

Referencias: 29v, 34r, 34v, 39v, 40r, 41r

\section{JUAN DE ZÚÑIGA}

Grado obtenido: B. A. 9-2-1556 Dr. Herrera

F. López, notario

Referencia: 29v

\section{BARTOLOMÉ LEDACIVO?}

Grado obtenido: B. A.

9-2-1556 Dr. Herrera

F. López, notario

Referencia: $29 \mathrm{v}$

\section{FRANCISCO DE JODAR}

Grado obtenido: B. A.

9-2-1556 Dr. Herrera

29-5-1557 Acto mayor presidido por el Dr. Herrera y aprobación

F. López, notario

Referencias: 29v, 34r

RODRIGO MEJÍAS

Grado obtenido: B. A.

9-2-1556 Dr. Herrera

22-6-1559 Acto mayor para L. A. presidido por Dr. Herrera

F. López

Referencias: 29v, 45r

A. DE PADILLA

Grado obtenido: B. A. 
9-2-1556 Dr. Herrera

F. López

Referencia: 29v

ANDRÉS JIMÉNEZ

Grado obtenido: B. A.

9-2-1556 Dr. Herrera

F. López

Referencia: 29v

DIEGO DE VALENZUELA

Grado obtenido: B. A.

9-2-1556 Dr. Herrera

12-6-1557 Acto mayor presidido por el Dr. Herrera y aprobación

22-4-1559 Acto menor presidido por el Dr. Herrera

26-4-1559 Repetición para L. A. presidido por Dr. Herrera

F. López y Sebastián Rodríguez, not.

Referencias: 29v, 34r, 45r, 45r

JUAN DE MÉRIDA

Grado obtenido: B. A.

9-2-1556 Dr. Herrera

F. López

Referencia: 29v

X. LÓPEZ

Grado obtenido: B. A.

9-2-1556 Dr. Herrera

F. López

Referencia: 29v

MARTÍN DE CO...

Grado obtenido: B. A.

9-2-1556 Dr. Herrera

F. López

Referencia: 29v

SEBASTIÁN GÓMEZ

Grados obtenidos: B. A. / L. A.

9-2-1556 Dr. Herrera 
20-5-1557 Acto mayor, presidido por el Dr. Herrera y aprobación 25-6-1558 Repetición para L. A. presidida por Mtro. Bautista de Sarantes y aprobada

22-10-1558 Acto menor de Artes para L. A., presidido por Dr. Herrera y aprobó 10-12-1558 Examen secreto de L. A. señalado por el Rector Pérez y aprobó 21-12-1558 Vicecanciller Fr. G. Caro le dio el grado

Sebastián Rodríguez, not.

Referencias: 29v, 33v, 41v, 43r, 43v

\section{DIEGO DE SANJUAN}

Grado obtenido: B. A.

9-2-1556 Dr. Herrera

F. López

Referencia: 29v

GASPAR DE...

Grado obtenido: B. A.

9-2-1556 Dr. Herrera

F. López

Referencia: $29 \mathrm{v}$

JUAN DE MEDINA

Grados obtenidos: B. A. / L. A. / M. A.

9-2-1556 Dr. Herrera

12-2-1556 Acto para Licencia

12-6-1557 Acto mayor, presidido por el Dr. Herrera y aprobación

4-5-1560 Repetición para L. A. presidida por Dr. Pérez

23-5-1560 Pide examen secreto al Rector Diego Pérez

24-5-156o Diego Pérez le preside y le aprueban de L. A.

3-6-156o Mfco. Diego Lucas dio el grado de L. A.

29-6-1560 Fr. Gerónimo Núñez, Canciller, dio el grado de M.A.

F. López, Sebastián Rodríguez, not.

Referencias: 29v, 34r, 47r, 48r, 48v

\section{FRANCISCO MARÍN}

Grados obtenidos: B. A. / L. A.

9-2-1556 Dr. Herrera

20-5-1557 Acto mayor, presidido por el Dr. Herrera y aprobación

25-5-1558 Repetición para L. A., presidida por Mtro. Ferrer y aprobada 12-6-1558 Examen secreto de Artes 
13-6-1558 Aprobado de L. A.

14-6-1558 Fr. Gerónimo Caro, O.P., Vicecanciller, le dio el grado

F. López y Sebastián Rodríguez, not.

Referencias: 29v, 33v, 39r, 40v, 41r

¿ं?

23-3-1556 Conclusiones quodlibetales para L.T., presididas por Dr. B. de Carleval, Rector

López, not.

Referencia: 29v

FR. GABRIEL DE SANTOYO

Grado obtenido: B. T.

13-4-1556 Fr. Gerónimo de Mendoza

López, not.

Referencia: 3or

MELCHOR DE HERRERA

Grado obtenido: L. A.

30-4-1556 Acto Mayor para licencia, presidido por Dr. Valentin Vélez 29-1-1562 Acto para L.A. presidido por Dr. Pérez, que le dio el grado

López, not.

Referencias: 30v, 54r

\section{CARZA}

Grado obtenido: B. A.

2-5-1556 Acto mayor de Licencia en Artes, presidido por Mtro. Ferrer

8-2-1557 Repetición presidida por el Dr. Herrera

López, not.

Referencias: 31r, 32v

DIEGO? AMEZCUA

Grado obtenido: B. A.

24-4-1557 Dr. Herrera

López, not.

Referencia: $33 \mathrm{r}$

JUAN BAUTISTA DE SERANTES

L. A. por Osuna

25-4-1557 Incorporación 
20-9-1564 Incorporación. Presentó su título de L.T. y juró ante el Canciller y Rector, y fue recibido e incorporado Fr. Sebastián de Sosa, Vicecan. le dio el título Rodríguez, not.; López, not.

Referencias: 33r, 71v

\section{ALONSO GARZÓN}

Grados obtenidos: B. A. / L. A. / M. A. / B. T.

29-9-1557 Mtro. Noguera

18-11-1557 Repetición para L. A., presidida por Dr. Paulo Ferrer y aprobada

28-11-1557 Examen secreto

29-11-1557 Aprobado de L. A.

2-12-1557 Diego Lucas, Canciller, le dio el grado

8-12-1557 Fr. Miguel de Yepes le dio el grado de M.A.

23-9-1563 Tentativa para B. T. Presidió el Dr. Pérez en presencia del Rector Mtro.

Hernan Núñez. Recibió el grado

Sebastián Rodríguez

Referencias: 35r, 35v, 36r, 36v, 6or

\section{MARTÍN LIGERO}

Grados obtenidos: L. A. / M. A.

30-10-1557 Repetición para L. A., presidida por Dr. Vélez y aprobada

23-11-1557 Examen secreto de Artes

24-11-1557 Aprobado L. A.

2-12-1557 Diego Lucas, Canciller le dio el grado de L.A.

8-12-1557 Fr. Miguel de Yepes le concedió el grado de M.A.

Sebastián Rodríguez, not.

22-6-1565 Incorporación a la Universidad del Dr. Martín Ligero, M. A. por Baeza y D.T. por la Universidad de Valencia en 31-5-156o. Fue recibido por el Rector Pedro Díaz Soriano Vega y juró como Prior de la Parroquial de San Vicente de Baeza Medel, secret.

Referencias: 35v, 36r, 36v, 8or, 8ov

\section{JORGE DE ROBLES}

Grados obtenidos: B. A. / L.A. 20-2-1558 Mtro. Paulo Ferrer

21-10-1559 Acto mayor para L. A. presidido por Dr. Vélez 20-4-156o Acto menor presidido por Dr. Pérez, Rector 22-6-156o Repetición y aprobación 3-1-1562 Petición al Rector Pérez para examen secreto 4-1-1562 Presidió Mtro. Medina 
11-1-1562 Mfco. Diego Flores le dio el grado

Sebastián Rodríguez, not.

Referencias: 37v, 45v, 48v, 52v, 53r

HERNANDO DE BIEDMA

Grado obtenido: B. A. 20-2-1558 Mtro. Paulo Ferrer

21-10-1559 Acto mayor para L. A. presidido por Dr. Vélez

8-6-156o Repetición para L. A. Presidió el Dr. Herrero

Sebastián Rodríguez

Referencias: 37v, 45v, 48v

MELCHOR DE MOLINA

Grados obtenidos: B. A. / L. A. / M. A. / B. T. / L. T. / D. T.

20-2-1558 Mtro. Paulo Ferrer

22-4-1559 Acto menor presidido por el Dr. Herrero

21-10-1559 Acto mayor para L. A. presidido por Dr. Vélez

11-5-1560 Repetición para L. A. presidida por Mtro. Luis de Medina: aprobada

19-5-156o Examen secreto de L. A. y aprobación, presidido por el Mtro. Medina 20-5-1560 Mfco. Diego Lucas le dio el grado de L. A.

3-6-1560 Mtro. Fco. de Herrera diole el grado de M. A.

8-12-1561 Tentativa para B. T. Presidió el Dr. Pérez y le dio el grado

17-6-1564 Acto de Teología: magna ordinaria para L.T. Presidió el Rector Ávila y aprobó

12-12-1571 Quodlibetos para L. T. Presidió el Rector Ávila y aprobó

21-1-1572 Puntos para examen secreto para L. T.

23-1-1572 Presidió el Dr. Herrera y fue admitido al grado de L. T. y D. T.

24-1-1572 El Canciller Ocón le dio el Título

Rodríguez, Juan Núñez not. y secr.

Referencias: 37v, 45r, 45v, 47v, 48r, 52v, 71r, 137v, 138r

\section{LOPE MARTÍNEZ}

Natural de Cazorla

Grados obtenidos: B. A. / M. A. / B. T.

20-2-1558 Mtro. Paulo Ferrer

22-6-1561 Acto mayor por repetición para L. A. presidido por Dr. Diego Pérez, Vicerrector

28-6-1561 Acto menor presidido por el Dr. Pérez

26-10-1561 Pidió al Dr. Pérez el examen secreto

27-10-1561 Presidió el Dr. Vélez para L. A. 
16-5-1563 Otorgóle el título M. A. Fr. Álvaro de Vergara, Canciller 23-6-1575 Tentativa parva de 12 conclusiones para B. T. que presidió el Dr. Ojeda y aprobó. El Dr. Salgado le dio el grado

Rodríguez, Mtro. Molina, not.

Referencias: 37v, 50v, 51v, 57r, 169r

MIGUEL DEL SALTO

Grado obtenido: B. A.

20-2-1558 Mtro. Paulo Ferrer

Rodríguez, not.

Referencia: $37 \mathrm{v}$

FRANCISCO DE AYUAR

Grado obtenido: B. A.

20-2-1558 Mtro. Paulo Ferrer

Rodríguez, not.

Referencia: $37 \mathrm{v}$

GONZALO DE AYALA

Grado obtenido: B. A.

20-2-1558 Mtro. Paulo Ferrer

8-10-1563 Repetición para L. A. Presidió el Dr. Pérez

Rodríguez, not.

Referencias: 37v, 6ov

MELCHOR DE CÓRDOBA

Grado obtenido: B. A.

20-2-1558 Mtro. Paulo Ferrer

Rodríguez, not.

Referencia: $37 \mathrm{v}$

FRANCISCO DE CÓZAR

Grado obtenido: B. A.

20-2-1558 Mtro. Paulo Ferrer

Rodríguez

Referencia: 37v

JUAN RODRÍGUEZ

Grado obtenido: B. A.

20-2-1558 Mtro. Paulo Ferrer 
Rodríguez

Referencia: $37 \mathrm{v}$

JUAN CASADO

Grado obtenido: B. A.

20-2-1558 Mtro. Paulo Ferrer

Rodríguez

Referencia: $37 \mathrm{v}$

MELCHOR DEL JESÚS

Grado obtenido: B. A.

20-2-1558 Mtro. Paulo Ferrer

Rodríguez

Referencia: 37v

JUAN GONZÁLEZ

Grado obtenido: B. A.

20-2-1558 Mtro. Paulo Ferrer

Rodríguez

Referencia: $37 \mathrm{v}$

AQUILES HERNÁNDEZ

Grado obtenido: B. A.

20-2-1558 Mtro. Paulo Ferrer

Rodríguez

Referencia: $37 \mathrm{v}$

MARTÍN DE SOMOZA

Grado obtenido: B. A.

20-2-1558 Mtro. Paulo Ferrer

Rodríguez

Referencia: $37 \mathrm{v}$

ALONSO / ÁLVARO DE HERRERA

¿Vecino de Baeza?

Grados obtenidos: B. A. / B. T.

20-2-1558 Mtro. Paulo Ferrer

10-6-1564 Tentativa para B. T. Presidió el Dr. Pérez y diole el grado Rodríguez

Referencias: 37v, 7or 
JUAN MARTÍNEZ

Grado obtenido: B. A.

20-2-1558 Mtro. Paulo Ferrer

Rodríguez

Referencia: $37 \mathrm{v}$

PEDRO DE COLMENARES

Grado obtenido: B. A.

20-2-1558 Mtro. Paulo Ferrer

Rodríguez

Referencia: $37 \mathrm{v}$

FR. CRISTÓBAL DE BLAS

Grado obtenido: B. A.

20-2-1558 Mtro. Paulo Ferrer

Rodríguez

Referencia: $37 \mathrm{v}$

\section{A. DE TEJERINA}

Grado obtenido: B. A.

20-2-1558 Mtro. Paulo Ferrer

Rodríguez

Referencia: 37v

PEDRO DE SABIOTE

Grado obtenido: B. A.

20-2-1558 Mtro. Paulo Ferrer

Rodríguez

Referencia: $37 \mathrm{v}$

HERNANDO DE CONEJERO

Grado obtenido: B. A.

20-2-1558 Mtro. Paulo Ferrer

Rodríguez, not.

Referencia: $37 \mathrm{v}$

JUAN DE VALVERDE

B. A.

Grado obtenido: L. A.

12-3-1558 Repetición de L. A. presidida por el Dr. Herrera y aprobada 
20-3-1558 Petición de puntos

21-3-1558 Examinado y aprobado de L. A.

23-3-1558 Fr. Miguel de Yepes, Canciller, le dio el grado

Rodríguez, not.

Referencia: $38 \mathrm{r}$

FR. GERÓNIMO CARO

Prior de Santo Domingo, O.P.

Grados obtenidos: B. A. / L. A. / M. A.

5-6-1558 Pidio ser admitido para los grados de B. A., L.A., M. A. y fue admitido.

Diego Lucas, Canciller, le concedió los grados de bachiller y licenciado. Recibido

y aceptado por la Universidad

Sebastián Rodríguez, notario

Referencia: 39v

ÁLVARO NÚÑEZ MARCELO

Grado obtenido: B. A.

11-3-1559 Le dio el grado Dr. Diego Pérez, Rector

Rodríguez, notario

Referencia: 44v

\section{FRANCISCO DE ESCOBAR}

B. A.

Grados obtenidos: L. A. / M. A.

22-6-1559 Acto mayor para L. A. presidido por Dr. Herrera

9-5-1560 Acto menor presidido por Mtro. L. de Medina

16-10-1561 Examen secreto de L.A.

17-10-1561 Presidió el Dr. Ávila

25-11-1561 Dr. Fco. de Herrera otorgóle el grado

20-5-1563 Otorgóle el grado Fr. Álvaro de Vergara, Canciller

Rodríguez, notario

Referencias: 45r, 47v, 51r, 51v, 58r

BARTOLOMÉ CEDACERO

Grado obtenido: B. A.

22-6-1559 Acto mayor para L. A. presidido por Dr. Herrera

Rodríguez, notario

Referencia: $45 r$

HERNANDO DE CONTRERAS

Grado obtenido: B. A. 
1-10-1559 Mtro. Juan Bautista de Serantes le dio el grado

Rodríguez, notario

Referencia: $45 \mathrm{r}$

FRANCISCO LÓPEZ CASTILLO

Grado obtenido: B. A.

1-10-1559 Mtro. Serantes le dio el grado

Rodríguez, notario

Referencia: $45 \mathrm{r}$

HERNÁN PÉREZ

Grados obtenidos: B. A. / L. A.

30-11-1559 Mtro. Sarantes

11-11-1561 Acto mayor para L. A. y repetición: presidió del Mtro. Luis de Medina

21-11-1561 Pidió examen secreto al Dr. Pérez para L. A.

22-11-1561 Presidió el Dr. Herrera

25-11-1561 Mtro. Fco. de Herrera otorgóle el grado

Rodríguez, not.

Referencias: 46r, 52r, 52v

DIEGO DE CARVAJAL

Grado obtenido: B. A.

30-11-1559 Mtro. Juan Bautista de Serantes

Rodríguez, not.

Referencia: 46r

AL. PALOMINO JIMENEZ

Grado obtenido: B. A.

30-11-1559 Mtro. Juan Bautista de Serantes

Rodríguez, not.

Referencia: $46 \mathrm{r}$

ALONSO LECHUGA

Grado obtenido: B. A.

30-11-1559 Mtro. Serantes

25-6-1563 Acto mayor para L. A.

5-5-1564 Presidió Mtro. Medina. Acto menor para L. A.: presidió el Dr. Pérez

Rodríguez, not.

Referencias: 46r, 6or, 68v 


\section{FRANCISCO LÓPEZ}

Grado obtenido: B. A.

30-11-1559 Mtro. Juan Bautista de Serantes

Rodríguez, not.

Referencias: $46 \mathrm{r}$

\section{ESTEBAN DE OJEDA}

Grados obtenidos: B. A. / L. A. / M. A.

30-11-1559 Mtro. Juan Bautista de Serantes

15-2-1560 Acto mayor para L. A., presisido Mtro. Medina

27-4-1560 Acto menor presidido por el Dr. Herrera

13-2-1561 Repetición para B. A. Presidió el Dr. Herrera

¿-10-1561 Pidió examen secreto

25-11-1561 Presidió el Dr. Herrera y obtuvo L. A.

18-5-1561 Mtro. Fco. de Herrera otorgóle el grado

Otorgóle el grado de M.A. Fr. Álvaro de Vergara, Canciller

Rodríguez, not.

Referencias: 46r, 47r, 5or, 51v, 52v, 57r

\section{A. CABALOS}

Grado obtenido: B. A.

30-11-1559 Mtro. Juan Bautista de Serantes

Rodríguez, not.

Referencia: 46r

\section{HERNANDO DE MOLINA}

Grados obtenidos: B. A. / L. A. / M. A.

30-11-1559 Mtro. Serantes

22-1-1562 Acto mayor para L. A. presidido Mtro. Molina

23-4-1562 Acto menor presidido por Mtro. Medina

14-5-1562 Repetición para L. A. Presidió Mtro. de Ávila

2-10-1562 Examen secreto de L.A.

3-10-1562 Presidió Mtro. de Ávila, aprobó pero se decidió que no se le hiciese M.

A., que no lo merecía

20-5-1563 Fr. Alonso de Vergara diole el grado de M.A.

Rodríguez, not.

Referencias: 46r, 53v, 54r, 54v, 55v, 58r

\section{JUAN FERNÁNDEZ}

Grado obtenido: B. A. 
30-11-1559 Mtro. Serantes

Rodríguez, not.

Referencia: 46r

JUAN HEREDERO

Grado obtenido: B. A.

30-11-1559 Mtro. Serantes

Rodríguez, not.

Referencia: 46r

LUIS DE HIGUERAS

Grado obtenido: B. A.

30-11-1559 Mtro. Serantes

Rodríguez, not.

Referencia: $46 \mathrm{r}$

\section{FRANCISCO DE SEPÚLVEDA}

Grados obtenidos: B. A. / L. A. / M. A. / B. T. / L. T. / D. T.

30-11-1559 Mtro. Serantes

14-12-1560 Acto para L.A. presidido por Dr. Luis de Molina

20-5-1561 Grado otorgado por el Canciller Diego Flores

26-1-1562 Acto menor para L. A. Presidió Mtro. Luis de Medina

29-1-1562 Repetición para L. A. Presidió Mtro. de Ávila

30-1-1562 Examen secreto de L. A. Petición al Dr. Pérez

19-5-1563 Presidido por Mtro. de Ávila

10-2-1564 Otorgóle el grado Fr. Álvaro de Vergara, Canciller

6-10-1571 Tentativa de B. T. Presidió el Dr. Medina

10-10-1571 Pidió los actos para B.T.

13-10-1571 Acto: magna ordinaria para L. T. Presidió el Dr. Medina, Rector y aprobó

15-1-1572 Pidió quodlibetos para L. T.

16-1-1572 Quodlibetos presididos por el Dr. Ávila

24-1-1572 Examen secreto ante el Rector Ávila, puntos

Presidió el Dr. Melchor Fernández y obtuvo el grado L. T. y D. T. El Canciller

Ocón le otorgó el título

Rodríguez, not.; Juan Núñez not. y secr.

Referencias: 46r, 49v, 54r, 53v, 53v, 53v, 57v, 67r, 133v, 134r, 134v, 138r

DIEGO DE SAN JUAN

Grado obtenido: B. A. 
30-11-1559 Mtro. Juan Bautista de Serantes

Rodríguez, not.

Referencia: 46r

ANTONIO DE CICARSA

Grado obtenido: B. A.

30-11-1559 Mtro. Juan Bautista de Serantes

Rodríguez, not.

Referencia: $46 \mathrm{r}$

ÁLVARO CARO

Grados obtenidos: B. A. / L. A.

30-11-1559 Mtro. Juan Bautista de Serantes

29-4-1562 Acto Mayor para L. A. presidido por Mtro. Medina

23-6-1562 Acto menor presidido por Mtro. Medina

12-2-1563 Repetición para L. A. Presidió el Rector Pérez

19-5-1563 Examen secreto de L. A.

20-5-1563 Presidió el Rector Pérez

21-5-1563 Diole el grado Fr. Álvaro de Vergara, Canciller

Rodríguez, not.

Referencias: 46r, 54v, 55v, 56v, 57v, $58 \mathrm{r}$

CRISTÓBAL DE LA ZARZA [o bien Çeça]

Grados obtenidos: B. A. / L. A. / B. T.

30-11-1559 Mtro. Juan Bautista de Serantes

29-4-1560 Examen secreto

30-4-1560 Presidio Dr. Herrera y aprobó para L. A.

12-5-1560 Juan de Odon le dio el grado

21-11-1564 Tentativa de B. T. presidida por Dr. Pérez

17-2-1565 Tentativa de B. T. Presidió el Dr. Pérez y recibió el grado

Rodríguez, not., Mendel, secretario

Referencias: 46r, 73r, 75r

DIEGO GONZÁLEZ

Grado obtenido: B. A.

30-11-1559 Mtro. Serantes

Rodríguez, not.

Referencia: 46r

LUIS DE GODOY

Grado obtenido: B. A. 
30-11-1559 Mtro. Serantes

Rodríguez, not.

Referencia: $46 \mathrm{r}$

\section{FRANCISCO PINO}

Grado obtenido: B. A.

30-11-1559 Mtro. Serantes

Rodríguez, not.

Referencia: 46r

ÁLVARO SABIOTE

Grado obtenido: B. A.

30-11-1559 Mtro. Serantes

Rodríguez, not.

Referencia: $46 \mathrm{r}$

\section{GASPAR DE LUCAS}

Grados obtenidos: B. A. / L. A. / M. A.

30-11-1559 Mtro. Serantes

14-12-1560 Acto para L.A. presidido por Mtro. Luis de Medina y aprobó

20-5-1561 Acto menor para B. A. Presidió Mtro. Luis de Medina

3-10-1561 Repetición para L. A. Presidió Mtro. Medina

5-11-1561 Pidió examen secreto para L. A. al Dr. Pérez

6-11-1561 Presidió el Mtro. Medina

25-11-1561 Mtro. Fco. De Herrera otorgóle el grado

19-5-1563 Otorgóle el grado Fr. Álvaro de Vergara, Canciller

30-5-1564 Tentativa para B. T. Presidió el Dr. Medina

Rodríguez, not.

Referencias: 46r, 49v, 50r, 51r, 52r, 52v, 57v, 69r

GASPAR DE AYALA

Grados obtenidos: B.A. / L. A. / M. A.

30-11-1559 Mtro. Juan Bautista de Serantes

22-5-1561 Acto mayor para L. A. Presidió Mtro. Luis de Medina

7-6-1561 Acto menor presidido por el Dr. Herrera

12-10-1561 Repetición para L. A. preside el Dr. Herrera

24-10-1561 Pidió al Dr. Pérez el examen secreto

25-10-1561 Presidido por el Dr. Herrera el examen L. A.

25-11-1561 Mtro. Fco. de Herrera otorgóle el grado

18-5-1563 Otorgóle el grado Fr. Álvaro de Vergara, Canciller 
Rodríguez, not.

Referencias: 46r, 5or, 51r, 52v, 57r

GASPAR DE ORDAS

Grado obtenido: B. A.

30-11-1559 Mtro. Juan Bautista de Serantes

Rodríguez, not.

Referencia: 46r

FRANCISCO COLODO / CODO

Grado obtenido: B. A.

30-11-1559 Mtro. Juan Bautista de Serantes

Rodríguez, not.

Referencia: 46r

JERÓNIMO DE ÁVILA

B. A.

30-11-1559 Mtro. Juan Bautista de Serantes

22-1562 Acto mayor para L. A. Presidió Mtro. Medina

23-4-1562 Acto menor presidido por Mtro. Medina

Rodríguez, not.

Referencias: 46r, 53v, 54r

\section{GASPAR DE VILLALTA}

Presbítero, vecino de Huéscar

Grados obtenidos: B. A. / L. A. / M. A. / B. T. / L. T. / D. T.

30-11-1559 Mtro. Juan Bautista de Serantes

14-12-1560 Acto para L. A. Presidió el Dr. Luis de Medina

20-5-1561 Acto menor para B. A. Presidió Mtro. Luis de Medina

30-10-1561 Repetición para L. A. Presidió Mtro. Medina

12-11-1561 Pidió examen secreto al Dr. Pérez

13-11-1561 Presidió Mtro. Medina el grado L. A.

25-11-1561 Mtro. Fco de Herrera otorgóle el grado

18-5-1561 Otorgóle el grado Fr. Álvaro de Vergara, Canciller

4-6-1565 Tentativa presidida por Dr. Medina

17-6-1565 Otorgóle el grado Dr. Luis de Medina

10-10-1571 Quería tener actos para L. T.

16-10-1571 Acto: ordinaria magna para L. T. Presidió el Dr. Luis de Medina y aprobó

29-5-1572 Quolibetos para L. T. Presidió el Rector Ávila y aprobó 
10-6-1572 Dr. Diego Pérez, Canciller, dio el grado

Rodríguez, Medel, J. Núñez, not. y secretario

Referencias: 46r, 49v, 5or, 52r, 57r, 79r, 134v, 135v, 141r

\section{FRANCISCO SANTESTEBAN}

Grado obtenido: B. A.

30-11-1559 Mtro. Juan Bautista de Serantes

Rodríguez, not.

Referencia: 46r

\section{ANDRÉS DE BAGO}

Grado obtenido: B. A.

30-11-1559 Mtro. Juan Bautista de Serantes

Rodríguez, not.

Referencia: 46r

\section{LUIS GONZÁLEZ}

Grado obtenido: B. A.

30-11-1559 Mtro. Serantes

29-4-1562 Acto mayor para B. A. presidido por el Mtro. Medina

23-6-1562 Acto menor presidido por el Mtro. Medina

Rodríguez, not.

Referencias: 46r, 54v, 55v

CRISTÓBAL MARTÍNEZ

Grado obtenido: B. A.

30-11-1559 Mtro. Juan Bautista de Serantes

Rodríguez, not.

Referencia: 46r

PEDRO DE MONSERRATE

Grados obtenidos: B. A. / B. T.

30-11-1559 Mtro. Serantes

18-5-1564 Tentativa para B. T. Presidió el Dr. Pérez y diole el grado

Rodríguez, not.

Referencias: 46r, 68v, 69r

HERNANDO CONEJERO

B. A.

Grados obtenidos: L. A. / M. A. 
30-5-1560 Acto mayor para L. A. Presidió Mtro. de Ávila y aprobándolo 7-6-1561 Acto menor presidido por el Dr. Herrera 22-5-1563 Repetición aprobada para L. A., presidida por Mtro. Diego de Ávila 28-5-1563 Examen secreto 29-5-1563 Presidió Mtro. D. de Ávila y aprobó 8-6-1563 Diole el grado el Mfco. Fr. Alonso de Vergara 10-10-1563 Mfco. Juan de Ocón le dio el grado de M.A.

Rodríguez, not.

Referencias: 48r, 5or, 58r, 59r, 59v, 61r

\section{JUAN CASANO?}

Grado obtenido: B. A.

6-6-156o Acto mayor para L. A. Presidió el Dr. Herrera 7-6-1561 Acto menor presidido por el Dr. Herrera

20-6-1562 Repetición para L. A. presidida por Mtro. Medina y examen secreto Rodríguez, not.

Referencias: 48v, 5or, $55 \mathrm{r}$

BLAS MEJÍA

Grado obtenido: B. A.

5-9-156o Diego Pérez, Rector

13-11-156o Repetición para L. A., presidida por Dr. Pérez

Rodríguez, not.

Referencia: 49r

\section{MARTÍN CARRILLO}

B. T.

Grado obtenido: L. T.

30-10-156o Repetición para L. T., presidida por el Dr. Herrera

31-10-156o Examen aprobado para L. T.

1-11-156o Mfco. Diego Flores le dio el grado

Rodríguez, not.

Referencia: 49r

FR. ALONSO DE ORTEGA

Grado obtenido: B. T.

16-8-1561 Tentativa para B. T., presidida por el Dr. Pérez

Le dio el grado Dr. V. Vélez, Rector

Rodríguez, not.

Referencia: $50 \mathrm{v}$ 


\section{FRANCISCO VÍÑEZ}

Grado recibido: B. A.

18-1-1562 Dr. Diego Pérez, Rector

Rodríguez, not.

Referencia: $53 \mathrm{r}$

MARTÍN PRIETO

Grado recibido: B. A.

18-1-1562 Dr. Diego Pérez, Rector

Rodríguez, not.

Referencia: $53 \mathrm{r}$

FRANCISCO DE VALENZUELA

Grado obtenido: B. A.

18-1-1562 Dr. Diego Pérez, Rector

17-2-1563 Acto mayor para L. A. Presidió el Dr. Pérez, Rector

Rodríguez, not.

Referencias: 53r, 56v

FRANCISCO DE HERRERA

Grado recibido: B. A.

18-1-1562 Dr. Diego Pérez, Rector

Rodríguez, not.

Referencia: $53 \mathrm{r}$

HERNANDO DE SEGURA

Grado recibido: B. A.

18-1-1562 Dr. Diego Pérez, Rector

Rodríguez, not.

Referencia: $53 \mathrm{r}$

\section{LUIS FERNÁNDEZ}

Pbro. Vecino de Baeza

Grados obtenidos: B. A. / L. A. / B. T.

18-1-1562 Dr. Diego Pérez, Rector

10-11-1565 Responsiones magnas. Presidió el Dr. Pérez y se calificó el acto por medianamente suficiente

30-1-1567 Acto menor para L. A. Presidió el Dr. Ávila y se calificó por medianamente suficiente

11-4-1567 Repetición para L. A. le presidió el Dr. Ávila y después de división de opiniones se pasó a setiembre el examen secreto 
23-5-1567 Pidió al Rector Pérez el examen secreto

24-5-1567 Presidió el Dr. de Ávila y aprobó L. A.; no M. A.

14-6-1567 Diole el título Juan de Ocón, Canciller

5-10-1571 Pide con 4 cursos al Dr. Ojeda la admisión para un acto para B. T.

6-10-1571 Lecciones para B. T.

9-10-1571 Tentativa. Presidió el Dr. Ávila, que concedió el grado

11-10-1571 Concesión del grado de B. T.

Rodríguez, Medel, secr., Gil de Morales, not. y secr., Núñez, notario

Referencias: 53r, 84v, 89v, 9or, 92r, 93v, 134r

JUAN BAUTISTA VANEGAS

Grado recibido: B. A.

18-1-1562 Dr. Diego Pérez, Rector

Rodríguez, not.

Referencia: $53 \mathrm{r}$

FERNANDO DE QUESADA

Grado recibido: B. A.

18-1-1562 Dr. Diego Pérez, Rector

Rodríguez, not.

Referencia: $53 \mathrm{r}$

JUAN DE LIZA?

Grado recibido: B. A.

18-1-1562 Dr. Diego Pérez, Rector

Rodríguez, not.

Referencia: $53 \mathrm{r}$

PEDRO TOBÍAS

Grado recibido: B. A.

18-1-1562 Dr. Diego Pérez, Rector

Rodríguez, not.

Referencia: 53r

ALONSO / ÁLVARO DE PEREZÓN

Grado recibido: B. A.

18-1-1562 Dr. Diego Pérez, Rector

Rodríguez, not.

Referencia: $53 \mathrm{r}$ 


\section{JUAN ÁLVAREZ}

Vecino de Jaén

Grados obtenidos: B. A. / L. A. / M. A. / B. T.

18-1-1562 Dr. Diego Pérez, Rector

20-2-1563 Acto mayor para L. A. Presidió Mtro. Medina

8-6-1563 Acto menor para L. A., Presidió el Rector Pérez

19-10-1563 Repetición para L. A. Presidió Mtro. Medina

24-10-1563 Petición de examen secreto al Rector Núñez

25-10-1563 Examen presidido por el Mtro. Luis de Medina

1-11-1563 Otorgóle el grado Juan de Ocón, Canciller

24-10-1565 Juan Ocón, Canciller

9-3-1568 Tentativa para B. T. Presidió el Dr. Fernández y le dio el grado

Rodríguez, Gil de Morales, not. y secr.

Referencias: 53r, 56v, 59v, 62r, 63r, 64r, 83v, 100r

\section{GASPAR DE HERRERO}

Grado obtenido: B. A.

18-1-1562 Dr. Diego Pérez, Rector

Rodríguez, not.

Referencia: $53 \mathrm{r}$

\section{RODRIGO DE ESPINO}

Vecino de Almería

Grados obtenidos: B. A. / L. A. / M. A.

18-1-1562 Dr. Diego Pérez, Rector

27-4-1564 Acto Mayor para L. A. Presidió el Dr. Pérez y aprobó

5-5-1564 Acto menor para L. A. presidido por Dr. Pérez

6-6-1564 Repetición para L. A. Presidió el Dr. Medina

9-6-1564 Petición de examen secreto para L. A. al Rector Núñez

10-6-1564 Presidió el Dr. Medina y aprobó

18-6-1564 Diole el grado el Canciller Carvajal

29-10-1565 Canciller Juan de Ocón le dio el grado de M. A.

Rodríguez, Medel, secr.

Referencias: 53r, 68v, 69v, 70r, 71r, 84r

\section{RODRIGO DE XIMENO}

\section{Vecino de Baeza}

Grado obtenido: B. A.

18-1-1562 Discípulo del Dr. Diego Pérez de Valdivia, Rector

22-10-1566 Responsiones magnas para L. A. Presidió el Dr. Pérez y no admitieron el acto por suficiente, por estar falto de artes. 
Rodríguez, not y Gil de Morales, secr.

Referencias: 53r, 89r

RODRIGO DE HERRERO

Grado recibido: B. A.

18-1-1562 Dr. Diego Pérez, Rector

Rodríguez, not.

Referencia: $53 \mathrm{r}$

DIEGO DEL ARCO

Grado recibido: B. A.

18-1-1562 Dr. Diego Pérez, Rector

Rodríguez, not.

Referencia: $53 \mathrm{r}$

FERNANDO RUIZ

Grado recibido: B. A.

18-1-1562 Dr. Diego Pérez, Rector

Rodríguez, not.

Referencia: $53 \mathrm{r}$

LUIS DEL ROPA?

Grado recibido: B. A.

18-1-1562 Dr. Diego Pérez, Rector

Rodríguez, not.

Referencia: $53 \mathrm{r}$

SEBASTIÁN AMADOR

Grado recibido: B. A.

18-1-1562 Dr. Diego Pérez, Rector

Rodríguez, not.

Referencia: $53 \mathrm{r}$

JUAN DE BALZINAS

Grado recibido: B. A.

18-1-1562 Dr. Diego Pérez, Rector

Rodríguez, not.

Referencia: $53 \mathrm{r}$ 


\section{ANTONIO ROMERO}

Vecino de Almería

Grados obtenidos: B. A. / L. A. / M. A.

18-1-1562 Dr. Diego Pérez

22-10-1563 Acto mayor para L. A. presidido por Dr. Pérez

7-4-1564 Acto menor para L. A. Presidió el Dr. Pérez

20-4-1564 Repetición. Presidió el Dr. Garzón

23-4-1564 Pidió examen secreto al Rector Núñez

11-5-1564 Presidió el Dr. Garzón, aprobándolo

28-10-1565 Otorgóle el grado de L.A. fray A. de Sepulveda, Canciller

El Canciller Juan de Ocón le dio el de M. A.

Rodríguez, not.; Medel, not.

Referencias: 53r, 62v, 67v, 68r, 68v, 83v

\section{MELCHOR CHACÓN}

Vecino de Baeza

Grados obtenidos: B. A. / L. A.

18-1-1562 Dr. Diego Pérez, Rector

14-11-1564 Acto mayor para L. A. presidido por Dr. Pérez y aprobó

19-12-1564 Acto menor para L. A. presidido por el Dr. Diego Pérez

19-5-1565 Repetición para L. A. Presidió el Dr. Medina, y se le difirió el examen

13-2-1567 El Rector Pérez le admitió al examen secreto y señaló puntos y fue su presidente y obtuvo el grado, no el de $\mathrm{M}$. A.

14-6-1567 Diole el grado Juan de Ocón, Canciller

Medel, secret. y Gil de Morales, secr. y not.

Referencias: 53r, 73r, 74r, 90r, 93v

\section{PEDRO MUÑOZ}

Grado obtenido: B. A.

18-1-1562 Dr. Diego Pérez, Rector

27-9-1563 Repetición para L. A. Presidió el Dr. Pérez

Rodríguez, not.

Referencias: 53r, 6ov

\section{PEDRO DE MEDINA}

Grado recibido: B. A.

18-1-1562 Dr. Diego Pérez, Rector

Rodríguez, not.

Referencia: $53 \mathrm{r}$ 


\section{MEDINA SALCEDO}

B. A., vecino de Baeza

Grado obtenido: L. A.

8-12-1569 Repetición para L. A. Presidió el Mtro. Sepulveda y aprobó

21-12-1569 Rector Pérez señaló examen secreto

22-12-1569 Presidió el Mtro. Sepulveda y aprobó

23-12-1569 El Canciller Ocón le dio el grado

Gil de Morales, notario

Referencias: 113v, 114v

\section{LUIS GODINO}

Grado recibido: B. A.

18-1-1562 Dr. Diego Pérez, Rector

Rodríguez, not.

Referencia: 53r

JUAN DE PEN

Grado recibido: B. A.

18-1-1562 Dr. Diego Pérez, Rector

Rodríguez, not.

Referencia: $53 \mathrm{r}$

\section{GARCI MORENO}

Clérigo, vecino de Úbeda

Grados obtenidos: B. A. / L. A.

18-1-1562 Dr. Diego Pérez

9-10-1564 Acto mayor para L. A. Presidió Dr. Pérez

24-3-1565 Acto menor para L. A. Presidió el Dr. Pérez

10-5-1565 Repetición presidida por Dr. D. de Ávila y aprobó

27-6-1565 Al Rector Pérez para L. A. capítulos

28-6-1565 Presidió el examen el Dr. de Ávila y le dieron el aprobado

5-10-1565 El Canciller Ocón le dio el grado

Rodríguez y Medel, secretarios

Referencias: 53r, 73v, 75v, 76r, 81v, 82r

\section{GERÓNIMO DE FIGUEROA}

Pbro.

Grados obtenidos: B. A. / L. A. / B. T.

18-1-1562 Dr. Diego Pérez, Rector

2-11-1563 Acto mayor para L. A. presidido por Dr. Pérez 
5-5-1564 Acto menor para L. A. presidido por Dr. Pérez 14-10-1564 Repetición para L. A. y presidió el Dr. Medina y aprobó 10-12-1564 Pidió examen secreto 11-12-1564 Presidió el Dr. Medina y aprobó 22-12-1564 Diole el grado Sebastián de Sosa, Vicecanciller 27-9-1571 Presentación para B. T. 29-9-1571 Lecciones para B. T.

Tentativa menor B. T. Presidió el Dr. Ojeda y le dio el grado Rodríguez, not.; Juan Núñez, secretario

Referencias: 53r, 64r, 68v, 72r, 73r, 74r, 132v

PEDRO DE OJEDA

Vecino de Jaén Grados obtenidos: B. A. / L. A. / M. A. / B. T. / L. T. / D. T. 18-1-1562 Dr. Diego Pérez, Rector 21-5-1563 Acto mayor para L. A. Presidió el Rector Pérez 22-9-1563 Repetición para L. A. 15-10-1563 Presidió Mtro. Medina 16-10-1563 Examen secreto 1-11-1563 Presidió el Rector Núñez 28-10-1565 Otorgóle el grado Juan Ocón, Canciller 26-9-1567 Tentativa para B. T. Presidió el Rector Pérez y le dio el grado 24-10-1570 Examen secreto para L. T. Presidió el Dr. Carleval 25-10-1570 Dio el grado el Dr. Pérez, Canciller 9-9-1571 El Canciller Juan Ocón dio el grado de D. T.

Rodríguez, not; Medel, secr.; Gil de Morales, not.; Bach. Juan Núñez, not. Referencias: 53r, 58r, 6or, 61v, 64r, 83v, 95r, 118r, 131v

¿ ?

Grado recibido: B. A.

18-1-1562 Dr. Diego Pérez, Rector

Rodríguez, not.

Referencia: $53 \mathrm{r}$

JERÓNIMO DE CÓRDOBA

Grado recibido: B. A.

18-1-1562 Dr. Diego Pérez, Rector

Rodríguez, not.

Referencia: $53 \mathrm{r}$ 


\section{MELCHOR DE SAN JUAN}

Vecino de Baeza

Grados obtenidos: B. A. / L. A. / M. A.

18-1-1562 Dr. Diego Pérez, Rector

22-5-1563 Acto mayor para L. A. Presidió el Rector Pérez

27-5-1564 Repetición para L. A. Presidió el Dr. Pérez

2-6-1564 Solicitó examen secreto al Rector Núñez

18-6-1564 Presidió el Dr. Pérez y aprobó

24-10-1565 Diole el grado de L. A. el Canciller Carvajal

El Canciller Juan de Ocón le dio el grado de M. A.

Rodríguez, not.; Medel, secret. y not.

Referencias: 53r, 58v, 69r, 71r, 83r

DIEGO TAMAYO

Grado recibido: B. A.

18-1-1562 Dr. Diego Pérez, Rector

Rodríguez, not.

Referencia: $53 \mathrm{r}$

\section{MARTÍN DE SOTO}

Grado recibido: B. A. 18-1-1562 Dr. Diego Pérez, Rector

Rodríguez, not.

Referencia: $53 \mathrm{r}$

JUAN DE OCÓN

Grado recibido: B. A.

18-1-1562 Dr. Diego Pérez, Rector

Rodríguez, not.

Referencia: $53 \mathrm{r}$

\section{PEDRO DE PEÑAS}

Grado obtenido: B. A.

18-1-1562 Dr. Diego Pérez, Rector

29-2-1564 Acto mayor para L. A. Presidióle el Dr. Pérez

3-6-1564 Acto menor presidido por el Dr. Pérez

Rodríguez, not.

Referencias: 53r, 69v

GASPAR DE ARANDA

Grado recibido: B. A. 
18-1-1562 Dr. Diego Pérez, Rector

Rodríguez, not.

Referencia: $53 \mathrm{r}$

\section{DIEGO DE NAVARRETE}

Vecino de Baeza

Grados obtenidos: B. A. / L. A. / B. T.

18-1-1562 Dr. Diego Pérez, Rector

20-1-1566 Discípulo del Mtro. Alonso Garzón. Le dio el grado

13-2-1567 Se presentó para L. A.

23-4-1567 Acto mayor: presidió el Mtro. Garzón y aprobó

5-5-1567 Acto menor: presidió el Mtro. Garzón y aprobó

16-6-1567 Repetición presidida por Dr. de Ávila y aprobó

12-10-1567 Dr. Pérez señaló puntos para examen para L. A.

13-10-1567 Examen secreto. Presidió el Dr. D. de Ávila y aprobó

18-10-1567 El Canciller Ocón le otorgó el grado

26-11-1569 Presidió el Dr. Ávila y le dio el grado

Rodríguez, not.; Medel, secr. y not. apost.; Gil de Morales, not. y secr.

Referencias: 53r, 86v, 89v, 91r, 91v, 93r, 95v, 97r, 113r

PEDRO ALFARO

Grado recibido: B. A.

18-1-1562 Dr. Diego Pérez, Rector

Rodríguez, not.

Referencia: $53 \mathrm{r}$

FERNANDO DE CABRERA

Grado recibido: B. A.

18-1-1562 Dr. Diego Pérez, Rector

Rodríguez, not.

Referencia: $53 \mathrm{r}$

MIGUEL DE MENDOZA

Grado recibido: B. A.

18-1-1562 Dr. Diego Pérez, Rector

Rodríguez, not.

Referencia: $53 \mathrm{r}$

JUAN GAMRES DE ÁVALOS

Grado recibido: B. A. 
San Juan

Referencias: 53r, 72v, 74r, 77r, 78r, 83v

PEDRO DE MUR

Grado recibido: B. A.

18-1-1562 Dr. Diego Pérez, Rector

Rodríguez, not.

Referencia: $53 \mathrm{r}$

\section{LUIS JORQUERA}

Grado recibido: B. A.

18-1-1562 Dr. Diego Pérez, Rector

Rodríguez, not.

Referencia: 53r

\section{FRANCISCO CANSINO DE NAVARRETE}

Natural de Baeza

Grados recibidos: B. A. / L. A.

18-1-1562 Dr. Diego Pérez, Rector

31-3-1565 Acto mayor para L. A. Presidió el Dr. Pérez y aprobó

28-4-1565 Acto menor: presidió el Dr. Pérez y aprobó

5-10-1565 Repetición para L. A. Presidió el Dr. D. de Ávila

16-10-1565 Pidió examen secreto al Rector Diego Pérez

17-10-1565 Presidió el Dr. D. de Ávila

26-10-1565 Juan Ocón, Canciller, otorgó el grado

Rodríguez, Medel, secret.

Referencias: 53r, 75v, 81r, 82r, 83v

\section{ALONSO MORENO DE GIL DIENTE}

Vecino de Baeza

Grados recibidos: B. A. / L. A. / M. A.

18-1-1562 Dr. Diego Pérez, Rector

24-10-1564 Acto mayor para L. A. Presidió el Dr. Pérez y le aprobaron

19-12-1564 Acto menor para L. A. presidido por Dr. Pérez

25-5-1565 Repetición para L. A. Presidió el Mtro. Garzón y aprobó

29-5-1565 Petición de examen secreto al Rector Pedro Díaz Soriano

30-5-1565 Presidió el Mtro. Garzón y junto a su Mtro. Pérez.

28-10-1565 Juan Ochon, Canciller, otorgóle grados de L. A y M. A.

Rodríguez, not.; Mtro. Benito vicesecret.; Mtro. Fco. de Sepulveda; Ldo. M. de San Juan

Referencias: 53r, 72v, 74r, 77r, 78r, 83v 


\section{LUIS DE AGUAYO}

Grado recibido: B. A.

18-1-1562 Dr. Diego Pérez, Rector

Rodríguez, not.

Referencia: $53 \mathrm{r}$

FERNANDO DÍAZ

Grado recibido: B. A.

18-1-1562 Dr. Diego Pérez, Rector

Rodríguez, not.

Referencia: $53 \mathrm{r}$

PEDRO DE XIMENO

Grado recibido: B. A.

18-1-1562 Dr. Diego Pérez, Rector

Rodríguez, not.

Referencia: $53 \mathrm{r}$

\section{ALONSO DE LOS REYES}

Natural de Jaén

Grados recibidos: B. A. / L. A.

18-1-1562 Dr. Diego Pérez, Rector

3-4-1576 Responsiones magnas para L. A. Presidió su Mtro. Dr. Salcedo y aprobó

8-10-1576 Repetición que presidió su Mtro. y aprobó

10-10-1576 Examen secreto ante el Rector Córdoba para L. A.

11-10-1576 Presidió el Mtro. Godoy y aprobó con división de pareceres en cuanto a M.A.

21-10-1576 Fr. Alonso de Rojas le dio el grado de L. A.

Rodríguez, not.; Mtro. de Molina, not y secr.

Referencias: 53r, 175v, 181r, 181v, 182r, 183r

CRISTÓBAL DE ROBLES

Grado recibido: B. A.

18-1-1562 Dr. Diego Pérez, Rector

Rodríguez, not.

Referencia: $53 \mathrm{r}$

GASPAR DE MOLINA

Grado recibido: B. A.

18-1-1562 Dr. Diego Pérez, Rector 
Rodríguez, not.

Referencia: $53 \mathrm{r}$

DIEGO ROMÁN

Grado recibido: B. A.

18-1-1562 Dr. Diego Pérez, Rector

Rodríguez, not.

Referencia: $53 \mathrm{r}$

DIEGO PACHECO

Grado recibido: B. A.

18-1-1562 Dr. Diego Pérez, Rector

Rodríguez, not.

Referencia: 53r

JUAN DE LORITE

Grado recibido: B. A.

18-1-1562 Dr. Diego Pérez, Rector

Rodríguez, not.

Referencia: $53 \mathrm{r}$

ALONSO DE PADILLA

Grado recibido: B. A.

18-1-1562 Dr. Diego Pérez, Rector

Rodríguez, not.

Referencia: 53r

JUAN GUTIÉRREZ

Grado recibido: B. A.

18-1-1562 Dr. Diego Pérez, Rector

Rodríguez, not.

Referencia: $53 \mathrm{r}$

LUIS DE LA CUEVA

Grado recibido: B. A.

18-1-1562 Dr. Diego Pérez, Rector

Rodríguez, not.

Referencia: 53r

LUIS DE NAVARRETE

Grado recibido: B. A. 
18-1-1562 Dr. Diego Pérez, Rector

Rodríguez, not.

Referencia: $53 \mathrm{r}$

ALONSO DE AYALA

Vecino de Baeza

Grados obtenidos: B. A. / L. A. / M. A.

18-1-1562 Dr. Diego Pérez, Rector

28-5-1563 Acto mayor para L. A. Presidió el Rector Pérez

5-6-1563 Acto menor presidido por el Dr. Pérez, Rector

12-6-1563 Repetición presidida por Mtro. de Ávila

12-10-1563 Presidió el Mtro. Núñez

20-10-1563 Otorgóle el grado Juan de Ocón, Canciller

18-6-1567 Grado de M. A. otorgado por Juan de Ocón, Canciller

Rodríguez, Gil de Morales, secretario

Referencias: 53r, 59r, 59v, 61r, 62r, 64r, 94r

ÁLVARO DE BURGOS

Grado recibido: B. A.

18-1-1562 Dr. Diego Pérez, Rector

Rodríguez, not.

Referencia: $53 \mathrm{r}$

CRISTÓBAL DEL PINO

Grado recibido: B. A.

18-1-1562 Dr. Diego Pérez, Rector

Rodríguez, not.

Referencia: 53r

CRISTÓBAL DE ALMANSA

Grado recibido: B. A.

18-1-1562 Dr. Diego Pérez, Rector

Rodríguez, not.

Referencia: $53 \mathrm{r}$

FRANCISCO COTILLAS

Grado recibido: B. A.

18-1-1562 Dr. Diego Pérez, Rector

Rodríguez, not.

Referencia: $53 \mathrm{r}$ 


\section{SANCHO DE VALENZUELA}

Vecino de Arjonilla, Jaén

Grados obtenidos: B. A. / L. A. / M. A.

18-1-1562 Dr. Diego Pérez, Rector

25-5-1563 Acto mayor para L. A. Presidió el Rector Pérez

12-6-1563 Acto menor: presidió el Dr. Pérez

8-10-1563 Repetición para L. A. Presidió el Dr. Pérez

16-10-1563 Repetición presidida por Mtro. Garzón

26-10-1563 Examen secreto

27-10-1563 Presidió Mtro. Garzón

1-11-1563 Canciller Juan de Ocón le otorgó el grado de L. A.

24-10-1565 Juan Ocón, Canciller le confirió el grado de M. A.

Rodríguez, not.; Medel, secr. y not.

Referencias: 53r, 58v, 59v, 60v, 61v, 63r, 64r, 83r

ÁLVARO TOLEDO

Grado obtenido: B. A.

18-1-1562 Dr. Diego Pérez, Rector

29-5-1563 Acto mayor para L. A. Presidió el Rector Pérez

Rodríguez, not.

Referencias: 53r, 59v

PEDRO DE VILCHES

Grado recibido: B. A.

18-1-1562 Dr. Diego Pérez, Rector

Rodríguez, not.

Referencia: $53 \mathrm{r}$

PEDRO DE NAVARRETE

Grado obtenido: B. A.

18-1-1562 Dr. Diego Pérez, Rector

26-10-1563 Acto Mayor para L. A.

3-6-1564 Acto menor presidido por el Dr. Diego Pérez

Rodríguez, not.

Referencias: 53r, 63v, 69r

PEDRO DE ARANDA

Grado recibido: B. A.

18-1-1562 Dr. Diego Pérez, Rector

Rodríguez, not.

Referencia: $53 \mathrm{r}$ 


\section{SEBASTIÁN RODRÍGUEZ}

Vecino de Baeza

Grados obtenidos: B. A. / B. T.

18-1-1562 Dr. Diego Pérez, Rector

23-1-1565 Tentativa para B. T. Presidió el Dr. Medina y le dio el grado

Ldo. Martín de San Juan

Referencias: 53r, 74r

\section{FRANCISCO DE AYBAR}

Pbro. Vecino de Iruela, diócesis de Toledo

Grados obtenidos: B. A. / L. A. / M. A.

14-3-1562 Acto mayor para L. A. Presidió Mtro. Medina

9-4-1562 Acto menor presidido por Mtro. de Ávila

23-5-1562 Repetición presidida por Mtro. D. de Ávila

12-6-1562 Examen secreto, presidido por Mtro. Diego de Ávila

21-6-1562 Mfco. Diego Flores le dio el grado de L. A.

21-10-1565 Diole el grado de M. A. el Canciller Juan Ocón

Rodríguez, not.

Referencias: 54r, 55r, 83r

GABRIEL DE ÁVILA

Grados obtenidos: B. A. / L. A.

14-4-1550 Dr. Diego Pérez le dio el grado

2-5-1562 Repetición para L. A. Presidió Mtro. Medina

6-9-1562 Examen secreto

7-9-2562 Presidió Mtro. Medina para L.A, pero no el de Mtro., que no lo merece 15-11-1562 Mfco. Gonzalo de Carvajal, Canciller, dio el grado de L.A.

Hurtado, notario

Referencias: 7v, 54v, 55v

CRISTÓBAL DE LA CASA

Grado obtenido: L. A.

15-5-1562 Repetición para L. A. presidida por el Mtro. Medina

6-10-1562 Examen secreto

7-10-1562 Presidió Mtro. Medina para L.A, pero no el de Mtro., que no lo merece 15-11-1562 Mfco. Gonzalo de Carvajal, Canciller dio el grado

Rodríguez, not.

Referencias: 54v, 56r

PEDRO MÉNDEZ

6-6-1562 Acto mayor para L. A. presidido por Mtro. Medina 
Rodríguez, not.

Referencia: $55^{\mathrm{r}}$

MTRO. HERNÁN NÚÑ̃Z

M. A., incorporación

15-5-1563 Mostró sus títulos, juró y se incorporó.

16-5-1563 Le otorgó el título Fr. Álvaro de Vergara, Canciller

Rodríguez, not.

Referencia: $57 \mathrm{r}$

\section{GERÓNIMO DE FALCES}

L. A.

Grado obtenido: M. A.

18-5-1563 Le otorgó el título Fr. Álvaro de Vergara, Canciller

18-5-1563 Presentación de título, incorporación y juramento ante el Rector y

Claustro

Rodríguez, not.

Referencias: $57 \mathrm{r}-57 \mathrm{v}$

\section{JUAN DE GANTE}

L. A.

Grado obtenido: M. A.

19-5-1563 Le otorgó el título Fr. Álvaro de Vergara, Canciller

19-5-1563 Presentación de título, incorporación y juramento ante el Rector y

Claustro

Rodríguez, not.

Referencias: 57r-57v

DIEGO DE RIBERA

Grado obtenido: B. A.

6-6-1563 Mtro. Diego de Ávila

18-5-1565 Acto mayor para L. A. preside Dr. de Ávila

Acto menor para L. A. Presidió el Rector Pérez, diferido por ocho meses

Rodríguez, not.; Medel, secret.

Referencias: 59v, 76v

\section{MELCHOR DE SAN PEDRO}

Grado obtenido: B. A.

8-6-1563 Acto menor para L. A. Presidió el Rector Pérez

Rodríguez, not.

Referencia: 59v 


\section{FRANCISCO DE VALENZUELA}

B. A.

Grados obtenidos: L. A. / M. A. / B. T.

8-6-1563 Repetición para L. A. Presidió Mtro. de Ávila

15-11-1563 Examen secreto. Presidió el Mtro. de Ávila

18-11-1563 Juan de Ocón, Canciller otorgóle el grado de L.A.

29-10-1565 Recibió el grado de M.A.

11-9-1567 Tentativa para B. T. Presidió el Rector Pérez que le dio el grado

Rodríguez, not.; Gil de Morales, secretario

Referencias: 59v, 65v, 66r, 84r, 94v

\section{BARTOLOMÉ DE NAVARRETE}

8-10-1563 Repetición

Rodríguez, not.

Referencia: 60v

DR. LOZANO

Incorporación: D. T.

1-11-1563 Juró ante el Rector Fernan Núñez

Rodríguez, not.

Referencia: 63v

\section{ALONSO DE VALENZUELA}

Grado recibido: B. A.

28-11-1563 Otorgólo Mtro. de Ávila

Rodríguez, not.

Referencia: 66r

MIGUEL DELGADO

Grado recibido: B. A.

28-11-1563 Otorgólo Mtro. de Ávila

Rodríguez, not.

Referencia: 66r

\section{PEDRO LOMBARDO}

Grado recibido: B. A.

28-11-1563 Otorgólo Mtro. de Ávila

Rodríguez, not.

Referencia: 66r 
PEDRO DE VERA

Grado recibido: B. A.

28-11-1563 Otorgólo Mtro. de Ávila

Rodríguez, not.

Referencia: 66r

FRANCISCO DE FUERTES

Vecino de Iruela

Grado obtenido: B. A.

28-11-1563 Otorgólo Mtro. de Ávila

1-6-1565 Acto mayor para L. A. Presidió Mtro. de Ávila, su maestro. Aprobó, aunque con defecto natural en la lengua

19-6-1565 Responsiones parvas para L. A. presididas por el Dr. de Ávila

Rodríguez, Medel, secret.

Referencias: 66r, 78v, 79v

LEONARDO LÓPEZ

Grado recibido: B. A.

28-11-1563 Otorgólo Mtro. de Ávila

Rodríguez, not.

Referencia: 66r

ALONSO / ÁLVARO MATIAS

Grado obtenido: B. A.

28-11-1563 Otorgólo Mtro. de Ávila

18-6-1565 Responsiones parvas para L. A. Presidió el Dr. D. de Ávila

Rodríguez, not.; Medel, secret.

Referencias: 66r, 79v

LÁZARO NOTARIO

Grado recibido: B. A.

28-11-1563 Otorgólo Mtro. de Ávila

Rodríguez, not.

Referencia: 66r

GASPAR DE NIN...

Grado recibido: B. A.

28-11-1563 Otorgólo Mtro. de Ávila

Rodríguez, not.

Referencia: 66r 


\section{LUIS XIMÉNEZ}

Grados obtenidos: B. A. / L. A. / B. T.

28-11-1563 Otorgólo Mtro. de Ávila

13-9-1572 Acto para B. T. Presidió el Dr. Ojeda

21-11-1572 Lecciones para B. T. con presencia del Dr. Almagro

29-1-1573 El Rector Ojeda dio el grado de B. T.

24-5-1577 Canciller Fr. Sebastián Ximénez le dio el grado de L.A.

Rodríguez, J. Núñez, not. y secr.

Referencias: 66r, 141v, 147v, 193r

\section{ALONSO VÁZQUEZ}

Vecino de Jaén

Grados obtenidos: B. A. / B. T.

28-11-1563 Otorgólo Mtro. de Ávila

8-6-1565 Acto mayor en L. A. Presidió el Dr. D. de Ávila, aprobado de mediana manera y se pide que se mire si ha aprovechado en otros actos

8-11-1565 Responsiones parvas para L.A. presididas por el Dr. D. de Ávila y fue reprobado

4-3-1568 Tentativa para B. T. Presidió el Dr. Fernández y se le dio el grado

Rodríguez, Medel, secret., Gil de Morales, secrt.

Referencias: 66r, 78v, 84r, 100r

\section{ANDRÉS ALVIN}

Grado recibido: B. A.

28-11-1563 Otorgólo Mtro. de Ávila

Rodríguez, not.

Referencia: 66r

\section{ALONSO RINCÓN?}

Grado recibido: B. A.

28-11-1563 Otorgólo Mtro. de Ávila

Rodríguez, not.

Referencia: 66r

ALONSO DE BAENA

Grado recibido: B. A.

28-11-1563 Otorgólo Mtro. de Ávila

Rodríguez, not.

Referencia: 66r 


\section{ALONSO DE AYLLÓN}

Grado recibido: B. A.

28-11-1563 Otorgólo Mtro. de Ávila

Rodríguez, not.

Referencia: 66r

NICOLÁS DE JESÚS

Grado recibido: B. A.

28-11-1563 Otorgólo Mtro. de Ávila

Rodríguez, not.

Referencia: 66r

HERNÁN RUBIO

Grado recibido: B. A.

28-11-1563 Otorgólo Mtro. de Ávila

Rodríguez, not.

Referencia: 66r

JUAN DE JESÚS

Grado recibido: B. A.

28-11-1563 Otorgólo Mtro. de Ávila

Rodríguez, not.

Referencia: 66r

\section{ALONSO DE VILCHES}

Vecino de Baeza, prior de Cazalilla, colegial

Grados obtenidos: B. A. / L. A. / M. A. / B. T. / L. T. / D. T.

28-11-1563 Otorgólo Mtro. de Ávila

28-5-1565 Acto mayor para L. A. presidido por Dr. Ávila

19-6-1565 Responsiones parvas: presidió el Dr. de Ávila

19-10-1565 Repetición presidida por el Dr. Ávila para L. A. y aprobó

5-12-1565 Pidió examen secreto

6-12-1565 Presidió el Dr. de Ávila y aprobó

12-12-1565 Diole el grado Juan de Ocón, Canciller

10-10-1568 Diole el grado Fr. Remigio Tamariz, Canciller

10-6-1570 El Dr. Ávila le dio el grado

16-11-1574 Acto de Teología: magna ordinaria para L.T. Presidió el Dr. Cavallería y aprobó

28-4-1575 Acto segundo para L.T. Presidió el Dr. Almagro y aprobó

30-5-1575 Tercer acto para L.T. Presidió el Dr. Almagro y lo aprobaron 
14-11-1575 Petición para sustituir el $4^{\circ}$ acto por un examen secreto 5-5-1576 Examen secreto ante el Rector Sepúlveda para L.T., presidió el Dr. Ojeda y aprobó los grados

5-5-1576 Dr. Antonio de Raya, maestrescuela de Jaén, dio el grado de D. T.

Rodríguez, not; Mtro. Fco de Sepulveda, Medel, secret., Gil de Morales, secretario, J. Núñez, not.; Mtro. Luis Molina, secr. y not. apost.

Referencias: 66r, 77v, 79v, 83r, 85v, 86r, 104r, 118r, 164r, 165v, 168r, 173v, 176r

PEDRO DE CEHEGÍN

Grado recibido: B. A.

28-11-1563 Otorgólo Mtro. de Ávila

Rodríguez, not.

Referencia: 66r

CRISTÓBAL DE BIEDMA

Vecino de Jaén, colegial

Grados obtenidos: B. A. / L. A.

28-11-1563 Otorgólo Mtro. de Ávila

15-5-1565 Responsiones magnas para L.A. presididas por el Dr. Ávila y aprobó

16-6-1565 Responsiones parvas para L. A. presididas por el Dr. Ávila

12-10-1565 Repetición para L. A. Presidió el Dr. Medina y aprobó

28-11-1565 Pidió examen secreto para L. A. al Mtro. Pérez

29-11-1565 Presidió el Dr. Medina y aprobó

13-12-1565 Diole el grado Juan de Ocón, Canciller

Rodríguez, Medel, secret.

Referencias: 66r, 79v, 82r, 85r, 86r

\section{GASPAR SALCEDO}

Vecino de Baeza

Grados obtenidos: B. A. / L. A. / M. A. / B. T.

28-11-1563 Otorgólo Mtro. de Ávila

26-5-1565 Acto mayor para L. A. presidido por Dr. Ávila y aprobó

19-6-1565 Responsiones parvas para L. A. Presidió el Dr. D. de Ávila

24-11-1565 Repetición para L. A. Presidió el Dr. Garzón y aprobó

11-12-1565 Pidió examen secreto al Rector Pérez

12-12-1565 Presidió el Dr. de Ávila y le dieron el grado

13-12-1565 Otorgó el grado Juan de Ocón, Canciller

10-10-1568 Tentativa para B. T. Presidió el Dr. Pérez y el dio el grado

Rodríguez, not., Medel, secret., Gil de Morales, secretario

Referencias: 66r, 77v, 79v, 84v, 86r, 104r 


\section{¿ ? SALCEDO}

Natural de Andújar

Grado obtenido: B. A.

10-10-1568 Otorgó el grado el Canciller Fr. Remigio Tamariz

10-5-1569 Responsiones magnas: presidió el Dr. Ávila y aprobó

Gil de Morales, secretario

Referencia: $105 \mathrm{v}$

\section{FERNANDO DE LORCA}

Hijo del Dr. Lorca, vecino de Cazorla

Grados obtenidos: B.A. / L. A.

28-11-1563 Otorgólo Mtro. de Ávila

9-5-1565 Responsiones magnas o acto mayor para L. A.: presidió el Dr. Ávila y lo dieron por bueno

16-6-1565 Acto menor para B. A. Presidió Mtro. de Ávila

9-10-1565 Repetición para L. A. Presidió el catedrático Garzón y aprobó

23-11-1565 Examen secreto ante el Rector Pérez para L. A.

24-11-1565 Presidió el Dr. Garzón y obtuvo el grado

13-12-1565 Diole el grado Juan de Ocón, Canciller

Rodríguez, not.; Medel, secret.

Referencias: 66r, 76r, 79v, 82r, 84v, 86r

\section{CRISTÓBAL DEL PRADO / PRADOS}

Vecino de Baeza

Grados obtenidos: B. A. / L. A. / M. A. / B. T.

28-11-1563 Otorgólo Mtro. de Ávila

26-10-1565 Responsiones magnas para L. A. presididas por el Dr. D. de Ávila y aprobó

8-11-1565 Acto menor presidido por el Dr. de Ávila

14-3-1566 Repetición para L. A. Presidió el Dr. Molina y le aprobaron

21-3-1566 Examen secreto señaló Dr. Medina

22-3-1566 Presidió el Dr. Ávila y tuvo un muy buen acto, pero al ser muy pequeño

de cuerpo, para M. A. esperase la ordenación por si tuviera más presencia corporal y si no tuviere estatura conveniente no se le concediese el grado

23-3-1566 Juan de Ocón, Canciller, le otorgó el grado de L. A.

12-1-1569 Acuerdo en favor para M. A.

24-4-1570 El claustro lo admitió como M. A.

16-5-2570 El Canciller Pérez de Valdivia le dio el grado

7-10-1570 Responsiones magnas para B. T. Presidió el Dr. Ávila 
17-11-1570 Dr. Ávila le dio el grado de B. T.

Rodríguez, Al. Medel, secretario; Gil de Morales, not. y secret.

Referencias: 66r, 83v, 84r, 87v, 115r, 116r, 117v, 118v

FERNANDO DE BIEDMA

Grado recibido: B. A.

28-11-1563 Otorgólo Mtro. de Ávila

Rodríguez, not.

Referencia: 66r

ANTONIO DE HUELAMO

Grado recibido: B. A.

28-11-1563 Otorgólo Mtro. de Ávila

Rodríguez, not.

Referencia: 66r

CRISTÓBAL DE BARBA

Grado recibido: B. A.

28-11-1563 Otorgólo Mtro. de Ávila

Rodríguez, not.

Referencia: 66r

\section{MIGUEL GARZÓN}

Grado recibido: B. A.

28-11-1563 Otorgólo Mtro. de Ávila

Rodríguez, not.

Referencia: 66r

FR. FRANCISCO DE LA CRUZ

Grado recibido: B. A.

28-11-1563 Otorgólo Mtro. de Ávila

Rodríguez, not.

Referencia: 66r

SIMÓN RUIZ

Grado recibido: B. A.

28-11-1563 Otorgólo Mtro. de Ávila

Rodríguez, not.

Referencia: 66r 


\section{FR. FRANCISCO DE MONTILLA}

B. T.

Grados obtenidos: L. T. / D. T.

17-12-1563 Acto mayor para L. T. Presidió el Dr. Medina

19-12-1563 Repetición para L. T. Presidió el Dr. Pérez

20-12-1563 Examen secreto ante el Rector Hernán Núñez

20-12-1563 Presidió el Dr. Medina y aprobó

20-12-1563 Fr. Sebastián de Sosa, Vicecanciller, le otorgó el grado

21-12-1563 Fr. Sebastián de Sosa, le otorgó el grado

Rodríguez, not.

Referencias: 66v, 67r

GABRIEL DE NAVARRETE

19-2-1564 Acto para B. A. presidido por Dr. Pérez

Rodríguez, not.

Referencia: $67 \mathrm{v}$

\section{MIGUEL DE CALMAESTRA}

Pbro. Natural de Arjonilla, dióc. de Jaén; prior de la Parroquial de Sto. Domingo de Úbeda

Grados obtenidos: B. T. / L. A. / M. A.

13-6-1564 Tentativa para B.T. Presidió el Dr. de Ávila y otorgóle el grado 16-6-1564 Pidió examen secreto para L.A. al Rector Núñez

17-6-1564 Presidió Mtro. de Ávila y aprobó

18-6-1564 Diole el grado el Canciller Carvajal

21-10-1565 Diole el grado de M. A. el Canciller Juan de Ocón

Rodríguez, not.

Referencias: 70v, 71r, 83r

FR. ALONSO DE MESA

O. P. Prior del Convento de la Magdalena de la Guardia

Grado obtenido: B. T.

31-8-1564 Tentativa B.T. Presidió el Dr. Luis de Medina y le dio el grado

Rodríguez, not.

Referencia: 71r

MARTÍN DE ZAMORA

Pbro. Natural de Almería

Grados obtenidos: L. A. / M. A. / B. T.

6-10-1564 Pidió al Rector Pedro Díaz repetición para L.A. 
16-10-1564 Presidióla el Mtro. Garzón

17-10-1564 Aprobó

27-10-1564 Fr. Sebastián de Sosa, Vicecanciller

21-10-1565 Otorgóle el grado el Canciller Juan de Ocón

18-2-1573 Acto para B. T. que presidió el Dr. Ojeda y le dio el grado

Rodríguez, not.; Núñez, not.

Referencias: 71v, 72r, 83r, 147v

\section{ANTONIO DE HERRERA}

Pbro. Vecino de Jaén

Grados obtenidos: B. T. / L. A.

27-10-1564 Tentativa de B. T. Presidió el Dr. D. Pérez que le dio el grado

5-10-1569 Se presentó ante el Rector Pérez para L. A.

8-10-1569 Repetición presidida por el Mtro. Ojeda, aprobó

10-10-1569 Señaló examen secreto. Presidió Mtro. Ojeda y aprobó el grado de L.A.

11-10-1569 El Canciller Tamariz le otorgó el grado

Rodríguez, not.; Mtro. Ojeda, not.; Morales, not.

Referencias: $72 \mathrm{v}, 108 \mathrm{v}$

\section{JUAN DE PEÑAS}

B. A. Natural de Huelma, Colegial de Santiago

Grado obtenido: L. A.

11-11-1564 Tuvo una repetición para L. A. presidida por el Dr. Pérez y aprobó

13-2-1565 Examen secreto para L. A. por el Dr. Pérez, que lo presidió

2-3-1565 Canciller Fr. Alonso de Sepulveda dio el grado

Rodríguez, not.; Al. Medel, not. y secret.

Referencias: 73r, 74v, 75r

\section{JUAN DE NAVA}

B. A. Vecino de Baeza

Grado obtenido: L. A.

28-11-1564 Acto mayor para L. A. Presidió el Dr. Pérez

19-12-1564 Repetición para L. A. Presidió el Dr. Pérez

2-10-1565 Acto menor presidido por el Dr. Diego Pérez y aprobó

6-6-1567 Dr. Ávila, Vicerrector, señaló examen secreto

7-6-1567 Presidió el Dr. Pérez y aprobó, no así M. A.

14-6-1567 Diole el titulo Juan de Ocón, Canciller

Rodríguez, not.; Gil de Morales, secr. y not.

Referencias: 73v, 74v, 92v, 93v 


\section{ALONSO DE GENZOR}

B. A., vecino de Andújar

Grado obtenido: L. A.

22-5-1565 Acto mayor para L. A. y presidió el Dr. Ávila a su discípulo y lo aprobaron N.D.

16-6-1565 Acto menor para L. A. presidido por el Dr. Ávila

3-12-1565 Pidió examen secreto al Rector

4-12-1565 Presidió el Dr. Pérez y le dieron el grado

13-12-1565 Diole el grado Juan de Ocón, Canciller

Medel, secret.

Referencias: 76v, 79v, 85v, 86r

FR. CRISTÓBAL ALDERETE

B. T. Vecino de Baeza. O.SS.T. Vicario Provincial de la Santísima Trinidad

Grados obtenidos: L. T. / D. T.

15-6-1565 Repetición de Teología para L.T., presidida por Mtro. Luis de Medina, y aunque faltaba estudio por ocupaciones, dieron por bueno dicho acto

19-6-1565 El Rector Pedro Díaz Soriano Vega dio capitulos para L. T.

20-6-1565 Presidido y examinado por el Dr. Medina, catedrático de Teología. Fr.

Sebastián de Sosa, Canciller, le otorgó el grado

24-6-1565 Fr. Cristóbal de Sosa, Vicecan., diole el grado

Medel, secret.

Referencias: 79r, 79v, 81r

\section{ALONSO MELLADO}

Vecino de Iznatoraf, dióc. de Jaén

Grado obtenido: B. A.

20-1-1566 Discípulo del Mtro. Alonso Garzón. Le dio el grado

Medel, secr.

Referencia: 86v

\section{ALONSO TOLEDANO}

Vecino de Pliego. Abadía de Alcalá la Real y Pliego

Grado obtenido: B. A.

20-1-1566 Discípulo del Mtro. Alonso Garzón. Le dio el grado

Medel, secr.

Referencia: 86v

\section{ALONSO DE MENDAÑA}

Grado obtenido: B. A. 
20-1-1566 Discípulo del Mtro. Alonso Garzón. Le dio el grado Medel, secr.

Referencia: 86v

\author{
ALONSO DE XODAR \\ Vecino de Baeza \\ Grado obtenido: B. A. \\ 20-1-1566 Discípulo del Mtro. Alonso Garzón. Le dio el grado \\ Medel, secr. \\ Referencia: 86v
}

\author{
ANTONIO FLORES DE BENAVIDES [FLOREZ] \\ Clérigo, Pbro. Vecino de Baeza \\ Grados obtenidos: B. A. / L. A. / M. A. / B. T. \\ 20-1-1566 Discípulo del Mtro. Alonso Garzón. Le dio el grado \\ 6-10-1569 Responsiones magnas: presidió Mtro. Garzón y aprobó \\ 7-11-1569 Repetición presidida por el Mtro. Garzón, aprobó \\ 14-11-1569 El Vicerrector Ávila señaló capítulos para examen secreto de L.A. \\ 15-11-1569 Presidió el Dr. Garzón y aprobó. El Canciller Ocón le dio el grado \\ 8-12-1569 El Canciller Fr. Pedro de Arias le dio el grado \\ 28-8-1573 Tentativa de 12 conclusiones presidió el Rector Ojeda y aprobó \\ 16-4-1575 Luego leyó lecciones para B. T. \\ 20-4-1575 El Rector P. de Ojeda le dio el grado \\ Medel, secr. y not. apost., Gil de Morales, secr., Mtro. Molina. secr. \\ Referencias: 86v, 108v, 111v, 113v, 165r
}

\title{
ANTONIO GÓMEZ
}

Pbro. Vecino de Escalona, dióc. de Toledo

Grados obtenidos: B. A. / L. A. / B. T.

20-1-1566 Discípulo del Mtro. Alonso Garzón. Le dio el grado

17-1-1570 Repetición para L. A. Presidió el Mtro. Ojeda y aprobó

2-5-1570 El Vicerrector Ávila le admitió al examen secreto y le dio puntos

3-5-1570 Aprobó L. A.

16-5-1570 El Canciller Pérez le dio el grado

30-10-1570 Acto de Teología. Presidió el Dr. Ávila

9-11-1570 Dr. Ávila le dio el grado

Medel, secr. y not. apost.; Gil de Morales, not. y secr.

Referencias: 86v, 115v, 117r, 117v, 118v

BALTASAR DE ARANDA

Vecino de Baeza 
Grado obtenido: B. A.

20-1-1566 Discípulo del Mtro. Alonso Garzón. Le dio el grado Medel, secr.

Referencia: $86 \mathrm{v}$

BARTOLOMÉ DE ASENCIO

Vecino de Úbeda

Grado obtenido: B. A.

20-1-1566 Discípulo del Mtro. Alonso Garzón. Le dio el grado

Medel, secr.

Referencia: $86 \mathrm{v}$

DIEGO DE TORRES

Vecino de Jaén

Grado obtenido: B. A.

20-1-1566 Discípulo del Mtro. Alonso Garzón. Le dio el grado

Medel, secr.

Referencia: $86 \mathrm{v}$

FRANCISCO LÓPEZ DE PANCORBO

Pbro. Vecino de Jaén

Grados obtenidos: B. A. / B. T.

20-1-1566 Discípulo del Mtro. Alonso Garzón. Le dio el grado

13-10-1572 Acto para B. T. Presidió el Dr. Ojeda y le dio el grado

Medel, secr. y not. apost., J. Núñez not. y secr.

Referencias: 86v, 143r

FRANCISCO GARCÍA CAÑUELO

Vecino de Bailén, dióc. de Jaén

Grado obtenido: B. A.

20-1-1566 Discípulo del Mtro. Alonso Garzón. Le dio el grado

Medel, secr. y not. apost.

Referencia: $86 \mathrm{v}$

FRANCISCO GARCÍA

Vecino de Iruela, dióc. de Toledo

Grado obtenido: B. A.

20-1-1566 Discípulo del Mtro. Alonso Garzón. Le dio el grado

Medel, secr. y not. apost.

Referencia: $86 \mathrm{v}$ 


\section{FRANCISCO DE SANTISTEVAN}

Vecino de Guadalajara, dióc. de Toledo

Grado obtenido: B. A.

20-1-1566 Discípulo del Mtro. Alonso Garzón. Le dio el grado

Medel, secr. y not. apost.

Referencia: $86 \mathrm{v}$

\section{FRANCISCO DE LORITE}

Vecino de Baeza

Grado obtenido: B. A.

20-1-1566 Discípulo del Mtro. Alonso Garzón. Le dio el grado

Medel, secr. y not. apost.

Referencia: 86v

\section{FRANCISCO RUIZ}

Vecino de Jaén

Grado obtenido: B. A.

20-1-1566 Discípulo del Mtro. Alonso Garzón. Le dio el grado Medel, secr. y not. apost.

Referencia: 86v

\section{FRANCISCO TERRONES}

Vecino de Andújar, dióc. de Jaén

Grados obtenidos: B. A. / L. A.

20-1-1566 Discípulo del Mtro. Alonso Garzón. Le dio el grado

13-2-1567 Se presentó para L. A.

30-4-1567 Acto mayor: presidió el Mtro. Garzón y aprobó

21-6-1567 Repetición para L. A. Presidió el Dr. Fernández y aprobó

18-10-1567 El Canciller Ocón le otorgó el grado

Medel, secr. y not. apost.; Gil de Morales, secretario

Referencias: 86v, 89v, 91v, 94r, 97r

FERNANDO DE CÓZAR

Vecino de La Calzada, dióc. de Toledo

Grado obtenido: B. A.

20-1-1566 Discípulo del Mtro. Alonso Garzón. Le dio el grado

Medel, secr. y not. apost.

Referencia: $86 \mathrm{v}$

FERNANDO DE VILLASEÑOR

Grado obtenido: B. A. 
20-1-1566 Discípulo del Mtro. Alonso Garzón. Le dio el grado Medel, secr. y not. apost.

Referencia: 86v

GABRIEL DE MESCUA /MESQUA NAVARRETE

Vecino de Baeza

Grados obtenidos: B. A. / L. A.

20-1-1566 Discípulo del Mtro. Alonso Garzón. Le dio el grado

13-2-1567 Se presentó para L. A.

28-4-1567 Responsiones magnas: presidió Mtro. Garzón

5-5-1567 Acto menor: presidió el Mtro. Garzón y aprobó

18-6-1567 Repetición para L. A. Presidió el Mtro. Garzón y aprobó

18-10-1567 El Canciller Ocón le otorgó el grado

Medel, secr. y not. apost.; Gil de Morales, notario

Referencias: 86v, 89r, 91r, 91v, 93v, 97r

\section{JUAN DE VITORIA}

Canónigo del Alcázar en Baeza

Grado obtenido: B. A.

20-1-1566 Discípulo del Mtro. Alonso Garzón. Le dio el grado Medel, secr. y not. apost.

Referencia: 86v

\section{JUAN BUENO}

Vecino de Castellar, dióc. de Jaén

Grado obtenido: B. A.

20-1-1566 Discípulo del Mtro. Alonso Garzón. Le dio el grado

Medel, secr. y not. apost.

Referencia: $86 \mathrm{v}$

\section{JUAN RAMÍREZ DE MOLINA}

Vecino de Baeza

Grado obtenido: B. A.

20-1-1566 Discípulo del Mtro. Alonso Garzón. Le dio el grado

Medel, secr. y not. apost.

Referencia: $86 \mathrm{v}$

JUAN GARRIDO

Natural de Iznatoraf, dióc. de Jaén

Grado obtenido: B. A. 
20-1-1566 Discípulo del Mtro. Alonso Garzón. Le dio el grado Medel, secr. y not. apost.

Referencia: 86v

JUAN MARQUÉS

Vecino de Castellar, dióc. de Jaén

Grado obtenido: B. A.

20-1-1566 Discípulo del Mtro. Alonso Garzón. Le dio el grado Medel, secr. y not. apost.

Referencia: 86v

JUAN DE LA TORRE

Vecino de Villacarrillo, dióc. de Jaén

Grado obtenido: B. A.

20-1-1566 Discípulo del Mtro. Alonso Garzón. Le dio el grado Medel, secr. y not. apost.

Referencia: 86v

\section{JUAN TENORIO}

Vecino de Bailen, dióc. de Jaén

Grado obtenido: B. A.

20-1-1566 Discípulo del Mtro. Alonso Garzón. Le dio el grado Medel, secr. y not. apost.

Referencia: $87 \mathrm{r}$

\section{JUAN DE ORTEGA}

Vecino de Torre-donjimeno, dióc. de Jaén

Grados obtenidos: B. A. / L. A.

20-1-1566 Discípulo del Mtro. Alonso Garzón. Le dio el grado 13-2-1567 Se presentó para L. A.

16-4-1567 Responsiones magnas. Presidió el Mtro. Garzón y lo dieron por bueno 3-5-1567 Acto menor. Presidió el Mtro. Garzón y aprobó

2-6-1567 Repetición para L. A. el Dr. Garzón y aprobó

18-10-1567 El Canciller Ocón le otorgó el grado

Medel, secr. y not. apost.; Gil de Morales, not. y secr.

Referencias: 87r, 89v, 90v, 91r, 92v, 97r

FERRAN PÉREZ DE MAGAÑA

Vecino de Bailén, dióc. de Jaén

Grado obtenido: B. A. 
20-1-1566 Discípulo del Mtro. Alonso Garzón. Le dio el grado Medel, secr. y not. apost.

Referencia: $87 \mathrm{r}$

JORGE MEXÍA

Vecino de Albanchez, dióc. de Jaén

Grado obtenido: B. A.

20-1-1566 Discípulo del Mtro. Alonso Garzón. Le dio el grado

Medel, secr. y not. apost.

Referencia: $87 \mathrm{r}$

\section{JORGE DE SAN ROMÁN}

Vecino de Baeza

Grados recibidos: B. A. / L. A. / M. A. / B. T.

20-1-1566 Discípulo del Mtro. Alonso Garzón. Le dio el grado

13-2-1567 Se presentó para L. A.

18-4-1567 Acto Mayor o responsiones magnas, aprobado

9-6-1567 Repetición para L. A. Presidió Mtro. Garzón y aprobó, aunque estuvo tibio y negligente

26-9-1567 Puntos para examen secreto

27-9-1567 Presidió para L. A. el Mtro. Garzón y aprobó

18-10-1567 El Canciller Ocón le otorgó el grado

16-5-1570 El Canciller Pérez le otorgó el grado de M.A.

14-1-1572 Tentativa para B. T. que presidió el Rector Ojeda y aprobó

4-5-1575 Magna ordinaria, primer acto para L.T. Presidió el Dr. Ojeda y aprobó

Medel, secr. y not. apost.; Gil de Morales, not. y secr.; Juan Núñez not. y secr.;

Mtro. Molina, secr.

Referencias: 87r, 89v, 90v, 93r, 95r, 97r, 117v, 137v, 165v

\section{LUIS DE LA PEÑA}

Vecino de Baeza

Grado recibido: B. A.

20-1-1566 Discípulo del Mtro. Alonso Garzón. Le dio el grado

Medel, secr. y not. apost.

Referencia: $87 \mathrm{r}$

\section{LUIS MUÑOZ}

Vecino de Baeza

Grado recibido: B. A.

20-1-1566 Discípulo del Mtro. Alonso Garzón. Le dio el grado 
Medel, secr. y not. apost.

Referencia: $87 \mathrm{r}$

LUIS DE PEREA

Vecino de Almedina, dióc. de Jaén

Grados recibidos: B. A. / L. A.

20-1-1566 Discípulo del Mtro. Alonso Garzón. Le dio el grado

13-2-1567 Se presentó para L. A.

26-4-1567 Responsiones magnas: presidió el Mtro. Garzón y aprobó

5-5-1567 Acto menor: presidió el Mtro. Garzón y aprobó

18-6-1567 Repetición para L. A. Presidió el Dr. Fernández y aprobó

18-10-1567 El Canciller Ocón le otorgó el grado

Medel, secr. y not. apost.; Gil de Morales, not.

Referencias: 87r, 89v, 91v, 94r, 97r

MARTÍN DE BENAVIDES VALENZUELA

Vecino de Baeza

Grado recibido: B. A.

20-1-1566 Discípulo del Mtro. Alonso Garzón. Le dio el grado Medel, secr. y not. apost.

Referencia: $87 \mathrm{r}$

MATEO RODRÍGUEZ

Vecino de Valdepeñas

Grado recibido: B. A.

20-1-1566 Discípulo del Mtro. Alonso Garzón. Le dio el grado 13-2-1567 Se presentó para L. A.

Medel, secr. Gil de Morales, secr.

Referencias: 87r, 89v

MELCHOR DE ÁVILA

Vecino de Baeza

Grado recibido: B. A.

20-1-1566 Discípulo del Mtro. Alonso Garzón. Le dio el grado

Medel, secr. y not. apost.

Referencia: $87 \mathrm{r}$

MIGUEL DE MEDINA CÁCERES

Vecino de Baeza

Grado recibido: B. A. 
20-1-1566 Discípulo del Mtro. Alonso Garzón. Le dio el grado Medel, secr. y not. apost.

Referencia: $87 \mathrm{r}$

PEDRO DE ESPINOSA

Vecino de Baena

Grado recibido: B. A.

20-1-1566 Discípulo del Mtro. Alonso Garzón. Le dio el grado

Medel, secr. y not. apost.

Referencia: $87 \mathrm{r}$

PEDRO MARÍN

Vecino de Castellar, dióc. de Jaén

Grado recibido: B. A.

20-1-1566 Discípulo del Mtro. Alonso Garzón. Le dio el grado

Medel, secr. y not. apost.

Referencia: $87 \mathrm{r}$

PEDRO DE PERALTA

Vecino de Úbeda

Grados recibidos: B. A. / L. A. / M. A.

20-1-1566 Discípulo del Mtro. Alonso Garzón. Le dio el grado

13-2-1567 Se presentó para L. A.

21-4-1567 Acto mayor presidido por el Mtro. Garzón y, aunque estuvo algo tibio, le aprobaron

3-5-1567 Acto menor: presidió el Mtro. Garzón y aprobó

12-6-1567 Repetición para L. A. Presidió el Dr. Fernández y aprobó

18-10-1567 El Canciller Ocón le otorgó el grado

8-12-1570 Canciller Fr. Diego de Villalobos dio el grado

28-6-1572 Acto para B. T. Presidió el Dr. Ojeda: lecciones

30/31-6-1572 Tentativa para B. T. Presidió el Mtro. Ojeda y aprobó

2-12-1572 Recibió el grado

Medel, secr. y not. apost.; Gil de Morales not y secr.; Ldo. Guerrero, not. apost.;

Juan Núñez, not y secr.

Referencias: 87r, 89v, 90v, 91v, 93r, 97r, 141v, 145r

RODRIGO ALONSO

Clérigo. Vecino de Baeza

Grado recibido: B. A. 
20-1-1566 Discípulo del Mtro. Alonso Garzón. Le dio el grado Medel, secr. y not. apost.

Referencia: $87 \mathrm{r}$

\section{RODRIGO DE MARTOS}

Vecino de Baeza

Grado recibido: B. A.

20-1-1566 Discípulo del Mtro. Alonso Garzón. Le dio el grado

5-10-1573 Acto mayor para L. A. Presidió Mtro. Cavallería y aprobó

Medel, secr. y not. apost.; Ldo. Núñez secr.

Referencias: 87r, 152r

CRISTÓBAL DE JARA

Vecino de Moratalla, dióc. de Cartagena

Grado recibido: B. A.

20-1-1566 Discípulo del Mtro. Alonso Garzón. Le dio el grado

Medel, secr. y not. apost.

Referencia: $87 \mathrm{r}$

CRISTÓBAL ADALID

Vecino de Fuentes, dióc. de Sevilla

Grado recibido: B. A.

20-1-1566 Discípulo del Mtro. Alonso Garzón. Le dio el grado

Medel, secr. y not. apost.

Referencia: $87 \mathrm{r}$

CRISTÓBAL LEAL

Vecino de Jaén

Grado recibido: B. A.

20-1-1566 Discípulo del Mtro. Alonso Garzón. Le dio el grado

Medel, secr. y not. apost.

Referencia: 87r

\section{JUAN FÉLIX DE QUIRÓS}

B. A., sacerdote natural de Granada y cura de Cónchar

Grado recibido: L. A.

9-7-1566 Repetición para L. A. y presidió el Mtro. Garzón y aprobó. El Vicerrector

Córdoba señaló el examen secreto

10-7-1566 Presidió el Dr. Garzón

11-7-1566 El Canciller Juan de Ocón diole el grado 
Medel, secr. y not. apost.

Referencias: $88 \mathrm{r}, 88 \mathrm{v}$

JUAN DE PEDRAZA

Prior de la parroquial del Salvador de Baeza

Pidió la graduación en M. A. y la incorporación de D. T.

Incorporación: D. T. por la Universidad de Sevilla a 6-6-1551

Grado recibido: M. A.

6-11-1567 Ante el Rector Pérez de Valdivia, y el Claustro fue graduado en M. A.

Referencias: $97 \mathrm{rv}$

\section{GIL DE MORALES}

Vecino de Úbeda, dióc. de Jaén

Grado recibido: B. A.

9-10-1567 El Dr. Diego de Ávila dio el grado a su discípulo

Testigos: Fco. Delgado, obispo de Jaén y Juan de Ocón, Canciller

Gil de Morales, secr. y not.

Referencia: 98r

FR. JUAN CHIRINOS

Natural de Córdoba. O.SS.T.

Grado recibido: B. A.

9-10-1567 El Dr. Diego de Ávila dio el grado a su discípulo

Testigos: Fco. Delgado, obispo de Jaén y Juan de Ocón, Canciller

Gil de Morales, secr. y not.

Referencia: 98r

JUAN DE NAVARRETE

Canónigo. Vecino de Baeza

Grado recibido: B. A.

9-10-1567 Dr. Diego de Ávila dio el grado a su discípulo.

Testigos: Fco. Delgado, obispo de Jaén y Juan de Ocón, Canciller

Gil de Morales, secr. y not.

Referencia: $98 \mathrm{r}$

MIGUEL PÉREZ DE HINESTROSA

De Aragón

Grado recibido: B. A.

9-10-1567 Dr. Diego de Ávila dio el grado a su discípulo.

Testigos: Fco. Delgado, obispo de Jaén y Juan de Ocón, Canciller 
Gil de Morales, secr. y not.

Referencia: 98r

JUAN DE URRUTIA [MTRO. URRUTIA]

Beneficiado Vecino de Sta. Cruz de Campezo, obispado de Calahorra

Grados recibidos: B. A. / B. T.

9-10-1567 Dr. Diego de Ávila dio el grado a su discípulo.

3-5-1569 Responsiones magnas. Presidió su maestro y aprobó

9-6-1573 Tentativa para B. T. Presidió el Dr. Almagro y aprobó

15-6-1573 Lecciones para B. T. y estuvo Mtro. Almagro

22-6-1573 Le dio el grado Mtro. Almagro

Gil de Morales, secr. y not.; Ldo. Núñez, secr.

Referencias: 98r, 105r, 150v

\section{DIEGO DE PERALTA}

Vecino de Baeza

Grados recibidos: B. A. / L. A.

9-10-1567 Dr. Diego de Ávila dio el grado a su discípulo.

15-6-1568 Responsiones magnas para L. A. Presidió el Dr. Diego de Ávila y aprobó

18-6-1568 Responsiones parvas. Presidió el Dr. de Ávila

13-10-1568 Repetición que presidió Mtro. Almagro y aprobó

10-5-1569 Acto mayor presidido por su maestro y aprobó

11-5-1569 El Rector Pérez señaló capitulos para examen secreto y obtuvo el grado

13-5-1569 El Canciller Ocón le dio el grado

Gil de Morales, secr. y not.

Referencias: 98r, 100v, 101r, 104v, 105v, 106r

DIEGO DE PERALTA [otro homónimo]

Vecino de Baeza

Grado recibido: L. A.

11-10-1569 Repetición presidida por el Mtro. Sepulveda y aprobado

19-10-1569 Solicitó al Rector Pérez examen secreto que presidió su Maestro, Sepúlveda, y aprobó

8-12-1569 El Canciller Ocón le dio el grado

Gil de Morales, secr. y not.

Referencias: 109v, 110r, 113v

DIEGO [CIURANA] DE PERALTA

Vecino de Baeza. Catedrático del Aula de Mayores 
Grados recibidos: B. A. / L. A. / M. A.

8-11-1576 Lecciones para B. A.

10-11-1576 Acto y examen por conclusiones para B. A. Presidió el Mtro. Almagro y aprobaron este acto por cuanto no avia aprobado los cursos

10-11-1576 El Dr. Pedro de Almagro le dio el grado

10-11-1578 Responsiones magnas para L. A.: presidió el Rector Salcedo y aprobó simpliciter

21-11-1578 Repetición para L. A. Presidió el Rector Salcedo aprobó simpliciter

22-11-1578 Examen secreto ante el Rector Salcedo y presidiéndole aprobó simpliciter

1-12-1578 Canciller Fr. Agustín Salucio le dio los grados

Mtro. Molina, secr. y not.

Referencias: 183v, 220v, 221r, 221v

\section{GONZALO DE HERRERA}

Vecino de Jaén

Grados recibidos: B. A. / L. A. / B. T.

9-10-1567 Dr. Diego de Ávila dio el grado a su discípulo

21-10-1569 Repetición para L. A. Presidió su maestro y aprobó

7-11-1569 El Rector Pérez señaló puntos de examen secreto

8-11-1569 Presidió su Mtro. y aprobó

8-12-1569 El Canciller Ocón le dio el grado

2-10-1572 Tentativa del Mtro. Herrera para B. T. Presidió el Rector Pérez y aprobó

8-10-1572 Lecciones para B. T.

15-10-1572 El Rector Pérez le dio el grado

Gil de Morales, secr. y not.; J. Núñez, not. y secr.

Referencias: 98r, 110r, 112r, 113v, 142v, 143r, 143v

\section{SALVADOR DE LA IRUELA}

Vecino de Úbeda

Grado recibido: B. A.

9-10-1567 Dr. Diego de Ávila dio el grado a su discípulo

Gil de Morales, secr. y not.

Referencia: 98r

\section{GASPAR HERNÁNDEZ / FERNÁNDEZ DE ESPINOSA}

Vecino de Úbeda

Grados recibidos: B. A. / L. A.

9-10-1567 Dr. Diego de Ávila dio el grado a su discípulo

26-4-1569 Acto mayor: presidió su maestro y aprobó 
27-9-1569 Repetición para L. A. Presidió el Dr. D. Pérez y aprobó 21-10-1569 Petición de examen secreto

25-10-1569 El Rector Pérez señaló puntos

26-10-1569 Examen secreto: presidió el Mtro. Ojeda y aprobó

8-12-1569 El Canciller Ocón le dio el grado

Gil de Morales, secr. y not.

Referencias: 98r, 105r, 110r, 113v

GERÓNIMO DE HERRERA

Vecino de Jaén

Grado recibido: B. A.

9-10-1567 Dr. Diego de Ávila dio el grado a su discípulo

30-4-1569 Responsiones magnas: presidió su maestro y aprobó

Gil de Morales, secr. y not.

Referencias: $98 \mathrm{r}, 105 \mathrm{r}$

\section{ALONSO DE FREILAS}

Vecino de Jaén

Grado recibido: B. A.

9-10-1567 Dr. Diego de Ávila dio el grado a su discípulo

Gil de Morales, secr. y not.

Referencia: 98r

ANDRÉS NOTARIO

Vecino de Andújar, dióc. de Jaén

Grado recibido: B. A.

9-10-1567 Dr. Diego de Ávila dio el grado a su discípulo

Gil de Morales, secr. y not.

Referencia: 98r

PEDRO DE MELGARES

Vecino de Baeza

Grado recibido: B. A.

9-10-1567 Dr. Diego de Ávila dio el grado a su discípulo

Gil de Morales, secr. y not.

Referencia: $98 \mathrm{r}$

PEDRO DE PAREJA

Vecino de Jaén

Grado recibido: B. A. 
9-10-1567 Dr. Diego de Ávila dio el grado a su discípulo

20-5-1569 Responsiones magnas: presidió su maestro y lo dieron por bueno Gil de Morales, secr. y not.

Referencia: $98 \mathrm{r}$

\section{GARCÍA DE CRIALES}

Vecino de Baeza

Grado recibido: B. A.

9-10-1567 Dr. Diego de Ávila dio el grado a su discípulo

Gil de Morales, secr. y not.

Referencia: 98r

\section{BARTOLOMÉ DE ERBAS}

Vecino de Jimena

Grado recibido: B. A.

9-10-1567 Dr. Diego de Ávila dio el grado a su discípulo

Gil de Morales, secr. y not.

Referencia: 98r

JUAN DE LAS VACAS / VARAS

Vecino de Jaén

Grado recibido: B. A.

9-10-1567 Dr. Diego de Ávila dio el grado a su discípulo

Gil de Morales, secr. y not.

Referencia: 98r

\section{ALONSO DE HERRERA}

Natural de Baeza

Grado recibido: B. A.

9-10-1567 Dr. Diego de Ávila dio el grado a su discípulo

Gil de Morales, secr. y not.

Referencia: 98r

\section{ALONSO RODRÍGUEZ MERINO}

Vecino de Baeza

Grados recibidos: B. A. / L. A. / M. A.

9-10-1567 Dr. Diego de Ávila dio el grado a su discípulo

23-9-1567 Responsiones magnas: presidió su maestro y aprobó

17-11-1570 Repetición para L. A. el Mtro. Cavallería y aprobó

28-11-1570 Postuló examen secreto presidido por el Dr. Soriano Vera 
29-11-1570 Presidió el Mtro. Cavallería y aprobó 1-1-1571 El Canciller Ocón ortorgó el grado 30-8-1573 Canciller Juan de Arias otorgó el grado

Gil de Morales, secr. y not.; Ldo. Guerrero, not. apost.; Ldo. Juan Núñez, not.

Referencias: 98r, 107v, 121r, 121v, 122v, 151r

JUAN DE MAUNCA?

Vecino de Las Montañas

Grado recibido: B. A.

9-10-1567 Dr. Diego de Ávila dio el grado a su discípulo

Gil de Morales, secr. y not.

Referencia: 98r

JUAN DE MONTILLA[R]

Vecino de Huéscar

Grados recibidos: B. A. / L. A.

9-10-1567 Dr. Diego de Ávila dio el grado a su discípulo

13-5-1569 Acto mayor para L. A. Presidió su maestro y aprobó

14-10-1569 Repetición para L. A. Presidió Mtro. Almagro y aprobó

23-11-1569 Examen secreto señalado por Dr. Ávila

24-11-1569 Presidió el Mtro. Almagro y aprobó

8-12-1569 El Canciller Ocón le dio el grado

Gil de Morales, secr. y not.

Referencias: 98r, 106r, 109v, 112v, 113v

\section{PEDRO DE LA CHICA}

Vecino de Linares

Grado recibido: B. A.

9-10-1567 Dr. Diego de Ávila dio el grado a su discípulo

13-5-1569 Responsiones magnas: presidió su maestro

Gil de Morales, secr. y not.

Referencia: 98r

\section{ALONSO DE VICTORIA}

Vecino de Jaén

Grado recibido: B. A.

9-10-1567 Dr. Diego de Ávila dio el grado a su discípulo

Gil de Morales, secr. y not.

Referencia: $98 \mathrm{r}$ 


\section{MIGUEL DE NAVARRETE ESCÓS}

Vecino de Baeza

Grados recibidos: B. A. / L. A. / M. A. / B. T.

9-10-1567 Dr. Diego de Ávila dio el grado a su discípulo

25-10-1569 Acto mayor presidido por su Mtro. y aprobó

7-11-1569 Admitido al grado de B.T.

14-11-1570 Repetición para L.A. Presidió Mtro. Salcedo

12-12-1570 Pidió puntos al Dr. Soriano: examen secreto

13-12-1570 Presidió Mtro. Salcedo y aprobó

1-1-1571 Juan Ocón, Canciller, otorgó el grado

30-8-1573 Canciller Juan de Arias le otorgó el grado

26-6-1577 Lecciones para B.T.

27-6-1577 Aprobó la tentativa para B.T. presidida por Dr. Ojeda y le dio el grado

Gil de Morales, secr. y not.; Ldo. Guerrero, not. y secr.; Mtro. Molina, not.

Referencias: 98r, 110r, 112r, 119r, 121v, 122v, 151r, 195r, 196r

GONZALO DE ALCOZER

Vecino de Baeza

Grados recibidos: B. A. / L. A. / B. T.

9-10-1567 Dr. Diego de Ávila dio el grado a su discípulo

27-5-1569 Responsiones magnas: presidió su maestro y aprobó

30-9-1569 Repetición para L.A. Presidió su maestro y aprobó

21-10-1569 Petición de examen secreto

27-10-1569 El Rector Pérez señala puntos

28-10-1569 Examen secreto: presidió el Dr. Ávila y aprobó

8-11-1569 El Canciller Ocón le dio el grado

11-10-1578 Tentativa parva para B. T. Presidió el Dr. Salcedo y aprobó

17-10-1578 Leyó lecciones para B.T.

29-10-1578 El Rector Salcedo le otorgó el grado

Gil de Morales, secr. y not.; Mtro. Luis de Molina, secretario

Referencias: 98r, 107r, 108r, 110r, 111r, 113v, 217v, 218v, 219v

\section{FRANCISCO PALOMINO}

Vecino de Lahiguera, dióc. de Jaén

Grados recibidos: B. A. / L. A. / M. A.

9-10-1567 Dr. Diego de Ávila dio el grado a su discípulo

6-5-1569 Acto mayor presidido por su maestro y aprobó

5-10-1569 Repetición para L. A. Presidió el Mtro. Garzón y aprobó

2-11-1569 El Rector Pérez señaló puntos para examen secreto 
2-11-1569 Presidió el Mtro. Garzón y aprobó

8-12-1569 El Canciller Ocón le dio el grado

13-3-1574 El Canciller P. de Arias le dio el grado de M.A.

Gil de Morales, secr. y not.

Referencias: 98r, 105r, 111r, 113v, 157r

JUAN SAETA

Vecino de Bejifar?

Grado recibido: B. A.

9-10-1567 Dr. Diego de Ávila dio el grado a su discípulo Gil de Morales, secr. y not.

Referencia: $98 \mathrm{r}$

JUAN LÓPEZ

Vecino de Freginal

Grado recibido: B. A.

9-10-1567 Dr. Diego de Ávila dio el grado a su discípulo Gil de Morales, secr. y not.

Referencia: 98r

FRANCISCO DE LA CRUZ

Vecino de Jerez de los Caballeros

Grado recibido: B. A.

9-10-1567 Dr. Diego de Ávila dio el grado a su discípulo Gil de Morales, secr. y not.

Referencia: $98 \mathrm{r}$

LUIS LOZANO

Vecino de Vilches

Grado recibido: B. A.

9-10-1567 Dr. Diego de Ávila dio el grado a su discípulo Gil de Morales, secr. y not.

Referencia: $98 \mathrm{r}$

ALONSO RUIZ QUEVEDO

Vecino de Yeste, dióc. de Cartagena

Grado recibido: B. A.

9-10-1567 Dr. Diego de Ávila dio el grado a su discípulo Gil de Morales, secr. y not.

Referencia: $98 \mathrm{r}$ 


\section{PEDRO DE BARRIONUEVO}

Vecino de Canete, dióc. de Córdoba

Grado recibido: B. A.

9-10-1567 Dr. Diego de Ávila dio el grado a su discípulo

Gil de Morales, secr. y not.

Referencia: 98r

\section{FRANCISCO MERINO}

Vecino de Baeza

Grado recibido: B. A.

9-10-1567 Dr. Diego de Ávila dio el grado a su discípulo Gil de Morales, secr. y not.

Referencia: 98r

\section{SANTIAGO PABLOS}

Vecino de Baeza

Grado recibido: B. A.

9-10-1567 Dr. Diego de Ávila dio el grado a su discípulo

Gil de Morales, secr. y not.

Referencia: 98r

FRANCISCO DE TORRES

Vecino de Úbeda

Grado recibido: B. A.

9-10-1567 Dr. Diego de Ávila dio el grado a su discípulo

Gil de Morales, secr. y not.

Referencia: 98r

\section{FRANCISCO DE GODOY}

Vecino de Baeza

Grado recibido: B. A.

9-10-1567 Dr. Diego de Ávila dio el grado a su discípulo

Gil de Morales, secr. y not.

Referencia: 98r

JUAN GUERRERO

Vecino de Úbeda

Grados recibidos: B. A. / L. A.

9-10-1567 Dr. Diego de Ávila dio el grado a su discípulo

24-5-1569 Responsiones magnas para L.A. Presidió su maestro D. de Ávila y aprobó 
17-10-1569 Repetición para L.A. Presidió el Mtro. Sepulveda y aprobó 4-11-1569 El Rector Pérez señaló capítulos para examen secreto

5-11-1569 Presidió el Mtro. Sepulveda y aprobó

8-12-1569 El Canciller Ocón le dio el grado

Gil de Morales, secr. y not.

Referencias: 98v, 106v, 109v, 111v, 113v

LUIS AMADOR

Vecino de Cazorla

Grado recibido: B. A.

9-10-1567 Dr. Diego de Ávila dio el grado a su discípulo

Gil de Morales, secr. y not.

Referencia: 98r

JUAN DE LA MUELA

Vecino de Cazorla

Grado recibido: B. A.

9-10-1567 Dr. Diego de Ávila dio el grado a su discípulo

Gil de Morales, secr. y not.

Referencia: 98r

DIEGO DE PALMA

Vecino de Baena

Grado recibido: B. A.

9-10-1567 Dr. Diego de Ávila dio el grado a su discípulo

Gil de Morales, secr. y not.

Referencia: 98r

PEDRO DE ALARCÓN

Vecino de Baeza

Grado recibido: B. A.

9-10-1567 Dr. Diego de Ávila dio el grado a su discípulo

Gil de Morales, secr. y not.

Referencia: 98r

\section{BERNARDO ALONSO}

Natural de Santa Olalla, obispado de Oviedo. Vecino de Astorga

Grados recibidos: B. A. / L. A. / M. A.

9-10-1567 Dr. Diego de Ávila dio el grado a su discípulo

21-6-1572 Tuvo los mismos testigos que el anterior 
24-10-1572 Responsiones magnas para L.A. Presidió el Mtro. Almagro y aprobó 17-11-1572 Repetición: presidió el Mtro. Salcedo y aprobó

18-11-1572 Examen secreto ante Dr. Ojeda, Vicerrector. Presidió Mtro. Salcedo y aprobó L.A y D.A.

29-3-1573 Canciller P. de Arias le dio el grado

28-8-1573 El Canciller Fr. Pedro de Arias le dio el grado

Gil de Morales, secr. y not.; Juan Núñez, not. y secr.

Referencias: 98v, 141v, 144v, 148v, 150v

\section{PEDRO RODRÍGUEZ}

Vecino de Baeza

Grado recibido: B. A.

9-10-1567 Dr. Diego de Ávila dio el grado a su discípulo

Gil de Morales, secr. y not.

Referencia: 98r

\section{PEDRO GUTIÉRREZ}

Vecino de Jaén

Grado recibido: B. A.

9-10-1567 Dr. Diego de Ávila dio el grado a su discípulo

Gil de Morales, secr. y not.

Referencia: $98 \mathrm{r}$

JUAN DE SAN JUAN

Natural de Sevilla y vecino de Baeza

Grado recibido: B. A.

9-10-1567 Dr. Diego de Ávila dio el grado a su discípulo

Gil de Morales, secr. y not.

Referencia: 98r

\section{JUAN DE HENARES?}

Vecino de Lorca, dióc. de Cartagena

Grado recibido: B. A.

9-10-1567 Dr. Diego de Ávila dio el grado a su discípulo

Gil de Morales, secr. y not.

Referencia: $98 \mathrm{r}$

MARCO DE TORRES

Vecino de Albanchez

Grado recibido: B. A. 
9-10-1567 Dr. Diego de Ávila dio el grado a su discípulo

Gil de Morales, secr. y not.

Referencia: 98v

\section{LUIS MARTÍNEZ}

Vecino de Bailén

Grado recibido: B. A.

9-10-1567 Dr. Diego de Ávila dio el grado a su discípulo

Gil de Morales, secr. y not.

Referencia: $98 \mathrm{v}$

LDO. SERA

Natural de Jaén

Grado recibido: B. T.

21-11-1567 Tentativa para B. T. Presidió el Dr. Pérez y le dio el grado

Gil de Morales, secr. y not.

Referencia: 99r

\section{RODRIGO DE HERRERA}

Grado recibido: B. A.

26-11-1567 Acto mayor para L. A. Presidió el Dr. Fernández y quedó reprobado

Gil de Morales, secr. y not.

Referencia: 99r

\section{MTRO. ALONSO MORENO}

¿M. A.? Vecino de Baeza

Grado recibido: B. T.

10-1-1568 Tentativa para B. T. Presidió el Dr. Melchor Fernández

14-1-1568 Lección pública y se le dio el grado

Morales, secr. y not.

Referencia: 99v

\section{JERÓNIMO MARTÍNEZ}

B. A. de Cazorla

Grado recibido: L. A.

21-2-1568 Repetición para L. A.

¿-4-1568 Presidió el Dr. Ávila y le aprobaron

8-6-1568 Petición de examen. El Dr. Carleval señaló puntos

9-6-1568 Examen secreto y aprobó el grado de L. A.

10-6-1568 El Canciller Ocón le dio el grado 
Gil de Morales, secr. y not.

Referencias: 99v, 101v

\section{DIEGO DE HUÉSCAR}

Grado recibido: L. A.

24-6-1568 B. A., discípulo del Mtro. de Diego de Ávila: tuvo responsiones magnas para L. A. Las presidió su Mtro. y aprobó

18-6-1568 Responsiones parvas

11-10-1568 Repetición para L. A. Presidió Mtro. Ojeda

29-3-1569 El Rector Pérez señaló examen secreto

30-3-1569 Presidió el Dr. Ávila y le aprobaron

13-5-1569 El Canciller Ocón le dio el grado

Gil de Morales, secr. y not.

Referencias: 100v, 101r, 104r, 104v, 106r

\section{ANTONIO PÉREZ}

B. A. Vecino de Montilla

Grados recibidos: L. A. / B. T.

20-9-1568 Repetición para L.A. Presidió el Dr. Pérez y aprobó

22-9-1568 Pidió al Rector Pérez el examen secreto para L. A. que presidió el Dr. Fernández y aprobó

25-9-1568 Tamariz, Canciller, le dio el grado

27-9-1568 Conclusiones para B.T. Presidió el Dr. Fernández y se le dio el grado

Gil de Morales, secr. y not.

Referencias: 101r, 102r, 102v, 103r

\section{PEDRO ALMAGRO DE MOLINA}

L. A. Pbro.Vecino de Almodovar del Campo, dióc. de Toledo

Grados recibidos: M. A. / B. T. / L. T. / D. T.

10-10-1568 Pidió recibir el grado de Magisterio

12-12-1570 Incorporación L.A. en Alcalá de Henares y fue admitido, juró y fue incorporado por el Canciller Fr. Remigio Tamariz y le dio el grado

13-10-1571 Tentativa magna para B. T.

14-10-1572 Rector Dr. Medina le dio el grado

30-3-1573 Magna ordinaria de L. T. Presidió el Rector Pérez y aprobó

31-3-1573 Examen secreto para L.T. ante el Dr. Ojeda

31-3-1573 Presidió el Dr. Carleval y aprobó para L.T. y D.T. Canciller Arias le otorgó el grado

19-4-1573 Canciller Remigio Tamariz O.P. le dio el grado de D. T.

Gil de Morales, secr. y not.; Guerrero, not.; Juan Núñez notario y secr.

Referencias: 103v, 122v, 134v, 143r, 149r, 149v 


\title{
DIEGO CASARES
}

Del curso del Dr. Pérez, B. A.

22-6-1569 Tuvo responsiones magnas para L.A. Presidió el Dr. Pérez y aprobó

Gil de Morales, secr. y not.

Referencia: $107 \mathrm{r}$

\section{DIEGO DE TORRES}

Vecino de Baeza

Grado recibido: B. A.

11-12-1569 Dr. Pedro de Ojeda dio el grado a su discípulo

Gil de Morales, secr. y not.

Referencia: $114 \mathrm{r}$

\section{ALONSO DE PADILLA}

Vecino de Úbeda

Grado recibido: B. A.

11-12-1569 Dr. Pedro de Ojeda dio el grado a su discípulo

Gil de Morales, secr. y not.

Referencia: $114 \mathrm{r}$

\section{ALONSO DE CAZORLA}

Beneficiado. Vecino de Úbeda

Grado recibido: B. A.

11-12-1569 Dr. Pedro de Ojeda dio el grado a su discípulo

Gil de Morales, secr. y not.

Referencia: $114 \mathrm{r}$

\author{
ALONSO DE GODOY \\ Vecino de Baeza \\ Grados recibidos: B. A. / L. A. / M. A. / B. T. \\ 11-12-1569 Dr. Pedro de Ojeda dio el grado a su discípulo \\ 2-4-1571 Responsiones maganas para L. A. Presidióle su maestro y aprobó \\ 14-9-1571 Repetición para L. A. Presidió su Mtro. y aprobó \\ 27-9-1571 Examen secreto ante el Dr. Ojeda \\ 28-9-1571 Presidió Mtro. Vilchez y aprobó \\ 30-11-1571 Graduó el Canciller Raya \\ 29-9-1571 El Canciller Fr. Pedro de Guzmán le dio el grado \\ 5-5-1575 Tentativa parva para B.T. que presidió Mtro. Cavallería y le dio el grado, \\ habiendo precedido las cuatro lecciones preceptivas \\ Gil de Morales, secr. y not. Juan Núñez, secr., Mtro. Molina, not. \\ Referencias: 114r, 125v, 130v, 132r, 136v, 165v, 166r
}




\section{RODRIGO DE OCHOA}

Vecino de Baeza

Grados recibidos: B. A. / L. A. / M. A.

11-12-1569 Dr. Pedro de Ojeda dio el grado a su discípulo

16-3-1571 Responsiones magnas para L. A. que presidió el Mtro. Ojeda y aprobó

4-9-1571 Repetición para L. A. Presidió el Mtro. Ojeda y aprobó

17-9-1571 Examen secreto ante el Vicerrector Ojeda

18-9-1571 Presidió Mtro. Almagro y aprobó

30-11-1571 Graduó el Canciller Raya

3-4-1574 Canciller Fr. Juan de Arias le dio el grado

19-3-1579 Lecciones para B. T.

Gil de Morales, secr. y not. Juan Núñez, secr.

Referencias: 114r, 124v, 130r, 131r, 136v, 158r, 234r

\section{MATEO DEL SALTO}

Vecino de Jaén

Grados recibidos: B. A. / L. A.

11-12-1569 Dr. Pedro de Ojeda dio el grado a su discípulo

8-5-1571 Responsiones magnas: presidió su Mtro. y aprobó

27-9-1571 Repetición: presidió su Mtro. y aprobó

13-10-1571 Examen secreto de L.A.

14-10-1571 Presidió el Mtro. Almagro y aprobó el grado

30-11-1571 Graduó el Canciller Raya

Gil de Morales, secr. y not; Mtro. San Román; Juan Núñez secretario

Referencias: 114r, 127r, 132v, 135r, 136v

ANTONIO DE PERALTA

Vecino de Jaén

Grado recibido: B. A.

11-12-1569 Dr. Pedro de Ojeda dio el grado a su discípulo

Gil de Morales, secr. y not.

Referencia: $114 \mathrm{r}$

\section{BARTOLOMÉ CIPRIANO}

Vecino de Pliego

Grados recibidos: B. A. / L. A. / M. A. / B. T.

11-12-1569 Dr. Pedro de Ojeda dio el grado a su discípulo

14-5-1571 Acto mayor para L.A. Presidió Mtro. Almagro

1-10-1571 Repetición para L. A. Presidió el Dr. Ojeda y aprobó

16-10-1571 Examen secreto ante el Rector Medina 
17-10-1571 Presidió Mtro. Salcedo y aprobó

30-11-1571 Graduó el Canciller Raya

18-4-1574 Canciller Fr. Pedro de Arias le otorgó el grado

4-12-1576 Tentativa magna para B. T. Presidió el Dr. Ojeda y aprobó

11-12-1576 Leyó la última de las cuatro lecciones. Dr. Pedro de Ojeda le dio el grado

Gil de Morales, secr. Mtro. San Román, Juan Núñez, not.; Mtro. San Roman, not.

Mtro. Luis de Molina, not. y secr.

Referencias: 114r, 128r, 132v, 135r, 136v, 148r, 184r

\section{GONZALO DE LUCENA}

Vecino de Jaén

Grados recibidos: B. A. / L. A.

11-12-1569 Dr. Pedro de Ojeda dio el grado a su discípulo

27-4-1571 Responsiones magnas para L. A. Presidió su Mtro. Tuvo que repetirlo

22-10-1571 Repetición para L. A. Presidió su Mtro. y aprobó

26-10-1571 Ante el Rector Ávila pidió capítulos para L.A.

27-10-1571 Presidió Mtro. Vilches y aprobó

30-11-1571 Le graduó el Canciller Raya

Gil de Morales, secr. y not.; Mtro. San Román; Núñez, notario

Referencias: 114r, 126r, 135v, 136r, 136v

\section{BERNAL SÁNCHEZ}

Vecino de Cózar

Grado recibido: B. A.

11-12-1569 Dr. Pedro de Ojeda dio el grado a su discípulo

Gil de Morales, not.

Referencia: $114 \mathrm{r}$

\section{LUIS DE MOLINA}

Vecino de Baeza

Grados recibidos: B. A. / L. A. / M. A.

11-12-1569 Dr. Pedro de Ojeda dio el grado a su discípulo

10-5-1571 Responsiones magnas: presidió su Mtro. y aprobó

28-4-1572 Repetición para L. A. Presidió su Mtro. Aprobó

23-1-1574 Examen secreto ante el Rector Almagro

24-1-1574 Presidió Mtro. M. de Peralta y aprobó

13-3-1574 El Canciller Fr. Juan de Arias el dio el grado de L.A.

10-4-1574 El Canciller Fr. Juan de Arias el dio el grado

Gil de Morales, secr. y not.; Mtro. San Román; J. Núñez, secr y not.

Referencias: 114r, 127r, 140v, 156v, 157r, 158r 
PEDRO DE VAL DE ELVIRA

Vecino de Úbeda

Grado recibido: B. A.

11-12-1569 Dr. Pedro de Ojeda dio el grado a su discípulo

29-3-1571 Responsiones magnas para L.A. Presidió Mtro. Ojeda. Calificadas de acto ruin

Gil de Morales, secr. y not.

Referencias: 114r, $125 \mathrm{r}$

MARIO DE BUSTOS

Vecino de Jaén

Grado recibido: B. A.

11-12-1569 Dr. Pedro de Ojeda dio el grado a su discípulo

Gil de Morales, secr. y not.

Referencia: $114 \mathrm{r}$

ESTEBAN DE MOLINA

Vecino de Baeza

Grado recibido: B. A.

11-12-1569 Dr. Pedro de Ojeda dio el grado a su discípulo

Gil de Morales, secr. y not.

Referencia: $114 \mathrm{r}$

JUAN FRANCISCO

Vecino de Baeza

Grados recibidos: B. A. / L. A. / M. A.

11-12-1569 Dr. Pedro de Ojeda dio el grado a su discípulo

21-3-1571 Responsiones magnas para L. A. Presidió el Mtro. Ojeda y aprobó

6-9-1571 Repetición presidida por el Mtro. Ojeda para L. A. y aprobó

19-9-1571 Examen secreto ante el Mtro. Ojeda

20-9-1571 Ojeda presidió el examen y aprobó el grado

30-10-1571 Graduó el Canciller Raya

29-9-1574 El Canciller Fr. Pedro de Guzmán otorgó el grado de M.A.

Gil de Morales, secr. y not.; Juan Núñez, not.; Mtro. Prado

Referencias: 114r, 125r, 13or, 131v, 136v, 161v

RODRIGO DE ARMIJO

Natural de Torres

Grados recibidos: B. A. / L. A. / B. T.

11-12-1569 Dr. Pedro de Ojeda dio el grado a su discípulo 
20-3-1571 Acto mayor para L. A. Presidió el Mtro. Almagro y aprobó 19-4-1571 Responsiones magnas: presidió Mtro. Pedro de Ojeda y dijo que la repitiese

8-10-1571 Repetición para L. A. Presidió su Mtro. y aprobó 15-10-1571 Pidió al Rector Ávila le señalase capítulos

22-10-1571 Presidió el Mtro. Cavallería y aprobó

23-10-1571 Graduó el Canciller Raya

30-11-1571 Tentativa parva para B.T. Presidió el Dr. Salcedo y aprobó

22-8-1577 Lecciones para B. T.

12-9-1577 Dr. Gaspar de Salcedo diole el grado

Gil de Morales, secr. y not.; Mtro. San Roman; Núñez, secretario

Referencias: 114r, 124v, 126r, 135r, 135v, 136rv, 196v, 200v

\section{JUAN DE GALARZA}

Vecino de Baeza

Grados recibidos: B. A. / L. A.

11-12-1569 Dr. Pedro de Ojeda dio el grado a su discípulo

30-11-1571 Graduó el Canciller Raya

Gil de Morales, secr. y not.; Núñez, not.

Referencias: 114r, 136v

\section{BARTOLOMÉ DE ARANDA}

\section{Vecino de Torres}

Grado recibido: B. A.

11-12-1569 Dr. Pedro de Ojeda dio el grado a su discípulo

Gil de Morales, secr. y not.

Referencia: $114 \mathrm{r}$

\section{ANDRÉS RUIZ}

Vecino de Huéscar

Grados recibidos: B. A. / L. A.

11-12-1569 Dr. Pedro de Ojeda dio el grado a su discípulo

4-5-1571 Acto mayor presidido por su Mtro. y aprobó

20-9-1571 Repeticiones para L. A. Presidió su Mtro. y aprobó

5-10-1571 Examen secreto ante su Mtro.

6-10-1571 Presidió el Dr. Ávila y aprobó

30-11-1571 Graduó el Canciller Raya

Gil de Morales, secr. y not.; Mtro. San Román; Juan Núñez, secretario

Referencias: 114r, 127r, 132r, 133r, 133v, 136v 


\section{BLAS DE JANDILLA}

Vecino de Andújar

Grado recibido: B. A.

11-12-1569 Dr. Pedro de Ojeda dio el grado a su discípulo

Gil de Morales, secr. y not.

Referencia: $114 \mathrm{r}$

\section{JUAN DE MUSA}

Vecino de Baeza

Grado recibido: B. A.

11-12-1569 Dr. Pedro de Ojeda dio el grado a su discípulo

Gil de Morales, secr. y not.

Referencia: $114 \mathrm{r}$

\section{BALTASAR DE HERRERA}

Vecino de Jaén

Grados recibidos: B. A. / L. A. / M. A.

11-12-1569 Dr. Pedro de Ojeda dio el grado a su discípulo

4-4-1571 Responsiones magnas para L. A. que presidió el Mtro. Cavallería y aprobó 19-9-1571 Repetición para L. A. y presidió su Mtro. y aprobó

24-9-1571 Examen secreto ante el Dr. Ojeda

25-9-1571 Presidió Mtro. Salcedo y aprobó

1-10-1571 Examen secreto ante el Dr. Ojeda

2-10-1571 Presidió el Mtro. Cavallería y aprobó

30-11-1571 Graduó el Canciller Raya

13-4-1574 El Canciller Arias le dio el grado

Morales, secr. y not.; Guerrero, not. y secr.; Juan Núñez notario

Referencias: 114r, 131v, 132r, 133r, 136v, 158r

\section{HERNANDO DE AGUAYO}

Vecino de Baeza

Grados recibidos: B. A. / L. A. / M. A.

11-12-1569 Dr. Pedro de Ojeda dio el grado a su discípulo

23-4-1571 Repeticiones magnas para L. A. Presidió el Mtro. Cavallería y aprobó 29-10-1571 Acto mayor: presidió su Mtro. y aprobó

5-11-1571 Repetición para L. A. que presidió su Mtro. y aprobó

6-11-1571 El Rector Ávila señaló capítulos de examen secreto para L. A. 30-11-1571 Presidió el Mtro. Almagro y aprobó

18-4-1574 Le graduó el Canciller Raya de L. A. y el Canciller Pedro de Arias de M.A. 
Gil de Morales, secr. y not.; Mtro. San Roman; Juan Núñez, not.

Referencias: 114r, 126r, 136r, 136v, 158r

\section{BERNARDINO DE CARRIÓN}

Vecino de Jaén

Grado recibido: B. A.

11-12-1569 Dr. Pedro de Ojeda dio el grado a su discípulo

2-5-1571 Responsiones magnas: presidió su Mtro. y aprobó

Gil de Morales, secr. y not.; Mtro. San Román

Referencias: 114r, 127r

\section{JUAN DE HERRERA}

Vecino de Jaén

Grados recibidos: B. A. / L. A.

11-12-1569 Dr. Pedro de Ojeda dio el grado a su discípulo

27-3-1571 Acto mayor: presidió el Mtro. Ojeda

12-9-1571 Repetición para L. A. Presidió el Dr. Ojeda y aprobó

30-11-1571 Le graduó el Canciller Raya

Gil de Morales, secr. y not.; Juan Núñez, not.

Referencias: 114r, 125r, 130v, 136v

\section{BENITO GARRIDO}

Vecino de Castro del Río

Grado recibido: B. A.

11-12-1569 Dr. Pedro de Ojeda dio el grado a su discípulo

Gil de Morales, secr. y not.

Referencia: $114 \mathrm{r}$

\section{BARTOLOMÉ DE LA CARRERA}

Vecino de Jaén

Grado recibido: B. A.

11-12-1569 Dr. Pedro de Ojeda dio el grado a su discípulo

Gil de Morales, secr. y not.

Referencia: $114 \mathrm{r}$

PEDRO DE LUBIA / TUBIA / SUBIA

Pbro. B. A.

Grados recibidos: L.A. / M. A. / B. T.

3-2-1570 Petición de L. A. Presidió el Mtro. Almagro y aprobó

11-5-1570 Dr. Ávila señaló puntos para examen secreto 
12-5-1570 Aprobó el grado de L. A. Presidió el Mtro. Almagro

16-5-1570 Le dio el grado de L. A. el Canciller Pérez

8-12-1570 El Canciller Fr. Diego Villalobos le dio el grado de M.A.

13-12-1572 Lecciones para B. T. Presidió el Mtro. Almagro

20-12-1572 Dr. Ojeda, Vicerrector, dio el grado

Gil de Morales, secr. y not.; Ldo. Guerrero, not. apost.; Núñez, not.

Referencias: 115v, 117r, 117v, 121v, 145v

PEDRO SALCEDO CÁCERES [MTRO. CÁCERES]

Vecino de Baeza

Grados recibidos: M. A. / B. T.

9-2-1570 El Canciller Ocón dio el grado

18-6-1572 Tentativa para B. T. Presidió el Dr. D. Pérez y aprobó

7-10-1572 Lecciones para B. T.

15-10-1572 El dio el grado el Rector Pérez

Gil de Morales; J. Núñez, not y secr.

Referencias: 116r, 141r, 143r

FR. DIEGO DE VILLALOBOS

O. P. Prior de Sto. Domingo de Baeza

Incorporación: D. T.

19-4-1570 Incorporación El Vicerrector D. de Ávila y la Facultad de Teología y Artes y se les recibió juramento y se les dio el grado

Gil de Morales, secr. y not.

Referencia: $116 \mathrm{r}$

FR. DIEGO DE SEPÚLVEDA

O. P.

Incorporación: D. T.

19-4-1570 Incorporación El Vicerrector D. de Ávila y la Facultad de Teología y Artes y se les recibió juramento y se les dio el grado

Gil de Morales, secr. y not.

Referencia: $116 \mathrm{r}$

\section{RAFAEL BAUTISTA FERRER}

D. T. y M. A. en Osuna

Incorporación: M. A. / D. T.

14-11-1570 Incorporación ante el Dr. Carleval, Rector de Baeza, y claustro, juró. Juan Guerrero, not. apost.

Referencia: $119 \mathrm{v}$ 


\section{BLAS DE LA CAVALLERÍA}

M. A. en Alcalá, natural de Almagro

Grados recibidos: B. T. / L. T.

14-11-1570 Incorporación ante el Dr. Carleval, Rector de Baeza, y claustro, juró 15-1-1571 Tentativa para B.T. Presidió el Dr. Ferrer

10-12-1571 Rector Dr. Diego de Ávila diole el grado

27-1-1574 Magna ordinaria para L. T. Presidió el Rector Almagro y aprobó

29-4-1574 Segundo acto para L.T. Presidió el Dr. Ojeda y aprobó

29-4-1574 Se le permuta un curso de teología escolástica que dio por los restantes actos para L.T.

[23-5-1574 Catedrático de Teología]

23-5-1574 Ante el Rector Almagro, examen secreto para L.T.

24-5-1574 Presidió el Dr. Carleval y se le dio el grado

26-5-1574 El Canciller Pedro de Arias le otorgó ese grado

Ldo. Juan Guerrero, not. apost.; Ldo. Núñez secr.

Referencias: 12or, 123v, 156r, 16or, 16ov

FR. BALTASAR CASTAÑO

O. de M.

Grado recibido: B. T.

24-11-1570 Acto para B. T. Presidió el Dr. Ferrer

5/6/7-4-1571 Leyó cuatro lecciones de Teología

7-4-1571 Dr. Ferrer diole el grado

Ldo. Juan Guerrero, not. apost.

Referencias: 121r, $127 \mathrm{~V}$

FR. JUAN DE AGUILAR

O. de M. Natural de Sevilla

25-11-1570 Acto para B. T. Presidió el Dr. Ávila

19/23-4-1571 Leyó lecciones de Teología para B. T.

Ldo. Juan Guerrero, not. apost.

Referencias: 121r, 128r

\section{DIEGO DE NAVARRETE}

Vecino de Baeza

Grado recibido: B. A.

17-12-1570 Dr. Pedro de Almagro, Catedrático de Artes, dio el grado a su discípulo 26-1-1572 Responsiones magnas presididas por su Mtro. y aprobó

Ldo. Juan Guerrero, not. y secr.; Núñez, secretario

Referencias: 123r, $139 \mathrm{v}$ 


\section{ANDRÉS SÁNCHEZ GALLEGO [ANDRÉS GALLEGO]}

Vecino de Lahiguera

Grados recibidos: B. A. / L. A. / M. A.

17-12-1570 Dr. Pedro de Almagro dio el grado a su discípulo 28-1-1572 Acto mayor para L. A. Presidió su Mtro. y aprobó 1-9-1572 Repetición para L. A. Presidió su Mtro. Almagro y aprobó

23-9-1572 Pidió para L. A. capítulos para examen secreto al Rector Pérez. Presidió el Dr. Vilches y alcanzó el grado.

29-3-1573 El Canciller Pedro de Arias le dio el grado de L. A. 13-2-1576 El Canciller Alonso de Rojas le dio el grado de M. A.

Ldo. Juan Guerrero, not. y secr.; Núñez, secretario; Mtro. Luis de Molina, not. apost.

Referencias: 123r, 139v, 141v, 142r, 148v, 174r

\section{HERNANDO / FERNANDO DE PEDRAZA [MTRO. PEDRAZA]}

Pbro. Vecino de Baeza

Grados recibidos: B. A. / L. A. / M. A. / B. T. / L. T. / D. T.

17-3-1572 Otorgólo Mtro. de Ávila

22-9-1572 Acto mayor para L. A. Presidió su Mtro. Almagro

15-10-1572 Repetición para L. A. Presidió su Mtro. Almagro y aprobó

16-10-1572 Examen secreto ante el Rector Pérez

29-3-1573 Presidió el Dr. Ojeda y alcanzó el grado de L.A.

8-9-1575 Canciller P. de Arias le dio el grado

7-6-1578 El Canciller Fr. Diego Manuel presidió tentativa y lecciones para B. T.

24-6-1578 Tentativa magna para B. T. presidida por el Rector Diego Pérez y aprobó simpliciter et absolute, n.d. El Rector Pérez le dio el grado

28-2-1580 Examen secreto ante el Rector Molina para L. T. Presidió el Dr. Ojeda y aprobó simpliciter.

7-3-1580 Fr. Juan de Vilches, Canciller, dio los grados de L.T. y D. T.

Rodríguez; J. Núñez, not. y secr.; Mtro. Molina, not.; Diego de Torres, not.; Mtro.

Molina, not.

Referencias: 66r, 140r, 142r, 143v, 148v, 169r, 210r, 213r, 214r, 253v, 254r

\section{HERNANDO DE PEDRAZA}

Vecino de Baeza

Grado recibido: B. A.

17-12-1570 Dr. Pedro de Almagro dio el grado a su discípulo

Ldo. Juan Guerrero, not. y secr.

Referencia: $123 \mathrm{r}$ 


\section{ALONSO DE BAENA}

Vecino de Baeza

Grado recibido: B. A.

17-12-1570 Dr. Pedro de Almagro dio el grado a su discípulo

Ldo. Juan Guerrero, not. y secr.

Referencia: $123 \mathrm{r}$

JUAN DE AGUILERA

Vecino de Alhama

Grado recibido: B. A.

17-12-1570 Dr. Pedro de Almagro dio el grado a su discípulo Ldo. Juan Guerrero, not. y secr.

Referencia: $123 \mathrm{r}$

CRISTÓBAL AMADOR

Vecino de Cazorla

Grado recibido: B. A.

17-12-1570 Dr. Pedro de Almagro dio el grado a su discípulo Ldo. Juan Guerrero, not. y secr.

Referencia: $123 \mathrm{r}$

\section{FERNANDO DE MOLINA}

Vecino de Guadix

Grado recibido: B. A.

17-12-1570 Dr. Pedro de Almagro dio el grado a su discípulo Ldo. Juan Guerrero, not. y secr.

Referencia: $123 \mathrm{r}$

FERNANDO JUARES

Vecino de Jaén

Grado recibido: B. A.

17-12-1570 Dr. Pedro de Almagro dio el grado a su discípulo

Ldo. Juan Guerrero, not. y secr.

Referencia: $123 \mathrm{r}$

FERNANDO DE LA FUENTE

Vecino de Jaén

Grado recibido: B. A.

17-12-1570 Dr. Pedro de Almagro dio el grado a su discípulo

Ldo. Juan Guerrero, not. y secr.

Referencia: 123r 


\section{FRANCISCO SANTISTEVAN}

Vecino de Begíjar

Grado recibido: B. A.

17-12-1570 Dr. Pedro de Almagro dio el grado a su discípulo

Ldo. Juan Guerrero, not. y secr.

Referencia: $123 \mathrm{r}$

\section{DIEGO DE ACEITUNO}

Vecino de Jaén

Grado recibido: B. A.

17-12-1570 Dr. Pedro de Almagro dio el grado a su discípulo Ldo. Juan Guerrero, not. y secr.

Referencia: $123 \mathrm{r}$

\section{DIEGO LÓPEZ}

Vecino de Loruesa $\dot{c}$ ?

Grado recibido: B. A.

17-12-1570 Dr. Pedro de Almagro dio el grado a su discípulo Ldo. Juan Guerrero, not. y secr.

Referencia: $123 \mathrm{r}$

\section{JUAN IBÁÑEZ}

Vecino de Baeza

Grado recibido: B. A.

17-12-1570 Dr. Pedro de Almagro dio el grado a su discípulo 27-9-1578 Repetición para L. A.

Ldo. Juan Guerrero, not. y secr.

Referencias: 123r, 215v

\section{LORENZO DE CASTRO}

Natural de Jaén

Grados recibidos: B. A. / B. T.

17-12-1570 Dr. Pedro de Almagro dio el grado a su discípulo 4-3-1572 Acto mayor: presidió su Mtro. y aprobó

15-10-1575 Tentativa para B. T. que presidió el Dr. Almagro y aprobó 22-10-1575 Rdo. Pedro de Almagro, cat. de Teología, le dio el grado Ldo. Juan Guerrero, not. y secr.; J. Muñoz, not. y secr.; Mtro. Molina, not. Referencias: 123r, 139v, 171r, 172r

\section{JUAN NÚÑEZ}

Vecino de Baeza y secretario de la Universidad 
Grados recibidos: B. A. / L. A.

17-12-1570 Dr. Pedro de Almagro dio el grado a su discípulo

20-3-1572 Responsiones magnas para L. A. que presidió su Mtro. y aprobó

8-10-1572 Repetición para L. A. Presidió el Mtro. Almagro y aprobó

22-10-1572 El Rector Pérez señala capítulos para examen secreto para L. A.

23-10-1572 Presidió el Dr. Salcedo y aprobó el grado

29-3-1573 Canciller P. de Arias le otorgó el grado

Ldo. Juan Guerrero, not. y secr.; Mtro. Montilla; Mtro. G. de Herrera, not; Ga-

rrido, not.

Referencias: 123r, 140r, 142v, 144r, 148v

\section{BERNARDINO DE RUS}

Vecino de Baeza

Grado recibido: B. A.

17-12-1570 Dr. Pedro de Almagro dio el grado a su discípulo

Ldo. Juan Guerrero, not. y secr.

Referencia: $123 \mathrm{r}$

\section{CRISTÓBAL MEJÍA}

Vecino de Jaén

Grado recibido: B. A.

17-12-1570 Dr. Pedro de Almagro dio el grado a su discípulo

Ldo. Juan Guerrero, not. y secr.

Referencia: $123 \mathrm{r}$

\section{FRANCISCO DE LA CHICA}

Vecino de Villalgordo

Grados recibidos: B. A. / L. A.

17-12-1570 Dr. Pedro de Almagro dio el grado a su discípulo

22-4-1572 Acto mayor: presidió su Mtro. y aprobó

21-10-1572 Repetición para L. A. y presidió su Mtro. Almagro y aprobó

21-11-1572 Pidió al Dr. Ojeda capítulos para examen secreto

22-11-1572 Presidió el Mtro. Cavallería y aprobó el grado

29-3-1573 Canciller P. de Arias le dio el grado

Ldo. Juan Guerrero, not. y secr.; Núñez, not. y secr.

Referencias: 123r, 140v, 143v, 114v, 145r, 148v

FRANCISCO MARTÍNEZ

Vecino de Moratalla

Grado recibido: B. A. 
17-12-1570 Dr. Pedro de Almagro dio el grado a su discípulo Ldo. Juan Guerrero, not. y secr.

Referencia: $123 \mathrm{r}$

PEDRO GARCÍA

Vecino de Huéscar

Grado recibido: B. A.

17-12-1570 Dr. Pedro de Almagro dio el grado a su discípulo

Ldo. Juan Guerrero, not. y secr.

Referencia: $123 \mathrm{r}$

GONZALO DE PERALTA

Vecino de Baeza

Grado recibido: B. A.

17-12-1570 Dr. Pedro de Almagro dio el grado a su discípulo

Ldo. Juan Guerrero, not. y secr.

Referencia: $123 \mathrm{r}$

PEDRO GALERA

Vecino de Baeza

Grado recibido: B. A.

17-12-1570 Dr. Pedro de Almagro dio el grado a su discípulo

Ldo. Juan Guerrero, not. y secr.

Referencia: $123 \mathrm{r}$

FERNANDO DE BAENA

Vecino de Pliego

Grado recibido: B. A.

17-12-1570 Dr. Pedro de Almagro dio el grado a su discípulo

Ldo. Juan Guerrero, not. y secr.

Referencia: $123 \mathrm{r}$

DIEGO DE EL ARCO

Grado recibido: B. T.

13/14/15/- 3-1571 Lecciones para graduarse de B. T.

15-3-1571 Tentativa menor: presidió el Mtro. Ávila y le dio el grado

Ldo. Juan Guerrero, not. y secr.

Referencia: $124 \mathrm{r}$

JUAN VIZCAÍNO DE GALARZA

B. A. vecino de Baeza 
Grado recibido: L. A.

18-5-1571 Responsiones magnas para L. A. Presidió el Mtro. Almagro y aprobó 5-10-1571 Repetición para L. A. Presidió el Dr. Ojeda

19-10-1571 Examen secreto ante el Rector Diego de Ávila y aprobó

Secr. Mtro. San Román; Núñez, secretario

Referencias: 128r, 133v

\section{CRISTÓBAL DE PERALES}

Grado recibido: B. A.

20-5-1571 Presidió su Mtro. Pedro de Almagro y el dio el grado

Secr. Mtro. San Román

Referencia: $128 \mathrm{v}$

GÓMEZ DE MOLINA

B. A.

Grados recibidos: L. A. / M. A.

22-5-1571 Repetición para L. A. Presidió el Dr. Ferrer y aprobó

28-5-1571 El Dr. Ferrer propuso examen secreto

29-5-1571 Presidió el Dr. Ferrer

17-6-1571 El Canciller Ocón le otorgó el grado de L.A.

El Canciller Ocón le graduó de M. A.

Secr. Mtro. San Román

Referencias: 128v, 129r, 129v

\section{SALVADOR DE SANTAMARÍA}

O. de M.

Grado recibido: B. T.

30-5-1571 Tentativa y lecciones para B. T.

Mtro. San Román, secretario

Referencia: $129 \mathrm{v}$

\section{PEDRO OCÓN}

Grado recibido: B. A.

23-6-1571 Acto para B. A. y le presidió el Mtro. Ojeda

Mtro. San Román, secretario

Referencia: $128 \mathrm{v}$

\section{ALONSO DE SALCEDO}

Vecino de Marmolejo

Grados recibidos: B. A. / L. A. 
8-12-1571 Mtro. Gaspar de Salcedo graduó a su discípulo 13-3-1573 Acto mayor para L. A. Presidió su Mtro. y aprobó 14-11-1573 Repetición para L. A. Presidió su Mtro. y aprobó 18-11-1573 Examen secreto ante el Rector Almagro 19-11-1573 Presidió Mtro. Cavallería y aprobó

29-11-1573 Canciller Pedro de la Hoya le dio el grado Juan Núñez not. y secr.

Referencias: 137r, 148v, 154r, 154v

CRISTÓBAL DE VILLALTA

Vecino de Carrillo

Grado recibido: B. A.

8-12-1571 Mtro. Gaspar de Salcedo graduó a su discípulo Juan Núñez not. y secr.

Referencia: $137 r$

HERNANDO DE TUREL

Vecino de Baeza

Grado recibido: B. A.

8-12-1571 Mtro. Gaspar de Salcedo graduó a su discípulo 3-3-1573 Acto mayor presidido por su Mtro. y reprobado Juan Núñez not. y secr.

Referencias: $137 \mathrm{r}, 148 \mathrm{r}$

\section{PEDRO DÍAZ CALDERÓN}

Vecino de Baeza

Grados recibidos: B. A. / L. A.

8-12-1571 Mtro. Gaspar de Salcedo graduó a su discípulo 10-3-1572 Acto mayor: presidió el Mtro. Almagro y aprobó 18-9-1572 Repetición para L. A. y presidió Mtro. Almagro y aprobó 8-10-1572 Capítulos para examen secreto ante el Rector Pérez 9-10-1572 Presidió el Mtro. Cavallería y aprobó L. A.; reprobado de Mtro. 29-3-1573 El Canciller P. de Arias le dio el grado de L. A. Juan Núñez not. y secr.

Referencias: 137r, 139v, 142r, 142v, 148v

\section{BARTOLOMÉ VIZCAÍNO}

Vecino de Baeza

Grados recibidos: B. A. / L. A. / M. A.

8-12-1571 Mtro. Gaspar de Salcedo graduó a su discípulo 
25-2-1573 Responsiones magnas o acto mayor para L. A. 18-9-1573 Presidió Mtro. Salcedo y pasó 30-10-1573 Repetición para L. A. Presidió su Mtro. y pasó

31-10-1573 Examen secreto ante el Rector Almagro y presidió el Mtro. Vilches y aprobó; aunque nunca M. A.

29-11-1573 Canciller Pedro de la Hoya le dio el grado de L. A. 13-4-1578 Actos para L.T. Presidió el Dr. Salcedo: aprobó por bueno 11-10-1578 Informaciones para M. A. para admitirlo sin aditamentos 13-10-1578 Canciller Fr. Diego Ocón le otorgó el grado de M. A. 13-5-1579 Tentativa para L.T. Presidió el Dr. Salcedo y aprobó Juan Núñez not. y secr.; Mtro. Luis Molina, secr.

Referencias: 137r, 148r, 151r, 154r, 154v, 209v, 217v, 218r, 236v

\section{PEDRO DE TORRES}

Vecino de Rus, diócesis de Jaén Grados recibidos: B. A. / L. A. / M. A. / B. T.

8-12-1571 Mtro. Gaspar de Salcedo graduó a su discípulo 10-3-1573 Acto mayor para L. A. Presidió su Mtro. y aprobó 13-10-1573 Repetición presidida por su Mtro. y aprobó 18-10-1573 Examen secreto ante el Rector Almagro 19-10-1573 Aprobó el examen de L. A. 29-11-1573 Canciller Pedro de la Hoya le dio el grado 6-5-1576 Antonio de Raya le dio el grado de M. A. 15-5-1579 Tentativa magna para B. T. presidida por Dr. Salcedo y aprobó 19-5-1579 Se le dio el grado de B. T.

Juan Núñez not. y secr.; Molina, sec. y not.

Referencias: 137r, 148v, 153r, 153v, 154v, 176v, 236v, 237v

\section{FRANCISCO DE MÉRIDA}

Vecino de Alcaudete

Grados recibidos: B. A. / L. A.

8-12-1571 Mtro. Gaspar de Salcedo graduó a su discípulo 1-4-1573 Acto mayor para L.A. Presidió su Mtro. y aprobó

2-10-1573 Repetición para L.A. Presidió su Mtro. y aprobó

9-10-1573 Examen secreto ante el Rector Almagro

10-10-1573 Presidió Mtro. Cavallería y aprobó

29-11-1573 Canciller Pedro de la Hoya le dio el grado

Juan Núñez not. y secr.

Referencias: 137r, 149r, 152r, 152v, 154v 


\section{SEBASTIÁN DE LARA}

Vecino de Úbeda

Grado recibido: B. A.

8-12-1571 Mtro. Gaspar de Salcedo graduó a su discípulo Juan Núñez not. y secr.

Referencia: $137 \mathrm{r}$

\section{BARTOLOMÉ REDONDO}

Vecino de Úbeda

Grado recibido: B. A.

8-12-1571 Mtro. Gaspar de Salcedo graduó a su discípulo Juan Núñez not. y secr.

Referencia: $137 \mathrm{r}$

\section{JUAN ALCALDE}

Vecino de Torrecampo, diócesis de Jaén

Grados recibidos: B. A. / L. A. / M. A. / B. T.

8-12-1571 Mtro. Gaspar de Salcedo graduó a su discípulo 6-3-1573 Acto mayor para L. A. presidido por su Mtro. y aprobó 28-9-1573 Repetición para L. A. Presidió su Mtro. y aprobó 5-10-1573 Examen secreto ante el Mtro. Vilches que presidió y aprobó 6-10-1573 El Canciller Pedro de la Hoya le dio el grado 29-11-1573 Dr. Antonio de Raya le dio el grado 6-5-1576 Actos para B. T. 5-3-1578 Dr. Pérez de Valdivia le dio el grado Juan Núñez not. y secr.; Dr. Molina, not. y secret.

Referencias: 137r, 148r, 151v, 152r, 152v, 154v, 176v, 205r

\section{JUAN GÓMEZ}

Vecino de Begijar

Grados recibidos: B. A. / L. A. 8-12-1571 Mtro. Gaspar de Salcedo graduó a su discípulo 28-4-1573 Acto mayor para L. A. Presidió su Mtro. y aprobó 16-10-1573 Repetición para L. A. Presidió su Mtro. y aprobó 22-10-1573 Examen secreto ante el Rector Almagro 23-10-1573 Presidió el Dr. Ojeda y aprobó 29-11-1573 Canciller Pedro de la Hoya le dio el grado Juan Núñez not. y secr.

Referencias: 137r, 149v, 153r, 153v, 154v 


\section{BENITO DE LOSADA}

Vecino de Jaén

Grado recibido: B. A.

8-12-1571 Mtro. Gaspar de Salcedo graduó a su discípulo

Juan Núñez not. y secr.

Referencia: $137 \mathrm{r}$

ANDRÉS DE LA META

Vecino de Alhambra

Grados recibidos: B. A. / L. A.

8-12-1571 Mtro. Gaspar de Salcedo graduó a su discípulo

7-4-1573 Acto mayor: presidió su Mtro.

9-10-1573 Repetición presidida por su Mtro. y aprobó

16-10-1573 Examen secreto ante el Rector Almagro

17-10-1573 Presidió el Dr. Urrutia y aprobó y dijo que no se le diese el grado hasta que tuviera manteo y bonete

29-11-1573 El canciller Pedro de la Hoya le dio el grado

Juan Núñez not. y secr.

Referencias: 137r, 149r, 152r, 153r, 154v

\section{ALONSO DE BAEZA}

Vecino de Baeza

Grado recibido: B. A.

8-12-1571 Mtro. Gaspar de Salcedo graduó a su discípulo

31-12-1579 Responsiones magnas para L. A. Presidió Mtro. Pedraza y aprobó

Juan Núñez not. y secr.; Luis de Molina, secretario

Referencias: $137 \mathrm{r}, 248 \mathrm{r}$

\section{LUIS DE NAVARRETE}

Vecino de Baeza

Grado recibido: B. A.

8-12-1571 Mtro. Gaspar de Salcedo graduó a su discípulo

Juan Núñez not. y secr.

Referencia: $137 \mathrm{r}$

\section{ANTONIO GÓMEZ}

Vecino de Elvas (Portugal)

Grados recibidos: B. A. / L. A. / M. A. / B. T.

8-12-1571 Mtro. Gaspar de Salcedo graduó a su discípulo

27-2-1573 Acto mayor presidido por su Mtro. y aprobó 
23-9-1573 Repetición presidida por su Mtro. y aprobó 30-9-1573 Capítulos para examen secreto ante el Rector Almagro que presidió y aprobó el grado 1-10-1573 Canciller Pedro de la Hoya le dio el grado de L. A. 29-11-1573 Dr. Antonio de Raya le dio el grado de M. A. 6-5-1576 Lecciones para L. T. 3-6-1577 Tentativa parva 10-6-1577 Le dio el grado el Dr. Pedro de Almagro, catedrático de Sto. Tomás Juan Núñez not. y secr.; Mtro. Luis de Molina

Referencias: 137r, 148r, 151v, 154v, 194rv

\section{JUAN MANJÓN}

Vecino de Baeza

Grado recibido: B. A.

8-12-1571 Mtro. Gaspar de Salcedo graduó a su discípulo Juan Núñez not. y secr.

Referencia: $137 \mathrm{r}$

\section{ANDRÉS DE ÁLAVA}

B. A. Vecino de Cazorla 24-3-1572 Responsiones magnas para L. A. Presidió su Mtro. Almagro y aprobó Juan Núñez, not. y secr.

Referencia: $140 \mathrm{O}$

\section{GIL RAMÍREZ DE ÁVALOS}

Vecino de Baeza

Grados recibidos: B. A. / L. A. / M. A. 26-3-1572 Acto para B. A. Presidió el Dr. Ávila le dio el grado 30-9-1573 Acto mayor para L. A. Presidió el Mtro. Vilches y aprobó 7-12-1573 Repetición para L. A. Presidió Mtro. Urrutia y aprobó 22-12-1573 Examen secreto ante el Rector Almagro 23-12-1573 Presidió Mtro. Urrutia y aprobó el grado 2-1-1574 Canciller Fr. Pedro de la Hoya le dio el grado de L.A. 31-1-1574 Canciller Fr. Pedro de la Hoya le dio el grado de M. A. Juan Núñez not. y secr.

Referencias: 140v, 151v, 155v, 156r

\section{DIEGO DE MONTANOS}

Grados recibidos: B. A. / L. A. 24-10-1572 Presidió su Mtro. Almagro una repetición para L. A. y aprobó 
2-12-1572 El Dr. Ojeda, vicerrector, dio capítulos para examen secreto 3-12-1572 Ojeda presidió y aprobó L. A.

29-3-1573 Canciller P. de Arias le dio el grado

Juan Núñez not. y secr.

Referencias: 144v, 145r, 148v

MELCHOR DE PERALTA

Grados recibidos: M. A. / B. T.

1-12-1572 Lecciones para B. T.

5-12-1572 El Dr. Ojeda dio el grado de B. T.

Juan Núñez not. y secr.

Referencia: $145 \mathrm{v}$

\section{FRANCISCO DE MOLINA}

Vecino de Baeza

Grados recibidos: B. A.

19-12-1572 Acto para B. A. Presidió el Dr. Ojeda y el Mtro. Blas de Cavallería dio el grado al discípulo

21-12-1572 Repetición

Juan Núñez, not. y secr.

Referencia: 146r

JUAN DE ZAMBRANA

Vecino de Cambil

Grado recibido: B. A.

19-12-1572 Acto para B. A. Presidió el Dr. Ojeda y el Mtro. Cavallería dio el grado al discípulo

Juan Núñez, not. y secr.

Referencia: $146 \mathrm{r}$

FRANCISCO DE AGUDO

Vecino de Almodóvar

Grado recibido: B. A.

19-12-1572 Acto para B. A. Presidió el Dr. Ojeda y el Mtro. Cavallería dio el grado al discípulo

Juan Núñez, not. y secr.

Referencia: $146 \mathrm{r}$

HERNANDO DE PLAZA

Vecino de Villarrobledo 
Grado recibido: B. A.

19-12-1572 Acto para B. A. Presidió el Dr. Ojeda y el Mtro. Cavallería dio el grado al discípulo

Juan Núñez, not. y secr.

Referencia: $146 \mathrm{r}$

\section{MARTÍN CANTERO}

Clérigo. Vecino de Baeza

Grados recibidos: B. A. / L. A. / M. A. / B. T.

19-12-1572 Acto para B. A. Presidió el Dr. Ojeda y el Mtro. Cavallería dio el grado al discípulo 30-3-1574 Acto mayor que presidió su Mtro.

6-10-1574 Repetición para L. A. y aprobó 10-10-1574 Examen secreto ante el Dr. Pérez. Presidió el Dr. Salcedo y aprobó 11-10-1574 Canciller Fr. Alonso de Rojas le otorgó el grado 10-3-1577 Leyó lecciones para B. T.

27-10-1578 Tentativa magna para B. T. Presidió el Rector Salcedo y aprobó simpliciter

29-10-1578 Rector G. de Salcedo le otorgó el grado

18-5-1578 Magna ordinaria para L. T. Presidió el Dr. Pedraza y aprobó simpliciter Juan Núñez, not. y secr.; Luis Molina secr.

Referencias: 146r, 147v, 162r, 162v, 219rv, 26ov

\section{CRISTÓBAL LÓPEZ DE DONMARCOS}

Vecino de Porcuna

Grado recibido: B. A.

19-12-1572 Presidió el Dr. Ojeda y el Mtro. Cavallería dio el grado al discípulo

Juan Núñez, not. y secr.

Referencia: $146 \mathrm{r}$

\section{JUAN DE SORIA OCHOA}

Vecino de Baeza

Grados recibidos: B. A. / L. A. / M. A. / B. T.

19-12-1572 Presidió el Dr. Ojeda y el Mtro. Cavallería dio el grado al discípulo

19-3-1574 Acto mayor que presidió su Mtro. y aprobó

7-10-1574 Examen secreto ante el Dr. Pérez que señaló puntos y presidió el Dr. Almagro y le dio el grado

8-10-1574 Canciller Fr. Alonso de Rojas le otorgó el grado

10-3-1577 Tentativa magna para B. T. Presidió el Rector Salcedo y aprobó simpliciter 
4-2-1579 Lecciones para B. T.

18-2-1579 Rector Salcedo le dio el grado

Juan Núñez, not. y secr.; Mtro. Molina, not y secr.

Referencias: 146r, 157v, 162r, 189r, 230r, 231r

\section{JUAN FERNÁNDEZ}

Vecino de Iruela

Grado recibido: B. A.

19-12-1572 Presidió el Dr. Ojeda y el Mtro. Cavallería dio el grado al discípulo Juan Núñez, not. y secr.

Referencia: $146 \mathrm{r}$

JUAN DE VEGA

Vecino de Baeza

Grado recibido: B. A.

19-12-1572 Presidió el Dr. Ojeda y el Mtro. Cavallería dio el grado al discípulo Juan Núñez, not. y secr.

Referencia: $146 \mathrm{r}$

PEDRO MUÑOZ

Vecino de Jaén

Grado recibido: B. A.

19-12-1572 Presidió el Dr. Ojeda y el Mtro. Cavallería dio el grado al discípulo Juan Núñez, not. y secr.

Referencia: $146 \mathrm{r}$

DIEGO DE ZAMBRANA

Vecino de Cambil

Grado recibido: B. A.

19-12-1572 Presidió el Dr. Ojeda y el Mtro. Cavallería dio el grado al discípulo Juan Núñez, not. y secr.

Referencia: $146 \mathrm{r}$

TOMÁS DE PERALES

Vecino de Bailén

Grado recibido: B. A.

19-12-1572 Presidió el Dr. Ojeda y el Mtro. Cavallería dio el grado al discípulo Juan Núñez, not. y secr.

Referencia: $146 \mathrm{r}$ 


\section{RODRIGO DE GUARDIA}

Vecino de Bailén

Grado recibido: B. A.

19-12-1572 Presidió el Dr. Ojeda y el Mtro. Cavallería dio el grado al discípulo Juan Núñez, not. y secr.

Referencia: $146 \mathrm{r}$

\section{JUAN DE PEDRAZA}

Vecino de Baeza

Grados recibidos: B. A. / L. A.

19-12-1572 Presidió el Dr. Ojeda y el Mtro. Cavallería dio el grado al discípulo 9-3-1574 Acto mayor para L. A. Presidió su Mtro.

22-9-1574 Repetición para L. A. que presidió su Mtro. y aprobó

26-9-1574 Acto secreto ante el Rector Pérez

27-9-1574 Presidió el Dr. Ojeda y aprobó el grado

Juan Núñez, not. y secr.

Referencias: 146v, 156v, 161r

JUAN RUIZ DE RIBERA

Vecino de Almagro

Grado recibido: B. A.

19-12-1572 Presidió el Dr. Ojeda y el Mtro. Cavallería dio el grado al discípulo Juan Núñez, not. y secr.

Referencia: $146 \mathrm{r}$

\section{MARTÍN FERNÁNDEZ DE LA PUERTA}

Vecino de Cambil

Grados recibidos: B. A. / L. A.

19-12-1572 Presidió el Dr. Ojeda y el Mtro. Cavallería dio el grado al discípulo 15-10-1574 Repetición para L. A. presidida por su Mtro. y aprobó

20-10-1574 Examen secreto ante el Rector Pérez que presidió el Mtro. Peralta y aprobó; aunque no de Mtro.

21-10-1574 Recibió el grado de L.A.

Juan Núñez, not. y secr.

Referencias: 146v, $163 \mathrm{r}$

\section{ALONSO DE REYNOSO}

Vecino de Baeza

Grado recibido: B. A.

19-12-1572 Presidió el Dr. Ojeda y el Mtro. Cavallería dio el grado al discípulo 
4-5-1574 Acto mayor para L.A. y presidió su Mtro. y aprobó Juan Núñez, not. y secr.

Referencias: 146v, 159r

\section{FRANCISCO DE TORRES}

Vecino de Baeza

Grados recibidos: B. A. / L. A. / M. A.

19-12-1572 Presidió el Dr. Ojeda y el Mtro. Cavallería dio el grado al discípulo

2-4-1572 Acto mayor presidido por su Mtro. y aprobó

12-10-1574 Repetición para L.A. que presidió el Dr. Cavallería, su Mtro. y aprobó 14-10-1574 Examen secreto ante el Rector Pérez, que presidió el Dr. Urrutia y aprobó

15-10-1574 Acuerdo sobre el grado de Magisterio: terminada la Teología se hiciese informe sobre moribus

19-2-1577 Canciller Alonso de Rojas le otorgó el grado de M. A.

3-3-1577 Magna ordinaria para L.T. Presidió el Dr. Becerra y aprobó

Juan Núñez, not. y secr.; Mtro. Molina. not. y secr.

Referencias: 146v, 157v, 162v, 163r, 188v, 189r

MIGUEL SALCEDO

Vecino de Arjona

Grado recibido: B. A.

19-12-1572 Presidió el Dr. Ojeda y el Mtro. Cavallería dio el grado al discípulo 12-3-1572 Acto mayor que presidió su Mtro.

Juan Núñez, not. y secr.

Referencias: 146v, 156v

\section{ALONSO DÍAZ DE SORIA}

Vecino de Jaén

Grado recibido: B. A.

19-12-1572 Presidió el Dr. Ojeda y el Mtro. Cavallería dio el grado al discípulo 12-3-1574 Acto mayor para L.A. Presidió su Mtro.

28-9-1574 Repetición para L. A. Presidió su Mtro. y aprobó

Juan Núñez, not. y secr.

Referencias: 146v, 157r, 161v

\section{ALONSO DE HERRERA}

Vecino de Jaén

Grado recibido: B. A.

19-12-1572 Presidió el Dr. Ojeda y el Mtro. Cavallería dio el grado al discípulo 
Juan Núñez, not. y secr.

Referencia: $146 \mathrm{r}$

HERNANDO [FERNANDO] MERINO

Vecino de Villacarrillo

Grado recibido: B. A.

19-12-1572 Presidió el Dr. Ojeda y el Mtro. Cavallería dio el grado al discípulo Juan Núñez, not. y secr.

Referencia: $146 \mathrm{r}$

CRISTÓBAL DE RIBERA

Vecino de Lahiguera

Grado recibido: B. A.

19-12-1572 Presidió el Dr. Ojeda y el Mtro. Cavallería dio el grado al discípulo Juan Núñez, not. y secr.

Referencia: $146 \mathrm{r}$

JUAN MARÍN

Vecino de Arjonilla

Grado recibido: B. A.

19-12-1572 Presidió el Dr. Ojeda y el Mtro. Cavallería dio el grado al discípulo Juan Núñez, not. y secr.

Referencia: $146 \mathrm{r}$

FRANCISCO MACÍAS

Vecino de Andújar

Grado recibido: B. A. / L. A.

19-12-1572 Presidió el Dr. Ojeda y el Mtro. Cavallería dio el grado al discípulo 26-8-1574 Acto mayor: presidió su Mtro. y aprobó

22-10-1574 Repetición que presidió su Mtro. y aprobó

24-10-1574 Examen secreto ante el Dr. Ojeda, que presidió y aprobó

Juan Núñez, not. y secr.

Referencias: 146v, 160v, $163 \mathrm{v}$

\section{ALONSO GUTIÉRREZ}

Grado recibido: B. A.

19-12-1572 Presidió el Dr. Ojeda y el Mtro. Cavallería dio el grado al discípulo Juan Núñez, not. y secr.

Referencia: $146 \mathrm{r}$ 


\section{PEDRO MUÑOZ DE BALLESTEROS}

Vecino de Almedina

Grado recibido: B. A.

19-12-1572 Presidió el Dr. Ojeda y el Mtro. Cavallería dio el grado al discípulo Juan Núñez, not. y secr.

Referencia: $146 \mathrm{r}$

\section{JUAN OCHOA}

Vecino de Baeza

Grado recibido: B. A.

19-12-1572 Presidió el Dr. Ojeda y el Mtro. Cavallería dio el grado al discípulo Juan Núñez, not. y secr.

Referencia: $146 \mathrm{r}$

\section{PEDRO MEXÍA}

Clérigo. Vecino de Villanueva del Arzobispo

Grado recibido: B. A.

19-12-1572 Presidió el Dr. Ojeda y el Mtro. Cavallería dio el grado al discípulo Juan Núñez, not. y secr.

Referencia: $146 \mathrm{r}$

\section{MELCHOR DE SORIA}

\section{Vecino de Jaén}

Grado recibido: B. A.

19-12-1572 Presidió el Dr. Ojeda y el Mtro. Cavallería dio el grado al discípulo Juan Núñez, not. y secr.

Referencia: $146 \mathrm{r}$

\section{FRANCISCO DE ESPINOSA}

Vecino de Jaén

Grado recibido: B. A.

8-6-1573 Presidió Mtro. Salcedo, que le dio el grado

Ldo. Núñez, secr.

Referencia: $149 \mathrm{v}$

\section{GASPAR DE GODOY}

L.A. por Sevilla. Vecino de Úbeda

Grados recibidos: M. A. / B. T.

16-6-1573 L. A. Incorporación

22-6-1573 Acto mayor de Artes y presidió el Mtro. Salcedo y aprobó L. A. 
30-8-1573 Petición al grado de Magisterio en la Universidad de Baeza 3-5-1575 Canciller Juan de Arias le otorgó el grado 25-5-1575 Tentativa parva para B.T. Presidió el Dr. Cavallería y aprobó 10-6-1577 Lecciones para B. T. El Dr. Gaspar de Salcedo le dio el grado Ldo. Núñez, secr.; Mtro. Molina, secr.

Referencias: 15or, 150v, 151r, 165v, 193v, 195r

\section{LUIS DE NAVARRETE}

Vecino de Baeza

Grado recibido: B. A. / L. A. / M. A. 30-11-1573 Mtro. Álvaro de Vilches, Catedr. de Artes, dio el grado a su discípulo 31-5-1575 Responsiones magnas para L. A. Presidió su Mtro. y aprobó 26-6-1577 Examen secreto ante el Rector 27-6-1577 Presidió Mtro. Gaspar de Godoy y aprobó 3-4-1580 Canciller Fr. Alonso de Rojas le dio el grado Canciller Fr. Fernando de Montesinos, O. de M., le dio el grado Ldo. Núñez notario; Mtro. Molina, not.

Referencias: 155r, 168v, 195v, $247 \mathrm{v}$

\section{HERNANDO GONZÁLEZ}

\section{Vecino de Baeza}

Grado recibido: B. A. 30-11-1573 Mtro. Álvaro de Vilches dio el grado a su discípulo

Ldo. Núñez, notario

Referencia: $155 \mathrm{r}$

\section{FRANCISCO DE ANDRADA VALENCIA}

Vecino de Baeza

Grado recibido: B. A. / L. A. / M. A. / B. T.

30-11-1573 Mtro. Álvaro de Vilches dio el grado a su discípulo

27-4-1577 Responsiones magnas L.A. Presidió el Dr. Almagro. Aprobó el acto por bueno

13-3-1578 Repetición presidida por el mismo y aprobó

20-3-1578 Examen secreto ante el Rector Pérez

21-3-1578 Presidió el Dr. Pedraza y aprobó. En cuanto al M.A., una tentativa magna 9-4-1578 Canciller Diego de Ocón, O.SS.T, le dio el grado

26-6-1579 Tentativa magna para B. T. Presidió Fr. Diego de Ocón y aprobó simpliciter

25-8-1579 Fr. Fernando Montesinos, Canciller

31-8-1579 Lecciones para B. T. Dr. Pedro de Ojeda le dio el grado 
Ldo. Núñez, notario; Mtro. Molina, not.

Referencias: 155r, 191v, 204v, 206r, 208r, 239rv, 240r

FRANCISCO DE MOLINA

Vecino de Úbeda

Grado recibido: B. A.

30-11-1573 Mtro. Álvaro de Vilches, dio el grado a su discípulo

15-4-1575 Responsiones magnas para L. A., que presidió su Mtro.

9-3-1576 Repetición para L. A. Presidió Mtro. Peralta y aprobó

Ldo. Núñez notario; Mtro. Molina, not. secr.

Referencias: 155r, 164v, 174r

JUAN DE XODAR

Vecino de Baeza

Grado recibido: B. A.

30-11-1573 Mtro. Vilches dio el grado a su discípulo

Ldo. Núñez, notario

Referencia: $155 \mathrm{r}$

\section{LUIS SALIDO}

Vecino de Santisteban

Grado recibido: B. A.

30-11-1573 Mtro. Vilches dio el grado a su discípulo

Ldo. Núñez, notario

Referencia: $155 \mathrm{r}$

\section{ALONSO DE NAVARRETE}

Vecino de Baeza

Grado recibido: B. A.

30-11-1573 Mtro. Vilches dio el grado a su discípulo

Ldo. Núñez, notario

Referencia: $155 \mathrm{r}$

\section{ALONSO REDONDO CRESPO}

Vecino de Úbeda

Grado recibido: B. A. / L. A.

30-11-1573 Mtro. Vilches dio el grado a su discípulo

20-5-1575 Responsiones magnas. Presidió el Dr. Almagro y aprobó

24-10-1575 Repetición para L. A. Presidió el Dr. Cavallería y aprobó

25-10-1575 Examen secreto ante el Rector Sepulveda. Presidió el Dr. Almagro 
26-10-1575 Aprobó el grado

5-2-1576 Canciller Fr. Alonso de Rojas le dio el grado

Ldo. Núñez, not.; Mtro. Molina, secr.; Mtro. Gaspar de Godoy; Mtro. Molina, secr.

Referencias: 155r, 168r, 172v, 173r, 173v

JUAN SALCEDO

Vecino de Baeza

Grados recibidos: B. A. / L. A.

30-11-1573 Mtro. Vilches dio el grado a su discípulo

30-9-1575 Repetición para L. A. Presidió Mtro. Peralta y aprobó

9-10-1575 Ante el Rector F. de Sepúlveda pidió examen secreto para L. A.

10-10-1575 Presidió el Dr. Salcedo y aprobó; pero del magisterio no se le de hasta de oy en quarenta años

5-2-1576 Canciller Fr. Alonso de Rojas le dio el grado

Ldo. Núñez, not. y Mtro. Molina, not.

Referencias: 155r, 170v, 173v

FRANCISCO MERINO

Vecino de Cazorla

Grado recibido: B. A.

30-11-1573 Mtro. Vilches dio el grado a su discípulo

Ldo. Núñez, notario

Referencia: $155 \mathrm{r}$

FRANCISCO DE BRIVIESCA

Vecino de Baeza

Grado recibido: B. A.

30-11-1573 Mtro. Vilches dio el grado a su discípulo

Ldo. Núñez, notario

Referencia: $155 \mathrm{r}$

FRANCISCO RODRÍGUEZ

Vecino de Castellar

Grado recibido: B. A.

30-11-1573 Mtro. Vilches dio el grado a su discípulo

Ldo. Núñez, notario

Referencia: $155 \mathrm{r}$

JUAN MORENO

Vecino de Baeza 
Grado recibido: B. A.

30-11-1573 Mtro. Vilches dio el grado a su discípulo

Ldo. Núñez, notario

Referencia: $155 \mathrm{r}$

JUAN DE MAGAÑA

Vecino de Jaén

Grado recibido: B. A.

30-11-1573 Mtro. Álvaro de Vilches dio el grado a su discípulo

4-5-1574 El Rector Almagro le dio el grado por pobre

Ldo. Núñez, notario

Referencias: 155r, 159v

\section{PEDRO GUTIÉRREZ}

Vecino de Jaén

Grado recibido: B. A.

30-11-1573 Mtro. Vilches dio el grado a su discípulo

13-4-1575 Responsiones magnas para L. A. presididas por el Dr. Cavallería

3-8-1576 Repetición para L. A. Presidió Mtro. Godoy, que se suspenda el examen secreto

Ldo. Núñez, notario; Mtro. Molina, secr.

Referencias: 155r, 164v, 179v

\section{ANDRÉS DE ALBANCHEZ}

Vecino de Baeza

Grados recibidos: B. A. / L. A.

30-11-1573 Mtro. Vilches dio el grado a su discípulo

13-5-1575 Responsiones magnas para L. A.

20-10-1575 Presidió Mtro. Melchor de Peralta y aprobó

23-10-1575 Repetición para L. A. Presidió el Dr. Salcedo, aprobó aunque tibio

24-10-1575 Examen secreto ante el Rector Sepúlveda para L. A. Presidió el Dr.

Pedraza y aprobó; pero... de M. A. si en ocho años...

5-2-1576 Canciller Fr. Alonso de Rojas le dio el grado de L. A.

Ldo. Núñez, notario; Mtro. Molina, not.

Referencias: 155r, 166r, 171v, 173r, 173v

\section{GONZALO GUTIÉRREZ}

Vecino de Jaén

Grados recibidos: B. A. / L. A.

30-11-1573 Mtro. Vilches dio el grado a su discípulo 
17-5-1575 Responsiones magnas para L. A. que presidió el Dr. Almagro y aprobó 6-10-1575 Repetición para L. A. Presidió Mtro. Pedraza y aprobó 13-10-1575 Gracia de derechos por pobre

14-10-1575 Examen secreto ante el Rector Sepúlveda para L. A., que presidió el Dr. Cavallería y aprobó 5-2-1576 Canciller Fr. Alonso Rojas le dio el grado Ldo. Núñez, notario; Mtro. Molina. Secr.

Referencias: 155r, 166v, 170r, 171r, 173v

BERMUDO/ BDO. SALIDO

Vecino de Baeza

Grado recibido: B. A. 30-11-1573 Mtro. Vilches dio el grado a su discípulo Ldo. Núñez, notario

Referencia: $155 \mathrm{r}$

JUAN FERNÁNDEZ DE MOLINA

Vecino de Torrejimeno

Grado recibido: B. A. 30-11-1573 Mtro. Vilches dio el grado a su discípulo Ldo. Núñez, notario Referencia: $155 \mathrm{r}$

JUAN GARRIDO

Vecino de Santisteban

Grado recibido: B. A. 30-11-1573 Mtro. Vilches dio el grado a su discípulo 23-3-1576 Responsiones magnas para L. A. que presidió el Dr. Salcedo y aprobó Ldo. Núñez not.; Mtro. Molina, not y secr.

Referencias: $155 \mathrm{r}, 174 \mathrm{v}$

GINÉS DE ROBLES

Vecino de Úbeda

Grado recibido: B. A.

30-11-1573 Mtro. Vilches dio el grado a su discípulo

Ldo. Núñez, notario

Referencia: $155 \mathrm{r}$

FRANCISCO / RODRIGO HURTADO

Vecino de Jaén 
Grados recibidos: B. A. / L. A.

30-11-1573 Mtro. Vilches dio el grado a su discípulo

7-5-1576 Repetición para L. A. Presidió su Mtro. y aprobó

28-5-1576 Examen secreto ante el Rector Sepúlveda

29-5-1576 Presidió el Dr. Salcedo y aprobó L. A.; para M. A. es necesaria una tentativa magna

4-6-1576 Fr. Alonso de Rojas le dio el grado

Ldo. Núñez notario; Mtro. Luis de Molina. secr. y not.; Mtro. Molina, not.

Referencias: 155r, 177r, 178v, 179r

\section{PEDRO CAÑETE DE GODOY}

Vecino de Úbeda

Grados recibidos: B. A. / L. A. / M. A.

30-11-1573 Mtro. Vilches dio el grado a su discípulo

22-3-1575 Responsiones magnas para L. A. presidido por el Dr. Almagro y aprobó

27-9-1575 Repetición para L. A. Presidió el Dr. Cavallería y aprobó

6-10-1575 Ante el Rector Sepúlveda examen secreto, que presidió el Dr. Almagro y aprobó

7-10-1575 Canciller Fr. Alonso de Rojas le dio el grado de L. A.

5-2-1576 Recibió el grado de M. A.

9-11-1579 Tentativa magna para B. T. Presidió el Dr. Becerra y aprobó

15-11-1579 Canciller Fr. Fernando Montesinos dio el grado

Ldo. Núñez notario; Mtro. Molina, not.

Referencias: 155r, 164r, 169v, 170r, 173v, 245r, 246v.

DIEGO DE BARRERA

Vecino de Baeza

Grado recibido: B. A.

30-11-1573 Mtro. Vilches dio el grado a su discípulo

Ldo. Núñez, notario

Referencia: $155 \mathrm{r}$

DIEGO DE NAVARRETE MELLADO

Vecino de Baeza

Grado recibido: B. A.

30-11-1573 Mtro. Vilches dio el grado a su discípulo

Ldo. Núñez, notario

Referencia: $155 \mathrm{r}$

FERNANDO GARRIDO DE SALCEDO

Natural de Baeza 
Grados recibidos: B. A. / L. A. / M. A. / B. T.

30-11-1573 Mtro. Vilches dio el grado a su discípulo

4-6-1575 Responsiones magnas para L. A. Presidió el Dr. Salcedo y aprobó

17-10-1575 Repetición para L. A. Presidió el Dr. Almagro y aprobó

19-10-1575 Examen secreto ante el Rector Sepúlveda. Presidió el Mtro. de Godoy y aprobó

20-10-1575 Canciller Fr. Alonso de Rojas le dio el grado

5-2-1576 Canciller Fr. Diego Ocón le otorgó el grado

13-10-1578 Lecciones para B. $\mathrm{T}$.

10-10-1579 Tentativa magna para B.T. Presidió el Dr. Becerra, aprobó simpliciter, y le dio el grado

Ldo. Núñez not.; Mtro. Molina, not.

Referencias: 155r, 168v, 171v, 172r, 173v, 218r, $243 \mathrm{rv}$

GERÓNIMO DÍEZ

Vecino de Jaén

Grado recibido: B. A.

30-11-1573 Mtro. Vilches dio el grado a su discípulo

Ldo. Núñez, notario

Referencia: $155^{\mathrm{r}}$

FRANCISCO DE HERRERA

Vecino de Jaén

Grado recibido: B. A.

30-11-1573 Mtro. Vilches dio el grado a su discípulo

Ldo. Núñez, notario

Referencia: $155 \mathrm{r}$

MIGUEL DE VALCÁRCEL

Vecino de Baeza

Grado recibido: B. A.

30-11-1573 Mtro. Vilches dio el grado a su discípulo

Ldo. Núñez, notario

Referencia: $155 \mathrm{r}$

JORGE DE CUEVAS

Vecino de Úbeda

Grado recibido: B. A.

30-11-1573 Mtro. Vilches dio el grado a su discípulo

Ldo. Núñez, notario

Referencia: $155 \mathrm{r}$ 


\section{SALVADOR DE SABIOTE}

Vecino de Úbeda

Grado recibido: B. A.

30-11-1573 Mtro. Vilches dio el grado a su discípulo

Ldo. Núñez, notario

Referencia: $155 \mathrm{r}$

\section{LUIS DE NÚÑEZ ÁLVAREZ}

Vecino de Baeza

Grado recibido: B. A.

30-11-1573 Mtro. Vilches dio el grado a su discípulo

Ldo. Núñez, notario

Referencia: $155 \mathrm{r}$

\section{GASPAR DE SALCEDO [MTRO. SALCEDO]}

Vecino de Baeza

Grados recibidos: L. T. / D. T.

17-1-1574 Acto de Teología: Magna Ordinaria para L. T. Presidió el Dr. Ojeda y aprobó

23-3-1574 Acto segundo para L.T. Presidió el Rector Almagro y aprobó 29-4-1574 Acto para L. T.

12-5-1574 Acto para L.T. Presidió el Rector Almagro y aprobó

21-5-1574 Examen secreto

22-5-1574 Presidió el Dr. Carleval y alcanzó el grado de L. T.

26-5-1574 Alcanzó el grado de D. T.

6-6-1574 El Canciller Pedro de Arias le otorgó ambos grados

Ldo. Núñez, notario

Referencias: 155v, 157v, 159rv, 16ov

\section{DIEGO DELGADILLO}

Vecino de Jaén

Alumno del Colegio de Sta. Catalina de Jaén y discípulo de Fr. Alonso Farfan

Grado recibido: B. A.

22-3-1575 Pidió el Rector Ojeda ser examinado para B. A.

23-3-1575 Presidió el Dr. Gaspar de Salcedo y le dio el grado

Mtro. Molina, secr.

Referencia: $164 \mathrm{r}$

JUAN DE SALCEDO

Vecino de Baeza, B. A. 
25-3-1575 Responsiones magnas para L. A. Presidió el Dr. Cavallería Mtro. Molina, secr.

Referencia: $164 \mathrm{~V}$

\section{FERNANDO GONZÁLEZ}

B. A. Vecino de Huéscar

Grado recibido: L. A.

23-4-1575 Responsiones magnas para L. A. Presidió su Mtro. Vilches y aprobó 16-10-1575 Examen secreto para L.A. ante el Rector F. de Sepúlveda

17-10-1575 Presidió el Mtro. Peralta y aprobó

5-2-1576 Canciller Fr. Alonso de Rojas le dio el grado

Mtro. Molina, secr.

Referencias: 165r, 171r, $173 \mathrm{v}$

\section{FRANCISCO CERÓN}

Grado recibido: B. A.

17-5-1575 Dr. Gaspar de Salcedo presidió y diole el grado

Mtro. Molina

Referencia: $166 \mathrm{v}$

\section{RODRIGO ÁLVAREZ BRIZEÑO}

Vecino de Baeza

Grados recibidos: B. A. / L. A. / M. A.

15-5-1575 Dr. Gaspar de Salcedo, Catedrático de Artes, dio el grado a su discípulo 30-3-1575 Responsiones magnas L. A. Presidió su Mtro. Aprobó simpliciter y por mediano

4-4-1578 Examen secreto ante el Rector Pérez, que presidió

5-4-1578 Aprobó simpliciter

9-4-1578 Canciller Diego de Ocón le dio el grado de L.A.

4-1-158o Canciller Fr. Juan de Vilches le dio el grado de M.A.

Mtro. Luis de Molina, notario

Referencias: 167r, 190v, 207r, 208r, 256v

\section{ANDRÉS FERNÁNDEZ}

Natural de Jaén

Grados recibidos: B. A. / L. A.

15-5-1575 Dr. Gaspar de Salcedo dio el grado a su discípulo

30-3-1576 Responsiones magnas para L. A. Presidió su Mtro. y aprobó

6-10-1576 Repetición para L. A., que presidió su Mtro. y aprobó

19-10-1576 Petición para examen secreto para L. A. 
20-10-1576 Presidió el Mtro. Peralta y aprobó

21-10-1576 Fr. Alonso de Rojas le dio el grado

Mtro. Luis de Molina, not.

Referencias: 167r, 175r, 180v, 181r, 181v, 183r

\section{LÁZARO PALOMINO}

Vecino de Baeza

Grados recibidos: B. A. / L. A. / M. A.

15-5-1575 Dr. Salcedo dio el grado a su discípulo

21-3-1576 Para L. A. Acto mayor

1-10-1576 Responsiones magnas que presidió su Mtro. y aprobó

2-10-1576 Examen secreto para L.A. ante el Rector Córdoba

21-10-1576 Presidió el Dr. Cavallería y aprobó. Fr. Alonso de Rojas le dio el grado de L. A.

26-4-158o Canciller Fr. Juan de Vilches le dio el grado de M. A.

Mtro. Luis de Molina, not.

Referencias: 167r, 174v, 180r, 183r, 258r

\section{DIEGO DE PEDRAZA}

Vecino de Baeza

Grado recibido: B. A.

15-5-1575 Dr. Gaspar de Salcedo dio el grado a su discípulo

Mtro. Luis de Molina, notario

Referencia: $167 \mathrm{r}$

\section{BERNABÉ DE BAREA}

Vecino de Baena

Grados recibidos: B. A. / L. A.

15-5-1575 Dr. Gaspar de Salcedo dio el grado a su discípulo

28-3-1576 Acto mayor para L. A. que presidió su Mtro. y aprobó

13-2-1577 Repetición para L. A. Presidió su Mtro. y aprobó por mediana

8-4-1577 Examen secreto ante Rector Córdoba, que presidió el Dr. Almagro y aprobó el grado.

9-4-1577 Sobre el grado de M.A., para más adelante, hubo división de pareceres 18-5-1577 Canciller Fr. Sebastián Ximénez le dio el grado de L. A.

Mtro. Luis de Molina, notario

Referencias: 167r, 175r, 168v, 191r, 193r

JUAN TOLEDANO

Vecino de Baeza 
Grado recibido: B. A.

15-5-1575 Dr. Gaspar de Salcedo dio el grado a su discípulo

8-4-1575 Responsiones magnas. Presidió su Mtro. y se resolvió hacer otro acto

Mtro. Luis de Molina, notario

Referencias: 167r, 207v

FRANCISCO FERNÁNDEZ ALVIN

Vecino de Baeza

Grado recibido: B. A.

15-5-1575 Dr. Gaspar de Salcedo dio el grado a su discípulo

12-5-1577 Responsiones magnas L. A. Presidió su Mtro. División: aprobado por mediano y repetición en dos años.

Mtro. Luis de Molina, notario

Referencias: 167r, 192v

ANDRÉS DE GANDÍA

Vecino de Baeza

Grado recibido: B. A.

15-5-1575 Dr. Gaspar de Salcedo dio el grado a su discípulo

Mtro. Luis de Molina, notario

Referencia: $167 \mathrm{r}$

\section{LUCAS DE LINARES}

Vecino de Baeza

Grado recibido: B. A.

15-5-1575 Dr. Gaspar de Salcedo dio el grado a su discípulo

Mtro. Luis de Molina, notario

Referencia: $167 \mathrm{r}$

\section{ANTONIO GUTIÉRREZ SERRANO}

Vecino de Baeza

Grados recibidos: B. A. / L. A.

15-5-1575 Dr. Gaspar de Salcedo dio el grado a su discípulo

8-6-1576 Responsiones magnas para L. A. Presidió su Mtro. y la repetición quedó suspendida un año

3-5-1577 Repetición para L. A. Presidió su Mtro. Véase la capacidad para el examen secreto para L. A.

17-5-1580 Examen secreto ante el Rector Molina para L. A.

18-5-1580 Presidió Mtro. Fr. Diego de Ávila: se decidió concederle el grado

20-5-1580 Canciller Fr. Juan de Vilches le dio el grado 
Mtro. Luis de Molina, not.

Referencias: 167r, 179v, 192r, 26or, 261r

\section{DIEGO GARZÓN}

Vecino de Baeza

Grado recibido: B. A.

15-5-1575 Dr. Gaspar de Salcedo dio el grado a su discípulo

Mtro. Luis de Molina, notario

Referencia: $167 \mathrm{r}$

\section{AGUSTÍN DE ALFARO SORIA}

Natural de Jaén

Grados recibidos: B. A. / L. A.

15-5-1575 Dr. Gaspar de Salcedo dio el grado a su discípulo

21-1-1577 Responsiones magnas para L. A. y aprobó

5-5-1577 Repetición para L. A. Presidió su Mtro. y aprobó simpliciter 25-10-1578 Examen secreto para L.A.

26-10-1578 Presidió Mtro. Ochoa y aprobó simpliciter

29-10-1578 Canciller Ocón le dio el grado

Mtro. Luis de Molina, not.

Referencias: 167r, 184v, 192r, 219r, 220r

\section{GONZALO DE ALARCÓN}

Vecino de Baeza

Grado recibido: B. A.

15-5-1575 Dr. Gaspar de Salcedo dio el grado a su discípulo

Mtro. Luis de Molina, notario

Referencia: $167 \mathrm{r}$

\section{ANTONIO DE BENAVIDES}

Vecino de Baeza

Grado recibido: B. A.

15-5-1575 Dr. Gaspar de Salcedo dio el grado a su discípulo

Mtro. Luis de Molina, notario

Referencia: $167 \mathrm{r}$

\section{CRISTÓBAL DE CÁMARA}

Vecino de Torrejimeno

Grado recibido: B. A.

15-5-1575 Dr. Salcedo dio el grado a su discípulo 
5-6-1576 Acto mayor para L. A. Presidió su Mtro. y fue reprobado

Mtro. Luis de Molina, not.

Referencia: $167 \mathrm{r}$

JUAN GARRIDO

Vecino del Castellar

Grados recibidos: B. A. / L. A.

15-5-1575 Dr. Gaspar de Salcedo dio el grado a su discípulo

17-10-1576 Habiendo tenido los actos para dicho efecto pidió el Rector Córdoba examen secreto

18-10-1576 Presidió Mtro. Pedraza y fueron de parecer que tornase a entrar en otro examen

21-10-1576 Claustro: por el controvertido dictamen porque el estatuto mandaba que el examen secreto se habia de notar en lo tocante al grado de Mtro. y no de Ldo., pues puesto allí no se le havia de negar el grado de Licencia y se otorgó. Pero en cuanto a Mtro., hasta de oy en cincuenta años

21-10-1576 Fr. Alonso de Rojas le dio el grado

Mtro. Luis de Molina, notario

Referencias: $167 \mathrm{r}, 183 \mathrm{r}$

MIGUEL DE LAGUNA

Vecino de Baeza

Grado recibido: B. A.

15-5-1575 Dr. Gaspar de Salcedo dio el grado a su discípulo

Mtro. Luis de Molina, notario

Referencia: $167 \mathrm{r}$

ANDRÉS LÓPEZ

Grado recibido: B. A.

15-5-1575 Dr. Gaspar de Salcedo dio el grado a su discípulo

Mtro. Luis de Molina, notario

Referencia: $167 \mathrm{r}$

PEDRO DE CÓZAR

Vecino de Baeza

Grado recibido: B. A.

15-5-1575 Dr. Gaspar de Salcedo dio el grado a su discípulo

Mtro. Luis de Molina, notario

Referencia: $167 \mathrm{r}$ 


\section{DIEGO LÓPEZ}

Vecino de Baeza

Grado recibido: B. A. / L. A.

15-5-1575 Dr. Gaspar de Salcedo dio el grado a su discípulo

10-4-1576 Responsiones magnas para L. A. que presidió su Mtro. y aprobó

10-10-1576 Repetición para L. A. que presidió su Mtro. y aprobó

13-10-1576 Examen secreto ante el Rector Córdoba presidió el Mtro. Ochoa y

aprobó

14-10-1576 Recibió el grado de L. A.

Mtro. Luis de Molina, notario

Referencias: 167r, 181r, 182v

GONZALO DE HERRERA

Vecino de Baeza

Grado recibido: B. A.

15-5-1575 Dr. Gaspar de Salcedo dio el grado a su discípulo

Mtro. Luis de Molina, notario

Referencia: $167 \mathrm{r}$

JUAN MARTÍNEZ

Vecino de Iruela

Grado recibido: B. A.

15-5-1575 Dr. Gaspar de Salcedo dio el grado a su discípulo

Mtro. Luis de Molina, notario

Referencia: $167 \mathrm{r}$

SEBASTIÁN ALONSO DE ARMIJO

Vecino de Pliego

Grado recibido: B. A.

15-5-1575 Dr. Gaspar de Salcedo dio el grado a su discípulo

13-10-1576 Responsiones magnas para L. A. que presidió su Mtro. y aprobó

5-1-1576 Repetición para L. A. Presidió su Mtro. y aprobó simpliciter y por mediana

Mtro. Luis de Molina, notario

Referencias: 167r, 182r, $174 \mathrm{~V}$

FR. DIEGO DE ÁVILA

O.SS.T. Catedrático de Artes. Ministro del Convento de Sta. Catalina

Grados recibidos: B. A. / B. T. / L. A. / M. A.

15-5-1575 Dr. Gaspar de Salcedo dio el grado a su discípulo 
7-6-1578 Tentativa magna para B. T. Presidió el Dr. Ojeda y aprobó por bueno 10-6-1578 Lecciones de Teología

-/-12-1578 Dr. Pedro de Ojeda le dio el grado

9-12-1578 Repetición: presidió el Rector Salcedo y aprobó simpliciter

10-12-1578 Examen secreto para L. A. ante el Rector Salcedo. Presidió Mtro. Peralta y aprobó por digno y suficiente

17-12-1578 Canciller Fr. Agustin Salucio dio los grados

Mtro. Luis de Molina, notario

Referencias: 167r, 210r, 210v, 222r, 222v, 223v

FR. GASPAR DE MEDINA

Grado recibido: B. A.

15-5-1575 Dr. Gaspar de Salcedo dio el grado a su discípulo

Mtro. Luis de Molina, notario

Referencia: $167 \mathrm{r}$

FR. FERNANDO GUTIÉRREZ

O. de M.

Grado recibido: B. T.

26-3-1576 Tentativa para B. T. Presidió el Dr. Cavallería y aprobó

2-4-1574 Leyó la última lección y el Dr. Cavallería le dio el grado

Mtro. Molina, not.

Referencias: 174v, 175r

\section{ALONSO DE PIDRULA}

Vecino de Baeza

Grados recibidos: B. A. / L. A.

19-5-1576 Alumno del Mtro. Pedraza

26-3-1577 Aprobado simpliciter

16-12-1578 Responsiones magnas L. A. Presidió su Mtro. Aprobó por mediano.

Faltóle virtud y recogimiento

9-1-1579 Repetición para L. A. Presidió su Mtro. y aprobó

10-1-1579 Examen secreto ante el Rector Salcedo

22-1-1579 Presidió Mtro. Ochoa y aprobó. El Magisterio, para dentro de seis años.

Mtro. Diego de Ávila le dio el grado de L. A.

Mtro. Luis de Molina, not. y secr.

Referencias: 177v, 223r, 226r, 229r

ANDRÉS DEL MORAL Y MEDINA

Vecino de Baeza 
Grados recibidos: B. A. / L. A.

19-5-1576 Alumno del Mtro. Pedraza

22-3-1577 Aprobado simpliciter

18-5-1577 Responsiones magnas para L. A. Presidió su Mtro.

27-8-1577 Aprobó simpliciter

28-8-1577 Repetición para L. A. Presidió su Mtro. Aprobó simpliciter

4-9-1577 Examen secreto ante el Rector Córdoba. Presidió el Dr. Almagro y apro-

bó el grado. Para M. A. tenía que hacer una tentativa magna

Canciller Fr. Alonso de Rojas le dio el grado

Mtro. Luis de Molina, not. y secr.

Referencias: 177v, 190r, 192v, 197rv, 200r

\section{FRANCISCO PÉREZ ROMERO}

\section{Vecino de Torre Pedro Gil}

Grado recibido: B. A.

19-5-1576 Alumno del Mtro. Pedraza. Aprobado simpliciter

Mtro. Luis de Molina, not. y secr.

Referencia: $177 \mathrm{v}$

\section{FRANCISCO VIRUÉS DE GODOY}

Grado recibido: B. A.

19-5-1576 Alumno del Mtro. Pedraza. Aprobado por razón de los cursos: cursibus per actis; falta de virtud y recogimiento

Mtro. Luis de Molina, not. y secr.

Referencia: $177 \mathrm{v}$

\section{FRANCISCO DE LEÓN}

\section{Vecino de Baeza}

Grado recibido: B. A.

19-5-1576 Alumno del Mtro. Pedraza. Aprobado simpliciter

Mtro. Luis de Molina, not. y secr.

Referencia: $177 \mathrm{v}$

\section{JUAN DE ALMANSA}

Vecino de Baeza

Grado recibido: B. A.

19-5-1576 Alumno del Mtro. Pedraza. Aprobado

Mtro. Luis de Molina, not. y secr.

Referencia: $177 \mathrm{v}$ 
FRANCISCO VILLAR DE BAGO

Vecino de Andújar

Grados recibidos: B. A. / L. A.

19-5-1576 Alumno del Mtro. Pedraza

13-3-1577 Aprobado simpliciter

16-5-1577 Responsiones magnas para L.A. Presidió su Mtro. y aprobó simpliciter 25-8-1577 Repetición para L.A. Presidió su Mtro. Aprobó simpliciter

26-8-1577 Ante el Rector Córdoba hizo el examen secreto. Presidió Mtro. Ochoa y aprobó

4-9-1577 Canciller Fr. Alonso de Rojas le dio el grado

Mtro. Luis de Molina, not. y secr.

Referencias: 177v, 189v, 191r, 192v, 196v, 197r, 200r

\section{ALONSO DE CUENCA}

Vecino de Baeza

Grado recibido: B. A.

19-5-1576 Alumno del Mtro. Pedraza. Aprobado, pero falta de virtud y recogimiento

Mtro. Luis de Molina, not. y secr.

Referencia: $177 \mathrm{v}$

JORGE DE LA PUERTA

Natural de Torrecampo, dióc. de Jaén

Grados recibidos: B. A. / L. A.

19-5-1576 Alumno del Mtro. Pedraza. Aprobado

2-6-1577 Responsiones magnas. Presidió su Mtro.

13-6-1578 Repetición: presidió su Mtro. y aprobó

21-1-1579 Examen secreto ante el Rector

22-1-1579 Presidió Fr. Diego de Ávila y aprobó. El magisterio, de oy en cincuenta años

Mtro. Luis de Molina, not. y secr.

Referencias: 177v, 194r, 211r, 226v, 229r

\section{LAURENCIO MARTÍNEZ}

Vecino de Alhambra

Grado recibido: B. A.

19-5-1576 Alumno del Mtro. Pedraza. Aprobado simpliciter

Mtro. Luis de Molina, not. y secr.

Referencia: $177 \mathrm{v}$ 


\section{FRANCISCO RUIZ}

Vecino de Jaén

Grado recibido: B. A.

19-5-1576 Alumno del Mtro. Pedraza. Aprobado

Mtro. Luis de Molina, not. y secr.

Referencia: $177 \mathrm{v}$

\section{GERÓNIMO VIZCAÍNO}

Vecino de Baeza

Grados recibidos: B. A. / L. A.

19-5-1576 Alumno del Mtro. Pedraza. Aprobado simpliciter

29-4-1678 Presidió su Mtro. y aprobó por razonable

24-10-1578 Repetición para L. A. Presidió Mtro. Pedraza y aprobó

19-2-1579 Examen secreto ante el Rector Salcedo: aprobó

20-2-1579 Se decidió que para magisterio debía esperar diez años

3-3-1579 Canciller Fr. Diego de Ávila le dio el grado

Mtro. Luis de Molina, not. y secr.

Referencias: 177v, 209r, 218v, 231v, 232v

\section{LUIS XIMÉNEZ}

Vecino de Bedmar, dióc. de Jaén

[Mal ejemplo, escándalo, diciendo palabras afrentosas; el Rector halló en su aposento una mujer, paseador, distraído...]

Grados recibidos: B. A. / L. A.

19-5-1576 Alumno del Mtro. Pedraza. Aprobado simpliciter

23-6-1577 Repetición para L. A. Presidió su Mtro. y aprobó simpliciter

29-8-1577 Examen secreto ante el Rector

30-8-1577 Presidió el Dr. Salcedo y hubo una protesta tal, que el claustro examinador suspendió la sesión y su voto. Los antecedentes se remontaban a la vida disoluta del graduando y su actitud ofensiva en el acto de la graduación de B. A. Posteriormente, el Rector hizo una defensa del laureando y le aprobó 31-8-1577 Ante la decisión del Rector, hubo argumentaciones en contra. Y decidieron que, si eligiesen Canciller para darle el grado, antes le leyeran lo que el notario escribió para que le constaran las razones de no estar aprobado 4-11-1577 Canciller Fr. Alonso de Rojas le dio el grado Mtro. Luis de Molina, not. y secr.

Referencias: 177v, 195r, 197v, 198rv, 199rv, 202r

JUAN PÉREZ DE GODOY

Vecino de Jaén 
Grado recibido: B. A.

19-5-1576 Alumno del Mtro. Pedraza. Aprobado pero falta de virtud y recogimiento; se le dio la carta de enfermos

Mtro. Luis de Molina, not. y secr.

Referencia: $177 \mathrm{v}$

PEDRO DEL POZO

B. A., vecino de Mengíbar

Grado recibido: L. A.

26-5-1576 Reflexiones magnas para L. A. Presidió el Dr. Salcedo, su Mtro. y aprobó 6-3-1577 Repetición para L. A. Presidió su Mtro. Aprobación por buena y por mediana

22-4-1577 Examen secreto con el Rector Córdoba

23-4-1577 Presidió M. de Peralta y aprobó el grado

18-5-1577 Canciller Fr. Sebastián Ximénez le dio el grado

Mtro. Luis de Molina, not. y secr.

Referencias: 178v, 189r, 190r, 193r

JUAN FLORES DE BENAVIDES

Vecino de Baeza

Grado recibido: B. A.

23-1-1577 Examen público para B. A. y fue aprobado en dicho grado y el Rector Juan de Córdoba le dio el grado

Mtro. Luis de Molina, not. y secr.

Referencia: $184 \mathrm{~V}$

\section{MARTÍN YÁÑEZ DE ÁVILA}

Vecino de Baeza

Grados recibidos: B. A. / L. A.

1-2-1577 Discípulo del Mtro. Peralta: aprobado

22-3-1577 Responsiones magnas para L. A. Presidió su Mtro. y aprobó simpliciter Mayo-1578 Repetición: presidió el Mtro. Ochoa y aprobó simpliciter

16-9-1578 Examen secreto ante el Rector G. de Salcedo

16-9-1578 Presidió Mtro. Ochoa y aprobó simpliciter

8-10-1578 Canciller Fr. Agustin Salucio le dio el grado

Mtro. Luis de Molina, not. y secr.

Referencias: 185r, 206v, 209v, 214v, 216v

ASCENCIO DE PEDRAZA

Vecino de Baeza 
Grados recibidos: B. A. / L. A.

1-2-1577 Discípulo del Mtro. Peralta: aprobado

14-4-1578 Responsiones magnas. Presidió su Mtro. Aprobó simpliciter

Mayo-1578 Repetición: presidió su Mtro. Aprobó simpliciter

25-9-1578 Examen secreto ante el Rector G. de Salcedo

26-9-1578 Presidió Mtro. F. de Pedraza y aprobó n.d. simpliciter

8-10-1578 Canciller Fr. Agustin Salucio le dio el grado

Mtro. Luis de Molina, not. y secr.

Referencias: 185r, 208v, 209v, 215v, 216v

\section{LUIS MEXÍA}

Vecino de Baeza

Grado recibido: B. A.

1-2-1577 Discípulo del Mtro. Peralta: aprobado

Mtro. Luis de Molina, not. y secr.

Referencia: $185 \mathrm{r}$

JUAN DE PERALTA

Vecino de Baeza

Grado recibido: B. A.

1-2-1577 Discípulo del Mtro. Peralta: aprobado

Mtro. Luis de Molina, not. y secr.

Referencia: $185 \mathrm{r}$

\section{ALONSO DÍAZ VÁZQUEZ}

Vecino de Baeza

Grados recibidos: B. A. / L. A.

1-2-1577 Discípulo del Mtro. Peralta: aprobado

15-11-1579 Repeticiones magnas para L. A.

4-2-1580 Repetición para L. A. Presidió Fr. Diego de Ávila y aprobó por mediana

11-5-1580 Examen secreto ante el Rector Molina

12-5-1580 Presidió Mtro. Diego de Ávila y aprobó

20-5-1580 Canciller Fr. Juan de Vilches le dio el grado

Luis de Molina, not. y secr.; Mtro. Álvarez

Referencias: 185r, 246v, 251r, 259r, 261r

\section{LUIS GERÓNIMO}

Vecino de Baeza

Grado recibido: B. A.

1-2-1577 Discípulo del Mtro. Peralta: aprobado 
10-3-1578 Responsiones magnas para L. A. Presidió su Mtro. Aprobaron por mediano

22-12-1578 Repetición para L. A. Presidió su Mtro. y aprobó

Mtro. Luis de Molina, not. y secr.

Referencias: $185 \mathrm{r}, 225 \mathrm{r}$

BALTASAR DE OCHOA

Vecino de Baeza

Grado recibido: B. A.

1-2-1577 Discípulo del Mtro. Peralta: aprobado

Mtro. Luis de Molina, not. y secr.

Referencia: $185 \mathrm{r}$

JUAN SUÁREZ

Vecino de Baeza

Grado recibido: B. A.

1-2-1577 Discípulo del Mtro. Peralta: aprobado

11-4-1578 Responsiones magnas. Presidió su Mtro. Aprobó simpliciter

Mtro. Luis de Molina, not. y secr.

Referencias: 185r, 208v

ANDRÉS DE COS

Vecino de Baeza

Grado obtenido: B. A.

1-2-1577 Discípulo del Mtro. Peralta: aprobado

Mtro. Luis de Molina, not. y secr.

Referencia: $185 \mathrm{r}$

PEDRO DE LEÓN

Pbro. Vecino de Baeza

Grados recibidos: B. A. / L. A.

1-2-1577 Discípulo del Mtro. Peralta: aprobado

10-6-1578 Responsiones magnas para L. A. Presidió su Mtro. Aprobó simpliciter 15-9-1578 Repetición que presidió el Mtro. Pedraza y aprobó

3-10-1578 Examen secreto para L. A. ante el Rector G. de Pedraza

4-10-1578 Presidió el Dr. Salcedo y aprobó con aditamento

8-10-1578 Canciller Fr. Agustin Salucio le dio el grado

Mtro. Luis de Molina, not. y secr.

Referencias: 185r, 210v, 214v, 216r, 216v 


\section{LORENZO DE QUESADA}

Vecino de Jaén

Grado obtenido: B. A.

1-2-1577 Discípulo del Mtro. Peralta: aprobado por mediano

Mtro. Luis de Molina, not. y secr.

Referencia: $185 \mathrm{r}$

\section{JUAN RUIZ}

Vecino de Huéscar

Grado obtenido: B. A.

1-2-1577 Discípulo del Mtro. Peralta: aprobado

Mtro. Luis de Molina, not. y secr.

Referencia: $185 \mathrm{r}$

\section{JUAN ALONSO}

Vecino de Cazorla

Grado obtenido: B. A.

1-2-1577 Discípulo del Mtro. Peralta: aprobado

Mtro. Luis de Molina, not. y secr.

Referencia: $185 \mathrm{r}$

\section{PEDRO DE AGUDO GUTIÉRREZ}

Natural de Palma, diócesis de Córdoba. Vecino de Baeza

Grados recibidos: B. A. / L. A.

1-2-1577 Discípulo del Mtro. Peralta: aprobado

30-3-1579 Responsiones magnas para L. A. Presidió su Mtro. y aprobó simpliciter 13-5-1580 Examen secreto ante el Rector Molina

14-5-1580 Presidió Mtro. Cantero y aprobó

20-5-1580 Canciller Fr. Juan de Vilches le dio el grado

Mtro. Luis de Molina, not. y secr.

Referencias: 185r, 235v, 259rv, 261r

\section{ALONSO DOCA}

Vecino de Andújar

Grado obtenido: B. A.

1-2-1577 Discípulo del Mtro. Peralta: aprobado

Mtro. Luis de Molina, not. y secr.

Referencia: $185 \mathrm{r}$

GONZALO MARTÍNEZ

Vecino de Almedina 
Grado obtenido: B. A.

1-2-1577 Discípulo del Mtro. Peralta: aprobado

Mtro. Luis de Molina, not. y secr.

Referencia: $185 \mathrm{r}$

\section{FRANCISCO PACHECO}

Vecino de Baeza

Grados recibidos: B. A. / L. A.

1-2-1577 Discípulo del Mtro. Peralta: aprobado

19-3-1578 Responsiones magnas. Presidió su Mtro. y aprobó simpliciter

Mayo-1578 Repetición presidida por su Mtro. y aprobó simpliciter

15-9-1578 Examen secreto ante el Rector G. de Salcedo

16-9-1578 Presidió Mtro. Godoy y aprobó simpliciter

8-10-1578 Canciller Agustín Salucio le dio el grado

Mtro. Luis de Molina, not. y secr.

Referencias: 185r, 210r, 214r, 116v

\section{ALONSO DE CONTRERAS}

Vecino de Jaén

Grado obtenido: B. A.

1-2-1577 Discípulo del Mtro. Peralta: aprobado

Mtro. Luis de Molina, not. y secr.

Referencia: $185 \mathrm{r}$

\section{GASPAR RODRÍGUEZ}

Pbro. Vecino de Baeza

Grados recibidos: B. A. / L. A.

1-2-1577 Discípulo del Mtro. Peralta: aprobado

7-3-1578 Responsiones magnas. Presidió su Mtro.

2-12-1578 Repetición para L. A. Presidió su Mtro.

-/-12-1578 Examen secreto ante el Rector Salcedo. Presidió el Mtro. Pedraza y aprobó; en cuanto al M.A., pasados cincuenta años

6-1-1579 Fr. Agustín Salucio le dio el grado

Mtro. Luis de Molina, not. y secr.

Referencias: 185r, 205r, 224r, 225v

\section{ALONSO ESCUDERO}

Pbro. Vecino de Porcuna

Grados recibidos: B. A. / L. A.

1-2-1577 Discípulo del Mtro. Peralta: aprobado 
12-11-1578 Responsiones magnas. Presidió su Mtro.

15-12-1578 Repetición para L. A. Presidió su Mtro. y aprobó simpliciter 21-12-1578 Examen secreto ante el Rector Salcedo

22-12-1578 Presidió Mtro. Godoy y aprobó

6-1-1579 Fr. Agustín Salucio le dio el grado

Mtro. Luis de Molina, not. y secr.

Referencias: 185r, 220v, 223r, 224v, 225v

P. PEDRO DE MONROY

Grado obtenido: B. A.

1-2-1577 Discípulo del Mtro. Peralta: aprobado

Mtro. Luis de Molina, not. y secr.

Referencia: $185 \mathrm{r}$

ANTONIO BARRERA

Vecino de Arjona

Grado recibido: B. A.

1-2-1577 Discípulo del Mtro. Peralta: aprobado

28-4-1577 Responsiones magnas: presidió su Mtro.; aprobó por mediano

Mtro. Luis de Molina, not. y secr.

Referencias: 185v, 209r

\section{ANTONIO DE LA FUENTE}

Vecino de Jaén

Grado obtenido: B. A.

1-2-1577 Discípulo del Mtro. Peralta: aprobado

Mtro. Luis de Molina, not. y secr.

Referencia: $185 \mathrm{r}$

\section{ALONSO MARÍN}

Vecino de Baeza

Grado obtenido: B. A.

1-2-1577 Discípulo del Mtro. Peralta: aprobado por mediano

Mtro. Luis de Molina, not. y secr.

Referencia: $185 \mathrm{v}$

JUAN FERNÁNDEZ

Vecino de Cazorla

Grado obtenido: B. A.

1-2-1577 Discípulo del Mtro. Peralta: aprobado por mediano 
Mtro. Luis de Molina, not. y secr.

Referencia: $185 \mathrm{v}$

ALONSO GARRIDO

Vecino de Ibros

Grado obtenido: B. A.

1-2-1577 Discípulo del Mtro. Peralta: aprobado por mediano

Mtro. Luis de Molina, not. y secr.

Referencia: $185 \mathrm{v}$

ANTONIO BECERRA

Vecino de Baeza

Grado obtenido: B. A.

1-2-1577 Discípulo del Mtro. Peralta: aprobado por muy mediano

Mtro. Luis de Molina, not. y secr.

Referencia: $185 \mathrm{v}$

FRANCISCO BARRERA

Vecino de Arjona

Grado obtenido: B. A.

1-2-1577 Discípulo del Mtro. Peralta: aprobado ratione cursum pero sin procesión y sin carta por conducta

Mtro. Luis de Molina, not. y secr.

Referencia: $185 \mathrm{v}$

JUAN GUTIÉRREZ

Vecino de Arjona

Grado obtenido: B. A.

1-2-1577 Discípulo del Mtro. Peralta: aprobado ratione cursum

Mtro. Luis de Molina, not. y secr.

Referencia: $185 \mathrm{v}$

PEDRO DE MERCADO

Vecino de Jaén

Grado obtenido: B. A.

1-2-1577 Discípulo del Mtro. Peralta: aprobado ratione cursum pero sin procesión y sin carta por conducta

Mtro. Luis de Molina, not. y secr.

Referencia: $185 \mathrm{v}$ 


\section{FERNANDO ZAMUDIO}

Vecino de Jaén

Grado obtenido: B. A.

1-2-1577 Discípulo del Mtro. Peralta: aprobado ratione cursum pero sin procesión y sin carta por conducta

Mtro. Luis de Molina, not. y secr.

Referencia: $185 \mathrm{v}$

\section{DIEGO RODRÍGUEZ DE LA VELLA}

Vecino de Jaén

Grado obtenido: B. A.

1-2-1577 Discípulo del Mtro. Peralta: aprobado ratione cursum pero sin procesión y sin carta por conducta

Mtro. Luis de Molina, not. y secr.

Referencia: $185 \mathrm{v}$

\section{PEDRO VÁZQUEZ DE DUEÑAS}

Grado obtenido: B. A.

1-2-1577 Discípulo del Mtro. Peralta: aprobado ratione cursum sin carta por conducta

Mtro. Luis de Molina, not. y secr.

Referencia: $185 \mathrm{v}$

JUAN DE UCEDA

Vecino de Baeza

Grado obtenido: B. A.

1-2-1577 Discípulo del Mtro. Peralta: aprobado ratione cursum sin carta por conducta

Mtro. Luis de Molina, not. y secr.

Referencia: $185 \mathrm{v}$

\section{MIGUEL GARCÍA}

Vecino de Valdepeñas

Grado obtenido: B. A.

1-2-1577 Discípulo del Mtro. Peralta: aprobado ratione cursum

Mtro. Luis de Molina, not. y secr.

Referencia: $185 \mathrm{v}$

CRISTÓBAL DE VILLANUEVA

Vecino de Bailén 
Grados recibidos: B. A. / L. A. 1-2-1577 Discípulo del Mtro. Peralta: aprobado

18-4-1578 Responsiones magnas: presidió su Mtro. Aprobó simpliciter 12-6-1578 Repetición para L. A. Presidió su Mtro. y aprobó simpliciter 1-10-1578 Examen secreto ante el Rector G. de Salcedo 2-10-1578 Presidió Mtro. G. de Godoy y aprobó simpliciter 8-10-1578 Canciller Fr. Agustín Salucio le dio el grado Mtro. Luis de Molina, not. y secr.

Referencias: 185v, 208v, 211r, 216r, 216v

\section{LUIS DE QUESADA}

Vecino de Jaén

Grados recibidos: B. A. / L. A.

1-2-1577 Discípulo del Mtro. Peralta: aprobado

4-4-1578 Responsiones magnas: presidió su Mtro., aprobado simpliciter

7-5-1578 Repetición: presidió el Mtro. Salcedo

Septiembre 1578 Examen secreto ante el Rector G. de Salcedo y aprobó L. A.; para

M. A. era necesaria una tentativa magna

8-10-1578 Canciller Agustín de Salucio le dio el grado

Mtro. Luis de Molina, not. y secr.

Referencias: 185v, 206v, 209r, 215r, 216v

FR. JUAN ZAPATA

O.S.A. Natural de Málaga, profeso en la provincia de México

Incorporación: D. T.

8-10-1577 Ha leído un trienio de Artes Liberales y cuatro cursos de Teología y su Generalísimo le había graduado de Mtro. y Dr.

9-10-1577 Pidió incorporación. Canciller Fr. Alonso de Rojas le dio las credenciales

Mtro. Luis de Molina, not. y secr.

Referencias: 201r, 201v

\section{ALONSO SÁNCHEZ}

Natural de Baeza

Grado recibido: B. A.

5-2-1578 Mtro. Gaspar de Godoy: aprobado simpliciter

Mtro. Luis de Molinas, secr.

Referencia: $202 \mathrm{~V}$

MARTÍN POLIDO DEL TRIGO

Natural de Arjonilla 
Grado recibido: B. A.

5-2-1578 Mtro. Gaspar de Godoy: aprobado simpliciter

Mtro. Luis de Molinas, secr.

Referencia: 202v

JUAN MANCHADO

Natural de Iruela, diócesis de Toledo

Grado obtenido: B. A.

5-2-1578 Mtro. Gaspar de Godoy: aprobado simpliciter

10-3-1579 Responsiones magnas para L. A. Presidió su Mtro. y aprobó n.d. simpliciter

20-6-1579 Repetición presidida por el Mtro. Ochoa y aprobó simpliciter

Mtro. Luis de Molinas, secr.

Referencias: 202v, 238v

ALONSO RUIZ

Natural de Valdepeñas

Grado obtenido: B. A.

5-2-1578 Mtro. Gaspar de Godoy: aprobado

14-5-1580 Responsiones magnas para L. A. Presidió Mtro. Fr. Diego de Ávila y aprobó por mediano

Mtro. Luis de Molinas, secr.

Referencias: 202v, 259v

\section{LUIS FERNÁNDEZ}

Natural de Úbeda

Grado obtenido: B. A.

5-2-1578 Mtro. Gaspar de Godoy: aprobado simpliciter

15-6-158o Responsiones magnas para L. A. Presidió Mtro. Diego de Ávila y n.d. aprobó simpliciter

Mtro. Luis de Molinas, secr.

Referencia: 202v

\section{ALONSO DE JAVALERA}

Natural de Andújar

Grado obtenido: B. A.

5-2-1578 Mtro. Gaspar de Godoy: aprobado

31-3-1579 Responsiones magnas para L. A. Presidió Mtro. Ochoa y aprobó 22-6-1579 Repetición para L. A. Presidió Mtro. de Ávila y resolvieron repetirla dentro de dos años 
Mtro. Luis de Molinas, secr.; Ldo. Alonso Díaz Vazquez, secretario

Referencias: 202v, 235v, 238v, 263r

\section{LUIS DE HERRERA}

Natural de Jaén

Grado recibido: B. A.

5-2-1578 Mtro. Gaspar de Godoy: aprobado simpliciter

Mtro. Luis de Molinas, secr.

Referencia: 202v

GONZALO GUTIÉRREZ DE ALCÁZAR

Natural de Jaén

Grados obtenidos: B. A. / L. A.

5-2-1578 Mtro. Gaspar de Godoy: aprobado

28-3-1579 Responsiones magnas para L. A. Presidió el Mtro. de Ávila y aprobó por mediano

29-10-1579 Repetición para L. A. Presidió el Mtro. de Ávila y aprobó simpliciter 6-11-1579 Examen secreto ante el Rector Molina para L.A. y aprobó

7-11-1579 Recibió el grado

Mtro. Luis de Molinas, secr.

Referencias: 202v, 235r, 244v, 246rv

\section{PEDRO DE AGUILERA}

Natural de La Guardia

Grado recibido: B. A.

5-2-1578 Mtro. Gaspar de Godoy: aprobado simpliciter

Mtro. Luis de Molinas, secr.

Referencia: 202V

\section{PEDRO DE SEGURA}

Natural de Jaén

Grado recibido: B. A.

5-2-1578 Mtro. Gaspar de Godoy: admitido ratione cursum

Mtro. Luis de Molinas, secr.

Referencia: 202v

ANTÓN LÓPEZ

Natural de Arjona

Grados obtenidos: B. A. / L. A.

5-2-1578 Mtro. Gaspar de Godoy: aprobado simpliciter 
30-4-1579 Responsiones magnas para L. A. Presidió Mtro. de Ávila y aprobó 8-2-1580 Repetición para L. A. Presidió Mtro. Pedraza y aprobó simpliciter 15-2-1580 Acto de Teología y aprobó simpliciter 22-3-1580 Examen secreto ante el Rector Molina 23-3-1580 Presidió Fr. Diego de Ávila y aprobó simpliciter 20-5-1580 Canciller Juan de Vilchez le dio el grado Mtro. Luis de Molinas, secr.

Referencias: 202v, 236v, 253r, 255v, 261r

\section{FRANCISCO DE NAVARRETE}

Natural de Torres, diócesis de Jaén

Grado obtenido: B. A.

5-2-1578 Mtro. Gaspar de Godoy: aprobado simpliciter

27-2-1579 Responsiones magnas para L. A. Presidió su Mtro. y aprobó simpliciter, menos uno por mediano

Mtro. Luis de Molinas, secr.

Referencias: 202v, 232r

\section{JUAN DE PANDURO}

Natural de Arjona

Grados obtenidos: B. A. / L. A.

5-2-1578 Mtro. Gaspar de Godoy: aprobado simpliciter

21-3-1579 Responsiones magnas para L.A. Presidió Mtro. de Ávila y aprobó n.d. simpliciter

4-11-1579 Repetición

3-12-1579 Examen secreto ante el Rector Molina

4-12-1579 Presidió Mtro. Pedraza y aprobó

Mtro. Luis de Molinas, secr.

Referencias: 202v, 235r, 244r

ALONSO MEXÍA

Natural de La Guardia

Grado recibido: B. A.

5-2-1578 Mtro. Gaspar de Godoy: aprobado

Mtro. Luis de Molinas, secr.

Referencia: 202V

PASCUAL FERNÁNDEZ

Natural de Valdepeñas

Grado recibido: B. A. 
5-2-1578 Mtro. Gaspar de Godoy: aprobado simpliciter Mtro. Luis de Molinas, secr.

Referencia: 202V

PEDRO FERNÁNDEZ

Natural de Marugán

Grado recibido: B. A.

5-2-1578 Mtro. Gaspar de Godoy: aprobado por mediano

Mtro. Luis de Molinas, secr.

Referencia: 202v

ALONSO DE PERALTA

Natural de Lopera

Grado recibido: B. A.

5-2-1578 Mtro. Gaspar de Godoy: aprobado

Mtro. Luis de Molinas, secr.

Referencia: 202v

FRANCISCO PÁEZ

Natural de Beas

Grado recibido: B. A.

5-2-1578 Mtro. Gaspar de Godoy: aprobado por mediano Mtro. Luis de Molinas, secr.

Referencia: 202V

FR. PEDRO NAVARRO

O.SS.T.

Grado recibido: B. A.

5-2-1578 Mtro. Gaspar de Godoy: aprobado simpliciter Mtro. Luis de Molinas, secr.

Referencia: 202v

\section{ALONSO DE ANDRADA}

Natural de Baeza

Grado recibido: B. A.

5-2-1578 Mtro. Gaspar de Godoy: aprobado simpliciter Mtro. Luis de Molinas, secr.

Referencia: 202v

BARTOLOMÉ DE GALEOTE

Natural de Baeza 
Grado obtenido: B. A.

5-2-1578 Mtro. Gaspar de Godoy: aprobado simpliciter

21-3-1579 Responsiones magnas para L.A. Presidió Mtro. Ochoa. Aprobaron n.d. simpliciter

22-5-1579 Repetición para L. A. Presidió Mtro. Ochoa y aprobó simpliciter

Mtro. Luis de Molinas, secr.

Referencias: 202v, 235r, 238rv

ANTONIO GARCÍA

Natural de Úbeda

Grado recibido: B. A.

5-2-1578 Mtro. Gaspar de Godoy: aprobado por mediano

Mtro. Luis de Molinas, secr.

Referencia: $202 \mathrm{~V}$

JUAN DE OCAÑA

Natural de Jaén

Grado recibido: B. A.

5-2-1578 Mtro. Gaspar de Godoy: aprobado por mediano

Mtro. Luis de Molinas, secr.

Referencia: $202 \mathrm{~V}$

JUAN DE SEGURA

Natural de Jaén

Grado recibido: B. A.

5-2-1578 Mtro. Gaspar de Godoy: aprobado ratione cursum

Mtro. Luis de Molinas, secr.

Referencia: 202V

DIEGO DE RIVERA

Natural de Beas, diócesis de Cartagena

Grados obtenidos: B. A. / L. A.

5-2-1578 Mtro. Gaspar de Godoy: aprobado por mediano

28-2-1579 Responsiones magnas que presidió su Mtro. y aprobó por mediano

16-6-1579 Repeticiones magnas para L. A. Presidió Mtro. de Ávila y aprobó por mediano

24-1-1580 Examen secreto ante el Rector M. de Molina para L. A.

25-1-1580 Presidió Mtro. Peralta y aprobó; en cuanto a M.A dentro de 24 años

26-1-1580 Fernando Montesinos, Canciller le dio el grado

Mtro. Luis de Molinas, secr.

Referencias: 202v, 232r, 238r, 250r 


\section{MIGUEL SÁNCHEZ}

Natural de Valdepeñas

Grado recibido: B. A.

5-2-1578 Mtro. Gaspar de Godoy: aprobado simpliciter

Mtro. Luis de Molinas, secr.

Referencia: 202v

GONZALO DE CARVAJAL

Natural de Baeza

Grado obtenido: B. A.

15-2-1578 Mtro. Gaspar de Godoy: aprobado

Mtro. Luis de Molinas, secr.

Referencia: 204r

\section{LUIS QUESADA DE CARVAJAL}

Natural de Baeza

Grados obtenidos: B. A. / L. A.

15-2-1578 Mtro. Gaspar de Godoy: aprobado simpliciter

5-3-1579 Responsiones magnas para L. A. Presidió su Mtro. y aprobó simpliciter 16-5-1579 Repetición

4-6-1579 Responsiones magnas para L. A. Presidió Mtro. Ochoa y con división de opiniones su aprobado

31-8-1579 Examen secreto ante Mtro. Cardona y aprobó simpliciter

1-9-1579 Canciller Fr. Juan de Vilches le dio el grado

Mtro. Luis de Molinas, secr.

Referencias: 204r, 232v, 238r, 240v, 248r

ANTÓN MARÍN

Natural de Bedmar

Grado recibido: B. A.

5-2-1578 Mtro. Gaspar de Godoy: aprobado por mediano

Mtro. Luis de Molinas, secr.

Referencia: 202v

\section{ALONSO ROSILLO}

Natural de San Clemente, diócesis de Cuenca

Grado obtenido: B. A.

5-2-1578 Mtro. Gaspar de Godoy: aprobado

17-3-1579 Responsiones magnas para L. A. Presidió Mtro. D. de Ávila y aprobó simpliciter 
27-10-1579 Examen secreto ante el Rector Molina

28-10-1579 Presidió Mtro. Pedraza y aprobó. Para Mtro., era necesaria una tentativa magna

Mtro. Luis de Molinas, secr.

Referencias: 202v, 244rv

CRISTÓBAL DE SEGURA

Natural de Úbeda

Grado recibido: B. A.

5-2-1578 Mtro. Gaspar de Godoy: aprobado por mediano

Mtro. Luis de Molinas, secr.

Referencia: 202V

\section{ALONSO TRUJILLO}

Natural de La Guardia

Grado recibido: B. A.

5-2-1578 Mtro. Gaspar de Godoy: aprobado

Mtro. Luis de Molinas, secr.

Referencia: 202V

FRANCISCO MARTÍNEZ

Natural de Segovia

Grado recibido: B. A.

5-2-1578 Mtro. Gaspar de Godoy: aprobado

Mtro. Luis de Molinas, secr.

Referencia: 202V

MARTÍN PÉREZ

Natural de Guelma

Grado recibido: B. A.

5-2-1578 Mtro. Gaspar de Godoy: aprobado por mediano

Mtro. Luis de Molinas, secr.

Referencia: 203r

\section{FRANCISCO MUÑOZ}

Natural de Heruela

Grado recibido: B. A.

5-2-1578 Mtro. Gaspar de Godoy: aprobado sin aditamento Mtro. Luis de Molinas, secr.

Referencia: 203r 


\section{FERNANDO MONTORO}

B. A.

5-2-1578 Mtro. Gaspar de Godoy: suspendió el grado

8-2-1578 Se le levantó la pena

Mtro. Luis de Molinas, secr.

Referencia: 203r

\section{FERNANDO ALONSO DE POZOHONDO}

Natural de Arjona

Grado recibido: B. A.

5-2-1578 Mtro. Gaspar de Godoy: aprobado simpliciter

Mtro. Luis de Molinas, secr.

Referencia: $203 \mathrm{r}$

\section{JUAN DE CISNEROS}

Natural de Baeza

Grados obtenidos: B. A. / L. A.

5-2-1578 Mtro. Gaspar de Godoy: aprobado simpliciter

7-4-1579 Responsiones magnas para L. A. Presidió Mtro. Ochoa y aprobó simpliciter

23-6-1579 Repetición para L. A. Presidió Mtro. de Ávila y aprobó por mediana y simpliciter

17-4-1580 Examen secreto ante el Rector Molina

18-4-1580 Presidió Mtro. Cantero y aprobó

20-5-1580 Canciller Juan de Vilchez le dio el grado

Mtro. Luis de Molina, secr.

Referencias: 203r, 235v, 238v, 257r, 261r

\section{ALONSO DÍAZ DE NAVARRETE}

Beneficiado de S. Miguel de Baeza

Grado recibido: B. A.

7-4-1578 Rector Almagro le aprobó el grado. El Dr. Gaspar de Godoy le dio el grado

Mtro. Luis de Molinas, secr.

Referencia: $207 \mathrm{~V}$

CRISTÓBAL MEXÍA DE MALPICA

Natural de Jaén

Grado recibido: B. A.

7-4-1578 Rector Almagro le aprobó el grado. El Dr. Gaspar de Godoy le dio el grado 
Mtro. Luis de Molinas, secr.

Referencia: $207 \mathrm{~V}$

MTRO. LUIS DE MOLINA

Pbro. Secretario y not. de la Universidad

Grado obtenido: B. T.

16-6-1578 Tentativa magna para B. T. Presidió el Rector Diego Pérez, que aprobó simpliciter et absolute, n.d.

17-6-1578 Lecciones de Teología

20-6-1578 El Rector Pérez le dio el grado

Bachiller Diego de Torres

Referencias: 211v, 212r, 212v

FR. DIEGO DE OCÓN

Natural de Úbeda. O.SS.T.

Incorporación: D. T.

22-1-1579 Admitido por la Facultad de Teología por ser L.T. en Sigüenza. Se decidió que se graduase de D. T., ya que había sido lector

Mtro. Luis de Molina, secr.

Referencias: 227r, 228v

\section{DIEGO SÁNCHEZ DE ÁVILA}

Natural de Baeza

Grado obtenido: B. A.

2-2-1579 Diole el grado su Mtro. Ochoa: aprobado simpliciter

8-3-1580 Responsiones magnas para L. A. Presidió Fr. Diego de Ávila y aprobó simpliciter

30-5-1580 Repetición para L. A. Presidió el Dr. Pedraza y n.d. aprobó simpliciter Mtro. Luis de Molina; Ldo. Alonso Díaz, secr.

Referencias: 228-229v, 254v, 262v

RODRIGO DE AYALA

Natural de Baeza

Grado obtenido: B. A.

2-2-1579 Diole el grado su Mtro. Ochoa: aprobado simpliciter

26-2-1580 Responsiones magnas para L. A. Presidió Mtro. Melchor de Peralta y aprobó simpliciter

26-5-1580 Repetición presidida por el Mtro. Cantero y aprobó simpliciter Mtro. Luis de Molina, secr.

Referencias: 228-229, 253r, 261v 


\section{BLAS TUREL}

Natural de Baeza

Grado obtenido: B. A.

2-2-1579 Diole el grado su Mtro. Ochoa: aprobado simpliciter

4-3-1580 Responsiones magnas para L. A. Presidió Mtro. Cantero y aprobó simpliciter

30-5-1580 Repetición presidida por Mtro. Fr. Diego de Ávila y n.d. aprobó simpliciter

Mtro. Luis de Molina, secr.; Ldo. Alonso Díaz Vazquez, secr.

Referencias: 228-229, 254r, 262r

\section{FRANCISCO DE NAVARRETE}

Natural de Baeza

Grado obtenido: B. A.

2-2-1579 Diole el grado su Mtro. Ochoa: aprobado simpliciter

1-3-1580 Responsiones magnas para L. A. Presidió Fr. Diego de Ávila y aprobó simpliciter

27-5-1580 Repetición para L. A. Presidió Fr. Diego de Ávila y n.d. aprobaron simpliciter

Mtro. Luis de Molina, secr.; Ldo. Alonso Díaz Vazquez, secr.

Referencias: 228-229, 253v, 262r

\section{MARTÍN CARRASCO}

Natural de La Puebla, diócesis de Toledo

Grado obtenido: B. A.

2-2-1579 Diole el grado su Mtro. Ochoa: aprobado simpliciter

23-3-1580 Responsiones magnas para L. A. Presidió Fr. Diego de Ávila y aprobó simpliciter

8-6-1580 Repetición presidida por Dr. Pedraza y aprobó

Mtro. Luis de Molina, secr.; Ldo. Alonso Díaz Vazquez, secr.

Referencias: 228-229, 256r, 263r

\section{FRANCISCO PALOMINO}

Natural de Úbeda

Grado obtenido: B. A.

2-2-1579 Diole el grado su Mtro. Ochoa: aprobado por mediano

10-5-1580 Responsiones magnas para L. A. Presidió Mtro. Cantero y aprobó simpliciter

Mtro. Luis de Molina, secr.

Referencias: 228-229, 258v 


\section{JUAN DE ANTOLINOS}

Natural de la diócesis de Jaén

Grado obtenido: B. A.

2-2-1579 Diole el grado su Mtro. Ochoa: aprobado por mediano

Mtro. Luis de Molina, secr.

Referencia: 228-229

\section{DIEGO BRAVO}

Natural de Baeza

Grado obtenido: B. A.

2-2-1579 Diole el grado su Mtro. Ochoa: aprobado simpliciter

20-4-1580 Responsiones magnas: presidió el Dr. Pedraza y aprobó por mediano y simpliciter

Mtro. Luis de Molina, secr.

Referencias: 228-229, 257v

\section{ANTÓN DE TORRES}

Natural de Belmar, diócesis de Jaén

Grado obtenido: B. A.

2-2-1579 Diole el grado su Mtro. Ochoa: aprobado simpliciter

Mtro. Luis de Molina, secr.

Referencia: 228-229

\section{JERÓNIMO BOLARIM}

Natural de Huéscar

Grado obtenido: B. A.

2-2-1579 Diole el grado su Mtro. Ochoa: aprobado

Mtro. Luis de Molina, secr.

Referencia: 228-229

MIGUEL DE LEÓN

Natural de Málaga

Grado obtenido: B. A.

2-2-1579 Diole el grado su Mtro. Ochoa: aprobado por mediano

Mtro. Luis de Molina, secr.

Referencia: 228-229

MILLÁN GARCÍA

Natural de Beas, diócesis de Cartagena

Grado obtenido: B. A. 
2-2-1579 Diole el grado su Mtro. Ochoa: aprobado simpliciter Mtro. Luis de Molina, secr.

Referencia: 228-229

\section{ALONSO DE MADRID}

Natural de Sabiote

Grado obtenido: B. A. 2-2-1579 Diole el grado su Mtro. Ochoa: aprobado simpliciter 21-5-1580 Responsiones magnas para L. A. Presidió el Dr. Pedraza. Aprobó por mediano y simpliciter Mtro. Luis de Molina, secr.; Ldo. Alonso Díaz Vázquez, secr.

Referencias: 228-229, 261v

\section{GONZALO DE SEGURA}

Natural de Yeste, diócesis de Murcia

Grado obtenido: B. A.

2-2-1579 Diole el grado su Mtro. Ochoa: aprobado

Mtro. Luis de Molina, secr.

Referencia: 228-229

\section{JUAN GARZÓN}

Natural de Baeza

Grado obtenido: B. A. 2-2-1579 Diole el grado su Mtro. Ochoa: aprobado simpliciter 15-3-1580 Responsiones magnas para L. A. Presidió el Dr. Pedraza y aprobó por mediano y simpliciter 6-6-1580 Repetición presidida por Mtro. Cantero y aprobó Mtro. Luis de Molina, secr.; Ldo. Alonso Díaz Vázquez, secr. Referencias: 228-229, 262V

\section{DIEGO GARZÓN}

Natural de Baeza

Grado obtenido: B. A. 2-2-1579 Diole el grado su Mtro. Ochoa: aprobado simpliciter 18-3-1580 Responsiones magnas para L. A. Presidió Mtro. Cantero y aprobó simpliciter 7-6-1580 Repetición presidida por Mtro. Fr. Diego de Ávila y n.d. aprobó simpliciter

Mtro. Luis de Molina, secr.; Alonso Vázquez, secr.

Referencias: 228-229, 255r, 262V 
ANTONIO MERLÍN DE ÁVALOS

Natural de Úbeda

Grado obtenido: B. A.

2-2-1579 Diole el grado su Mtro. Ochoa: aprobado

Mtro. Luis de Molina, secr.

Referencia: 228-229

\section{FRANCISCO OCHOA DE ARANDA}

Grado obtenido: B. A.

2-2-1579 Diole el grado su Mtro. Ochoa: aprobado

Mtro. Luis de Molina, secr.

Referencia: 228-229

\section{JUAN DE CORPAS}

Natural de Bailén

Grado obtenido: B. A.

2-2-1579 Diole el grado su Mtro. Ochoa: aprobado por mediano Mtro. Luis de Molina, secr.

Referencia: 228-229

\section{LUIS DE LINARES}

Natural de Úbeda

Grado obtenido: B. A.

2-2-1579 Diole el grado su Mtro. Ochoa: aprobado

Mtro. Luis de Molina, secr.

Referencia: 228-229

\section{JUAN DE GODOY}

Natural de Alcalá la Real

Grado obtenido: B. A.

2-2-1579 Diole el grado su Mtro. Ochoa: aprobado por mediano Mtro. Luis de Molina, secr.

Referencia: 228-229

\section{ALONSO DE MACIANEZ}

Natural de Lahiguera de Andújar

Grado obtenido: B. A.

2-2-1579 Diole el grado su Mtro. Ochoa: aprobado por mediano Mtro. Luis de Molina, secr.

Referencia: 228-229 


\section{PEDRO GÓMEZ}

Natural de Albanchez

Grado obtenido: B. A.

2-2-1579 Diole el grado su Mtro. Ochoa: aprobado

Mtro. Luis de Molina, secr.

Referencia: 228-229

\section{DIEGO DE CASARUBIOS}

Natural de Hellín

Grado obtenido: B. A.

2-2-1579 Diole el grado su Mtro. Ochoa: aprobado simpliciter

Mtro. Luis de Molina, secr.

Referencia: 228-229

\section{LUIS OCHOA DE OJEDA}

Natural de Baeza

Grado obtenido: B. A.

2-2-1579 Diole el grado su Mtro. Ochoa: aprobado por mediano Mtro. Luis de Molina, secr.

Referencia: 228-229

JUAN DE MÍREZ

Natural de Jaén

Grado obtenido: B. A.

2-2-1579 Diole el grado su Mtro. Ochoa: aprobado ratione cursum Mtro. Luis de Molina, secr.

Referencia: 228-229

\section{ALONSO MARÍN DE LESMA}

Natural de Baeza

Grado obtenido: B. A.

2-2-1579 Diole el grado su Mtro. Ochoa: aprobado por mediano

Mtro. Luis de Molina, secr.

Referencia: 228-229

PEDRO DE QUADROS

Natural de Olvera

Grado obtenido: B. A.

2-2-1579 Diole el grado su Mtro. Ochoa: aprobado por mediano

Mtro. Luis de Molina, secr.

Referencia: 228-229 


\section{FRANCISCO DE SEGURA}

Natural de Huelma

Grado obtenido: B. A.

2-2-1579 Diole el grado su Mtro. Ochoa: aprobado por mediano

Mtro. Luis de Molina, secr.

Referencia: 228-229

\section{ALONSO DÍAZ DE CARLEVAL}

Natural de Baeza

Grado obtenido: B. A.

2-2-1579 Diole el grado su Mtro. Ochoa: aprobado por mediano

Mtro. Luis de Molina, secr.

Referencia: 228-229

\section{LORENZO DE CERVANTES}

Natural de Úbeda

Grado obtenido: B. A.

2-2-1579 Diole el grado su Mtro. Ochoa: aprobado

Mtro. Luis de Molina, secr.

Referencia: 228-229

\section{FR. LUIS BAUTISTA}

Profeso O.SS.T.

Grado obtenido: B. A.

2-2-1579 Diole el grado su Mtro. Ochoa: aprobado por mediano

Mtro. Luis de Molina, secr.

Referencia: 228-229

\section{ANTONIO DE LARA}

Natural de Andújar

Grado obtenido: B. A.

5-2-1579 El Rector Salcedo y el Mtro. Juan Francisco: aprobado por mediano

6-2-1579 Mtro. R. Ochoa le dio el grado

Mtro. Luis de Molina, secr.

Referencia: $230 \mathrm{v}$

\section{JUAN ALONSO NAVARRO}

Natural de Andújar

Grado obtenido: B. A.

6-2-1579 Mtro. Peralta y Francisco: aprobado por mediano. Mtro. R. Ochoa le dio el grado 
Mtro. Luis de Molina, secr.

Referencia: 230v

\section{RODRIGO OCHOA}

Catedrático de Filosofía y Artes de Baeza

Grado obtenido: B. T.

18-3-1579 Tentativa magna para B. T. presidida por el Rector Salcedo y aprobó simpliciter con el aplauso posible

20-3-1579 Rector Salcedo le dio el grado

Mtro. Luis de Molina, secr.

Referencias: 233r, 234r

\section{LUIS DE MONTORO}

Natural de Jaén, clérigo

Grado obtenido: B. A.

19-3-1579 Acto y examen para B. A. (conforme a los estatutos y a la nueva Reformación) aprobó simpliciter. El Rector Salcedo le dio el grado

Mtro. Luis de Molina, secr.

Referencia: 233v

\section{FRANCISCO DE TORRES}

\section{A. Natural de Baeza}

Grado obtenido: B. T.

20-3-1579 Tentativa magna para B. T. Presidió el Rector Salcedo y aprobó

21-3-1579 Lecciones para B. T.

6-5-1580 El Rector Salcedo le dio el grado

Parva ordinaria para L. T. Presidió el Dr. Pedraza y aprobó

Mtro. Luis de Molina, secr.; Fco. Pérez de Andrade

Referencias: 234rv, 258r

\section{JUAN SALCEDO DE PARRAGA}

B. A. Natural de Andújar, diócesis de Jaén. Hermano del Dr. Salcedo

Grado obtenido: B. T.

28-4-1579 Cuatro cursos de teología y lectura de lecciones en la Universidad de Granada

29-4-1579 Tentativa parva para B. T. presidida por Mtro. Pedraza y aprobó simpliciter. El Rector Molina le dio el grado

22-9-1579 Tentativa magna para B. T., presidida por Dr. Salcedo y aprobó simpliciter

24-9-1579 Lecciones para B. T. 
25-9-1579 Mtro. Gaspar Salcedo le dio el grado

Mtro. Luis de Molina, secr.

Referencias: 236r, 241rv

\section{FRANCISCO DE BECERRA}

Natural de Úbeda, catedrático de Prima

Incorporación: D. T.

Grado recibido: M. A.

25-9-1579 Incorporación del D. T. en la Universidad de Sigüenza 24-10-1575. Se decidió que leyese cuatro años continuos y quedase de catedrático perpetuo 29-6-1580 Canciller Juan de Vilches le otorgó el grado

Mtro. Luis de Molina, secr.

Referencias: 242rv, 265v

\section{MELCHOR DE SORIA}

Incorporación

25-9-1579 M. A. por la Universidad de Alcalá 17-11-1574

6-10-1579 B. T. en Alcalá en 4-6-1578

Mtro. Luis de Molina, secr.

Referencia: 242rv

\section{PEDRO GUTIÉRREZ DE AGUDO}

B. A.

13-10-1579 Repetición para L. A. Presidió Mtro. Cantero y aprobó

Mtro. Luis de Molina, secr.

Referencia: $243 \mathrm{v}$

\section{JUAN FRANCISCO DE VILLALVA}

M. A.

Grado recibido: B. T.

6-11-1579 Tentativa para B. T. presidida por Dr. Ojeda y aprobó simpliciter

5-1-1580 Lecciones para B. T.

15-1-1580 Dr. Pedro de Ojeda le dio el grado

Mtro. Luis de Molina, secr.; Alonso Vázquez, secr.

Referencias: 246v, 249rv

\section{MIGUEL NAVARRO}

Natural de Pamplona

Grado obtenido: B. A.

30-11-1579 Examen de B. A. y aprobó; pero no para pasar adelante en dicha facultad 
1-12-1579 Mtro. Fr. Diego de Ávila le dio el grado

Alonso Vázquez, secr.

Referencia: $247 \mathrm{r}$

\section{ANTONIO PRETEL}

Natural de Segura, diócesis de Cartagena

Grado obtenido: B. A.

10-1-1580 Mtros. Juan y Melchor de Soria le examinaron de B. A. y le aprobaron 17-1-1580 Examen secreto: Presidió el Dr. Pedrosa y aprobó

Fr. Diego de Ávila le dio el grado

Mtro. Luis de Molina, secr.

Referencias: 249r, 249v

ANTONIO DÁVALOS

Natural de Úbeda

Grado obtenido: B. A.

17-1-1580 Fr. Diego de Ávila le dio el grado

Mtro. Luis de Molina, secr.

Referencia: 249v

\section{JUAN DONOSO}

Natural de Villanueva de Arzobispo

Grado recibido: B. A.

6-2-1580 Aprobado simpliciter por Mtro. Fr. Diego de Ávila, O.SST.

Mtro. Luis de Molina, secr.

Referencia: 251r

\section{ANTONIO GODINO}

Natural de Baeza

Grado recibido: B. A.

6-2-1580 Aprobado por Mtro. Fr. Diego de Ávila

Mtro. Luis de Molina, secr.

Referencia: 251r

CRISTÓBAL DE ROSALES

Natural de Jaén

Grado recibido: B. A.

6-2-1580 Aprobado simpliciter por Mtro. Fr. Diego de Ávila

Mtro. Luis de Molina, secr.

Referencia: $251 \mathrm{~V}$ 


\section{FERNANDO TOLEDANO}

Natural de Baeza

Grado recibido: B. A.

6-2-1580 Aprobado por Mtro. Fr. Diego de Ávila

Mtro. Luis de Molina, secr.

Referencia: 251v

\section{DIEGO NOGUERA}

Natural de Baeza

Grado recibido: B. A.

6-2-1580 Aprobado por Mtro. Fr. Diego de Ávila Mtro. Luis de Molina, secr.

Referencia: 251v

\section{FRANCISCO DE AYALA}

Vecino de Castildelgado

Grado recibido: B. A.

6-2-1580 Aprobado por Mtro. Fr. Diego de Ávila Mtro. Luis de Molina, secr.

Referencia: 251v

\section{ALONSO DE SEGURA}

Natural de Sabiote

Grado recibido: B. A.

6-2-1580 Aprobado por Mtro. Fr. Diego de Ávila

Mtro. Luis de Molina, secr.

Referencia: 251v

\section{DIEGO FERNÁNDEZ DE AQUINO}

Vecino de Baeza

Grado recibido: B. A.

6-2-1580 Aprobado por Mtro. Fr. Diego de Ávila

Mtro. Luis de Molina, secr.

Referencia: 251v

\section{AGUSTÍN DE LUNA}

Natural de Baeza

Grado recibido: B. A.

6-2-1580 Aprobado simpliciter por Mtro. Fr. Diego de Ávila

Mtro. Luis de Molina, secr.

Referencia: 251v 


\section{BENITO DE VITORIA}

Natural de Baeza

Grado recibido: B. A.

6-2-1580 Aprobado por Mtro. Fr. Diego de Ávila

Mtro. Luis de Molina, secr.

Referencia: 251v

JUAN ROMÁN

Natural de Iznatoraf

Grado recibido: B. A.

6-2-1580 Aprobado por Mtro. Fr. Diego de Ávila Mtro. Luis de Molina, secr.

Referencia: 251v

JUAN OROZCO

Natural de Úbeda

Grado recibido: B. A.

6-2-1580 Aprobado por Mtro. Fr. Diego de Ávila Mtro. Luis de Molina, secr.

Referencia: 251v

FERNANDO LÓPEZ

Natural de La Manchuela de Jaén

Grado recibido: B. A.

6-2-1580 Aprobado por Mtro. Fr. Diego de Ávila Mtro. Luis de Molina, secr.

Referencia: 251v

JUAN DE ORTEGA

Natural de Albanchez

Grado recibido: B. A.

6-2-1580 Aprobado por Mtro. Fr. Diego de Ávila Mtro. Luis de Molina, secr.

Referencia: $251 \mathrm{~V}$

FRANCISCO DE CARMONA

Natural de Baeza

Grado recibido: B. A.

6-2-1580 Aprobado por Mtro. Fr. Diego de Ávila

Mtro. Luis de Molina, secr.

Referencia: $251 \mathrm{v}$ 
FERNANDO DE ARELLANO

Natural de Los Hinojosos

Grado recibido: B. A.

6-2-1580 Aprobado por Mtro. Fr. Diego de Ávila Mtro. Luis de Molina, secr.

Referencia: $251 \mathrm{v}$

\section{LUIS DE LOS SANTOS}

Natural de Baeza

Grado recibido: B. A.

6-2-1580 Aprobado por Mtro. Fr. Diego de Ávila Mtro. Luis de Molina, secr.

Referencia: 251v

JUAN DE ARANDA

Natural de Jaén

Grado recibido: B. A.

6-2-1580 Aprobado por Mtro. Fr. Diego de Ávila Mtro. Luis de Molina, secr.

Referencia: 251v

JUAN DE BUSTOS

Natural de Cazorla

Grado recibido: B. A.

6-2-1580 Aprobado por Mtro. Fr. Diego de Ávila Mtro. Luis de Molina, secr.

Referencia: $251 \mathrm{v}$

MIGUEL GÓMEZ DE ORTEGA

Natural de Andújar

Grado recibido: B. A.

6-2-1580 Aprobado por Mtro. Fr. Diego de Ávila

Mtro. Luis de Molina, secr.

Referencia: 251v

ANDRES GARCÍA CARRILLO

Natural de Jaén

Grado recibido: B. A.

6-2-1580 Aprobado por Mtro. Fr. Diego de Ávila

Mtro. Luis de Molina, secr.

Referencia: 251v 
FRANCISCO DE ROBREDILLO

Natural de Úbeda

Grado recibido: B. A.

6-2-1580 Aprobado por Mtro. Fr. Diego de Ávila

Mtro. Luis de Molina, secr.

Referencia: $251 \mathrm{v}$

MELCHOR DE SANESTEVAN

Grado recibido: B. A.

6-2-1580 Aprobado por Mtro. Fr. Diego de Ávila Mtro. Luis de Molina, secr.

Referencia: 251v

\section{PEDRO TENORIO}

Natural de Baeza

Grado recibido: B. A.

6-2-1580 Aprobado por Mtro. Fr. Diego de Ávila Mtro. Luis de Molina, secr.

Referencia: 251v

\section{SEBASTIÁN DE PORTALES}

Natural de Jaén

Grado recibido: B. A.

6-2-1580 Aprobado por Mtro. Fr. Diego de Ávila Mtro. Luis de Molina, secr.

Referencia: 251v

\section{JUAN DE MARMOLEJO}

Natural de Andújar

Grado recibido: B. A.

6-2-1580 Aprobado por Mtro. Fr. Diego de Ávila Mtro. Luis de Molina, secr.

Referencia: 251v

FRANCISCO GARCÍA

Natural de Jaén

Grado recibido: B. A.

6-2-1580 Aprobado por Mtro. Fr. Diego de Ávila Mtro. Luis de Molina, secr.

Referencia: 251v 


\section{CRISTÓBAL DE JARANDILLA}

Natural de Jaén

Grado recibido: B. A.

6-2-1580 Aprobado por Mtro. Fr. Diego de Ávila

Mtro. Luis de Molina, secr.

Referencia: 251v

\section{ANDRÉS MORENO}

Natural de Baeza

Grado recibido: B. A.

6-2-1580 Aprobado simpliciter por Mtro. Fr. Diego de Ávila Mtro. Luis de Molina, secr.

Referencia: 251v

\section{FRANCISCO SÁNCHEZ}

Vecino de Ariza, diócesis de Sigüenza

Grado obtenido: B. A.

6-2-1580 Aprobado simpliciter

21-6-1580 Mtro. Fr. Diego de Ávila le dio el grado

Mtro. Luis de Molina, secr.; Alonso Díaz, secr.

Referencias: 251v, 263r

\section{LORENZO PÁEZ}

Natural de Úbeda

Grado recibido: B. A.

6-2-1580 Aprobado simpliciter por Mtro. Fr. Diego de Ávila Mtro. Luis de Molina, secr.

Referencia: 251v

\section{FERNÁN GÓMEZ}

Natural de Hornos

Grado recibido: B. A.

6-2-1580 Aprobado por Mtro. Fr. Diego de Ávila

Mtro. Luis de Molina, secr.

Referencia: $251 \mathrm{v}$

JORGE DE PERALTA

Natural de Úbeda

Grado recibido: B. A.

6-2-1580 Aprobado simpliciter por Mtro. Fr. Diego de Ávila 
Mtro. Luis de Molina, secr.

Referencia: $251 \mathrm{~V}$

\section{ALONSO DE ESPINOSA}

Natural de Baeza

Grado recibido: B. A.

6-2-1580 Aprobado por Mtro. Fr. Diego de Ávila

Mtro. Luis de Molina, secr.

Referencia: 251v

SEBASTIÁN ANTOLINO DE FUENMAYOR

Natural de Baeza

Grado recibido: B. A.

6-2-1580 Aprobado por Mtro. Fr. Diego de Ávila

Mtro. Luis de Molina, secr.

Referencia: 251v

LÁZARO DE SABIOTE

Natural de Linares

Grado recibido: B. A.

6-2-1580 Aprobado por Mtro. Fr. Diego de Ávila

Mtro. Luis de Molina, secr.

Referencia: $251 \mathrm{v}$

\section{CRISTÓBAL SÁNCHEZ}

Natural de Baeza

Grado recibido: B. A.

6-2-1580 Aprobado por Mtro. Fr. Diego de Ávila

Mtro. Luis de Molina, secr.

Referencia: $251 \mathrm{~V}$

\section{FRANCISCO DE HINOJOSA}

Natural de Castellar

Grado obtenido: B. A.

15-3-1580 Mtros. Juan y Luis de Soria le aprobaron por suficiente 18-3-1580 Mtro. Fr. Diego de Ávila

Mtro. Luis de Molina, secr.

Referencia: $255 \mathrm{r}$

LUIS MUÑOZ

Natural de Castellar 
Grado obtenido: B. A.

15-3-1580 Mtros. Juan y Luis de Soria le aprobaron por suficiente

28-3-1580 Mtro. Fr. Diego de Ávila le dio el grado

Mtro. Luis de Molina, secr.

Referencias: 255r, 256r

\section{MARTÍN ALONSO DE ADAM}

Natural de Mestanza, diócesis de Toledo

Grado obtenido: B. A.

25-3-1580 Mtros. Juan y Luis de Soria le aprobaron por suficiente simpliciter 28-3-158o Mtro. Fr. Diego de Ávila le dio el grado

Mtro. Luis de Molina, secr.

Referencia: 256r

\section{MIGUEL FRANCO}

Natural de Andújar

Grado obtenido: B. A.

5-1-1580 Mtros. Juan y Luis de Soria examinaron y le aprobaron de B. A.

Mtro. Fr. Diego de Ávila le dio el grado

Alonso Díaz Vázquez, secr.

Referencia: $256 \mathrm{v}$

\section{CRISTÓBAL MARON ¿MARIN?}

Vecino de Baeza

Grado obtenido: B. A.

28-6-1580 Mtros. J. de Soria, M. Cantero, R. Alvarez Brizeño le examinaron y aprobó simpliciter

29-6-1580 Mtro. Fr. Diego de Ávila le dio el grado

Ldo. Alonso Díaz Vazquez, secr.

Referencia: 263v

\section{MIGUEL SÁNCHEZ DE ORTEGA}

Canónigo de Sta. María del Alcázar de Baeza

Natural de Villarejo de la Peñuela, dióc. de Cuenca

Incorporación: D. T.

29-6-1580 Incorporación de D. T. El Canciller Fr. Juan de Vilches, prior del Convento de Sto. Domingo de Baeza, le concedió el grado

Ldo. Alonso Díaz, secr.; Luis de Molina, secr.

Referencias: 263v, 266v 


\section{RAFAEL RAMIS BARCELÓ / PEDRO RAMIS SERRA}

\section{ALONSO PRETEL}

Incorporación: M. A. y D. T.

D.T. por la Universidad de Sigüenza 3-11-1580 y M.A. por la Universidad de Zaragoza 4-6-1558

29-6-1580 Fue incorporado a la Universidad de Baeza

Referencia: $264 \mathrm{v}$ 


\section{PROGRAMA HISTORIA DE LAS UNIVERSIDADES \\ PUBLICACIONES \\ ISSN: $1886-0710$}

1. Estado de la Universidad de Alcalá (1805), estudio preliminar de José Luis Peset, edición de Diego Navarro, Madrid 1999, 120 pp.

http://hdl.handle.net/10016/7875

2. La investigación en la universidad, edición de Carmen Merino, Madrid 1999, $217 \mathrm{pp}$.

http://hdl.handle.net/10016/7876

3. Aurora Rivière Gómez, Orientalismo y nacionalismo español. Estudios árabes y hebreos en la Universidad de Madrid (1843-1868), Madrid 2000, 143 pp.

http://hdl.handle.net/10016/7905

4. Manuel Martínez Neira, El estudio del derecho. Libros de texto y planes de estudio en la universidad contemporánea, Madrid 2001,318 pp.

http://hdl.handle.net/10016/7877

5. Daniel Comas Caraballo, Autonomía y reformas en la Universidad de Valencia (1900-1922), Madrid 2001, 334 pp.

http://hdl.handle.net/10016/7878

6. Carolina Rodríguez López, La Universidad de Madrid en el primer franquismo: ruptura y continuidad (1939-1951), Madrid 2002, 490 pp.

http://hdl.handle.net/10016/7879

7. Ramon Aznar i Garcia, Cánones y leyes en la universidad de Alcalá durante el reinado de Carlos III, Madrid 2002, 349 pp.

http://hdl.handle.net/10016/7880

8. Enrique Villalba Pérez, Consecuencias educativas de la expulsión de los jesuitas de América, Madrid 2003, 246 pp.

http://hdl.handle.net/10016/7881

9. Archivos universitarios e historia de las universidades, edición de José Ramón

Cruz Mundet, Madrid 2003, 345 pp.

http://hdl.handle.net/10016/7882

10. La enseñanza del derecho en el siglo XX. Homenaje a Mariano Peset, edición de Adela Mora Cañada, Madrid 2004, 578 pp.

http://hdl.handle.net/10016/7883 
11. Manuel Martínez Neira / José M. ${ }^{a}$ Puyol Montero / Carolina Rodríguez López, La universidad española 1889-1939. Repertorio de legislación, Madrid 2004, 389 pp. http://hdl.handle.net/10016/7884

12. Hacia un modelo universitario: la Universidad Carlos III de Madrid, edición de Adela Mora Cañada y Carolina Rodríguez López, Madrid 2004, 365 pp. http://hdl.handle.net/10016/7885

13. Manuales y textos de enseñanza en la universidad liberal, edición de Manuel Ángel Bermejo Castrillo, Madrid 2004, 750 pp.

http://hdl.handle.net/10016/7886

14. Susana Guijarro González, Maestros, escuelas y libros. El universo cultural de las catedrales en la Castilla medieval, Madrid 2004, CD + 349 pp.

http://hdl.handle.net/10016/7887

15. Filosofía para la universidad, filosofía contra la universidad, edición de Faustino Oncina Coves, Madrid 2008, 360 pp.

http://hdl.handle.net/10016/3506

16. Manuel Martínez Neira / José María Puyol Montero, El doctorado en derecho. 1930-1956, Madrid 2008, 340 pp.

http://hdl.handle.net/10016/3386

17. Germán Perales Birlanga, El estudiante liberal. Sociología y vida de la comunidad escolar universitaria de Valencia. 1875-1939, Madrid 2009, 326 pp.

http://hdl.handle.net/10016/4376

18. Alfons Aragoneses, Un jurista del Modernismo. Raymond Saleilles y los orígenes del derecho comparado, Madrid 2009, 259 pp.

http://hdl.handle.net/10016/5778

19. Antonio López Vega, Biobibliografía de Gregorio Marañón, Madrid 2009, 187 pp. http://hdl.handle.net/10016/6178

20. Pio Caroni, La soledad del historiador del derecho. Apuntes sobre la conveniencia de una disciplina diferente, Madrid 2010, 225 pp.

http://hdl.handle.net/10016/6560

21. Francisco Crosas López, De enanos y gigantes. Tradición clásica en la cultura medieval hispánica, Madrid 2010, 169 pp.

http://hdl.handle.net/10016/8346

22. Manuel Martínez Neira / Natividad Araque Hontangas, El marqués de Morante y la Universidad de Madrid, Madrid 2011, 277 pp.

http://hdl.handle.net/10016/10578 
23. Antonio Planas Rosselló / Rafael Ramis Barceló, La facultad de leyes y cánones de la Universidad Luliana y Literaria de Mallorca, Madrid 2011, 186 pp. http://hdl.handle.net/10016/11325

24. Francisco Ayala / Eduardo L. Llorens / Nicolás Pérez Serrano, El derecho político de la Segunda República, estudio preliminar, edición y notas de Sebastián Martín, Madrid 2011, CLXXXIX + 396 pp.

http://hdl.handle.net/10016/11365

25. Pablo Campos Calvo-Sotelo, La evolución histórica del espacio físico de la universidad. Impulsos conceptuales, paradigmas arquitectónicos, estrategias institucionales y propuestas recientes de innovación, Madrid 2011, 236 pp.

http://hdl.handle.net/10016/12017

26. Andry Matilla Correa, Los primeros pasos de la ciencia del Derecho Administrativo en Cuba. José María Morilla y el Breve tratado de Derecho Administrativo (1847), Madrid 2011, 329 pp.

http://hdl.handle.net/10016/12033

27. José María Puyol Montero, La autonomía universitaria en Madrid (1919-1922), Madrid 2011, 545 pp.

http://hdl.handle.net/10016/12289

28. Manuel Cachón Cadenas, Historias de procesalistas, universidades y una guerra civil (1900-1950), Madrid 2012, 681 pp.

http://hdl.handle.net/10016/14588

29. María Paz Alonso Romero, Salamanca, escuela de juristas. Estudios sobre la enseñanza del derecho en el Antiguo Régimen, Madrid 2012, 722 pp.

http://hdl.handle.net/10016/15129

30. Carlos Nieto Sánchez, San Clemente de Bolonia (1788-1889): el fin del Antiguo Régimen en el último colegio mayor español, Madrid 2012, 480 pp.

http://hdl.handle.net/10016/15708

31. Natividad Araque Hontangas, Manuel José Quintana y la Instrucción pública, prólogo de Jean-Louis Guereña, Madrid 2013, 427 pp.

http://hdl.handle.net/10016/17196

32. La Universidad Central durante la Segunda República: Las Ciencias Humanas y Sociales y la vida universitaria, edición de Eduardo González Calleja y Álvaro Ribagorda, Madrid 2013, 376 pp.

http://hdl.handle.net/10016/17394

33. Manuel Martínez Neira, La creación del cuerpo de catedráticos de universidad (1812-1857). Estudio histórico-jurídico, Madrid 2013, 358 pp.

http://hdl.handle.net/10016/18077 
34. Luis Enrique Otero Carvajal (dir.), La Universidad nacionalcatólica. La reacción antimoderna, Madrid 2014, 1098 pp.

http://hdl.handle.net/10016/18911

35. Manuel Martínez Neira, La regulación de las oposiciones a cátedras universitarias: $1845-1931$, Madrid 2014, $146 \mathrm{pp}$.

http://hdl.handle.net/10016/19338

36. Aulas modernas. Nuevas perspectivas sobre las reformas de la enseñanza secundaria en la época de la JAE (1907-1939), edición de Leoncio López-Ocón, Madrid 2014, 364 pp.

http://hdl.handle.net/10016/19883

37. María Ángeles Longás Lacasa, Historia de la Biblioteca de la Universidad de Mallorca (1767-1829), Madrid 2015, 437 pp.

http://hdl.handle.net/10016/21552

38. Fernando Liendo Tagle, Pablo de Olavide y la nueva planta de los estudios, Madrid 2016, 176 pp.

http://hdl.handle.net/10016/23895

39. Rafael Ramis Barceló, Doctores hispanos en leyes y cánones por la Universidad de La Sapienza de Roma (1549-1774), Madrid 2017, 274 pp.

http://hdl.handle.net/10016/24015

40. Julián Gómez de Maya, De Al-Ricotí al rector Sabater: estudios históricos sobre la Universidad de Murcia y sus antecedentes, Madrid 2017, 388 pp.

http://hdl.handle.net/10016/24848

41. Luigiaurelio Pomante, A Great Research Lab on University History and Higher Education in Spain: Instituto Antonio de Nebrija de Estudios sobre la Universidad (1997-2009), Madrid 2017, 253 pp.

http://hdl.handle.net/10016/25309

42. Pablo Campos Calvo-Sotelo / Laura Luceño Casals, Las formas de la educación. Vínculos entre dimensión docente y dimensión arquitectónica en disciplinas creativas, como expresión de innovación universitaria, Madrid 2018, 169 pp.

http://hdl.handle.net/10016/26594

43. Rafael Ramis Barceló / Pedro Ramis Serra, Los primeros grados de la Universidad de Baeza (1549-1580), Madrid 2018, 234 pp.

http://hdl.handle.net/10016/27079 